STAKEHOLDERS’ PERSPECTIVES OF THE

IMPLEMENTATION OF THE INCLUSIVE EDUCATION

POLICY IN SAMOA: A CULTURAL FIT

By

Rasela Tufue-Dolgoy

A thesis submitted for the degree of

Doctor of Philosophy

at Victoria University of Wellington

September 2010 




\begin{abstract}
This is a qualitative study designed to investigate how the concept of inclusive education (IE) is understood and applied at a number of levels in the Samoan education system. It aims to identify barriers and facilitators to the implementation of the IE policy in this context. The study seeks an answer to the question: What are the beliefs, experiences, expectations and practises of key stakeholders of IE? The stakeholders include practising teachers in primary education classrooms, policymakers in education, parents of children who are physically and intellectually challenged, teacher-trainers, and local community leaders. The study uses a phenomenologically oriented approach to gain insight into participants' perspectives and experiences about IE and the implementation of this policy in Samoa. It draws upon document analysis, individual interviews, and focus group discussions as methods for data collection. The results indicate a paradox in participants' beliefs and practices of IE. Participants, particularly the policy implementers (teachers), tend to be inclusive in their thinking and behaviour at home. However, in the classroom, although participants seem to operate from an inclusive mindset, the practice tends to be exclusive and thus grounded in the medical model of disability. Rather than creating inclusive environments, IE appears to have created another type of exclusion. A number of implications for practice are detailed and future research ideas are outlined.
\end{abstract}




\section{Acknowledgments}

First, I must pay tribute to my Almighty God in Heaven (my chief supervisor) for without him I would never have been able to survive this journey.

Many people have helped me with this study and deserve my deepest gratitude. I thank the teachers, teacher educators, policy makers, parents, church, and community leaders for their contribution to the study via their voices.

My supervisors contributed to this study in different ways. Thanks to Dr Lex McDonald for providing constructive advice and guidance throughout the study and Dr Lise Claiborne for her valued support before she left for Massey University (2008).

There are a number of other individuals who must be thanked. Associate Professor Tagaloa Dr Peggy Fairbairn-Dunlop, Auckland University for always having time to discuss ideas, read some of my work despite her demanding schedule. The Samoan scholar, Orator-Chief Hon Mano'o Lutena Mulitalo for his knowledge on the Samoan culture, and not withstanding his busy schedule, is always willing to make time for robust discussions, provide feedback and edit some of my work. Gratitude is also expressed to Dr Josephine Mwanzia for reading some of my work and to Momoe Malietoa-von Reiche for her willingness to share ideas and to listen to my frustrations.

I greatly appreciate the financial support provided by the New Zealand Government (NZAID) Agency for International Development through their scholarship scheme award. Thanks to the Victoria University of Wellington (VUW) Faculty of Education for supporting me to present part of this study at two conferences. The National University of Samoa need to be thanked for granting me study leave.

Special thanks to my church family, the Wellington Seventh Day Adventist Church and the Samoan group in particular for their spiritual support which provided a source of strength and peace. I wish to thank my family especially my sister Nia Lole for their love and prayers. My colleagues at the Faculty of Education, National University of Samoa deserve my gratitude. Fa'amalo le tapua'i. Thanks to my $\mathrm{PhD}$ colleagues Truphena Oduol and Sailajah Sukumaran for providing a shower and a 
meal during the many nights spent at the office. Irene Sattar is greatly thanked for formatting the final report. Thank you all.

Finally, this thesis is dedicated to the memories of three dear persons who embarked on this journey with me but sadly could not make it to the end. My husband Reevan Dolgoy who passed away in 2006, my mother Olive Schuster-Tufue in 2008 and a very dear friend Mulo Sasa in 2010. They are greatly missed for they were an inspiration and an anchor of support. When they were gone I was like a ship without a sail but through God's grace, support was provided through many individuals.

May God bless all those individuals who have contributed one way or another to the completion of this study. Fa'afetai tele lava. 


\section{Table of Contents}

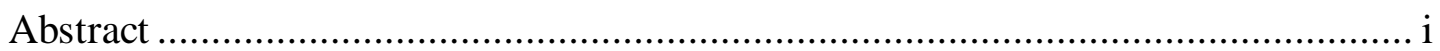

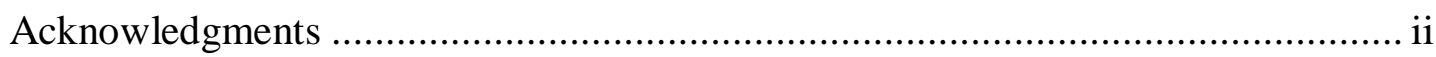

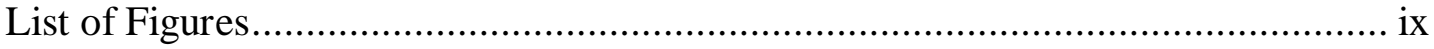

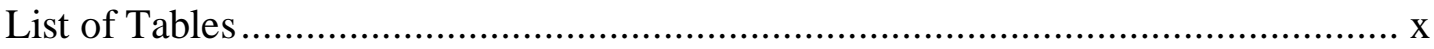

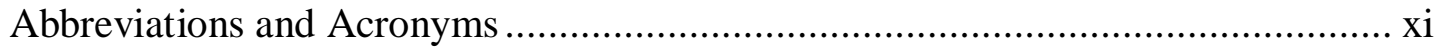

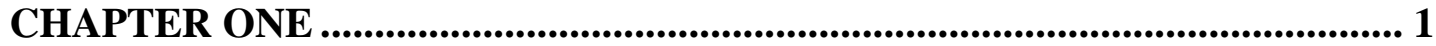

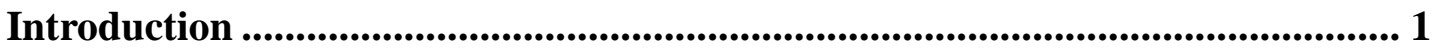

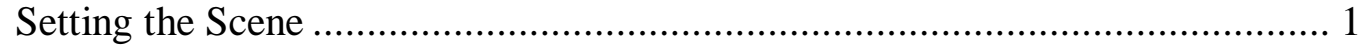

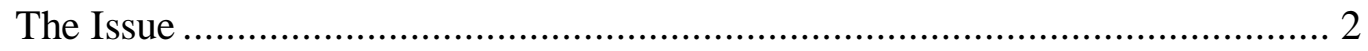

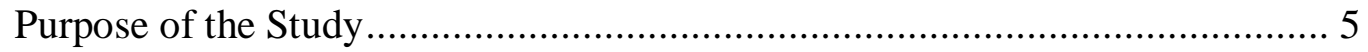

Research Objectives and Questions............................................................ 6

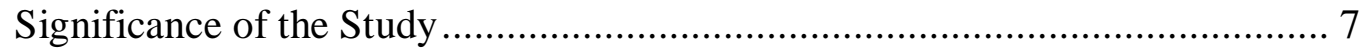

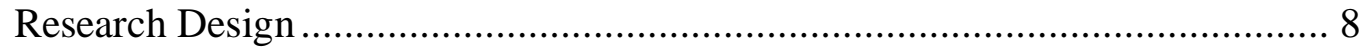

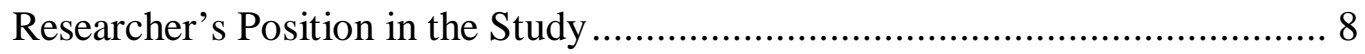

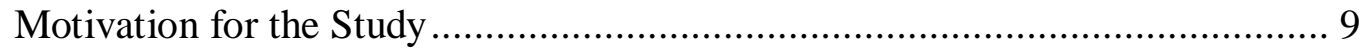

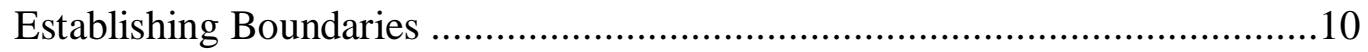

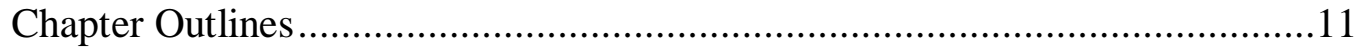

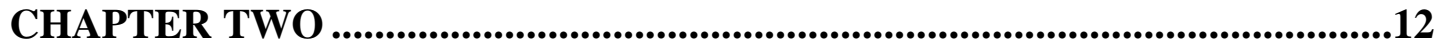

Inclusive Education: Literature Review ...........................................................12

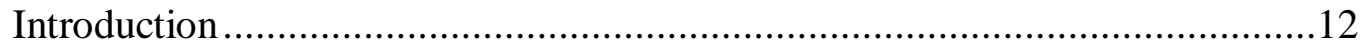

The Inclusive Education Concept...............................................................13

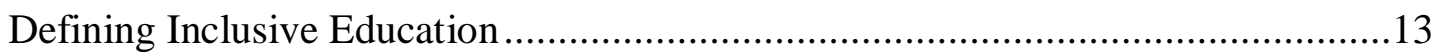

Influences on the Inclusive Education Movement................................................14

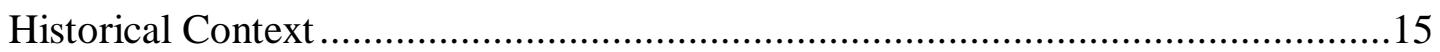

Emergence of Special Education System ..................................................16

Criticism of Special Education - Medical Model ................................................17

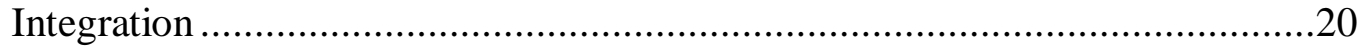

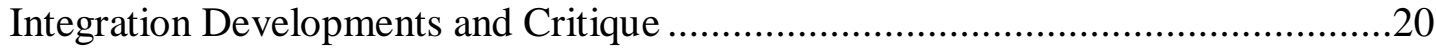

International Policies and Legal Aspects.....................................................21

Inclusive Education - A Social Model .........................................................23

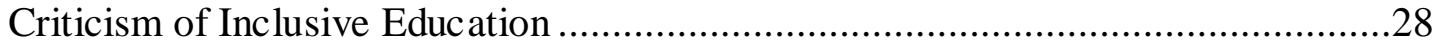

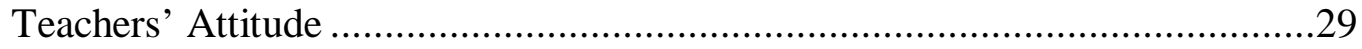

Teacher's Attitude - International Studies..........................................................30 


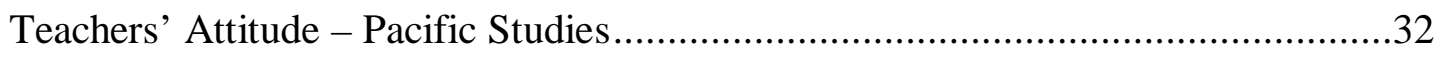

Parent's Attitudes - International Studies ...................................................34

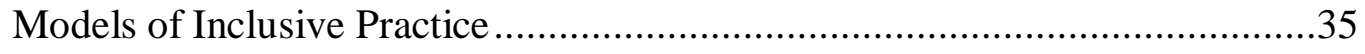

Teacher Professional Development ...........................................................38

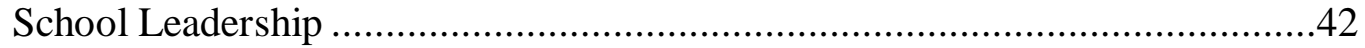

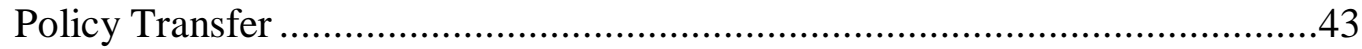

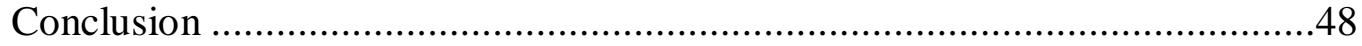

CHAPTER THREE .........................................................................................49

Culture and the Samoan Context .....................................................................49

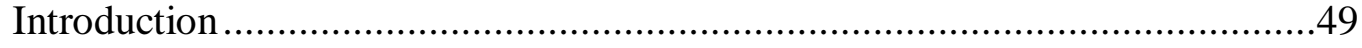

Samoa - The Research Location ...............................................................50

Hofstede’s Model on Culture ....................................................................52

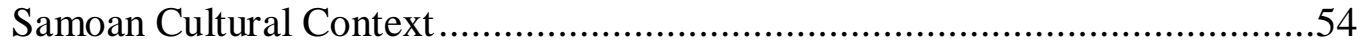

Role of Cultural Values in Education.........................................................60

Value of Support in Polynesian Contexts .....................................................62

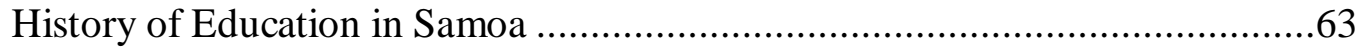

Educ ational Policy 2006-2015 - Goals ......................................................65

Inclusive System of Education .................................................................68

International Involvement and IE Development ...............................................68

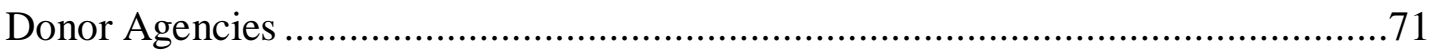

Education and Students with Disabilities..........................................................72

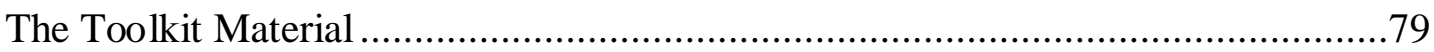

Change and Cultural consideration .............................................................. 80

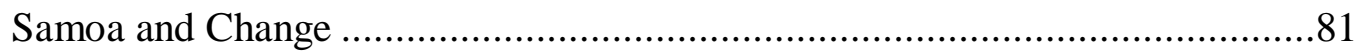

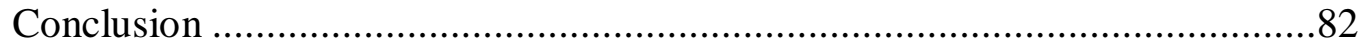

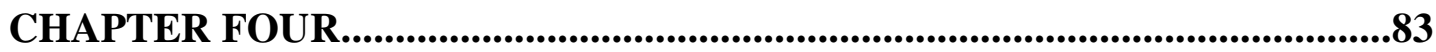

Research Design and Methodology ...........................................................83

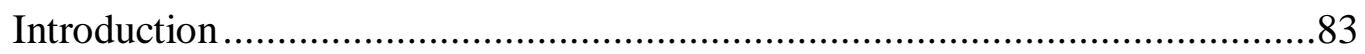

‘Ola’ A Samoan metaphor - Framework for Research Process ........................83

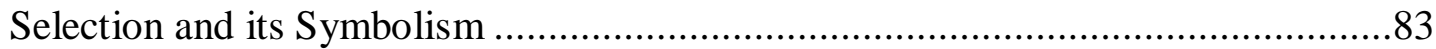

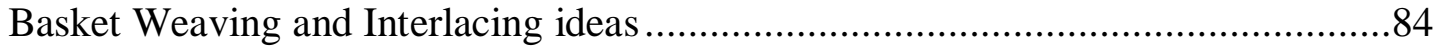

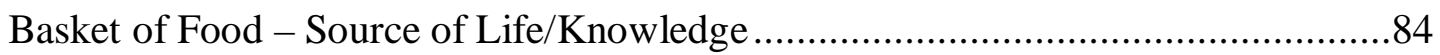

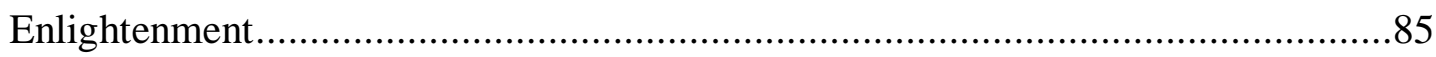

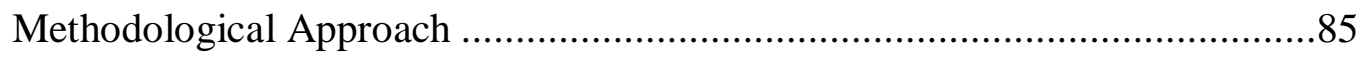

Philosophical Assumptions Underpinning the Research Design of the Inquiry ........86 


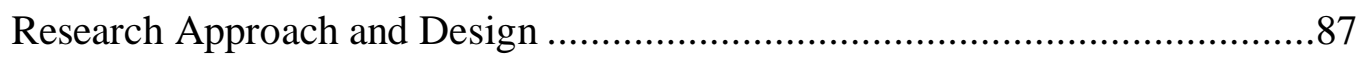

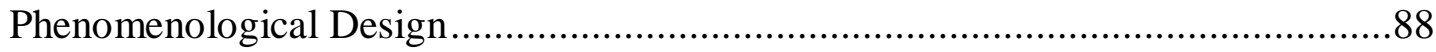

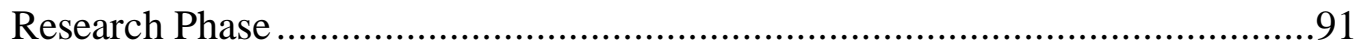

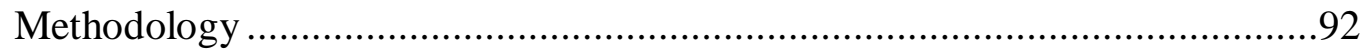

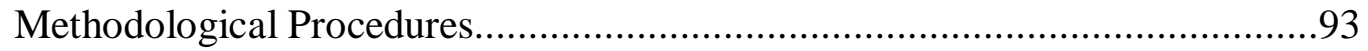

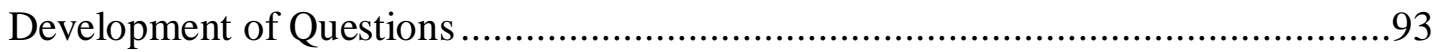

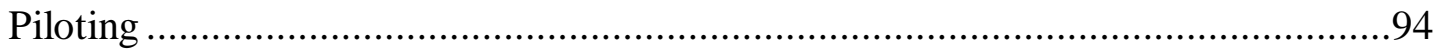

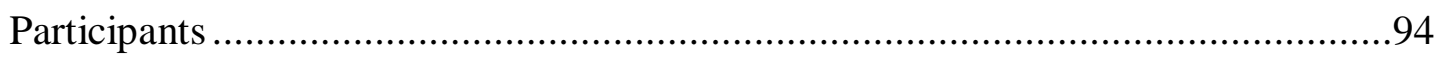

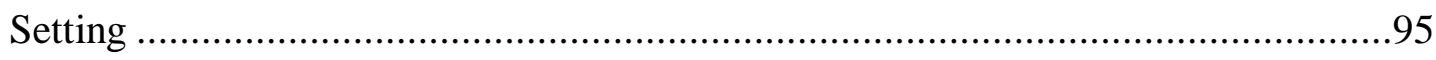

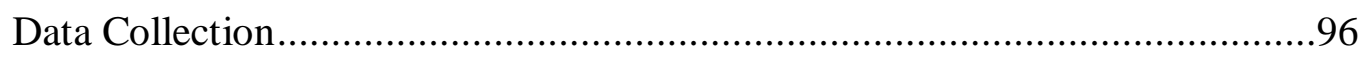

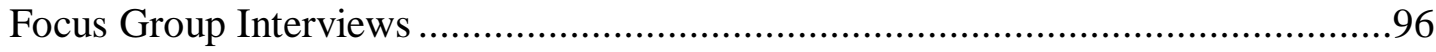

Semi Structured In-depth Individual Interviews ................................................98

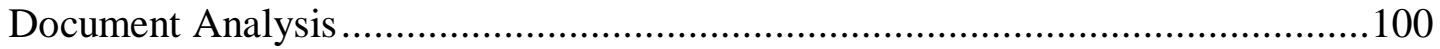

Data Analysis of Individual and Focus Group Interviews.............................101

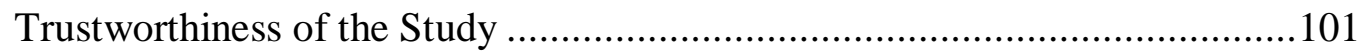

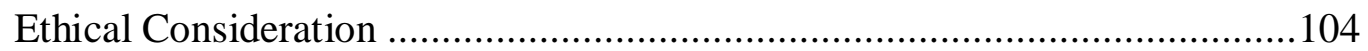

Perceived Limitations of the Study ............................................................105

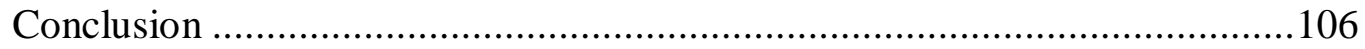

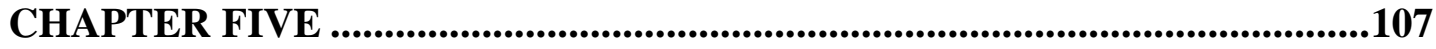

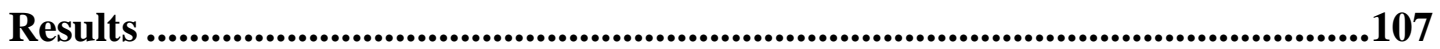

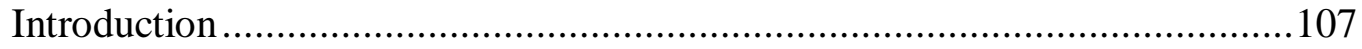

The Findings: Codes and Patterns ..............................................................109

1. Interpretation - Definitions and Philosophy of IE..........................................109

Summary of IE Interpretations and Philosophy Pattern ...............................112

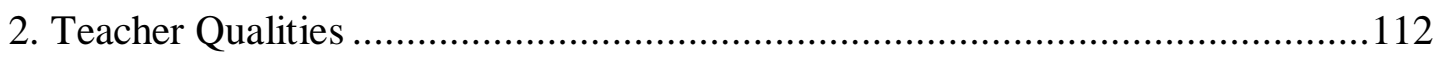

Summary of Teacher Qualities Pattern.......................................................123

3. Practice: Opportunities and Restraints .......................................................124

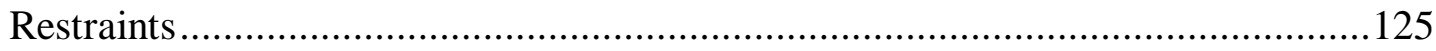

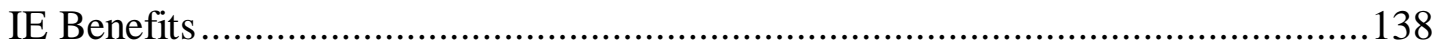

Summary of Opportunities and Constraints Pattern.......................................143

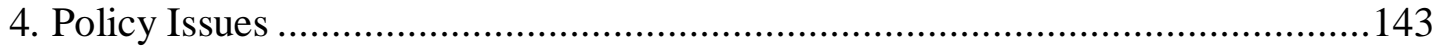

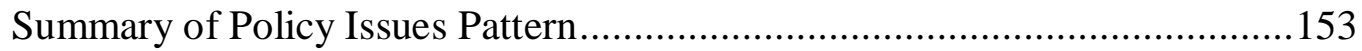

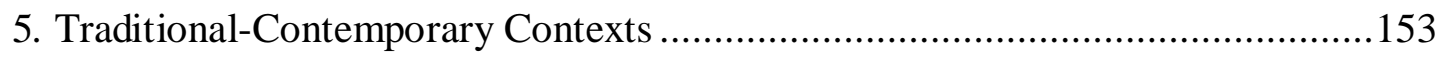

Summary of Traditional and Contemporary Contexts Pattern........................159

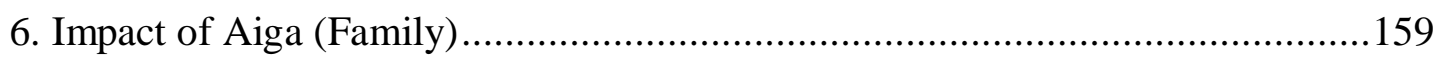


Summary of Family Impact Pattern .........................................................163

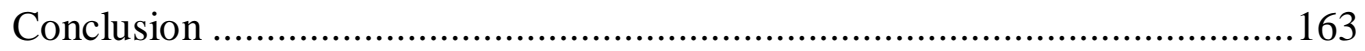

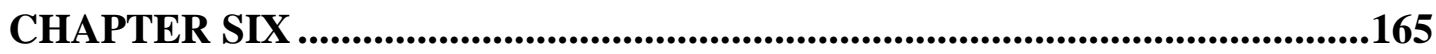

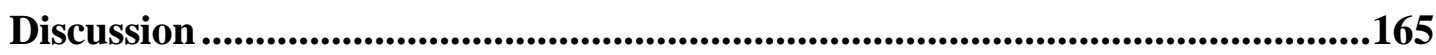

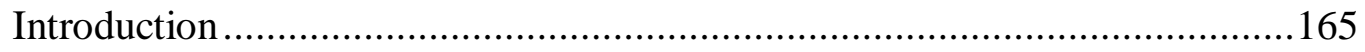

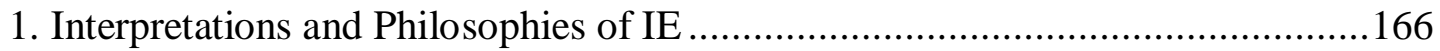

2. Teacher Quality Attitudes, Experiences and Practices ....................................167

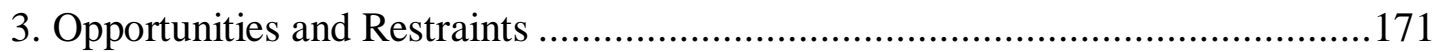

4. Policy Issues: Professional Development and Change .....................................179

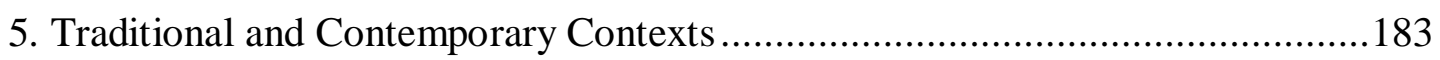

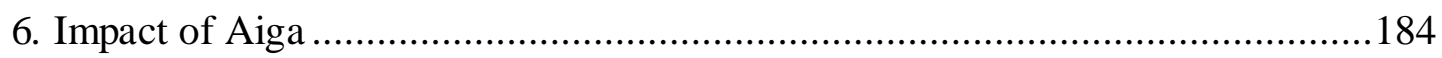

Theme 1: Understanding, Attitude and Practice Conundrum .........................186

Theme 2: Interdependence and Support ....................................................186

Theme 3: Transfer of Training Issues.......................................................187

Meta Theme: The Paradox of the Samoan Culture and IE Implementation.....188

Multi-Systems Models: IE Interpretation and Policy Usage ..........................190

Implications for Practice .........................................................................194

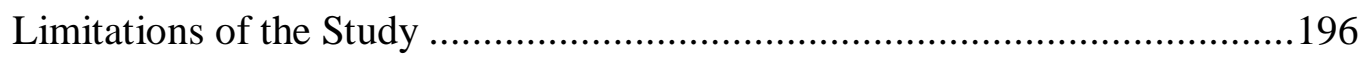

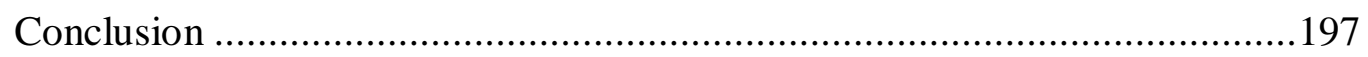

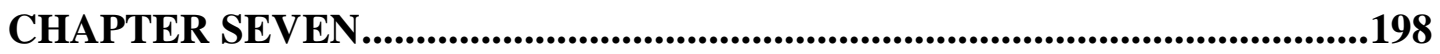

Conclusion ....................................................................................198

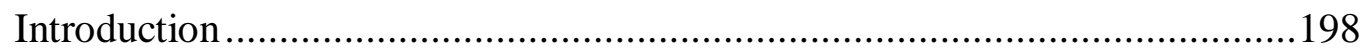

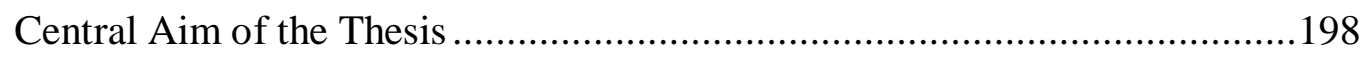

Summary of Main Findings ...................................................................199

Recommendations for the Future ............................................................201

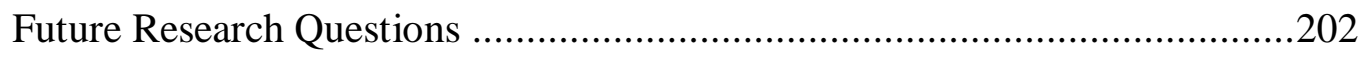

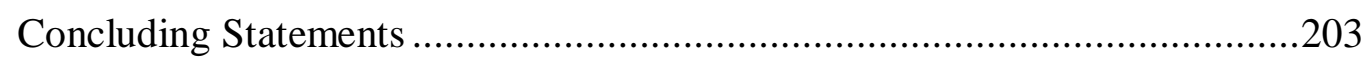

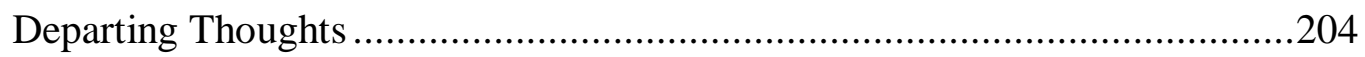

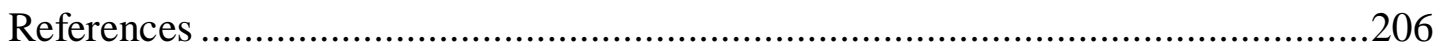

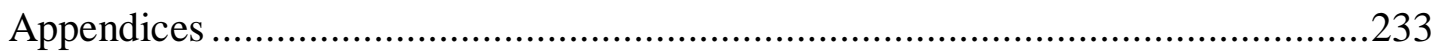

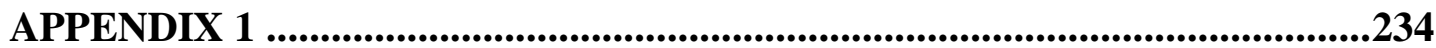

Table of Findings - Codes, Patterns and Themes............................................234

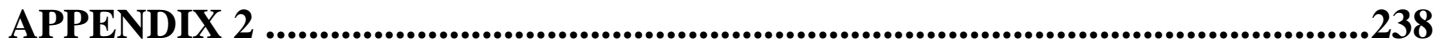

Focus Group Questions For........................................................................238

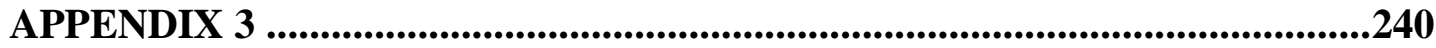


Proposed Individual Interview Questions For:

APPENDIX 4 ....................................................................................................242

Focus Group Information Sheet..........................................................................242

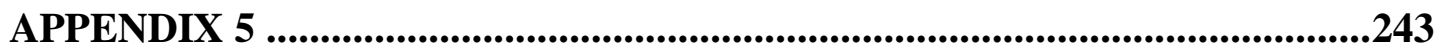

Information for Individual and Focus Discussions........................................243

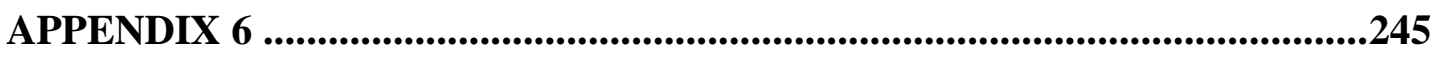

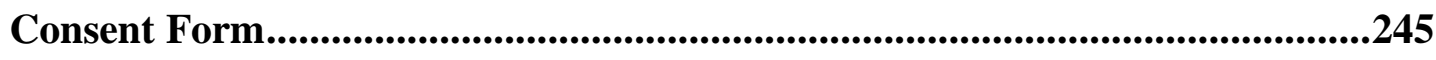

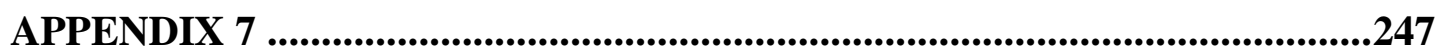

Letter to undertake Research in Schools ..........................................................247

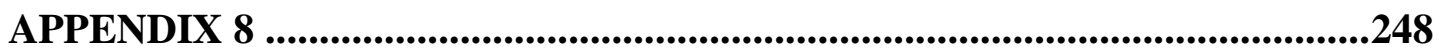

Ethics Letter of Approval .......................................................................248 


\section{List of Figures}

Figure 2.1 Spectrum of educational transfer (Source: Phillips, 2009, p. 1070).

Figure 2.2 Policy borrowing in education: Composite processes (Phillips \& Ochs, 2003). .45

Figure 2.3 Forces that direct the processes of borrowing (Johnson, 2006) .............................45

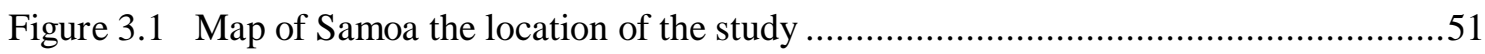

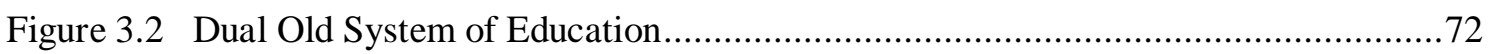

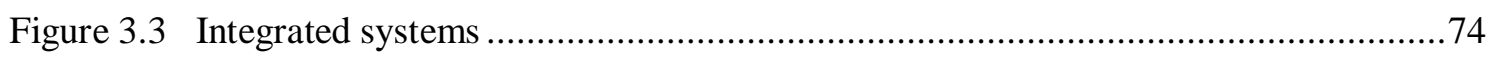

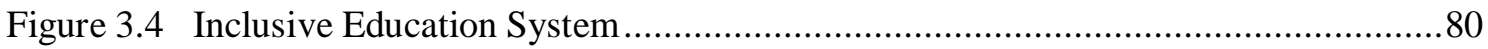

Figure 4.1 Methodological terminology and structure adopted in the study ...........................86

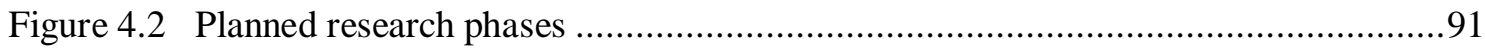

Figure 6.1 A systems model of interpreting IE implementation ..........................................191

Figure 6.2 Education Policy Systems Development Model ................................................193 


\section{List of Tables}

Table 2.1 Model for social policy analysis: Barriers to policy implementation ......................47

Table 3.1 Salient features of collectivist and individual cultures ..........................................54

Table 3.2 Aspects and learning in collectivist and individualist cultures ..............................59

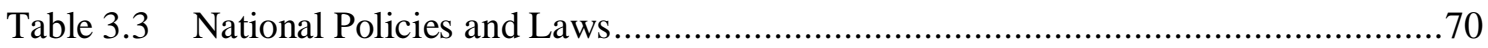

Table 3.4 Survey on children with disabilities - National Summary of Types of

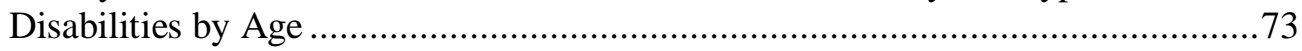

Table 3.5 Significant developments for Introduction of IE in Samoa ...................................79

Table 4.1 Overview of Research Objectives and Methodologies ...........................................93

Table 4.2 Characteristics of teachers involved in the study ...............................................95

Table 4.3 Organisation of participants for focus group interviews........................................98

Table 4.4 Criteria for research evaluation in qualitative and quantitative approach...............102

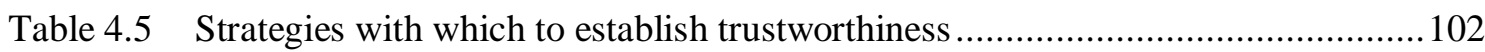

Table 5.1 Abbreviation for the different groups and individuals........................................108

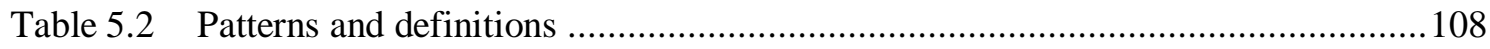

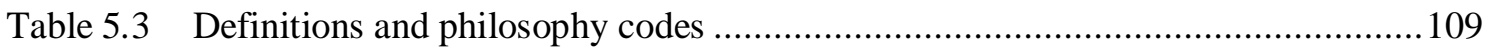

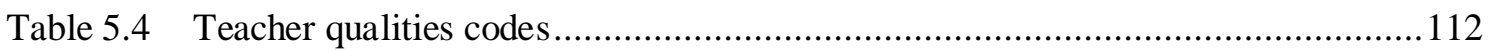

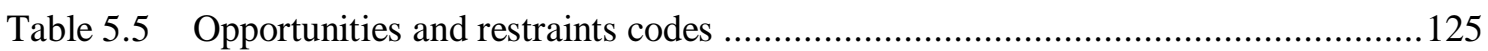

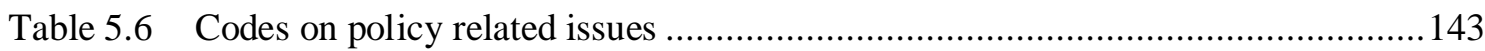

Table 5.7 Codes for traditional and contemporary contexts...............................................153

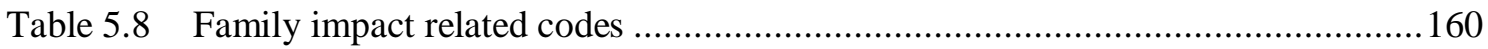

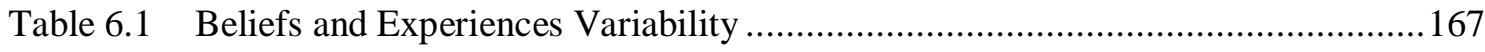

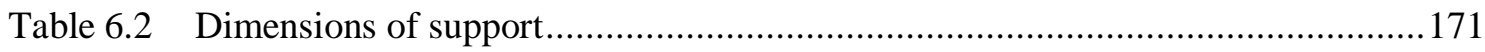

Table 5.9 Codes, Patterns, Definitions and Themes ............................................................234 


\section{Abbreviations and Acronyms}

$\begin{array}{ll}\text { AIGA } & \text { Augmenting Institutions for General Attainment } \\ \text { EFA } & \text { Education For All } \\ \text { ESD } & \text { Education for Sustainable Development } \\ \text { CEO } & \text { Chief Education Officer } \\ \text { CMAD } & \text { Curriculum Material and Assessment Division } \\ \text { FBEAP } & \text { Forum Basic Education Action Plan } \\ \text { GoS } & \text { Government of Samoa } \\ \text { IE } & \text { Inclusive Education } \\ \text { ISP } & \text { Institutional Strengthening Project } \\ \text { MESC } & \text { Ministry of Education Sports and Culture } \\ \text { MDG } & \text { Millennium Development Goals } \\ \text { MP } & \text { Member of Parliament } \\ \text { FOE } & \text { Faculty of Education } \\ \text { NCF } & \text { National Curriculum Framework } \\ \text { NGO } & \text { Non Government Organisation } \\ \text { NUS } & \text { National University of Samoa } \\ \text { PRIDE } & \text { Pacific Regional Initiative for the Delivery of Basic Education } \\ \text { PWD } & \text { People With Disability } \\ \text { SDS } & \text { Strategy for the Development of Samoa } \\ \text { SNE } & \text { Special Needs Education } \\ \text { SNEAC } & \text { Special Needs Education Advisory Committee } \\ \text { SPBEA } & \text { South Pacific Board For Educational Assessment } \\ \text { SPELL } & \text { Samoa Primary Education Literacy Level } \\ \text { SPP } & \text { Strategic Policies and Plans } \\ \text { SRO } & \text { School Review Officers } \\ \text { UN } & \text { United Nations } \\ \text { UNDP } & \text { United Nations Development } \\ \text { UNESCO } & \text { United Nations Educational, Scientific and Cultural Organisation } \\ & \end{array}$




\section{CHAPTER ONE}

\section{Introduction}

This chapter sets the scene for the inquiry. It begins by situating the thesis within the cultural, political, economic and educational contexts of Samoa. Following this, the rationale for the study is stated along with, the purpose, research questions and significance as well as the researcher's location in the study.

\section{Setting the Scene}

Although a small island state and only a dot on the world map, Samoa has been well integrated economically, socially and politically into the globalised world and change since its first contacts with the Western world over almost two centuries ago (Davidson, 1967; Gilson, 1970; Grattan, 1948; Keesing, 1934; Macpherson, 1994; O’Meara, 1990; Shankman, 1976). The same can be said for education in Samoa; for example, the educational policies and planning are influenced today by global mandates such as the Education For All (EFA), United Nations Educational Scientific and Cultural Organisation (UNESCO), the Education for Sustainable Development strategies (ESD) and the Millennium Development Goals (MDGs), as well as regional commitments such as the Forum Basic Education Action Plan (FBEAP), the Pacific Region Initiative for the Delivery of Basic education (PRIDE) and the Pacific Plan (Government of Samoa, 2006a, p. 11).

In 2005, UNESCO introduced and piloted in Samoa the Inclusive Education (IE) strategy in a teachers' resource manual entitled 'The Toolkit' to facilitate a more inclusive learning environment (McCullough, 2000). IE is grounded in the rights of the child discourse that everyone has a right to be educated (Daniel, 1999), and relates to factors such as quality education and cost effectiveness. The IE movement signifies a paradigm shift in the provision of education for children with special needs. It has moved from the deficit approach whereby the focus was on the student as a 'problem' (medical model) to an ecological perspective whereby issues relating to student, class, school, community and culture are examined as a means of ensuring better learning outcomes for the student with special teaching needs (Moore et al., 1999). 
Inclusion is defined as a process of addressing and responding to the diverse needs of all learners and of minimising exclusion from, and within, the education system (UNESCO, 2003). It is seen as a strategy to help to achieve EFA. ${ }^{1}$ The EFA fundamental principle, to provide an opportunity for all children to learn, is closely related to that of IE which suggests that all children having the opportunity to learn together.

In Samoa, as will be noted in later chapters, IE has been perceived in terms of providing educational opportunities for children with special needs and disabilities. While the Government of Samoa's policy focus embraces the importance of education for all, including people with disabilities, in practice there are still a number of people who do not have this opportunity and are being ignored (Lene, 2005). The practice in Samoa, as in many other parts of the world, IE has been interpreted to be the strategy by which children with special needs, who in the past had been segregated and placed in special schools, could be integrated into the general classroom to enjoy equal access to education.

This thesis examines the concept of IE as it is debated in the global literature and thus the key issues concerning inclusion of children with special needs in general classrooms (globally) will be presented before focusing specifically on the Samoan experience. The research will examine Samoan people's perceptions about the concept of IE and the implementation of the global IE policy in Samoa. In doing so, it brings to the fore factors and challenges that affect implementation of this policy in a small Pacific nation state.

\section{The Issue}

It is well documented that people with disabilities are often marginalized and are not viewed favourably by many cultures, religious beliefs or ethnic groups (Pfeiffer, Guinan, Ratcliffe, Robinson \& Stodden, 2004). In the developing countries of the world two thirds of people with disability live in the Asia Pacific region (ADB, 2005). According to the Pacific Islands Forum Secretariat, the number of people with disability living in the Pacific Islands is approximately 800,000 which makes up between 6 and 10 percent of the total population (PIFS, 2008; Price, Radio \& Toga, 1999).

\footnotetext{
${ }^{1}$ The goal of EFA is for all children to enrol into education systems by 2015.
} 
Internationally over the past 20 years, an acknowledgement of the rights and opportunities that need to be afforded to people with disabilities has emerged, and various international conventions and policy statements have committed governments throughout the world to make better provision for people with disabilities. The Samoan Government and education authorities have subscribed to these views. ${ }^{2}$

Reports detailing the Samoan situation, and indeed the Pacific context, show that for many years children with special needs did not have an equitable opportunity for education. This was due in part to national resource constraints for education and the need to provide basic education for all, given the huge school age population. Cultural perceptions relating to the causes of disability (McKinstry \& Price, 2004) was an important factor and questions were raised as to whether education would be of any value for those with disabilities. Only in 1980 was an NGO school set up for those children with disabilities and it did not have a place in the mainstream school system. Records of incidence of disabilities were not kept. Samoa's first national effort to survey numbers and needs for people with disabilities was not undertaken until the 1990s and this research was carried out by Smith (1990) and Kupa (1995) from a medical viewpoint rather than an educational perspective. Up until this time disability was considered a medical and a Non Government Organisational (NGO) issue.

In 1994, education became compulsory in Samoa but in practice the education of those with special needs was undertaken outside the schooling system (in special schools) by NGOs. Most of these special schools were established in the urban area of the main island (Upolu) and one on the island of Savai'i and with this arrangement most children with disabilities were not able to access education. Towards the end of the Twentieth Century the Government did take steps to identify all children with special needs and disabilities out of school (McCullough, 2005) and established special needs units within government schools for integration, as well as providing training for teachers (Samoa Educational Policy 1995-2005). This was because census data indicated there was a real need.

The 2001 Samoan census of population and housing identified 2,295 persons with disabilities out of a population 176,848 (1.3\%). Lene (2005) surveyed a broad group

\footnotetext{
${ }^{2}$ For example ESCAP (1993; 1994); United Nations ( 2003), UNESCO (1994; 2000)
} 
of Samoans with disability (15years+) and identified 2,874 people with disabilities, a total of 1,516 women and 1,358 men. The results indicated that in the population of people with disability from birth to 15 years, 188 men and 218 women had not had access to any educational facility or had only attended school for a maximum of 3 years. Lene found that people born with a disability or those who had become disabled within the first 5 years of life comprised the highest percentage of those excluded from the education system (48\% of people disabled at birth and $50 \%$ acquired their disability within the first 5 years of life). Deaf individuals or those with speech impairments had the highest rates of non attendance at school. It was found that in general, individuals with disability had only 3 years of formal education. Lene (2005) noted that in regard to education, individuals who were born with a disability were found to have experienced the greatest exclusion from education. There were also some concerns regarding the quality of the educational experiences received by this group of people. Lene (2005) attributed the low (1\%) income generated rate and minimal inclusion in community activity for people with disabilities to poor quality educational experiences. The same issue of quality in Samoan education is raised by other educationalists as an issue that could have a bearing on the high percentage of at-risk children in literacy and numeracy within general classrooms (Afamasaga, 2006).

All of the data indicated that special needs inclusion is important in Samoa in terms of individual development, community development and for the national development of Samoa. However, while Samoan government policies emphasise integration of children with special needs in government schools, there was still a considerable number of children for whom this is not made possible. Essentially, the right to education is being addressed in Samoa through the application of an IE model.

Documentation shows that global imperatives drive educational reforms across the world but often, and especially in developing countries, there is insufficient attention given to social, economic, political and cultural considerations (Johnson, 2006; Mitchell, 2005; Phillips, 2009; Robeyn, 2006). This thesis argues that although international bodies, have good intentions in initiating global policies and programmes, these will fail if there is a lack of participation and connection between those involved at all levels and if the local context is over-looked. This means that coordinated action with the international consultants who import the policies, the 
policy developers and implementers at the national, school, and community levels is necessary. The study by Rombo (2007) which looked at cultural features and practices that influenced IE in Papua New Guinea and indicated that one of the challenges that impacted on IE was the lack of coherence between those involved in policy development and practitioners; policies developed at the national level did not permeate to the school level. Thus, what Robeyn (2006) states is worthy of consideration "that global agendas and conditionalities cannot guarantee full participation by all and that identifying barriers to inclusion can be more productive if they are examined in relation to other constraining factors [such] as social norms and cultural beliefs” (p. 77). Borrowing of policies brings its own problems and issues (Phillips \& Ochs, 2003). Given these concerns, there is a need for research on how the concept of IE has been adopted, transferred, interpreted and applied at a number of levels in the Samoan education system. This thesis examines the efficacy of these IE educational reform policies and projects through the eyes of key stakeholders.

\section{Purpose of the Study}

The purpose of this research study was twofold: first, to gather qualitative information on perspectives, beliefs, experiences and values of stakeholders with regards to the concept of IE. It was designed to explore how the concept of IE was perceived, understood, and applied by people within a small Pacific nation state and the implementation of IE policy initiatives within this context. The second purpose was to ascertain if this data could be used to develop a framework or model(s) for facilitating IE in Samoa which could have some applicability to similar contexts. In doing so, it aims to contribute to the growing body of literature that seeks to understand the way people within developing countries adopt policies and in particular view the IE phenomenon and their conceptualisation of it. It also contributes to the debate in the international literature concerning exclusionary issues encountered by individuals with special needs in these contexts, and at the same time to further global understanding of factors that impact on the implementation of IE policies in such contexts. 


\section{Research Objectives and Questions}

The research objectives for this research were:

1. to identify the beliefs, experiences, expectations, and practices of key stakeholders regarding IE in Samoa

2. the development of an explanatory model(s) that could assist future development of education policies and implementation.

In order to achieve the research objectives, the following research questions were formulated:

1. What are the key stakeholders (parents - community members, education policy makers, teacher educators, curriculum advisers, and teachers)

- $\quad$ Attitudes and expectations of IE?

- $\quad$ Perspectives about policy introduction and implementation of IE?

2. What are the views of teachers about their experiences and preparation for IE? How do teachers describe their experiences of teaching in inclusive classrooms? What are teachers' practices in inclusive classrooms?

3. What do the three stakeholder groups (policymakers, implementers, parentscommunity members) perceive as factors that could inhibit or facilitate IE practices in Samoa?

4. How does the Samoan culture and IE phenomenon interplay within the educational context?

Given that IE is still in its infancy in Samoa, the researcher's objective was to locate what people perceive as factors that could impact on the implementation of the IE policy. In addition, it was important to understand what the implications would be for the introduction and implementation of the IE policy on practicing teachers, education policies, teacher education, curriculum development and support services, as well as community participation. There is limited research undertaken in this respect within the Pacific and as McDonald (2005) noted inclusion has not been a priority in many Pacific nations due to historical, economic, cultural, and geopolitical imperatives. Consequently, the medical paradigm and the categorisation 
perspective have continued to characterise many Pacific Island education systems. The biological/medical model argues that the problem, in relation to learning, lies within the student and therefore the student needs to be fixed (Gould, 1981). Thus, from this perspective students are grouped and categorised according to abilities and disabilities. This view contradicts with the social and ecological model which attributes the disability issues to the society and the environment; the concept of IE is grounded within the ecological and social perspective. The current study is particularly important because it is the first study on how the concept of IE is perceived, interpreted and practiced in Samoa.

\section{Significance of the Study}

The implications and significance of this study in Samoa to educational policy and practice related to IE cannot be overemphasized. Numerous studies (Salisbury, 2006, Al-Zyoudi, 2006) have been undertaken globally on the challenges of implementing inclusive policies as an educational reform, however, within the Polynesian context data is very scant. One recent study (Meredith, 2009) has been conducted which identified challenges for including people with disability in education and society in Tokelau (another small Pacific island nation). This study was from the perspective of the community and included various participants (Tokelauan and non Tokelauan) including professionals from the government and education as well as parents of children with disabilities.

This current study aims to examine perceptions of key stakeholders (policymakers, teacher educators, practicing teachers, parents) of IE in Samoa regarding the concept of IE and factors that impact on the introduction and implementation of the IE policy in this context. The study aims to inform the practice of educationalists, teacher trainers, and teachers. Furthermore, it will be useful for educational planners and policy makers for planning educational programmes that address the needs of students with special needs and disabilities. The thesis will also inform programme service users and donor agencies who have an interest in the value of dollars invested in implementation of educational reforms such as IE. Furthermore, a significant value of the thesis is that it will produce new knowledge based on a group of Polynesian people's indigenous ideologies about the concept of IE and how they perceive, understand and conceptualise this phenomenon. 


\section{Research Design}

The research utilised a phenomenologically oriented approach to answer the research questions and to explore the research problem. This design was selected as it allowed the participants to voice their opinion and share experiences and feelings about the concept of IE and the implementation of this policy in Samoa.

\section{Researcher's Position in the Study}

The purpose of this section is to describe my beliefs and relationships in relation to the subject of study. I believe it is crucial to state my role in this study for it not only allows the reader to situate the researcher in the study, but it also provides the context for addressing the validity issues and the choice of paradigm (Tsoi Horseman, 1989).

I am a teacher educator at the National University of Samoa. My interest is in nurturing young teachers in teaching methods and strategies appropriate to students with special needs in classroom settings of IE. Prior to becoming a university lecturer, I taught in primary schools. My experience as a primary school teacher enabled me to relate to some of the experiences that teachers undergo and the change demands placed upon them such as the IE initiative.

My interest, beliefs and experiences in IE were enriched through a special education course I undertook in New Zealand in the late 1990's. This course exposed me to a number of key issues including the human rights perspective and approach to education. From a human rights stance, I strongly believe that everyone has a right to a healthy life, to be educated and be part of a social milieu. I believe it is therefore the responsibility of the state or the government to ensure that these rights are protected. I believe that government in general should ensure equal educational opportunities for all, including children with special needs, not just a few. My view is that everyone has something to contribute for the benefit of society.

In this research study I am both an outsider and insider. The human rights stance ascribes to me an outsider role, where I interrogate the subjects and context of the study from a global standpoint, my IE perspective is largely drawn from Western ideologies. Considering that my formal schooling and teacher training were grounded in Western epistemologies, I was able to investigate the phenomenon of IE in a local context from within a Western theoretical lens. Further, I used the lens of a teacher 
educator to interrogate the perspectives of implementers of IE (teachers). As detailed later in the ethical considerations, bias could influence my interpretation of participants’ views.

I also played an insider role because the human rights perspective resonates well with the Samoan axiom that - 'no one is ineffectual' - an adage which participants in this study repeatedly cited. As a Samoan by descent, I not only share in this belief but also my knowledge of the Samoan culture and context in which I researched allowed me space to investigate the phenomenon of IE with an insider perspective. The insider role can also be traced to my career as a university lecturer and primary school teacher from which I have gained rich knowledge and experience about the Samoan education system.

In relation to the phenomenological research approach adopted for this study, I am an outsider in terms of Western philosophies which guided my own understanding of the approach. Conversely the descriptive nature of the approach itself where individuals' experiences are articulated and described (a common occurrence in Samoan) places me in the position of an insider. It is also fair to acknowledge that my Christian beliefs significantly influence my own world view.

\section{Motivation for the Study}

A number of factors have driven this study. Firstly, my teaching experience, observations, the use of an IE toolkit, and the debates that surround the concept of IE have impacted on my beliefs. From my own teaching experience in government primary classrooms over two decades I realised that I did not have the requisite skills and knowledge to cater for the needs of a child with a disability. This became a reality when a very close friend from my schooling years approached me requesting that her child, who was visually impaired, be placed in my class. My response, which still haunts me whenever this scenario is replayed in my mind, was to decline my friend's request for I was paralysed by feelings of fear and dread as I realised that I was not prepared. This fear stemmed mainly from lack of experience, knowledge and understanding in dealing with a child with a disability. I had never dealt with a child with a disability before either at home or in my teaching experience. Given this experience I was keen to locate teachers' views regarding their experiences and practices concerning the teaching of such students. 
Secondly, through observation I noted that despite the compulsory attendance requirement the Samoan government had enacted, there are still a number of children, with and without disability, who are not attending school; and if they are in school most children with disability regardless of the degree of the disability are placed in special schools. Therefore, I wanted to gain the participants' perspectives with regard to educational placement for such students. Furthermore I was interested in their views regarding the value of IE.

Thirdly, the introduction of the concept of IE through a set of tool kit materials, which has as its underlying principle the concept of equity and social rights, motivated me to find out from participants their beliefs regarding the appropriateness of this type of professional development in Samoa.

Lastly, from scrutinizing the literature it was noted that the notion of IE which Samoa has borrowed and subscribed to through various United Nations conventions, was a controversial phenomenon globally. For example, there is even a controversy that surrounds the definition of the concept (Sikes, Lawson, \& Parker, 2007; Swart, Engelbrecht, Eloff \& Pettipher, 2002). I was therefore interested to understand IE more fully and attempt to arrive at a clearer position on its contribution and potential.

\section{Establishing Boundaries}

This study, although acknowledging other students who were marginalized one way or another in Samoan society, was geared towards students with special needs in terms of physical, intellectual or sensory disabilities. Why this group of students? It appeared that this cluster was particularly marginalized within society and in school. A number of students with learning difficulties, who are - so called - slow learners or 'at risk' can be found in many Samoan classrooms. These 'slow learners' are often not the focus of the teacher's attention because in Samoa many teachers concentrate more on the higher ability learners since they raise the profile and status of the school. Students with disabilities are usually located in special schools in the education system, if not left at home. Very few of these students could be found in government or general schools in Samoa. The Ministry of Education is currently implementing the IE policy which guarantees the placement of these students within government schools and teachers no longer have a choice regarding acceptance or not of these students in their classrooms. The question is are teachers prepared for this move and will they focus upon these students and their needs as they do with the 
other students? Many teachers have not encountered these students before, and accordingly, I want to find out whether teachers have the requisite attitude and skills to teach these students.

\section{Chapter Outlines}

This chapter has introduced the context of the study, the researcher's position and the research agenda. Chapter Two provides a review of the literature that frames the study. The worldwide movement towards inclusive teaching is discussed in addition to new legislation and the practical application of such legislation to IE. The larger body of research on models of inclusivity, as well as research on teacher attitudes, teaching and theories, barriers/facilitators and benefits of the inclusive phenomenon is presented. Chapter Three presents a discussion on the political, economic, historical, cultural and social profile of Samoa, the locale of the study. The systems of education in Samoa and policies that relate to IE as well as the notion of change are highlighted. Chapter Four presents a discussion of the research design and methods of data collection, and analysis. A Samoan metaphor ola or basket as a conceptual framework to tie together all aspects of the methods design is presented. Chapter Five organises the results according to the main aims and objectives of the study. It presents codes and patterns that emerged from the data. Chapter Six presents a detailed discussion of patterns and significant themes that emerged. Chapter Seven presents the conclusions that have been derived from the results, outlines implications and recommendations and the future research that is needed. 


\section{CHAPTER TWO}

\section{Inclusive Education: Literature Review}

\section{Introduction}

In the past two decades, the systems of special education globally have undergone significant changes. This has been with respect to perspectives regarding the educational provision for children with disabilities. These changes occurred through a number of stages ranging from education of children with special educational needs or disabilities within a segregated environment, through the integration stage, where these students were supported within mainstream schools to the current type of education delivery of IE (Terzi, 2008). However, the construct of IE is - complex. This is due to its differing meanings and conceptualisation by various cultures - the nature of education policies and practices that are intended to support 'inclusion' as well as ideas of inclusion in relation to the United Nations Educational Scientific and Cultural Organisation (UNESCO) definition of effective and quality education (UNESCO, 1994), and the rights-focused definition (Rouse \& Florian, 1998) of IE which lays emphasis on participation.

This chapter review critiques the literature on IE particularly the perceptions and attitudes to inclusion of children with special needs in the mainstream and perceptions towards implementation of the IE policy. The review is used to create a theoretical framework through which the thesis examines IE in later chapters. The review explores factors that affect IE programmes and policy implementation globally and how this information could influence policy and practice of inclusion of students with special needs within the general classroom, and in particular suggests that within the Samoan context there is a need to examine perceptions and beliefs about IE and to develop a model(s) of explanation that would assist in the implementation of educational change in this context. The Samoan IE implementation could also be applicable to other developing nations.

This review is made up of three sections: (1) the concept and definition of IE, its influences, characteristics, practices, and the models and theories that underpin it, (2) the concept of change and teacher professional development (3) the notion of transfer in relation to training ideas and policy. 


\section{The Inclusive Education Concept}

The concept of IE "has attracted much attention in recent years" (Kisanji, 1999, p. 2) and has been viewed as a right for all individuals to participate in society including those with a disability (Rouse \& Florian, 1998). However, IE (at least in the Western world), is a relatively new trend. Previously (about 25 years ago), special education was a common form of educational support for students with specific disabilities. At the time, special education was perceived to be the best service delivery for these students, particularly those with severe/high needs (Moore et al., 1999). The underpinning philosophy in this service delivery model located the problem within the child. More recently, there has been a shift of thinking from the focus on the child's specific problems arising from his/her disability (the medical model) to the child's potential (the social model). This model characterizes IE (Moore et al., 1999). In this model, the placement of students with special needs within general classrooms impacts upon all individuals involved in the education arena including administrators, teachers, students and parents. This requires major adjustments to meet needs of these students in the general classrooms (Conte, 1994).

The model of inclusion suggests that all teachers should be teachers of special education. However, numerous studies revealed that the attitudes of many teachers were not favourable towards the inclusion of students with special needs, let alone accommodate their needs in the general classrooms (Fakolade, Adeniyi \& Tella 2009; Jones \& Guskin, 1984). Historically, negative attitudes have often been reflected toward disabled persons in general (Coleridge, 1993) and these negative attitudes have placed limitations on students with special needs and inhibit the possibility of their success (Altman, 1981; Antonak, 1994; Harth, 1977). The implication here is that teachers' attitudes impact on the inclusion of students with special needs and it is crucial to explore these perceptions and views about the IE phenomenon (Barnett \& Kabsems, 1992; Berryman, 1988; Darocill, 1989).

\section{Defining Inclusive Education}

Research on IE suggests that its meaning may be contextual (Katsiyannis, Conderman, Franks, 1995; Mitchell, 2005; O’Hanlon, 1995) and that it will assume different forms in various places depending on the situation. Swart, Engelbrecht, Eloff and Pettipher (2002) suggest that IE has different meanings in different 
contexts, despite a commitment demonstrated to it by many countries. Examples of this difference in definitions are discussed below.

Roach (1995) defined the term inclusion as serving students with a full range of abilities and disabilities in the general education classroom, with appropriate in class support. In a similar vein, Bennet, Deluca and Burns (1997) viewed the concept of inclusion as the integration of children with developmental disabilities into general classroom for a whole day with special support. According to the United Nations Educational Scientific and Cultural Organisation, inclusive education has wide applicability:

“... schools should accommodate all children regardless of their physical, intellectual, social, emotional, linguistic or other conditions. This could include disabled and gifted children, street and working children, children from remote or nomadic populations, children from linguistic, ethnic or cultural minorities and children from other disadvantaged or marginalised areas of groups” (UNESCO, cited in Aniftos \& McLuskie, n.d, p. 4).

A more restrictive perspective was observed by Peters (2004) who noted that most countries focus their IE efforts on moderately and severely disabled children in the four categories, physical, impairments, blindness, deafness and cognitive impairments.

These perspectives present alternative typologies of IE and diversity of definition and this has resulted in different conceptualisation and practices of IE (Clark, Dyson, Millward, \& Skidmore, 1997; Dyson \& Millward, 1997; Florian, 1998; Topping \& Maloney, 2005). In subsequent sections of this chapter, the key influences behind the move to IE will be explored.

\section{Influences on the Inclusive Education Movement}

The evolution of the IE concept is a construct of many influences including philosophical and political movements, legislative enactments, varying definitions and understandings of disability, economic considerations and the results of evaluations of the effectiveness of special education. These influences will be discussed below in terms of a historical analysis that portrays the IE. 


\section{Historical Context}

Towards the end of the 20th (century and into the beginning of the 21st century) substantial changes have been witnessed concerning the care and education of children with special needs (Gallagher, 2006). This section will trace the forces that have influenced the shift in thinking about the care and education of children with (special needs) disabilities.

Up until at least 250 years ago in most Western countries, arrangements for adults and children with disabilities, or those who appeared to be different, was defined by the lack of care, segregation and inequality (Safford \& Safford, 1996). Those with disabilities were isolated physically within societies, given lesser roles and labelled the "fool" or the "idiot". Many were left to die or became source of amusement. Care for the more financially fortunate was by their families (Doll, 1972; Safford \& Safford, 1996).

In ancient Greece and Rome, decisions were often fatal for children who appeared different from the norm as they were either shunned or killed. These decisions were also supported by the greatest philosophers of that age - for example, Plato proposed that "the offspring of the inferior, or of the better when they chance to be deformed, will be put away in some mysterious, unknown place as they should be” (Edman, 1928, p. 410). Aristotle also defined that there should be "a law that no deformed child shall live” (Edman, 1928, p. 310)

Support and care afforded to people with physical and mental disabilities was first recognised in the Middle Ages when the church took over this caring role. However, strategies and techniques related with special education did not take form until the Renaissance era with its growing focus on humanity. By the 16th century, the work of Pedro Ponce de Leon in supporting deaf pupils in Spain in their speech, reading and writing led to an increased interest in the education of children with hearing impairments within Europe. Children with hearing and visual disabilities first received some steady care in the 18th and 19th centuries (Safford \& Safford, 1996).

In the late 1700's an institution for the blind was opened in Paris by Valentin Hauy to support 12 blind children. Success stories of this initiative resulted in the establishment of schools for the blind in other countries, in other European countries and in the USA (Liverpool, 1791; London, 1799; Vienna, 1804; Berlin, 1806, 
Amsterdam and Stockholm, 1808; Zurich, 1809; Boston, 1829; and New York City 1831).

Scientific attempts to educate children with intellectual disabilities originated in the efforts of Itard, a French physician and otologist. In his book (1807) 'The Wild Boy of Aveyron', he related his 5-year effort to train and educate a boy who had been found running wild in the woods of Aveyron. Itard's work, with the detailed work of Seguin, one of his students, raised the possibilities of educating persons with mental or emotional disabilities. However, it was not until the 20th century when the systematic study of children with disabilities began as a result of the works of people like Werner, Strauss, Montessori, Vygotsky, who introduced some strategies to assist with the development of children with mental retardation (Matson \& Muick, 1991). Special education for people with disabilities became universal in developed countries in the late 20th century.

\section{Emergence of Special Education System}

The works of Jean-Marc-Gaspard Itard (1775-1838) and Edouard Seguid (1812-1880) led to the development of contemporary special education (Hallahan \& Kauffman, 2003). They initiated ideas such as: individualized instruction, the use of functional skills to promote autonomy, the provision of positive feedback to enhance acceptable performance, and the acknowledgment that every child can learn and should be offered education. This emerging system of special education was underpinned by the belief that students with disabilities needed to be educated in an environment separated from their peers and this idea was due to the perceived restrictions that could be caused by their impairments. Nilholm (2003) viewed 'special education' as an “education in which regular education is not thought to be sufficient and is thus closely connected with the differences between children who are so to speak, within the normal curves of regular education” (p. 10). The development of the intelligence test early in the 20th century further consolidated the idea that students could be categorised into groups for which different education was necessary (Crisp, 2007; Matson \& Muick, 1991)

The special needs education movement was a key influential factor that led various countries to acknowledge education for children with disabilities. It resulted in highlighting the issue of the individual's right to education and focused on individualised, child-focused educational models - which utilised a wide range of 
good teaching practices to support students' learning styles. Special education also worked towards developing close relationships with families and promoted the development of teaching methods and aids to make education more accessible. However, in this model, the student with a disability was considered the problem, and minimal attention was directed at investigating the school/class systems that contributed to the issue. The next section will present limitations of the special education system and offer a critique of disability from various perspectives.

\section{Criticism of Special Education - Medical Model}

In the 1960's and 70's, special education was considered in a positive light without criticism. The staff were acknowledged for their commitment to such a challenging cause and they were granted substantial resources (Gallagher, 2006). However, beginning in the mid 70s and into the 1980's, critical voices began to emerge questioning how well the special education programmes were working (Finn, Rotherham \& Hokanson, 2001). Critique of this model or practice was driven by changes in liberal, critical and progressive democratic thought which greatly influenced the education system (Egelbrencht \& Snyman, 1999). The criticisms focused on the moral and ethical rights, exclusive structures, classification and labelling categories, costs as well as a questioning of effectiveness. These perspectives arose from a varied range of arguments as indicated in the key issues below.

\section{Essentialist perspective}

In this paradigm, school failure was related to some defect, pathology, or inadequacy located within the student. This is also termed the medical or psycho-medical model (Brown, 2005; Clark, Dyson, Millward \& Skidmore, 1995). McLaughlin and Jordan (2005) noted that this paradigm presupposed that disability was a stable health condition within the individual that could be diagnosed and categorised. This meant that resources were developed specifically for the individual's disabilities based on these categories and to be delivered within special schooling. Skidmore (2004) argued that this psycho-medical approach, with an emphasis on assessing and fixing the individuals deficit, provided a rationale for special education. In this perspective, disability was viewed as a health problem, not a social issue. In using the medical model, failure was attributed to the individual, not the system. However Slee (2005) 
along with others criticized this model on the grounds that it reduced people to an essential set of characteristics creating teacher low expectations.

\section{Human rights perspective}

In the latter part of the 20th century and from a human rights position, many educators and professionals in the field of special education were questioning the principles behind the placement of children in special schools (Ainscow, 1999). They argued that segregation was morally and educationally inefficient. Jordan and Goodey (1996) were most radical and related this form of segregation to a form of educational apartheid. Furthermore, Nilholm (2003, p. 10) stated that special education cannot be seen as: “a rational answer to children's differences which of course do exist, but rather as an activity that marginalizes and marks children” and Skrtic (1991) supportive of this statement described special education as irrational.

\section{Exclusionist view}

From a sociological perspective, Tomlinson (1982) and others (for example Skrtic, 1986; 1991) critiqued special education as an exclusionary phenomenon which interrupted the rights of the individual to an education. In the same vein, Oliver (1992) was critical of the exclusionary nature of special education which inhibited equal educational opportunities for people with disabilities. The exclusion practice of special education was considered damaging to the individual in that negativity would be ingrained in the student's minds and this could lead to antisocial behaviour (Schafer \& Olexa, 1971).

The idea of classification and labelling, a feature of the special education was also viewed as unmerited. Rioux (cited in Florian, 2007) stated that classification of children, based on their perceived learning ability, often led to exclusion from school which was unjustifiable. Barnes, Mercer and Shakespeare (1999), Barton (1995), and Oliver (1996) added that common practices of segregating children led to the creation of vast numbers of children who were denied ordinary childhood experiences and the potential to live ordinary lives.

\section{Materialist perspective}

The system of special education was often critiqued as inefficient. The proponents of inclusive education argued the need for collating resources to support students within one system of inclusive education. It was believed that from an economic point of 
view, the inclusive system was more cost effective (Stainback \& Stainback, 1989; Wang, Reynolds \& Walberg, 1989). Arguments were directed towards evaluation cost and procedures. Stainback, Stainback \& Bunch (1989a) asserted that evaluation procedures were costly and served no legitimate purpose, thus resources could be utilised in a more educationally-relevant and efficient way.

There were also concerns regarding the cost efficiency of the simultaneous running of a number of categorical programmes (Baker \& Zigmond, 1990; STAFF, 1988). There was a view that the needs of students would be more efficiently met by collating resources together and be used in one system - that of the general classroom. Further, supporters of IE (Gartner \& Lipsky, 1987; Stainback \& Stainback, 1987a; 1987b; 1989; Stainback, Stainback \& Jackson, 1992) argued that replication of services was rampant in dual approaches, which is fiscally irresponsible.

\section{Effectiveness}

Many advocates and professionals questioned the necessity, appropriateness, benefits and effectiveness of segregated provision (Ainscow, cited in Terzi, 2008). Based on his study which focused on the benefits of the special education arrangement for the mentally retarded and learning disabled children, Dunn (cited in Cohen, 2005) argued about the non beneficial outcomes of the special educational arrangement for these students. Though his conclusions were challenged as applying only to those students with mild mental retardation, he challenged the worthiness of the special education service delivery (MacMillan, Semmel \& Gerber, 1995; Semmel, Gerber \& MacMillan, 1995).

Florian (2007) maintained that special education was seen as a fulfilment of the right to education for children with disabilities and with the expectations that the implementation of rights-based special education laws would promote social and economic acceptance and enable disabled children to participate in community life as adults. However, a series of national surveys (Harris \& Associates, 1986; 1987; 1989) undertaken in USA found that disabled people were less well educated, less likely to be employed and less likely to participate in social activities than non disabled groups with the result that special education was not preparing children with disabilities for post school life (Florian, 2007, p. 8). 


\section{Integration}

Given the questioning of the effectiveness of segregated placements and the issue of human rights, there was a reconceptualisation of the special needs concept. This was based on the premises that it was immoral to segregate students and that the difficulties experienced by learners resulted from the manner in which schools were organised and from forms of teaching (Ainscow, 1999). It was on these grounds that Ainscow (1999) made a suggestion that schools needed to be reformed with an improvement in pedagogy to address diverse needs of learners. Viewing individual differences as opportunities for enriching learning, rather than problems, was a recommended alternative perspective. With such a conceptualisation, a consideration of difficulties by educators and experienced by learners would provide an agenda for reforms, and insight into how such reforms could be brought about. This kind of approach was considered to be more successful in contexts where there was collaboration that encouraged and supported problem solving.

On the basis of these arguments, there was a progressive shift towards more integrated settings, where children with disabilities were educated within mainstream schools (Ainscow, 1999; Pijl \& Meijer, 1994). Pijl and Meijer (1994, p. 4) defined integration as "a collective noun for all attempts to avoid the segregated and isolated education of students with special needs, and furthermore specified integration as 'conceived' in terms of the organisational structure and in terms of the nature of integration”. In general, integration was viewed as the least restrictive environment for students with disabilities and promoted the placement of students with disabilities in the regular classroom for any part of the day (Menzies \& Falvey, 2008). In support of mainstreaming, Jordan and Goodey (cited in Rouse \& Florian, 1997) maintained that being in mainstream schooling provided a pathway for people with disabilities to be socially accepted in mainstream society.

\section{Integration Developments and Critique}

The notion and practice of integration however did not appear to be a feasible alternative and a number of concerns were expressed (Ainscow, 1999; Rouse \& Florian, 1997). These resulted in the inclusive education movement.

Firstly, there was the issue of quality. Many professionals in the field of special education questioned the narrow interpretation of integration. Integration was viewed as the 'main-dumping' of children with special educational needs in mainstream 
schools, with no consideration to the quality of the education provided (Lewis, 1995).

In many cases integration was just a variation of special educational practices in the sense that it was developed as a means to avoid segregation (Lewis, 1995; Pijl, Meijer \& Hegarty, 1997) but very little improvement in terms of the actual content and practice of education. Furthermore, professionals in the field of special education critiqued the emphasis on the practice of identifying children with disabilities or special educational needs, and this resulted in attention to the individual's social development as well as the relation between special educational needs, and the schooling systems. What occurred was that the integration movement led to incorporation of children into regular schools and classes, without changes being made to accommodate the learners. Therefore there was a call to change the educational systems to accommodate the diversity of children (Ainscow, 1999).

The second, influential factor behind the move from integration to inclusive education was attributable to disabled people's movements and by self-advocacy groups who pushed for equal consideration and entitlement. These groups also argued for accessibility to education. Because of these movements, the recognition of the rights afforded to disabled people and the affirmation of the rights of children with disabilities and special educational needs to be educated in regular schools was acknowledged (Terzi, 2005).

The effect was that IE was developed as a means to remove barriers and discrimination, and to ensure the full participation of all children in their schooling. This notion of a human right, and rights in relation to IE, was reinforced by international policies and often resulted in laws being enacted to confirm provision for these students. For example, the PL94-142 in the USA was the fore-runner of a number of enactments throughout the world that set in place the move towards IE.

\section{International Policies and Legal Aspects}

International policies (UN, 1989; UNESCO 1994) also played a significant role in strengthening arguments concerning the need for all children to be educated within the regular classroom. For example, the main document which assumed a human rights viewpoint (and with stated IE aims at the international level) emerged from the 1994 Salamanca World Conference of Special Needs Education and was expressed 
in the 'Salamanca Statement' developed by 92 governments and the 25 international organisations (Lindsay, 2003). The statement highlighted the need for adequate provision for children, youths and adults with special educational needs (UNESCO, 1994). It noted specifically that:

Every child has a fundamental right to education and must be given the opportunity to achieve and maintain an acceptable level of learning ... those with special educational needs must have access to regular schools which should accommodate them within a child-centred pedagogy capable of meeting these needs [UNESCO, 1994, p. 10].

The Salamanca Statement represented an important international declaration at policy level, on which governments and international agencies were called to act in order to promote and establish inclusion in education. In this sense, it was a significant imperative because it encouraged the worldwide trend towards providing different responses to the educational demands of children with special educational needs to those traditionally associated with segregated and special provision (Ainscow, 1999).

Apart from such influential policies, the growing awareness of the notion of diversity resulted in legislation in many countries to enforce rights of students with disabilities to be educated within the mainstream classroom. In a number of countries legislation has impacted upon the provision of education for students with special needs. For example the congress of the United States in 1975 proclaimed Public Law 94-142, or the Education for All Handicapped Children's Act as a number of disabled children did not have access to the state's public schools. The legislation, now renamed the Individuals with Disabilities Education Act (IDEA) (1), was written to ensure access to a free and appropriate education for children with disabilities - an education that acknowledged their unique needs and provides related services to meet these individual needs (Sands, Kozlesky, \& French, 2000).

In the UK, the Warnock Committee Report (1978) and the 1981 Education Act endorsed the principles of integration. Australia too, has produced two pieces of legislation which work towards supporting the rights of people with disabilities. These are the Disability Services Act (1986) and the Anti Discrimination Act (1991). In New Zealand there was a response to PL94-142, the Warnock Report and to the Australian Act and this was contained in the New Zealand Education Act 1989, 
Section 8 which legislated for equal rights to primary and secondary education. This New Zealand Act stated that individuals with special educational have the same rights as individuals without special needs to be educated in government schools.

This type of legislation illustrated that various countries had commitment towards IE. The question of the effectiveness of this type of service delivery however still remains topical and has resulted in heated debates in the literature of special education. The next sections will examine the concept of IE and its characteristics, its practice as well as concerns that have been identified in the literature. The social model of disability, as it relates to IE is the point of departure for this discussion.

\section{Inclusive Education - A Social Model}

Elsewhere in this chapter, the medical model of disability has been discussed and inherent in this medical approach was the notion that the student's failure to learn was attributed to a problem within the student. From the same stance, Naicker (2005) argued that the underpinning philosophies concerning failure to learn establish the belief that the problem was located within the learners with very little mention of system deficiencies. The social model of disability that focused on the ways in which society contributed to the construction and maintenance of handicap challenged the traditional assumption that society merely responded to it (Graffam, 2005). The social model made an assertion that special needs were created socially (social constructs) and that special education was a system in which structural inequalities at the macro social level were reproduced in the institutional form. Within this paradigm, barriers were viewed as being caused by society and this limits access for people with disabilities - The barriers were in place because they served the interests of the social majority (Graffam, 2005; Mc Laughlin \& Jordan, 2005; Mitchell, 2005; Skidmore, 2004). However, Skidmore (2004) has critiqued this sociological approach for lack of empirical support, adding that at the practical level there was little mention of the interest and role of schools and teachers. Taking this inclusive debate further, he argued that from an organisational perspective the limitations and inadequacies in the way schools were organised was a cause of learning difficulties for students.

The notion of the social model of disability is supported by Bronfenbrenner's ecological systems theory (Boyd \& Bee, 2006; Paquette \& Ryan, 2001). 
His theory defined layers of environment which shaped the child's development and these layers interacted with one another and shaped development. The micro system included the family, classroom or systems in the immediate environment in which the child is operating. The mesosystem involved the interaction between the two microsystems, the child's home and school. The exosystem referred to the environment in which the child was indirectly involved and was external to his experience and yet had an influence such as the workplace of the child's parents. The macrosystem was concerned with the larger cultural context which included the values and beliefs of the culture in which a child is growing up. The final level in Bronfenbrenner's theory was the chronosystem. This system dealt with the influential factors pertaining to the child such as his life experiences, which include the history of the individual as well as events that occur in his life (Boyd \& Bee, 2006; Paquette \& Ryan, 2001). As noted in this discussion, these systems interacted and impacted on the development of the child. In relation to the education system, the school environment which included the teacher played a major role in shaping the child's development and thus issues that explicitly caused exclusion need to be addressed if inclusion is to occur.

Bronfenbrenner's approach has considerable merit for understanding IE. It explains that the total environment needs to be considered to provide an environment that is conducive to learning. For IE to be effective there must be consideration given to the child, the family, the school and the culture.

The discussion that follows will consider the arguments in support of IE. It will also offer a critique of this service delivery model before examining the factors that influence the implementation of inclusive education programmes and policies.

Cohen (2005) argued that part of the reason why there were debates about special education was that there was contradictory evidence about the effectiveness of this service delivery model (special education). IE was argued as an alternative service delivery model driven by the idea of value and rights which emphasised the notion of an inclusive community (Jenkins, Pious, Jewell, 1990; Lilly, 1988; Pearpoint \& Forest, 1992; Stainback \& Stainback, 1992). The model was grounded in the 'rights' discourse, and was motivated by the concept of cost efficient from the materialist perspective, and underpinned by a philosophy of democracy as detailed below. 


\section{Rights discourse}

From the human rights perspective, the concept of IE has been viewed as a 'rights' agenda, promoted by those who believed that inclusion was a matter of human rights and a liberal society (Florian, 2005; Thomas, 1997). The debates centred around the rights of children with disabilities to attend mainstream schools (Ainscow, 1991; Forest, 1988; Slee, 1993; Stainback \& Stainback, 1992; 1996) and the ways in which schools needed to change to make this perspective a 'reality'.

\section{Democracy and egalitarianism}

The inclusive movement was also driven by a shift in philosophical perspectives, and political movements which resulted in the development of a liberal progressive society which recognized and promoted the concept of diversity and egalitarianism. The IE proponents maintained that IE was underpinned by philosophy of egalitarianism and democracy. Pearl and Tony (1999) proposed that IE was not an end in itself but rather considered as an avenue for democratic citizenship. According to Slee (cited in Florian, 2007) "inclusive schooling is a precondition of democratic education” (p. 160). Knight (2000) alluded to the same notion when he argued that inclusive education is a precondition of a democratic education. The principle of ‘inclusion’ becomes a means contributing to defined ends; 'inclusion' is not treated as an end in itself. Proposed here is a cognitive democratic theory of education that merges ‘inclusive education' and social inclusion, within broader epistemological principles (p. 17).

\section{Cost efficient}

One of the arguments in support of the inclusive phenomenon was in relation to cost efficiency. For example, in the critique of special education as stated earlier in this chapter, it was argued that IE was a more cost efficient way of service delivery when all resources were collated to support all students within one classroom (Stainback et al., 1989a). There was however little evidence to support this allegation.

\section{A value issue}

Arguing from a moral and ethical position, Stainback and Stainback (1988) maintained that inclusion was a 'right' thing to achieve, and they also argued that inclusion was an ethical other than a research issue. The idea of being included for ethical, moral, and legal reasons creates a just society and was deemed very crucial 
(Biklen, 1992; Ferguson \& Asch, 1989; Snow, 1989; Strully, 1986; 1987; Worth, 1988).

Furthermore, the inclusive process was seen as a way to assist in 'adjusting' the student with disability into the community. For example, Ferguson and Asch, (1989); Wehman (cited in Karagiannis, 1990); and Stainback and Stainback (1996) made a case that parents perceived inclusion as their child's passport to fitting into the community life. Karagiannis, Stainback and Stainback (1996) argued that inclusion of these students in school was a sign of equality and value in society and that they should not have to go through a 'magnifying glass' (via assessments and tests) to assess their rights to be in an educational environment (and in the society). This argument takes into account the importance of being a valued member of a community, and the school community was viewed as a place where diversity is valued and where each individual has something to contribute.

\section{Benefits}

One of the arguments for inclusive education was driven by its perceived mutual benefits for learners and the teacher. For example, Stainback and Stainback (1996) maintained that placing students with disabilities in inclusive settings benefit not only students with disabilities but other students, as well as the teacher and the society at large. With regards to children with disabilities, research showed an improvement in area of socialization skills (Guralnick, 1990; Johnson \& Johnson, 1987; Strain \& Odom, 1986; Van den Pol, Crow, Rider and Offer, 1985); academic achievement (Madden \& Slavin, 1983) as well as communication skills (Cullinan, Sabornie, \& Crossland, 1992). The argument was that through interaction with the environment and contact with people, children with disabilities would model appropriate behaviours. Vandercook, Fleetham, Sinclair and Tetlie (1988) maintained that, integration gave the opportunity for children to grow together and learn from one another. Furthermore, skills attitudes and values that were necessary for inclusion would be acquired.

Advocates for full inclusion of children with developmental disabilities indicated that it was the children's democratic right to be educated with their peers and that integrating them with non-disabled children enhanced interpersonal skills. There was also a view that students with disabilities could teach non-disabled learners to move beyond dysfunctional stereotypes. Taylor (1999) developed this point further, by 
stating that all students with behaviour disorders were not aggressive, and students with learning disabilities could be highly capable in some academic areas. It is important to note however that simply mainstreaming students with disability does not guarantee they would learn (Marston cited in Karagiannis, Stainback \& Stainback, 1996). Learning occurs only when these students are provided with support (Brinker \& Thorpe, 1983; 1984; Epps \& Tindal, 1987).

\section{The benefits for regular students}

Stainback, Stainback and Forest (1989) found that the non-disabled learners themselves learn some cooperative learning skills via inclusion. This idea was also echoed by Taylor (1999) who maintained that inclusion offers the non-disabled student an opportunity to develop appreciation for the complexity of human characteristic as well as an appreciation for individual differences. For example, the non-disabled students would come to realise that having an impairment like a speech problem does not necessarily indicate limited intelligence and cognitive impairment. Furthermore, Van Krayenoord, Elkins, Palmer and Richards (2000) reported that positive attitudes were developed within students who did not have disabilities about students with disabilities but McGregor and Forlin (2005) found that "the presence of students with disabilities alone is not always likely to produce a significant improvement in the attitudes of mainstream students” (p. 11). They argued that students in mainstream became more accepting of students with disabilities provided there was an active, structured inclusion programme which included monitoring to ensure that mainstreaming is a positive experience.

\section{Teacher benefits}

Benefits have also been noted to accrue to teachers - for example the collaborative and psychological support from working together with other teachers, can lead to improvement of 'professional skills' (Elliot \& Sheridan, 1992). A further benefit for teachers related to the notion of empowerment via knowledge learned via this educational collaboration and consultation. Research has found that a number of teachers show a willingness to work together with special school teachers in planning for an inclusive environment, provided they are involved in in-service training and in the planning process (Giangreco, Dennis, Cloninger, Edelman \& Schattman, 1993). 


\section{Criticism of Inclusive Education}

Although the benefits of IE have been acknowledged, IE that was underpinned by the social model of disability has been criticized because it reinforced the dichotomy of the artificial categorisation of disabled-non-disabled (Goggin \& Newell, 2003). It was also argued that the needs of special education students cannot be met in regular education classes without specialists support to teach them (Fuchs \& Fuchs, 1994; Kauffman, 1994). In addition, it was often noted that there was inadequate resource to support the students. In the United States, the term 'main-dumping' was given to the process of moving students with disability from the special schools to the mainstream (Stainback \& Stainback, 1990). This term referred to not being prepared to receive students with disability in terms of the resources needed. There was also a concern that education of 'typical' students would be disrupted in the inclusive environment. There has been little evidence however supporting this latter point.

It is reasonable therefore to add that, while the importance and potential benefits of including children with disabilities in mainstream education are often maintained and are supported by research, the application of inclusive practice is challenging for many educators. For example, the criticisms already mentioned have resulted from an issue of the effectiveness of the inclusive programmes. Many programmes suffer from lack of resources and administrative support. Teachers in inclusive classrooms are often required to include students with disabilities without sufficient classroom support or training (Henderson, 1994) and that even with an increase in empirical research which supports inclusive practice there are still many gaps.

Barry (1995) made this point clear in his assertion that including students with special needs in general classrooms impacted on those responsible for the education of these students and attitude was perceived as one of the major issues. It was further claimed that the attitude of those involved defined and determined the effect of inclusive practices on the students who are placed in this setting. Clearly, the success of any policy implementation depends predominantly on the teachers - thus the inclusive classroom is an educational context in which teachers require new ways of thinking about their roles and new skills to respond to the challenges of IE.

This raises an important issue. IE needs to be considered from the perspective of the key actors and yet the implementers, the teachers have had minimal voice in this. Studies need to be undertaken to examine the perceptions of the range of key 
stakeholders and central to this understanding are the beliefs, and attitudes of the teachers. The next discussion focuses mainly on studies that have been undertaken on views and attitudes of teachers and parents.

\section{Teachers' Attitude}

The concept of the attitudes and perspectives that teachers portray are considered learned and have become this way because of the influences of personal experiences, parental and collective experiences and also physiological factors (Oskamp,1991). Thus attitude can be argued as having a cognitive (learned) component, an affective (feelings/emotional) component as well as a behavioural component (Opdal, Wormnaes \& Habayeb, 2001; Swart et al., 2002). Fishbein and Ajzen (1975) maintain that beliefs convey "... the information that a person has regarding some attribute of an object ... the object of a belief may be a person, a group of people an institution, a behaviour a policy, and event” (p. 12).

Teachers hold certain beliefs about their work, the students they teach and their confidence to impact performance of students (Pajares, 1992). Some teachers are believed to have attitudes so entrenched in their beliefs, especially in relation to students and their learning, that the likelihood of these beliefs to undergo some type of change is minimal or next to impossible. The same applies to theories and values teachers hold as these shape their teaching practices and preferences for students (Kagan, 1992). It is well established that teachers' expectations about students will affect their instructional tolerance that is the range of variance in disabilities a teacher can effectively accommodate. This in turn necessitates the exclusion of some students with disabilities because teachers’ knowledge is finite (Good \& Brophy, 1990).

Some research that have been undertaken over the past two decades explored the attitudes, beliefs and concerns of general classroom teachers about inclusion of students with special needs into the general classroom. The following section will provide a summary of studies on teacher attitudes towards including students with special needs and factors that have been highlighted in the literature as influencing these attitudes. Studies on the views of parents of students with/without special needs will also be discussed. 


\section{Teacher's Attitude - International Studies}

It has been argued that teachers' attitudes can determine the day-to-day practices of classroom teachers. Internationally, several studies have investigated school educators' attitudes toward inclusive education (e.g., Forlin, 2004; 2003; Forlin, Jobling \& Caroll, 2001; Hobbs \& Wrestling, 1998; Idol, 1997; Loreman, 2002; Subban \& Sharma, 2006). Generally, it was identified that teachers in many countries appear to be more supportive of IE in rhetoric but have misgivings in the actual implementation. The literature identified a number of factors that appeared to influence teachers' attitudes and these were related to the educational environment (support services, classroom layout, class size, curriculum, funding and time); the student (severity of disability, lack of time to teach student with disability); as well as the teacher (training, experience) (Avramidis \& Norwich, 2002; Bradshaw \& Mundia, 2006). These factors will be discussed below.

Shruggs and Mastropieri (1996) conducted a meta-analysis involving 28 survey reports executed between 1958 and 1995, of teacher attitudes towards mainstreaming in USA, Canada and Australia. It found that although two thirds of teachers were supportive of the concept of integration in general, one third or less believed that they had insufficient time, skills, training and resources necessary to feel confident or competent in meeting the needs of students with disabilities in their classrooms. Vaughn, Schumm, Jallad, Slusher \& Saumell (1996) also identified high class roles, funds, teachers' overload and issues related to standardized evaluation to affect teachers' attitude to inclusion.

Issues have also been encountered by teachers in the regular classroom setting that were related to time factor and the challenge in acquire resources to support certain disabilities in the classroom (Harris \& Stephenson, 2003; Jahnukainen \& Korhonen, 2003; Jenkins, 2002; Westwood, 2003; Wrights \& Sigafoos, 1998). Sutherland (2000) reported that the high school teachers expressed feelings of helplessness as they felt that they did not have the time or the expertise to deal with the high needs of these students. The same concern was noted by Watson (2004) in a study conducted with secondary teachers. He reported "teacher isolation, frustration, and a sense of teachers being overburdened" (p. 11), in trying to meet the needs of students with learning difficulties in the mainstream. 
Expectations of teachers are also an important consideration. Studies showed that the manner in which many teachers behave towards "students for whom they hold high expectations" differed from the way they related to "students for whom they hold low expectations" (Good \& Brophy, 1990 p. 29). Factors related to the child that affected teachers' attitude included the severity of the student's disability, the challenges posed by the student behaviour and the lack of time to teach students with disabilities. Brennan (2002) stated that inclusion of students with disability impacts on teacher's workload thus affecting the learning of students with disability.

Research suggested that, irrespective of teaching experience, the severity of disability showed an inverse relationship with positive attitudes - as the perception of severity increased, teachers' positive attitudes decreased (Forlin, Douglas, Hattie, 1996). This notion was supported by other studies which revealed that teachers had a preference for kinds of disabilities that should be integrated into the general classroom (Avramidis, Bayliss \& Burden, 2000; Ward, Centre \& Bocher, 1994; Westwood \& Graham, 2000). The emotional and behavioural disordered students were less favoured and were regarded as cause of teacher stress (Forlin, 1995). Teachers appeared more acceptable of students with mild disabilities rather than students with more severe disabilities and challenging behavioural problems (Dupoux, Wolman \& Estrada, 2005; Huang \& Diamond, 2009; Ward, Centre \& Bochner, 1994).

Generally, teachers find it challenging teaching students with severe disabilities, but especially those with social maladjustments and emotionally disorders due to a lack of training and support and large class sizes (Leyser \& Tappendorf, 2001; Scruggs \& Mastropieri, 1996). Waddington and Reed (2006) in their study on professionals and parents views regarding students with autistic spectrum disorders (ASD) cited child factors such as behavioural problems and learning difficulties as primary reasons for the exclusion of these children from the mainstream.

Another factor that is important for impacting on attitudes relates to the educational context. It has been argued by teachers that various educational reforms often driven by educational authorities contribute to the pressure on teachers to implement reform after reform and sometimes before one policy is fully implemented another one is underway. Other contextual concerns raised by teachers relate to appropriate support services, classroom layout and restructuring of buildings, class size, curriculum, 
funding, and time. Slee and Allan (2001) argued that there was too much emphasis on talk and minimal consideration given to policies that caused exclusivity. Their arguments were geared toward such concepts as 'marketisation of schooling', national curriculum, and standardized testing, and the establishment of pupil referral units that become part of the educational setting. They argued that these variables led to exclusion. Using focus groups, Waddington and Reed (2006) investigated views of professionals and parents with autistic spectrum disorders (ASD) about inclusion of children with ASD into regular schools. The findings showed a consensus between professionals and parents that school factors such as school commitment and funding were critical success factors for inclusion.

\section{Teachers’ Attitude - Pacific Studies}

A few studies have been undertaken in the Pacific area on perceptions and beliefs of people from some Pacific Island nations about the inclusion of people with disabilities in education. For example, in Tokelau, Meredith (2006) suggested that the medical or deficit model of disability prevailed. The author speculated that there might be a possible change in attitude towards IE however; there was no supportive evidence for this assertion. Rombo's (2007) study in Papua New Guinea, which involved teachers and school administrators, identified school and cultural factors which impacted on IE. One of the indicated factors related to the teachers' understanding of special and IE. In another study, Daveta (2009) examined the perspectives and attitudes of Fijian teachers from primary, secondary and special schools regarding the inclusion of children with disabilities in schools. The findings revealed that although teachers were supportive of the IE concept, they were uncertain about the inclusion of students with severe disabilities. Factors that influenced teachers' attitudes were related to training, funding, as well as resources (such as specialised personnel and equipment) to support students with disabilities.

In Samoa, a comparative study (Tufue, 2001) was undertaken regarding attitudes of teachers from a government regular school that had no special needs unit, and teachers from the school with a special needs unit. It investigated the attitudes of teachers about the integration of children with disabilities in the general classroom. It was found that teachers in the special unit were more supportive of the idea of integration as opposed to teachers from the same school who taught in regular classrooms. Furthermore, teachers from the regular government school that had no special needs unit were not supportive of integrating children with disabilities. The 
findings also indicated that teachers who taught in special needs units felt "miserable" and alienated within this setting due to negative attitudes and lack of support from teachers in general classrooms and from the education ministry.

These findings were supported by other global studies (above) which found negative attitude of teachers as the major influential factor in the implementation of IE programmes and policies (Sharma, Loreman \& Earle, 2006). Concerns appear to stem from the notion that teachers would need additional tools and skills for coping with the social and emotional problems that accompany inclusive schooling (Idol, 1997). For example, a study on school improvements which relates to teaching strategies for including all learners, was conducted on teacher education in 14 countries in 1980 by UNESCO. The study found that the majority of teachers were willing to accept learners with special needs in their classes but lacked confidence because of lack of training. Training was something that most teachers perceived as crucial (Salend 1984) and considered it as the vehicle to learn about how to deal with learners with special needs (Ainscow cited in Kisanji, 1999). The lack of training and experience concerning students with special needs was seen as leading to additional teacher stress as the teachers were already coping with a diverse set of student needs.

However, it is worth noting that experience influenced teacher attitude towards teaching students with special needs. For example, studies found that teachers who have had experience teaching students with special needs tend to be more favourable towards teaching these students in the regular classroom. Villa, Thousand, Meyers and Nevin (1996) found that teacher commitment occurred at the end of the implementation period when teachers had gained mastery of the necessary professional expertise to implement inclusive programmes. This could be explained by LeRoy and Simpson's (1996) findings that as the confidence of teachers both in their teaching efficacy and in successful inclusion increased, their experience in teaching children with special needs also increased. Avramidis, Bayliss and Burden (2000) in their survey on mainstream teachers' towards inclusion, found that teachers who had more positive attitudes attributed this to the active experiences they had in implementing inclusive programmes. Their study revealed that participants who demonstrated competency to deal with students special needs showed a positive attitude towards inclusion. A further finding revealed that gaining substantial training in special education led to a significantly higher positive attitude than those who received no training about inclusion. This finding suggests the importance of training 
in changing attitude (Avramidis, Bayliss \& Burden, 2000; Avramidis \& Norwich, 2002).

\section{Parent's Attitudes - International Studies}

Parent's views also need to be considered, as increasingly their voice is being recognised as a potent force in determining development in special education (Moore, et al., 1999). Findings from an Australian study which consisted of 354 parents of children with disabilities about their attitudes towards IE found that many parents favoured inclusion, some parents preferred inclusion if there was an availability of extra resources, while a small number of parents preferred placement within a special school (Elkins, van Kraayenoord \& Joblin, 2003). Wrights and Sigafoos (1998) found that parents were concerned about loss of students' self worth within the mainstreamed setting.

Parents also have an important contribution to make to the education of their children. For example, a study on attitudes of parents and professionals regarding educational support available for children with autism found that parents viewed specific training on autism for teachers crucial for the success of any mainstream placement. Parents and professionals also agreed that the quality of delivery, staff training and effective adaptation of the curriculum was fundamental to creating an inclusive environment (Jindal-Snape, Douglas, Topping, Kerr \& Smith, 2005).

Another voice that impacts upon teachers belongs to the parents of 'typical' students within the regular classroom who have objected to including students with special educational needs (disabilities) in the regular classroom. These parents viewed inclusion of students with special needs (in terms of disability) as affecting typical student's learning. The typical criticism was including these students slows down the learning of other students as the students with special needs would consume much of the teachers' time with less time available to be spent on other students. Irmsher (1995) noted the concerns of many teachers and parents of children without special needs regarding inclusion of students with special needs. They believed that the result would lower the academic standard within the mainstream classroom.

This review on teachers' and parents' attitude (towards including students with special needs into general classrooms) showed that including students with special needs was a cause of concern for many teachers due to a range of factors. Attitudes 
of parents on the other hand noted a positive attitude towards inclusion from parents of children with special needs and an adverse attitude from parents of non-disabled children. Given the teachers' role in implementing policies it is crucial that their needs be taken into consideration. In relation to this, a consideration of effective teaching strategies that teachers could draw upon to facilitate the inclusive classroom teaching is imperative. The next section will discuss the models of inclusion including the teaching strategies that have been argued as more effective for an inclusive setting.

\section{Models of Inclusive Practice}

The argument as to what constitutes a 'practical' type of inclusion is still ongoing. For example, there have been moves towards what has been described a more 'cautious' or responsible form of inclusion (refer to Vaughn \& Schumm cited in Evans \& Lunt, 2002). Inclusion proponents argue that individual pupils have an overriding right to an appropriate education although some would say that there is a small minority of pupils with severe and complex needs who cannot be mainstreamed (e.g., Pijl \& Meijer, 1991).

According to Heiman (2004), there are four different models of inclusion: (a) in-andout, (b) two-teachers, (c) full inclusion and (d) rejection of inclusion. In her study of inclusive education in the United Kingdom and Israel, Heiman found that most of the teachers in United Kingdom and Israel viewed the in-and-out model as more effective for the students with learning disabilities. These teachers believed this approach was the most beneficial for students with disabilities because they not only receive special instructions but also mix with own peers in regular settings. The twoteacher model was popular in Israel but less so in the United Kingdom. This model involved the regular class but with a special education trained teacher focusing on the students with disabilities. A small number of teachers in both countries believed that full inclusion was the appropriate model for the regular classroom. They thought that with additional support and cooperation between teachers and with the services of the educational system, full inclusion could succeed and be the most beneficial for all.

In Heiman's study, some teachers in both countries rejected inclusion completely. These teachers preferred separate classes for students with disabilities so they could progress at their own pace. It was believed that this approach was effective since 
special needs students in the inclusive class would never be able to reach the academic level of the mainstream students. Similar models were observed in Malaysia where the full inclusion appeared to be the least method used and most teachers would apply 'hybrid' models such as two-teachers and in-and-out approaches.

The above study highlights the idea that IE can be viewed in many different ways and that often the full inclusion model was least preferred by teachers.

\section{Effective inclusive practice}

Inclusive practice is noted in the literature as being one of the main challenges and from this stance, Aefsky (1995) maintains that teaching children with developmental disabilities in inclusive settings is a task that requires the people to work cooperatively to provide best practices for a child with developmental disabilities. He highlights some sound educational practices that are utilised in educational settings such as, 'cooperative learning, peer tutoring and community building in classrooms and schools' which can also be utilised in the inclusive classroom. Giangreco (1997) also shares the same view by identifying the common features of schools where inclusive education is reported to be thriving. These features entail collaborative teamwork, a shared framework, family involvement, general educator ownership and clear role relationships among the professionals involved.

It has become apparent then that one of the keys to an effective model of IE is the adoption of an effective instructional environment, balanced with positive teacher attitude. Barry (1995) has for example argued about the importance of developing a curriculum to suit diverse levels of disabilities. Rather than differentiating the curriculum due to the student's disability, he argued that the instructional process should be modified and adapted to meet the needs of the child with disability so that they could be included in the general classroom learning. Barry also suggested the importance of having innovative teachers who utilise creative teaching strategies, such as learning centres, cooperative learning, concept teaching, directed teaching and team teaching, for inclusion purposes.

This view concerning the importance of instructional practices is largely accepted by many educational professionals and writers but other factors also need to be taken into consideration such as time, teacher knowledge and training. Such factors are 
related to teacher attitudes towards teaching students with special educational needs. Woley, Werts, Cladwell, Snyder and Lisowski, (1995) noted that when inclusion is implemented, attitudes must change. Therefore, it is important for teachers to be prepared emotionally and intellectually be able to deal with issues they will encounter. The development of positive attitudes towards children with disabilities needs to be adopted by key adults within the inclusive environment (Forest, 1987a; 1987b; Johnson \& Johnson, 1984; Karagiannis \& Cartwright, 1990; Stainback \& Stainback, 1988; Strully, 1986; 1987). However, it can be argued that positive attitude does not occur in a vacuum, attitude change takes place through professional development and training.

It can be concluded that although there is considerable discussion and debate about IE, there are some generally accepted notions that define its implementation throughout educational systems. The key arguments for inclusion revolve around the ideas summarised by Bennett, Deluca and Bruns (1997); Giangreco, Cloninger and Iverson (1998); Gillies, (2004); Marsden, (1996); Stainback and Stainback, (1995); and Trainer, (1991) which identify that:

- $\quad$ segregation of students is morally unacceptable and this is an argument centred more around social benefits than academic achievements. The typical student also can benefit from the opportunities afforded by mixing with special needs students;

- $\quad$ everyone benefits from inclusion. Typical students become more sensitive to the needs of others, more tolerant and develop empathy toward others. Students with special needs improve socially and academically and teachers also benefit in terms of expanding their understanding of students needs and develop a wider range of teaching skills; and

- $\quad$ a mixture of IE practices and pull-out provision is often favoured by many.

However, there are concerns about IE (Banerji \& Dailey, 1995; Barkley, 1998; Epsin, 1998; Kauffman \& Hallahan, 1995; Lieberman, 1988; Sale \& Carey, 1995; van den Bos, Nakken, Nicolay \& van Houten, 2007; Weiner, 1969) and these include that:

- there is a need for individualised instruction and a structured environment for the students with special teaching needs; 
- it placates parents and the public but little is actually done to support the students;

- $\quad$ it is a philosophy adopted for non-educational reasons and is often impractical;

- $\quad$ the IE context may be inappropriate for students with disabilities because they can be ridiculed by other students; and

- $\quad$ IE is not a cost-effective response.

The next section will generally discuss the notion of change and issues related to change implementation, then more specifically comment about how teachers (policy implementers) deal with the change phenomenon. Discussion will follow regarding the concept of teacher professional development as a means to promote change of teacher thinking and behaviour.

\section{Teacher Professional Development}

Change in schools and classrooms is a complex phenomenon because it requires transformation in professional development, curriculum and student support services as well as changes in teacher attitudes and beliefs (Fullan \& Miles, 1992). Teachers need to be supported to understand the importance of an instructional reform and they need to have the confidence in their own ability to "develop and implement programmes that will lead to improved student achievement” (Weiner, 2005, p. 65). Professional development programmes should be able to convince teachers "that properly communicated, coherent and well-designed initiatives are worth the time and effort to employ because the outcomes are consistent with their values and objectives” (Weiner, 2005, p. 65). If professional development fails to convince teachers of the value of an initiative this could generate teacher stress and ineffectiveness.

Meverech's (1995) study of teachers' classroom practice following the introduction of a curriculum improvement programme found that teachers were initially rigid in utilizing the new teaching methods; however their attitudes became more accepting towards the imposed change, when they had developed the competence to employ the new skills and methods. This finding implies that a change in thinking and behaviour does occur when teachers have gained the ability and confidence to deal with change. This complements the point made by Guskey (1995) about encouraging 
teachers to discard old beliefs and behaviours. There is a strong argument that professional development changes teacher behaviour and way of thinking with the objective that it will in turn lead to improved student achievement. This importance of effective professional development to induce positive attitude to change cannot be overemphasised.

According to the literature (Abadiano \& Turner, 2004; Garet, Porter, Desimone, Birman \& Yoon, 2001; Klinger, 2004; NJCLD, 2000; OECD, 1998; Penuel, Fishman, Yamaguchi \& Gallagher, 2007), effective professional development entails a range of activities and approaches some of which include: facilitating links between the design of the professional development, teacher learning implementation and student outcomes, provision of long-term support, teachers as knowledge generators, collaboration, continuous professional development, school-based processional development, support networks, management support, resource availability and flexibility of practice. These have all been identified as important for effective professional development.

Although certain practices have been identified as important for professional development, Guskey (2003) makes the point that not all of these activities enhance practice or learning outcomes and he suggested the importance of developing context specific school programmes. He noted that teacher development and practice may be enhanced by success factors such as relevance, interaction, and active learning, but the specific context of the teacher learners was the critical factor to be taken into account. He suggested that a programme was designed to meet these needs and conditions and implied was the importance of developing professional development activities that were more meaningful for teachers.

Professional development needs to be effective. The literature notes that one important aspect of effective professional development is teacher motivation. Guskey (1986) noted that one of the main reasons for failure in educational programmes is due to lack of consideration given to what motivate teachers to be involved in professional development programmes. It is therefore crucial that consideration be given to motivational factors which inspire teachers to participate in learning experiences so they will be able to improve students’ learning achievement.

Motivation according to Hynds and McDonald (2009), refers to "perceived incentives and disincentives that influenced the teachers' initial and sustained 
engagement in a professional development programme” (p. 5) Motivation strategies that were noted (Oregon School Boards Association, (OSBA), (2009) to improve teachers performance included extrinsic factors such as "incentives payments, development of career ladders and differentiated teaching roles as well as intrinsic qualities - such as self-respect, responsibility, and a sense of accomplishment” (cited in Hynds \& McDonald, 2009, p. 5). Other researchers investigating teacher motivation in terms of professional development identified a mix of extrinsic and intrinsic factors. For example Stout (1996) noted "salary improvement, improved certification, career opportunities and knowledge/skill acquisition” as key teacher motivators. Livneh and Livneh (1999) identified "salary enhancement and networking opportunities" as important factors that increase participation in professional development (cited in Hynds \& McDonald, 2009, p. 5).

It can be argued that the concept of transfer of learning and knowledge is the core of professional development. That is, ideas learnt from training/professional development should be transferred into the educational setting. Deese (cited in McDonald, 2009) made this very clear: "There is no more important topic in the whole psychology of learning than transfer of learning ... practically all educational and training programmes are built upon the fundamental premise that human beings have the ability to transfer what they have learned from one situation to another" (p. 213). McDonald (2009) added, unless there is transfer of learning occurring, professional development is meaningless.

What this literature is implying is that teacher learning is closely linked to the context, motivation and transfer of that learning. McDonald (2009) makes the point that these are key features of any professional development programme and that there is a complexity in teacher change. This is supported by other models of professional development transfer (e.g., Brooks \& Dansereay, 1987; Perkins, Barell \& Fogarty, 1989; Veenman, van Tulder \& Voeten, 1994; Walberg \& Genova, 1982; Wallace, 1992; Yelon, 1992).

One of the important factors that needs to be considered is the manner in which educational change is enhanced (Guskey, 1986). It was noted that due to the complexity of the teacher change phenomenon, educational change needs to be examined from a systemic position. Fullan (1992) noting the importance of planning for change made the following propositions: 
1. There is a need for active initiation and participation - change requires some impetus to get started.

2. Pressure and support is required - successful change always include elements of both pressure and support. Pressure without support leads to resistance and alienation; support without pressure leads to drift or waste of resources.

3. A relationship exists between behaviour and beliefs - in many cases changes in behaviour precede rather than follow changes in beliefs.

4. There is an overriding problem of ownership - Ownership is not easily acquired.

Fullan further noted that effective change depends very much on the combination of factors, such as, the disposition or character of change, (need and relevance of change), characteristics of the local level (e.g., support involving district, school and teachers), and the external relationships which interact to produce conditions necessary for change or non-change (government role, external assistance).

Topping and Maloney (2005) noted however that the correct policy does not guarantee good practice. A number of studies (Fulcher, 1989; Loxley \& Thomas, 1997; Weatherly \& Lipsky, 1977) have shown that the best intentions can be destabilized at local level if the conditions are not right, that is if people are not prepared for and committed to the change. The central dilemma in policy implementation is perhaps best expressed by Cuban (1990):

Most get implemented in word rather than deed, especially in classrooms. What often ends up in districts and schools are signs of reform in new rules, different tests. Seldom are the deepest structures of schooling that are embedded in the school's use of time and space, teaching practices, and classroom routines fundamentally altered even at those historical moments when reforms seek those alterations as the goal (Cuban 1990, p. 9)

According to Fullan (1993) school reform efforts have often failed because they have been imposed from the top without input from and partnership with those who do the work. The importance of partnership at the national, regional and local school levels when change is contemplated is important. He further elaborated that legislation at the national level should consider ground rules and at the regional level, finance should be made available for schools to carry out their inclusive practices. A key 
principle according to Fullan is the idea that the drive for change should be initiated from those who do the work in the schools.

This bottom up change model, although appearing to be a sound idea, can be questioned in a social environment and traditional setting and in a culture like Samoa. Samoan culture is very hierarchical in nature (Duranti, 1990; 1992; Fairbairn-Dunlop, 1991; Freeman, 1984; Huffer \& So’o, 2000; Ochs, 1988; Odden \& Rochat, 2004; Shore, 1982; 1996) where decisions are made by those in authority (such as matai) and it is for these reasons that a bottom up approach could be problematic. The idea of an untitled person overriding the decisions of the chief is not normative behaviour. In the school, the principal is the authority figure who assumes the leadership role and even questioning the authority of that person is unlikely. This raises the issue of ascribed or achieved leadership in education particularly when referring to leadership in societies like Samoa.

\section{School Leadership}

The international literature has identified the critical role of school principals in shaping relationships with teachers. It has also noted that in many contexts they have the unquestionable control. Not withstanding this authority, teachers expect principals to be involved in fair decision making and to support teachers in disputes (Blasé \& Anderson, 1995). Generally, teachers show respect and allegiance to these principals who are fair on them and who (Lortie, 1975, p. 200) utilise their authority to protect and support them in achieving their instructional goals (Blasé, 1987; Lortie, 1975). Teachers have no respect for principals who fail to support them.

Studies of teachers' perspectives discovered a difference in leadership of school principals which impact on teachers. It also revealed that few principals demonstrated a democratic-collegial type leadership but most used strategies ranging from openly directive and authoritarian to diplomatic and subtle strategies to rein control over teachers (Ball, 1987; Blasé, 1993; Johnson, 1984).

Blasé (1987; 1988b) found that teachers perceived principals who are open and effective (e.g., accessible, consistent, knowledgeable, communicative, decisive, problem oriented, supportive, participatory/consultative, fair, rewarding and delegatory) as very approachable and they related well to these principals. This is opposed to those principals who are unilateral, prejudiced and authoritarian. 
Furthermore, this positive manner of leadership impacted positively on teachers' motivation and performance, as well as teacher relationship with students and parents.

What this implies is that school leadership plays an important part in the professional life of the teachers and that it impacts on teachers. Open and effective principals led to higher levels of teacher motivation and involvement and transfer skills as opposed to authoritarian and unsupportive principals who often caused teacher stress.

\section{Policy Transfer}

An important consideration with regard to IE in Samoa is that it is a 'borrowed' policy from the international arena. There has been considerable discussion in the comparative education literature concerning this process and this current research therefore needs to be interpreted in terms of how and why IE became part of the Ministry of Education policy.

Phillips and Ochs (2004) define borrowing in terms of influence and identify it as a conscious adoption of policy from one context to another (Phillips \& Ochs, 2004). They indicate that it is best understood in terms of a continuum from imposed educational transfer through to voluntary adoption. Figure 2.1 below details this continuum and the various signposts along it.

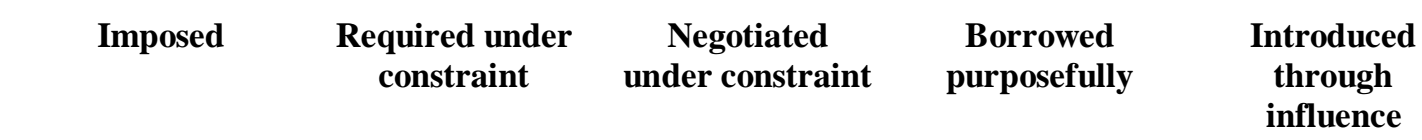

1

2

3

4

5

(1) Totalitarian/authoritarian rule

(2) Defeated/occupied countries

(3) Required by bilateral and multilateral agreements

(4) Intentional copying of policy/practice observed elsewhere

(5) General influence of educational ideas/methods

Figure 2.1 Spectrum of educational transfer (Source: Phillips, 2009, p. 1070)

Johnson (2006) describes a set of metaphors that fit with Phillips idea and they define the forces that operate in terms of the underlying political, economic (etc) forces that direct this process of borrowing of educational policy. 
- $\quad$ Telling (imposed often by the colonial power)

- $\quad$ Rebelling (by the newly independent nation)

- $\quad$ Compelling (negotiated under constraint; expectations for loans, etc)

- $\quad$ Selling (globalisation and international educational markets; many developed countries engage in this willingly)

- $\quad$ Gelling (coming together of indigenous and foreign sources of knowledge.

As indicated in the previous discussion, Samoa has borrowed the IE policy because of a mixture of forces but mainly due to the influence of bilateral and multilateral agreements and the purposeful desire to improve education for all students. In terms of the process that countries move through to incorporate this borrowed policy, Phillips and Ochs (2003) have identified a four stage process of cross-national attraction, decision, implementation and indigenisation/internalisation. Refer to Figure 2.2 below. Although this current research project is related to all the phases of this process, the emphasis is upon the stakeholders' perceptions about the implementation and internalisation/indigenisation processes. An important consideration is that the process is set in a context influenced by demographic, geographic, religious, linguistic, cultural, social, philosophical, administrative, economical, political, technological, historical and national character factors. It is interesting to note however that it is a somewhat linear process and does not emphasis an interactive process (e.g., interaction between implementation and adaptation).

Cross-national attraction refers to the preconditions for borrowing and is about the impulses directing the interest and the potential in the policy. Impulses such as the following create an interest in policies from abroad:

- creeping internal dissatisfaction (on the part of parents, teachers, students, inspectors, etc);

- $\quad$ widely reported and influential research by academics;

- $\quad$ economic change/competition; 
- $\quad$ new world, regional or local configurations (e.g., globalising tendencies, effects of education and training policy);

- innovation in knowledge and skills; and

- $\quad$ political change and other imperatives.

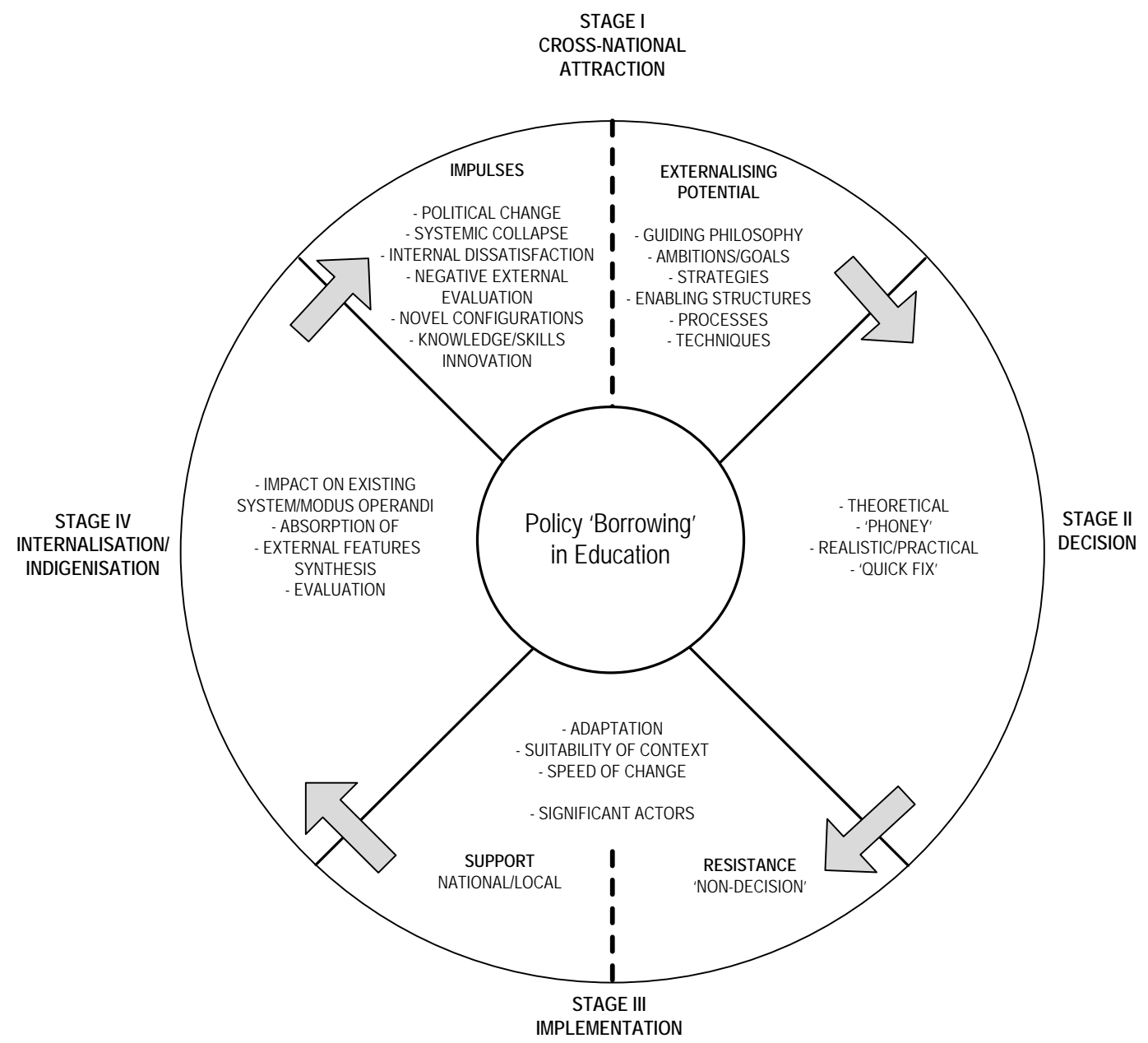

Figure 2.2 Policy borrowing in education: Composite processes (Phillips \& Ochs, 2003)

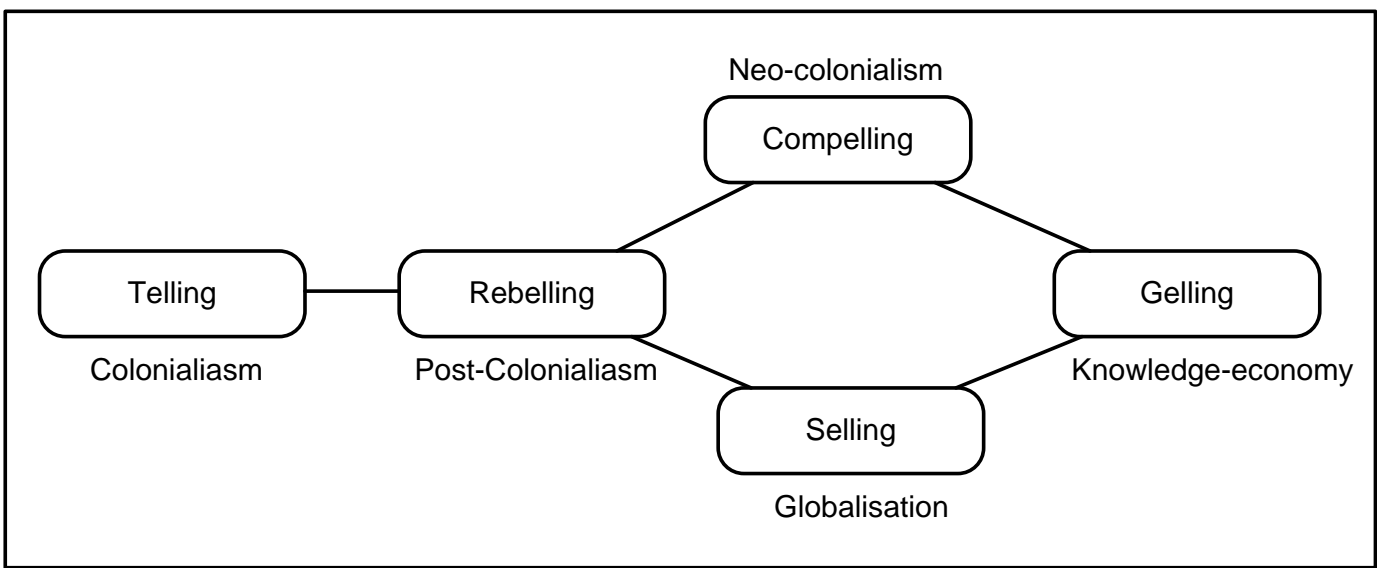

Figure 2.3 Forces that direct the processes of borrowing (Johnson, 2006) 
In Samoa, many of these impulses came to bear upon the adoption of the policy of IE policy. Once these impulses come to bear, consideration is then given to whether the policy can be adapted to meet the local context. For example, are the guiding philosophies, and goals appropriate? Can the new system be managed and can structures be set in place to direct it? Does it fit within the normative structures that already exist? Can the end-users utilise and operationalise the policy implementation appropriately?

The next stage is that a decision is made to borrow the policy. Essentially, there are four reasons why this may occur; it is a decision based upon:

- theoretical considerations - a guiding belief structure; broad ideological approach defines it;

- $\quad$ a phoney rationalisation - for example it may be an instant electoral idea but not developed further;

- $\quad$ realistic/practical reasons - it has proven to be effective in another context; and

- a quick fix - for example, used when there is an immediate political necessity (and other issues not taken into consideration).

Stage three of the process concerns the implementation of the policy. At this phase, there is an agreement that something is amiss and a consensus develops to address the issue. An important consideration here is that the complexity of details need to be considered and the responses of significant others taken into account.

In the final stage the internalisation and indigenisation process occurs. By this time the policy has become part of the system of the borrower country, and it is possible to assess its effects on the pre-existing arrangements in education and the modus operandi. How far does it become adopted and to what extent is it synthesised with the existing systems? Does a dual system operate once it is implemented? An important consideration at this phase is the evaluation of the policy borrowingreflection and evaluation should occur to ascertain the realistic or unrealistic expectations of borrowing. 
Haskin's and Gallagher's (1981) model for social policy analysis (Gallagher \& Clifford, 2000) has also identified a range of contextual factors that can impact upon policy implementation. Table 2.1 identifies these issues as potential barriers.

Table 2.1 Model for social policy analysis: Barriers to policy implementation

\begin{tabular}{|l|l|}
\hline Institutional & $\begin{array}{l}\text { These barriers arise when the proposed policy conflicts with the current } \\
\text { operation of established social and political institutions. A call for } \\
\text { interagency coordination might create difficulties in blending the } \\
\text { existing policies and operations across health, social services, and } \\
\text { educational agencies. If a lead agency is identified to carry out the } \\
\text { policy, is that agency given sufficient authority and resources }\end{array}$ \\
\hline Psychological & $\begin{array}{l}\text { A proposed policy can come into conflict with deeply held personal } \\
\text { beliefs of clients, professionals or leaders who must implement the } \\
\text { policy. Perhaps some people resent the fact that they were not consulted } \\
\text { before the policy was established. Any time someone loses authority or } \\
\text { status, there can be personal resistance. }\end{array}$ \\
\hline Sociological & $\begin{array}{l}\text { Sometimes the new policy conflicts with established mores or cultural } \\
\text { values of subgroups within the society. For example, it may be } \\
\text { traditional in some cultural subgroups for family members to show } \\
\text { deference to those in authority (e.g., physicians, agency heads). The } \\
\text { notion of family empowerment might be a difficult one for them to } \\
\text { entertain. }\end{array}$ \\
\hline Economic & $\begin{array}{l}\text { Often, the promise of resources to carry out a programme is not } \\
\text { fulfilled, not because of deviousness, but because of the multitude of } \\
\text { issues to be met and the limited financial resources at the state or } \\
\text { federal level. }\end{array}$ \\
\hline Political & $\begin{array}{l}\text { Some programs become identified with one or the other political party, } \\
\text { and such programs become hostage when the opposing political party } \\
\text { comes into power. There is a periodic overturn of political leaders } \\
\text { through retirement or elections-changes that can cause disjunction in } \\
\text { the support or understanding of the program on the part of political } \\
\text { leaders }\end{array}$ \\
\hline $\begin{array}{l}\text { The delivery of services to rural areas has long plagued those who have } \\
\text { tried to provide comprehensive health and social services. Personnel } \\
\text { resources tend to remain in large-or middle-sized urban areas, causing } \\
\text { substantial difficulties in covering outlying areas. }\end{array}$ \\
\hline
\end{tabular}

Source: Haskin's and Gallagher's (1981) model for social policy analysis (Gallagher \& Clifford, 2000)

A critical dimension on this issue of policy implementation is the contextual elements that impact upon the arrangements. As indicated by McDonald (2001), professed development programmes in the Pacific need to carefully consider the local culture as an important variable when implementing programmes. 
The process of policy borrowing is complex but it can provide a framework for implementing policy change and implementation. This research study considers this constellation of factors and specifically examines the key stakeholders' perceptions about the implementation and the indigenisation of the IE policy in Samoa.

\section{Conclusion}

This chapter has summarised the literature on IE, implementation of policy and the importance of context in particular culture. The review examines the conception of IE, its characteristics, as well as its practices and it discusses the historical events and influential factors that brought about this movement. The theories and models that underpin IE as well as debates surrounding the IE concept have also been detailed. The complexities involved in policy implementation in general and specifically in relation to the IE policy have been highlighted. Furthermore, the concept of professional development with respect to teachers and what motivates teachers to be involved in professional development has been discussed. Central to this discussion is the concept of transfer and factors that could facilitate transfer of learning/training in to the educational setting. The role of culture has also been examined in relation to change and this foreshadows the importance of the Samoan cultural context considered in the next chapter. The notion of policy borrowing in relation to IE has also been examined. 


\section{CHAPTER THREE \\ Culture and the Samoan Context}

\section{Introduction}

The IE movement as an international imperative has driven educational reforms in countries across the world including the Pacific nations. ${ }^{3}$ Samoa became part of this movement when it subscribed to various international and regional conventions as already mentioned in Chapter one. The government of Samoa acknowledges the use of education as a vehicle for developing productive citizens for a progressive nation (Government of Samoa, 2006a, p. 11). As noted in earlier chapters, the Samoan education system has undergone a number of changes over the past few decades. This chapter aims to highlight the changes and influences that have driven them.

This chapter is in two sections. The first section describes the location of the study, as well as giving a social, economic, political and cultural profile of Samoa. It provides a broad description of the cultural milieu, where this study occurs. It will consider the Fa'aSamoa ideology and outline the manner in which the Fa'aSamoa is organised and the manner in which the society responds to change. Furthermore, the place of children within Samoan culture will be discussed as well as the implications this has on IE. The second section considers the trends in educational development in Samoa, and then focuses specifically on policies concerning children with disabilities or special educational needs within the education system. It begins by outlining the development of the educational system and the arrangements that were available previously and those currently available to support students with disabilities. Following this, there is a description of the international influences as well as the regional and national initiatives that have impacted on the education of children with disabilities and special needs

To preface this chapter however, the definition of special needs as outlined in the Samoan Special Needs Education Policy (Government of Samoa, 2006c) needs to be considered. It states:

\footnotetext{
${ }^{3}$ The term Pacific nations, used in the thesis, refers to the Polynesian, Melanesian, Micronesian area. These regions are not only united by geographically but also there are similarities in culture and practices. But it cannot be assumed that Pacific (Melanesian, Micronesian, Polynesian) cultures operate in a similar manner. However, in much of this research study, the literature in discussion centres upon Polynesia and in particular the Samoan context.
} 
Students with special needs are those whose abilities, performance or behaviour is significantly different from their peers. This will include students who are talented and gifted as well as those with high learning needs. While the vast majority of such students can be assisted with additional support as part of their regular classroom experience, a small number of students have disabilities or impairments that require ongoing specialist support and access to highly specialised programmes and facilities (p. 3).

\section{Samoa - The Research Location}

This section will attempt to present some aspects of the Samoan life perceived to be relevant to this study; the aim is to provide a description of the setting for the study. It gives the political, economic, historical, cultural, and social profile of Samoa within which international and local ideas about disability and IE need to be considered. It then discusses how the culture is organised and the place of the child within this milieu. Subsequently, it examines the Fa'aSamoa notion of identity leading to the concept of acceptability in relation to disability. Aspects of culture that impact upon teaching and learning in the classroom are important to outline for this study as well. The concept of support is then considered from the Samoan perspective of tapua'i. This discussion concludes by examining the idea of change and how it is responded to in a traditional society such as Samoa.

Samoa is located in the middle of the South Pacific halfway between New Zealand and Hawaii and consists of four inhabited islands covering 2,785 square kilometres. The two larger islands, Upolu and Savaii (refer Figure 3.1), are volcanic and have fertile coastal strips. The population of Samoa is 176,710 of which 38,836 live in the capital, Apia on Upolu. The population has a high youth ratio with $41 \%$ under the age of 15. Approximately 99\% of the population is Christian (Statistical Services Division, Government of Samoa, 2001). These details have significance for the study - it is a non-western nation, has a Pacific Island culture and is a country with a small population and relatively few resources which impacts on provisions for special education and IE. 


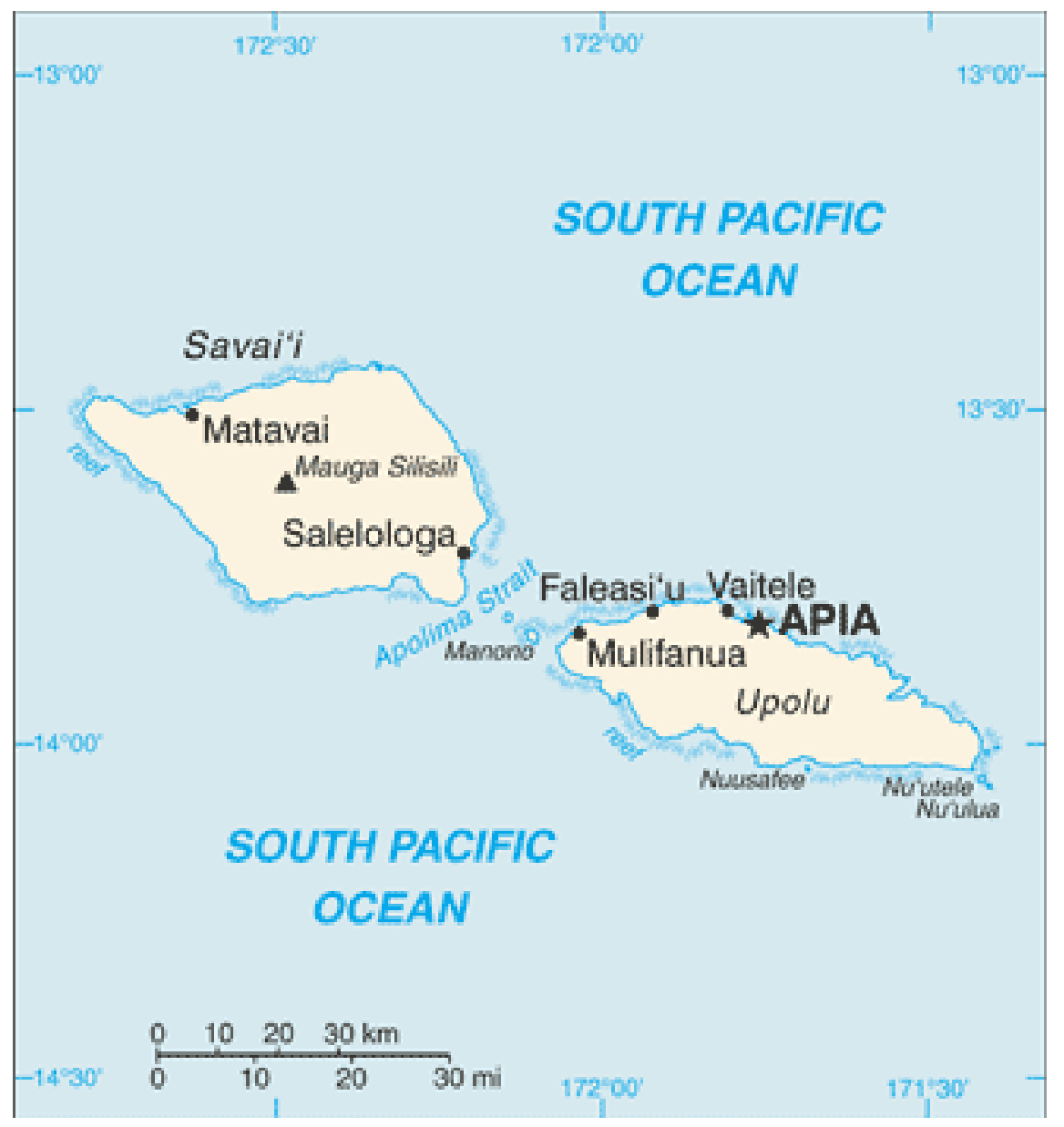

Figure 3.1 Map of Samoa the location of the study

Out of the total Samoan population approximately $41 \%$ are in the age group from 0 14 years old, 55\% are in the age group 15-64, and 4\% are in the 65 years and above (Government of Samoa, 2004). Lene (2005) surveyed a broad group of Samoan people 15 years and above and identified 2,874 people with disabilities - 1,516 women and 1,358 men with disabilities. An earlier survey undertaken by McCullough to identify all children aged 0-14 with disabilities in Samoa identified 1,188 children with disabilities in and out of school. This was $6 \%-7 \%$ of the total population of Samoa (McCullough, 2000). Lene's (2005) study found that the majority of people with disability $(2398,83 \%)$ resided in rural areas and that this group (particularly women) had minimal involvement in community/village activities. It also indicated that lack of access (e.g., mobility aides), families attitudes (e.g., being ashamed of their family member's disability) and families' lack of understanding of people with intellectual disability led to the exclusion of these people. It is important therefore that with a burgeoning population and an acknowledgement that education is important, that provision for all students is made. 
Samoa's economy is predominantly village-based subsistence agriculture, often supplemented largely by either fishing or by remittances from family members who reside overseas (Samoa National Development Report, 2006). These remittances, in addition to international aid, are crucial in sustaining the economy, facilitating infrastructure development, and perpetuating standards of living (Asian Development Bank, 2000; Fairbairn-Dunlop \& Associates, 1998; Liu, 1991; Meleisea, 2000). Financial constraints significantly impact on educational development (FairbairnDunlop \& Associates, 1998; Government of Samoa, 2003; Government of Samoa, 2002) which have led to Samoa's continuous dependence on international aid to fulfil its educational aspirations (Coxon, 2003; Government of Samoa, 2003; Tolley, 2003). Financial resourcing of projects is often problematic.

The majority of the Samoan population dwell on customary land (Fairbairn-Dunlop \& Associates, 1998). The matai (chief) heads every Samoan family, elected by his family or tribe. He is responsible in "representing the family in village fono (village council of matai) resolving family differences, protecting family interests (e.g. lands and titles), upholding and advancing family prestige and honour, and providing leadership in the family to ensure that every family member is adequately cared for and protected.” (So’o, Va'a, Lafotanoa \& Boon, 2006, p. 149). This caring and nurturing attitude is embedded in the culture of the Fa'aSamoa as will be noted in discussions in subsequent sections.

\section{Hofstede's Model on Culture}

Thaman (1997) defines culture as "a way of life of a group of people, which included their language and a body of accumulated knowledge, understandings, beliefs, skills and values” (p. 120). There are many ways of examining culture, one of the most well known being Hofstede's (1980) approach. Hofstede initially identified four distinct cultural dimensions that served to distinguish one culture from another: individualism/collectivism, uncertainty avoidance, masculinity/femininity, and power distance. He later added a fifth dimension - long term/short term orientation.

Individualistic cultures (e.g., many Western societies) value independence and are based upon beliefs that personal goals and interests are more important than group interests (Hofstede, 1980; Schwarts, 1992; Triandis, 1989). In contrast, collectivists tend to view themselves as members of an extended family or organization, and place group interests ahead of individuals needs and the Samoan society is an 
example of this. These societies with collectivist features, feel a greater need for consensus and written rules, and are intolerant of deviations from the norm. Samoa is a society governed by rules, with higher levels of uncertainty avoidance.

In contrast, individualistic societies, characterized by low uncertainty avoidance rely less on written rules and are more risk tolerant. Individuals from individualistic society tend to be masculine-oriented, more aggressive, ambitious, and competitive whereas individuals in feminine-oriented societies are more modest, humble, and nurturing. Individuals in societies characterised by higher levels of power distance tend to follow formal codes of conduct, and are reluctant to disagree with superiors and this is clearly the disposition of the Samoan society (Hofstede, 1980). Individuals in societies that are lower in power distance, on the other hand, do not feel as constrained by perceived or actual differences in status, power or position. These value differences will impact in the educational arena - for example in Samoa teachers are more likely to seek support from others, demonstrate an increased deference to authority, seek more detailed clarification and be more centred on relationships.

Features of the collectivist culture (as characterised by Samoa) compared to the individualist culture of the West from where the policy of IE originated are summarised (Table 3.1) as a framework to understand the discussion of the different values underpinning the imported policy of inclusive education and the values of the local policy context for implementation. One of the dangers of Hofstede's approach is that it can be reductionist. It could imply that individuals from one culture are the same - in each culture there are of course differences. Hofstede's ideas need to be interpreted as such. 
Table 3.1 Salient features of collectivist and individual cultures

\begin{tabular}{|l|l|}
\hline Collectivism & Individualism \\
\hline 1. Foster interdependence and group success & $\begin{array}{l}\text { 1. Fosters independence and individual } \\
\text { achievement }\end{array}$ \\
\hline $\begin{array}{l}\text { 2. Promotes adherence to norms, respect for } \\
\text { authority/elders, group consensus }\end{array}$ & $\begin{array}{l}\text { 2. Promotes self-expression, individual } \\
\text { thinking, personal choice }\end{array}$ \\
\hline $\begin{array}{l}\text { 3. Associated with stable, hierarchical roles } \\
\text { 4. Associated with shared property, group } \\
\text { ownership }\end{array}$ & $\begin{array}{l}\text { 3. Associated with equalitarian relationships } \\
\text { and flexibility in roles }\end{array}$ \\
\hline
\end{tabular}

Adapted from Trumbull et al. (2001)

In Samoa, although to date no studies have been undertaken on Hofstede's (1980) dimensions, on the basis of the examination of other traditional societies, it would seem that there is an emphasis upon collectivism, uncertainty avoidance, femininity (a nurturing character), power distance (between authority and others) and a mixture of short-term and long-term orientation. The opposite can be inferred for many Western societies. In this research there is an investigation of an imported Western ideology (IE) impacting upon the educational arrangements and belief structures of a traditional culture. Hofstede's framework is a useful tool of analysis for this understanding and points to the need for potential accommodations to be made.

\section{Samoan Cultural Context}

The Samoan culture is a construct of contemporary and historical influences which impact on the world views of its people and the manner in which they live and act (Va'a, 2006). The concept 'social' refers to the manner in which rules and expectations control social relationships amongst the Samoans. "These rules and expectations are referred to as va and faia. In Samoan society, every person has a place or role with a status attached to it. Nobody is of no account (e leai se tagata $e$ noa) (p. 120). As mentioned earlier, the Samoan culture is also hierarchical; the chiefs or matai, are ranked highest and the untitled persons with children the lowest.

The social structure of Samoa rests on kinship values, which places the village or nu'u and the family or aiga at the centre. The wellbeing of the village and family will ensure the welfare of the individual (Fairbairn-Dunlop, 1991; Meleisea, 1987a). As noted above, each family within the village is represented by a matai (holder of a chiefly title) who has responsibility and control over the family members and land. A 
council of matai called fono, consists of all the titled (matai) people of the village, governs the village. The fono is the forum by which matters are debated and decisions made; all matai have equal say in its proceedings and decisions (Meleisea, 1987b). Thus, all members of the society including those with disability are considered important and have a place in the family and society.

As alluded to earlier on, Samoa is a stratum society. The highly stratified disposition of the Samoan society places emphasis upon status and authority (Macpherson \& Macpherson, 1987). Its authoritarian and stratified nature can at times prevent comfortable relationships between home and school. In Samoa, home and school implies relationships of power, jurisdiction, and exclusivity. Teachers are considered to be in authority and parents are seldom invited to provide input into curriculum or tutoring. Overseas in many countries in special education and IE the partnership between the school and the parents is an important dimension. However one of the ironies is that although Samoa is a highly stratified society, it is very inclusive which is exemplified by the notion of collectiveness. An examination of the Samoan culture is essential to further an understanding of this society and Hofstede's 1980 model is useful to interpret this characteristic. The nature of his model and its applicability to a culture such as Samoa has already been detailed.

\section{Samoan Notion of Identity}

In Samoa, traditional identity is referred to one's standing or fa'asinomaga. In trying to bridge the gap between social and the personality, Mageo (1991) and Shore, (1996) argue that loto meaning 'will' or ‘emotion' is an inner phenomenon that needs to be controlled. They argued that loto is personal and fa'asinomaga has a social aspect. Fa'asinomaga refers to one's ascribed status/roles in relation to the Samoan system of family connection. For example, without family, ones identity/standing is under question. Samoan identity is based on one's standing in the community or family and is always framed in relation to others. Gerber (1975), Mageo (1997), Shore (1982) and Schoeffel (1979) have argued that in Samoa one has many identities depending on the context. For example, one can be raised as a child of someone.

In the public arena in Samoa, identity or standing is also based upon profession, income and authority over others (Dolgoy, 2000). For example, there is keen competition for jobs of higher status in the civil service. These initiatives are driven 
by needs such as, personal satisfaction and freedoms, increased rank, identity in the community, earning one's own salary, and for the elevation of family status. Ones identity can also be associated with self-esteem, based as it is on both personal accomplishment and maintenance of one's reciprocal obligations. In this type of arrangement, the position or place of a person with disability is uncertain.

\section{Samoan Notion of Disability}

The concept of disability is not in the Samoan vocabulary. Phrases and elaborate explanations are used in reference to the disability (Fitzgerald, 1993, p. 8). Fitzgerald noted that perceptions and attitudes toward people who appear to be different differ both within and across societies. In the Pacific, attitudes towards people with disabilities varied from being cared for and acceptance by families, others are shunned or abandoned or being teased or ridiculed. She added that these perceptions and attitudes fall on a continuum ranging from seeing the disabled person as sacred (a blessing/gift) to viewing him/her as a curse. Mostly in Samoa, it appears that families care for their members with disabilities but this may not mean that the individual engages in the usual roles and responsibilities of family members. It will vary from family to family and disability to disability.

\section{Social Acceptability in the Fa'aSamoa}

The status of disability in Samoa therefore raises the issue of acceptability. Reetz and Hoover's (1992) touched upon this notion in relation to the acceptability of disability. Social acceptability applies to all aspects of interactions and sharing in Samoa - to be socially unacceptable can easily lead to exclusion, stigma, shame and its associated emotions of anger or depression. Disabilities that are related to social acceptability, shame, anger, and impression management would find correlates in Samoa. Any disability or social phenomenon outside the norm is viewed with suspicion and is considered a sign of deficiency. Deficiency is not viewed only as an individual quality, it also has implications for the individual's family (i.e., "next door lives the family of the stupid one”). Physical and mental disabilities are often viewed as curses or as part of the motif of a family or individual being cursed. For example, the fa'afafine, the effeminate men of Samoa, are called mala. The word mala derives from the word malaia, which means curse. 


\section{Samoan Culture and School}

Not surprisingly, culture, social structure, resistance and ambivalence regarding change are part of a complex and changing system of Samoan life. This has implications for schooling. The home and school implies relationships of power, authority and exclusivity. In Samoan classrooms, the authority of Samoan teachers is unquestioned. This is a reflection of role hierarchies that arise from a traditional system and democratic processes between those of perceived differential status are not often tolerated. Teachers set agendas, define situations just as they would in the traditional cultural system.

Furthermore, it can be argued that the Samoan cultural system is extremely competitive with village and inter-family rivalry at times fierce. This very Samoan system of competition has been noted by this researcher in a number of Samoan classrooms; at times taking the form of outright insults by children of other children who have not done well, or have gotten the wrong answers in classroom quizzes. It is not unusual to 'rub it in' to the losing side.

On the other hand, there is also a traditional Samoan notion of minding relationships (Fairbairn-Dunlop, 1991) and requires recognition within our educational system of interaction and conversationalism. There are aspects of Samoan culture that support conversationalism that the educational system could take into consideration in programme development. Samoa's is still a strongly defined oral tradition and the culture, its history, the histories of families, and aspects of the traditional legal discourse are passed on orally and stored in memories. Some individuals are known as the custodians of the traditional oral knowledge of the family. Samoan children learn traditions through listening and observing. Observations include a range of products and activities including family and national traditions to the traditional technology of Samoa (e.g., farming, plantation work, fishing, boat building, and some hunting practices).

\section{Value of Education for a Student with Special Needs}

There are aspects of the culture that require analysis and understanding for socialisation education to become meaningful. For example, consider the impatience with the slow learner. Parental impatience may be for a number of reasons. There is a tacit non-clarification rule in Samoa - that is, Samoans in authority expect individuals after a certain age not to ask for clarification of commands or instructions 
(Pereira, 2005). It is not unusual for parents to lose patience with children as a result of a request for clarification and such requests could result in verbal chastising. Children with learning disabilities could be discounted early in their lives, a child could be withdrawn from school and directed into manual or plantation labour. Poorly educated, or at risk children may leave the nuclear family, move to another family within the extended family. Very large families often only emphasise the education of those who progress 'normally' and relinquish responsibility for those who make minimal progress. What is often heard being said is that it is not worth the time and money to stay with them until they eventually develop.

The idea that the family's status is intimately related to educational attainment may have problematic connotations. This is even more the case these days when higher education has become increasingly valued and rewarded. The education of children may not necessarily be provided to the child for intrinsic value or for the future use of the individual. Children are educated in large part for the benefit of the family and for status and material resources. This is a reality in Samoa based on the traditional system of indigenous exchange values. Indigenous exchange values is used here as analogus to the Samoan concept of reciprocity. For example, Samoan parents generally support their children's education with the expectation that the child would do well (Pereira, 2005) and in turn raises the status of the family. The child would in turn try to reciprocate by striving to succeed. This may be fine for a bright child but, for a child (with special needs), who may not be strong academically, negative prejudice discouraging to his development may be established early due to some of these cultural patterns.

\section{Equality and Equity}

Egalitarianism, equity and equal opportunity are frequently used terms in the international literature related to students with special needs/disability. However, it was noted (Duranti, 1990; Gerber, 1985; Ochs, 1988; Odden \& Rochat, 2004; Poasa, Mallinckrodt, \& Suzuki, 2000; Schoeffel, 1979; Shore 1996; Sutter, 1980) that these values are not held as strong cultural values in Samoa or in the wider Pacific region. The ideas are often contradicted by practice for the hierarchical nature of the Samoan society implies that the concept of power and standing in society is paramount. Thus, people are treated and regarded differently according to their status, income, as well as their profession. However, quality and equity are some of the fundamental principles which have underlined Samoan educational policies. It is noted 
nevertheless, that teachers do not necessarily implement these principles because of the strong cultural values. Accordingly, teachers may behave differently towards students depending on the students' background and family status. This can impact on the inclusion of students with special needs within the regular classroom.

An issue to consider in terms of equity, equal opportunity (etc) is the question of the importance of diversity in any society. In promoting equality and equity, one of the shortcomings could be a devaluing of the acceptance of the rich tapestry of diversity. In any inclusive environment diversity needs to be valued and cherished for the contributions it can make - it is not intended that all an inclusive classroom be a homogeneous classroom.

The idea of power and authority located in Hofstede's model is important to consider in relation to IE. For example, teachers may defer to authority but not implement ideas - the literature has suggested that many policies agreed to, fail in practice (Cuban, 1990). The Table 2.1 outlining barriers to policy implementation highlighted the difference in values between the imported policy and the values of the local.

\section{Learning Variance in Two Cultures}

The difference in the two cultural sets (individualistic and collectivist) as noted by Hofstede also indicates a difference in which individuals from two sets of cultures learn. Table 3.2 below is provided as a lens through which to understand how individuals from both societies (collectivist and individualistic) conduct their everyday experiences, and in relation to teachers, how they go about making pedagogical decisions (teaching and learning) in the classroom.

Table 3.2 Aspects and learning in collectivist and individualist cultures

\begin{tabular}{|l|l|l|}
\hline & \multicolumn{1}{|c|}{ Collectivist Societies } & \multicolumn{1}{c|}{ Individualistic Societies } \\
\hline Education & $\begin{array}{l}\text { 1. Education is a way of gaining } \\
\text { prestige in one's social } \\
\text { environment and of joining a } \\
\text { higher status group. }\end{array}$ & $\begin{array}{l}\text { 1. Education is a way of improving } \\
\text { one's economic worth and self- } \\
\text { respect based on ability and } \\
\text { competence. }\end{array}$ \\
\hline $\begin{array}{l}\text { Learning } \\
\text { Attitudes }\end{array}$ & $\begin{array}{l}\text { 1. Students expect to learn "how } \\
\text { to do". }\end{array}$ & $\begin{array}{l}\text { 1. Students expect to learn "how to } \\
\text { learn". }\end{array}$ \\
$\begin{array}{l}\text { 2. Positive association in society } \\
\text { with whatever is rooted in } \\
\text { tradition. }\end{array}$ & $\begin{array}{l}\text { 2. Positive association in society } \\
\text { with whatever is "new". }\end{array}$ \\
\hline
\end{tabular}




\begin{tabular}{|c|c|c|}
\hline & Collectivist Societies & Individualistic Societies \\
\hline $\begin{array}{l}\text { Social } \\
\text { Interactions }\end{array}$ & $\begin{array}{l}\text { 1. Individual students will only } \\
\text { speak up in class when called } \\
\text { upon personally by the } \\
\text { teacher. } \\
\text { 2. Individual students will only } \\
\text { speak up in small groups. }\end{array}$ & $\begin{array}{l}\text { 1. Individual students will only speak } \\
\text { up in class in response to a general } \\
\text { invitation by the teacher. } \\
\text { 2. Individual will speak up in a large } \\
\text { group. }\end{array}$ \\
\hline $\begin{array}{l}\text { Harmony and } \\
\text { Conflict }\end{array}$ & $\begin{array}{l}\text { 1. Formal harmony in learning } \\
\text { situations would be } \\
\text { maintained at all times. } \\
\text { 2. Neither the teacher nor any } \\
\text { students should ever be made } \\
\text { to lose face. }\end{array}$ & $\begin{array}{l}\text { 1. Confrontation in learning } \\
\text { situations can be salutary; } \\
\text { conflicts can be brought into open. } \\
\text { 2. Face - consciousness is weak. }\end{array}$ \\
\hline
\end{tabular}

Adapted from Hofstede (1986) and Chang \& Chin (1999)

In terms of learning, the cultural differences as illustrated in the model could impact on teacher pedagogy and teacher and student interactions in the classroom. In many senses, the implementation of IE in a collective society is problematic because IE is essentially focused upon individual within a group. As will be noted, the data revealed a discrepancy in the way teachers carry out their classroom practice and the values inherent in the curriculum (i.e., the curriculum is grounded in Western discourses and values but overshadowing the Faa'Samoa). As the model illustrated, students from collectivist society tend to speak up only when called upon. This is the case in Samoa which can be argued could impact on curriculum delivery and policy implementation.

\section{Role of Cultural Values in Education}

In many specific ways, culture impacts upon the school and the learning of students. For example, Kerber and Smith (1962) in a review of the literature have noted that culture imposes a certain stamp on the school and the character of education. In relation to culture, Kerber \& Smith (1962) note that a school is always constructed by ordinary human beings whose value judgments and educational selections are necessarily influenced by factors of time, place, status, interest, belief, knowledge and custom. They are referring both to how cultural values influence educational policy and curriculum and teachers. That is, the teacher is the individual agent of the educational structure and is also just an ordinary human being whose values, shaped by culture, will come to the fore and have an influence. In spite of the provision of a structure for teaching, cultural values, persistent traditional modes and techniques of 
pedagogy may be still present, well ingrained and a fall-back position for teaching and classroom management (Rowland, 2000).

As alluded to previously, Kerber and Smith (1962) point to the clash of the cultures of tradition and the school (Western) ideology. They note that individuals can be blocked in their expansion of cultural sets. That is, the cultural frames of reference established during primary socialization within the family maybe in conflict with the cultural set of the school. But also the opposite can be true; the family values can thwart the attainment of learning outcomes.

In discussing the relationship between educational practice and the wider social context, Helu Thaman (1988) noted that the educational values and practices in Tonga, are significantly influenced by the wider cultural context. For example, the notion of behaving appropriately, valuing social relations and tradition, show respect for rank and authority and to exhibit restraint in one's interactions are greatly valued in the Tongan society. Given the emphasis the Tongan society placed on these values, there is an implication that the primary role of education was moral and social. In Samoa, a number of studies also note that cultural values and practices in the wider community impact what happens in the school (Va'a, 1987; Moli, 1993; Esera, 1996).

The view that culture may be inhibiting the process of change and implementation is an important consideration. It is possible that the fixed character of the Fa'aSamoa system, while supportive, may be in some respects fundamentally incompatible with the child-centred, flexible more humanistic approach to (Western) education. In Samoa during childhood there is a period of flexibility toward the child's behaviour and thinking but then life is increasingly normalized for the child into the formalized Fa'aSamoa. Children are usually expected to take orders without questions. The child begins to receive a range of cultural wisdoms without questions, and critical input is seldom perceived to be part of this learning process. This hierarchical system tends to remain in various ways throughout a person's life and maybe problematic for contemporary education arrangements including individuals with special needs.

This form of socialisation has two effects in relation to the pedagogical situation. The first may be the positioning of the child in a psychological state in which it is difficult or impossible to change to a more flexible way of relating to adults (i.e., teachers). The second issue relates to the teachers. How difficult would it be for 
teachers raised as children and adults in a more authoritarian structure, to switch to a more flexible, humanistic pedagogical mode? How can they themselves become less rigid, less structured, more flexible and less authoritarian without some form of personal and cultural orientation (Rowland, 2000).

Obviously such issues need to be considered in the development and implementation of policies and practices. There is a need to take into account cultural values of the individuals in the teaching and learning context and furthermore, teachers are more likely to be enthused over implanting policy if they understand and 'own' it.

\section{Value of Support in Polynesian Contexts}

In a study undertaken in the Cook Islands (a small Polynesian state), McDonald (2002) identified the importance of cultural considerations in implementing professional development programmes. Like Samoa, the Cook Island is a traditional society that exemplifies the Polynesian way. It was important in this study to identify the mores of the culture and the implication this had for implementation of ideas. It was recognised that comfortable means of communication with each other, attitudes and values, generosity toward others and an acknowledgement of Christian principles was important for the professional development programme. Elements inherent within the Polynesian society - kinship, status and respect, sharing and caring, and unity through consensus were vital for understanding teacher behaviour (Ritchie \& Ritchie, 1985). Values related to family and community, respect, hierarchical authority, consensus, peer group socialisation, the importance of the past and present, appreciation for privileges, the friendliness and emotional spontaneity were highly valued (Ritchie \& Ritchie, 1979; Ritchie \& Ritchie, 1985).

There were two important concepts identified which dictated behaviour in the Polynesian setting. First was love which accentuates kindness and concern for others and second was akama. The latter refers to a state of shame as a result of being ridiculed or criticised by another individual due to a wrong doing (McDonald, 2004, p. 8). This akama conception can cause psychological malaise for the individual whether it is the student in the classroom or the teacher in their work. Most often teachers are not comfortable in implementing change if being criticised by others, especially those in authority. Support from others was a key idea for successful implementation of ideas. All of these characteristics were deemed to be important contextual factors in the implementation ideas in this traditional society. This idea of 
support is essential and has a much deeper meaning in the context of the Faa'Samoa as shown below.

\section{'Tapua'i' - Samoan Notion of Support}

In the Samoan culture there is a very important concept of support termed tapua' $i$ (Ochs, 1988). This concept of support in the Samoan culture Fa'aSamoa is often related to the notion of success as illustrated by many Samoan sayings. One example is: A le tapua'ia se faiva e le a'e ma le manuia meaning that - an unsupported task will not be successful. Many of these Samoan aphorisms emphasise the notion of tapua'i. This signifies the importance of this concept in the Samoan culture. There are various levels of tapua'i. For example, at the village level, between the titled and untitled, at the church level between the pastor and the parish/community, at the family aiga level, between the parents and their children, this concept is employed.

The tapua'i concept implies a relationship, for example, one’s relationship with God, through prayers and worship. Tapua'i therefore has a spiritual dimension. Literally, it means worshipping when people gather together in church or elsewhere to give reverence to God. In its everyday practice, tapua'i is a very quiet manner of sitting and reverently hoping (praying silently) for the success of an individual or a collective pursuit (Samoan scholar, personal communication, 2008). It can also be applied when those in authority or of higher status gather to support others (i.e., those with less status) at work. In the implementation of this IE change, tapua'i is an important form of support to consider and to be offered to those who are involved in these initiatives. Lack of this form of support could impinge on these initiatives. The whole family (aiga) can also be involved in this tapua'i concept for the success of their children's education.

\section{History of Education in Samoa}

Four major influences succeeded in bringing about the Samoan education system of today. These are: "the culture of the indigenous Samoan, the nineteenth century Christian Mission efforts, the Twentieth Century colonialism (first under Germany then New Zealand) and the efforts of Samoan educational leaders who administered and managed schooling since Samoa's political independence in 1962 (Government of Samoa, 2007, p. 31). 
Prior to the arrival of the missionaries, traditional education had been in existence in Samoa. This involved people acquiring life skills through observation and getting involved in everyday traditional activities. The notions of values, beliefs and practices were learned informally (Government of Samoa, 2007). There is no doubt about the importance of this traditional curriculum to the needs of the Samoan people because it equipped them to take their place in the family and society for many centuries. There was no vying for white collared jobs then and hence individuals were adequately prepared.

The establishment of village mission schools in the early 19th Century was brought about by the arrival of the European missionaries and this was the beginning of formal schooling in Samoa. In such a system, the curriculum was based on Christian beliefs and there was no involvement of the community in curriculum development. Decisions were made by the missionaries to develop the bible into the Samoan vernacular and people learned to read and write in the native language (Lameta, 2005).

At the turn of the Century, Germany declared a protectorate over (Western) Samoa and administered it from 1900 until 1914. The authorities pushed for the German language to be taught in the mission schools although they found no problem in leaving education in the hands of the missionaries. After the First World War, New Zealand was awarded trusteeship over Western Samoa and education continued via a colonial administration, but this time with a New Zealand flavour. In mid 1940's, a team of educationalists led by the New Zealand Director of Education made recommendations regarding a better education system to educate young Samoans to assume leadership position in an independent Samoa. In 1945, the New Zealand scholarship scheme made it possible for Samoan students to undergo advanced education (Ma’ia’i, 1957).

The next decade saw an upgrade in existing schools in Samoa and secondary education was also introduced. The curriculum and most of the staff were imported from New Zealand and essentially schooling was modelled on the New Zealand approach (Government of Samoa, 2007). Despite efforts over the years to make the curriculum more fitting to the Samoans, the bulk of the programme, mainly in the upper primary to secondary levels, still resembled the New Zealand approach. This was in part due to the continued use of New Zealand examinations as criteria for 
determining student's success at the end of secondary school. As part of this schooling system herself, the researcher noted that the New Zealand School Certificate was used as a basis for selecting 5th form students who would advance further, while the University Entrance exam determined form 6 graduates for higher education.

Taufe'ulungaki (1987) argued that the education system of all countries in the Pacific region have been adopted and borrowed from the education system of their colonizers. This was not only the system but also the administration style, curricula, training, resources and the very aims and purposes of their education systems. The New Zealand Government's intention was to promote the idea that education was a secular system under the responsibility of the state.

Once independence arrived in 1962 pressure was put on the government by the Samoan people to expand the school system to the districts and the government took over responsibility for cost, provision of constructing material and teachers while maintenance was done through the village (Government of Samoa, 2007). Entry to these schools was available to the children from the village and its locale but there was no detailing of support for students with disabilities in this era. The only recognition for education in relation to children with disabilities occurred in the late 1970's to the early 1980s as alluded to earlier. The current system of including children with special needs or disabilities into the government schools (general classroom) is something that should be applauded. However, the nature of the current system could create barriers to learning of these students in several ways as will be discussed.

\section{Educational Policy 2006-2015 - Goals}

The educational policy of Samoa over the years has been guided by the principles of equity, quality, relevancy, efficiency and sustainability, the same guide that is in the current 2006-2015 education policy (Government of Samoa, 2006a). The identified goals for education include:

- $\quad$ quality improvement at all levels of education;

- $\quad$ achievement of universal primary education;

- $\quad$ expand and improve early childhood education; 
- improve adult literacy and access to life skills and continuing education for adults and youth;

- eliminate gender disparities in schools and achieve gender equity (girls are performing better than boys) etc; and

- poverty reduction, development of good governance, elimination of disease and achievement of environmental sustainability.

They are critical but the feasibility of the idea can be questioned. Subsequently, areas of needs pertaining to special needs education from the educational policy 2006-2015 have also been identified in the policy. It is imperative therefore for the researcher to relate these to this study for it could assist in gaining an understanding of the situation in Samoa concerning implementation of special needs education and teacher training. In the same educational policy document (Government of Samoa, 2006a) specific issues pertaining to special needs as well as teacher training were highlighted.

The current educational policy (MESC Strategic, Policies and Plan 2006-2015) has a dedicated component to the development of IE. The vision for IE in this policy is "a national education system supporting sustainable quality IE and sports for all persons with special needs” (Government of Samoa, 2006a).

The key policy statements are as follows:

- Facilitate the enrolment and participation of children with disabilities. Special attention will be given to girls and women with disabilities;

- $\quad$ Develop sound knowledge and best practices for IE;

- Work in collaboration with NGOs and the $\mathrm{MOH}$ to ensure the future sustainability of early intervention for children with disabilities;

- $\quad$ Capacity building for SNEAC will be encouraged;

- $\quad$ Ongoing support for SNE teachers;

- MESC will support public awareness programmes on IE and people with disabilities; 
- In collaboration with Ministry of Works, Transport and Infrastructure national guidelines for appropriate accessible educational and public facilities will be enforced. Document, record and adopt appropriate models of good practice for educational and sporting provision; and

- Development of sign language in teacher education and training.

Although these are important statements, they are grounded in a medical model of disability. For example, it uses terms such as disabilities and implies a 'special' set of knowledge and practise. Furthermore, the use of terms such as SNE (special needs education) implies that there is a separate group of students and special teachers for the special needs. This is in opposition to the principles of IE where all are included and all teachers are teachers in an inclusive environment.

\section{Special Needs Policy}

In conforming to this vision, MESC in 2006 drafted the Samoa-Special Needs Education Policy with the commitment to provide appropriate programmes to support students with special needs or at risk resulting from economic circumstances. However, as indicated above, one issue is that it is underpinned by the philosophical beliefs of the medical model that contradicts the social model of disability (refer chapter two for medical and social model). The Special Needs Policy which addresses an approach to IE states that 'where possible all students' needs should be met in normal schools. There is the implication in this clause that there are students whose needs may not be met in the IE environment. In the educational policy documents (Government of Samoa, 1995), there is the implication that there are two distinct categories of learners: those who are the majority with ordinary needs and a smaller minority with special needs who require support and specialised programmes to engage in some form of learning. Furthermore, the idea of special needs education as a second system education, and ordinary education as a first system is entrenched. In these documents, the term learners with special needs is used specifically to refer to learners with disabilities and those experiencing learning difficulties.

As noted, an attempt made by the government to adopt and implement the IE policy can be perceived in a positive light. However, there are a number of issues (alluded to) that need to be considered if implementation is to occur. 


\section{Primary Education in Samoa Today}

IE (and therefore this study) can only be understood within the context of the system that it is contained within. As in any system, there are features that can be considered as facilitators of the system and also other factors identified as barriers. Further to this, it is important to acknowledge that although the law stipulate attendance for all children aged 5-14 years, because of limited human resources and coordination of these, many children do not still attend.

The provision of primary education is a partnership between the Government and communities. MESC appoints and pays the salaries of principals and teachers and distributes stationery and curriculum materials to schools. However, the local communities (villages and district) are responsible for provision of school buildings, furniture and equipment, in addition to the maintenance of the school and its environment (Government of Samoa, 2006a). Parents pay for these maintenance fees, which can vary from SAT5 TO SAT50. Furthermore, parents contribute in funding their child's education in other ways, for example, school uniform costs, transport, lunches, other school requirements. Accordingly, all parents contribute to the costs of education; free education does not exist in Samoa (Government of Samoa, 2006a). Although MESC does not require parents of children with disabilities to contribute additional costs to their child's education there are still children with and without special needs who do not attend schools. The current system can be questioned for its credibility to address the needs of all children, mainly those with disabilities. Compared to the old traditional education a question can be asked as to which system is more inclusive where all would learn, the current more formal education or the old traditional informal type learning.

\section{Inclusive System of Education}

\section{International Involvement and IE Development}

At the outset, the various influences that have impacted the support for children with disabilities or special needs in Samoa have been outlined. One section detailed the characteristics and issues of policy borrowing into another country's system. This section examines the Samoan government involvement in IE at the macro level and preparation made at the micro level to support the implementation of IE policy. Preparations entail laws, legislation, and policies to support IE as well as resources, training, grants, etc. This is crucial for it provides the backdrop against which to 
analyse and understand the data in terms of introduction and implementation of the IE policy in Samoa. I will first outline the various international conventions that Samoa has subscribed to, for this was the beginning of the inclusive journey for Samoa.

\section{International Policies}

As noted in chapter one, Samoa has subscribed to various international educational plans and recognizes its commitment to these international agreements (Government of Samoa, 2006a, p. 11). It has also responded to plans and frameworks related specifically to special needs education such as: the Asian and Pacific Decade of Disabled Persons with Disabilities, the Salamanca Statement and Framework for Action and the Biwako Millennium Framework.

Samoa's involvement in international policies shows its commitment to the education of its people. However, the question is how quality driven is the education that is offered to each individual, especially those students with special needs. The question of quality in educational endeavours is often raised by educators (Afamasaga, 2006).

\section{Government Educational Initiatives}

The government initiative with regards to support for the education of students with special educational needs is important to understand because it indicates the commitment of the government supporting its people with disabilities/special needs. In relation to this current study, it forms a basis for analysing and understanding the data collected on perceptions and attitudes regarding the IE policy in Samoa and may serve to understand factors that could influence these educational initiatives. This section considers the legislative and government policies and laws that exist to support the implementation of IE. The table below states the various laws and policies that Samoan government's have in place to support its educational endeavours, these laws in turn influence IE initiatives. 
Table 3.3 National Policies and Laws

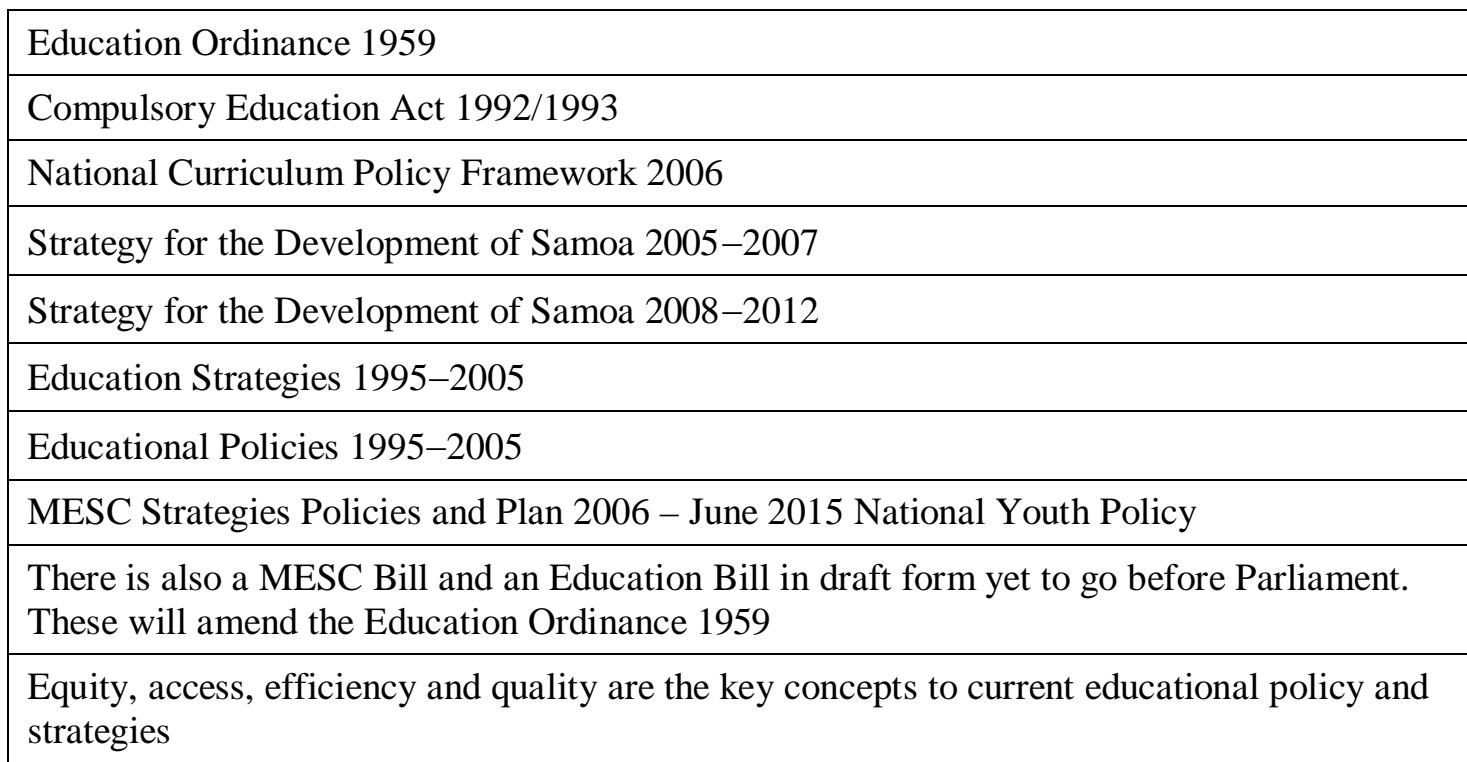

Sources: Samoa Department of Education (2002), McCullough, (2005)

\section{National Policies and Laws that Guide Education in Samoa}

Policy development in Samoa has received a lot of attention and is a reflection of the commitment of the Samoan Government to general and special education provision. For example, the strategic plan for Samoa development identified education as one of the six priority areas for the period 2005-07 (Government of Samoa, 2007, p. 20, Government of Samoa, 2008, p. i). "The implementation of these priority strategic and associate activities, is expected to realize the National Vision which is: For every Samoan to achieve a better quality of life”.

In relation to education, the guiding vision is a quality holistic education system that recognised and realised the spiritual, cultural, intellectual and physical potential of all participants, enabling them to make fulfilling life choices (Government of Samoa, 2008). Some of the areas that are pinpointed as important, and which relates to this study, include the following:

1. Improvement of teacher quality which included support for teacher training in Special Needs Education and Early Childhood Education will be continued.

2. Improving curriculum and assessment practices where special attention is directed at the curriculum for ECE and those with special needs.

3. Improving school facilities and equipment for special needs education where school committees will be strengthened to maintain school buildings and facilities. 


\section{Government Grant}

The Government has also made a commitment to special education in the form of grants. Commitment to improving the quality and effectiveness of education is a key element in the Samoan government's economic strategy. As discussed earlier, in support of this policy, the education sector consistently receives the largest portion of the National Budget, accounting for between 22 and $25 \%$ of total Government spending. Since 1999, the Government of Samoa has allocated SAT3 million for distribution to all educational levels including Special Needs Schools. The government involvement in the education of people with special needs cannot be overemphasised. However, it cannot be guaranteed that this fund is adequate to address the needs and support this initiative. There are many needs in terms of resources to support teaching in the classroom. In addition, many believe that some students have needs that are not met within a typical regular classroom arrangement. Thus, adequate funds are needed to make this a reality.

\section{Donor Agencies}

\section{AIGA Project}

The donor agencies are recognised as a driving force in driving educational initiatives and policies as reflected in the introduction and implementation of the IE policies in Samoa. Donor agencies, such as UNDP, UNESCO, AUS Aid in trying to address the issue of people with disabilities have assisted the MESC in executing the project Augmenting Institutions for General Attainment (AIGA) which ended in 2003.

\section{PRIDE Project}

In 2006, the PRIDE Sub-Project on IE commenced to help support the development of systems to facilitate IE. This included meetings to consider strategies, teacher training concerning support for children with specific disabilities, media campaign to help get accurate information about disability to the general public and accessible guidelines for the design of schools.

\section{Institutional Strengthening Project (ISP)}

AUS Aid funded the ISP project introduced systems and processes in school staffing, school management, school improvement, and performance appraisal all aimed at improving school performance. Other systems and processes were introduced to 
provide support and improve the quality of service provided not only to teachers and schools but also to the public.

As shown above, the role of overseas donors in driving policies forward is clearly noted. However, the dependency caused by such arrangements needs consideration. In relation to IE, overseas donors and volunteers were involved in implementing awareness campaigns and teacher training workshops in the form of forums which brought in new ideas about the integration, mainstreaming and inclusion of children with special needs. However, although this aid support is considered valuable, Sanga (2005) argued that there is the concern that the underpinning values of donor agencies (via the consultants and volunteers who implement these changes) may encroach on the values of the recipients thus may cause tensions and impact on implementation. As mentioned earlier, the concept of dependency is something that needs to be taken into consideration. One Samoan educator made her position clear on this issue by this statement "Grant funding while welcomed has created a dependent mentality which is not conducive to sustainability” (Afamasaga (2006, p. 90).

\section{Education and Students with Disabilities}

A number of stages can be seen in the development of Samoa's educational policies and practices in relation to students with disabilities. First, before the 1970s it had been the practice in Samoa for children and adults with disabilities to be cared for by their families. From the early 1970s to the 1980s the NGOs assumed responsibility for special needs education and established centres for children with special needs education (McCullough, 2000). This resulted in a dual educational system; the regular and special education as illustrated in Figure 3.2 below:
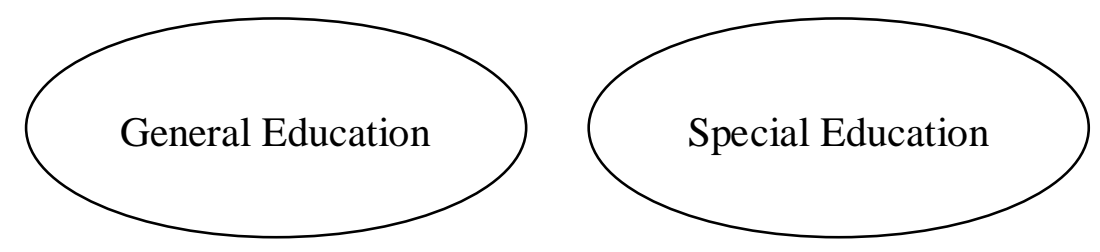

Figure 3.2 Dual Old System of Education

Another change was brought by the Education Amendment Act 1991-1992 which made education compulsory for all children aged 5 to 14 years. This resulted in the Samoan Government and the public placing some focus on equity issues and the 
education of children with disabilities. The Samoan education system was open to any student given the family's ability to pay but there were no polices that exempted any child. This meant that the education system was open to all children; however because of attitudes and training issues, barriers to the education of these students remained.

The Samoan Education Policy document of 1995-2005 was a further landmark, as it promoted the integration of children physical and learning disabilities into government primary classrooms (Government of Samoa, 1995). This enactment reaffirmed the government's commitment to special education, including strategies to improve education standards such as teacher training (for special needs), and grants for special education schools (Government of Samoa, 2002). As part of this drive, a national survey (Table 3.4) for the identification of children with disabilities from birth to 14 years of age was undertaken (McCullough, 2000) and this survey identified 1,219 children with disabilities ages $0-14$ years of age.

Table 3.4 Survey on children with disabilities - National Summary of Types of Disabilities by Age

\begin{tabular}{|l|l|c|c|c|c|}
\hline \multicolumn{1}{|c|}{ Category } & \multicolumn{1}{|c|}{ Disabilities } & $\mathbf{0 - 4}$ & $\mathbf{5 - 1 0}$ & $\mathbf{1 1 - 1 4}$ & Total \\
\hline $\begin{array}{l}\text { Learning } \\
\text { impairment }\end{array}$ & $\begin{array}{l}\text { Slow learners, Learning disabled, } \\
\text { Behaviour problems }\end{array}$ & 10 & 308 & 145 & 463 \\
\hline $\begin{array}{l}\text { Physical } \\
\text { impairment }\end{array}$ & $\begin{array}{l}\text { Celebral Palsy, Physical disabilities, } \\
\text { cleft palate, club foot, speech defects }\end{array}$ & 29 & 120 & 58 & 207 \\
\hline $\begin{array}{l}\text { Intellectual } \\
\text { impairment }\end{array}$ & $\begin{array}{l}\text { Autism, Down syndrome, Intellectual } \\
\text { Disability, Hydrocephalus }\end{array}$ & 24 & 77 & 43 & 144 \\
\hline $\begin{array}{l}\text { Hearing } \\
\text { impairment }\end{array}$ & Deaf, hard of hearing & 11 & 77 & 29 & 117 \\
\hline Epileptic & Seizures (both controlled and not) & 8 & 76 & 29 & 113 \\
\hline $\begin{array}{l}\text { Visual } \\
\text { Impairment }\end{array}$ & Blind, visually impaired & 12 & 46 & 15 & 73 \\
\hline $\begin{array}{l}\text { Multi- } \\
\text { Impaired }\end{array}$ & $\begin{array}{l}\text { Both intellectual and physically } \\
\text { disabled }\end{array}$ & 7 & 35 & 18 & 60 \\
\hline Other & Disabling illnesses/sickness & 2 & 22 & 18 & 42 \\
\hline Total & (number of disabilities per group) & 103 & 761 & 355 & 1219 \\
\hline
\end{tabular}

The findings from this survey resulted in the establishment of integrated special needs units within government schools in some district areas. The nature of this service delivery was essentially support in separate classrooms by special needs 
trained teachers. This model resulted in number of unforeseen consequences that impacted upon the teachers and students.

1. The movement of teachers from special needs positions to the regular schools.

2. The teachers who taught in special needs units felt discouraged due to unfavourable attitudes of other teachers and perceptions of limited support.

3. Segregation seemed to increase for a number of these integrated students.

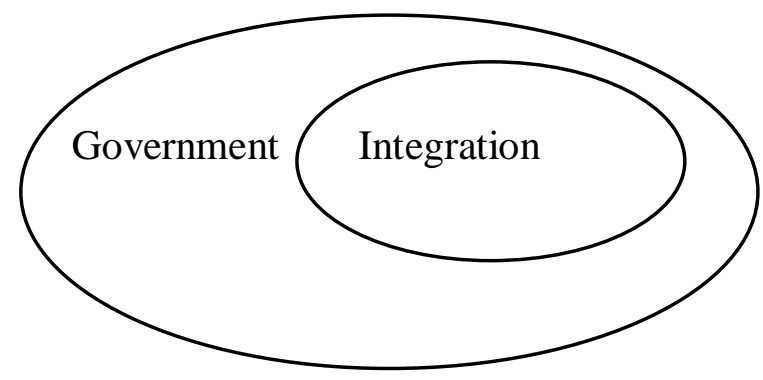

Figure 3.3 Integrated systems

Another change in Samoa's educational policies relates to its identification with a number of international regional understandings about students with special needs. The Salamanca Statement and Framework for Action on Special Needs acknowledged IE as the most desirable strategy for executing the 'Education For All' scheme. The Biwako Framework viewed IE in a more holistic manner than the integrated model and considered IE as an opportunity for children and youth with disabilities to be educated. ${ }^{4}$ At a more local/regional level, the Pacific Forum Education Ministers' meeting also suggested 'development of IE policies and programmes to enable children with disabilities to attend their local schools' (Secretariat, 2002). In response to these policy demands, Samoa's implementation of the IE programmes was operationalised and a set of professional development toolkit materials and teachers' manual were introduced by the UNESCO. ${ }^{5}$

\section{Local Developments}

As previously mentioned, the current system within the primary level was developed as a result of the Ministry of Education 10 year policies and strategies 1995-2005 and the Ministry has been involved in the introduction and development of IE

\footnotetext{
${ }^{4}$ The Biwako Millennium Framework for Action Pacific Forum leaders meeting held in NZ, 2002

${ }^{5}$ The toolkit material is discussed in more detail on p. 91
} 
programmes. For example, in 1998, the Special Needs Advisory Committee (SNEAC) (with representation from NGOs and Government sectors) was established and it became one way to facilitate IE policy. The committee's role was to advise the Chief Executive Officer of MESC on matters related to special needs and IE and the needs of families. The position of a SNE Coordinator position was also established within the MESC in 2001. This was to aid in developing a national system that would assist children with special needs (disability) access quality education. As a result, in-service teacher training was provided and support was offered for SROs, principals, SNE teachers and students in schools. Furthermore, public awareness programs for parents and communities about the rights and needs of children with disabilities were conducted as well as the development of inclusive MESC policies (Government of Samoa, 2007). However, there are gaps as noted below.

\section{Curriculum}

One of the main barriers to IE relates to the inflexible nature of the curriculum. In the Curriculum Material and Assessment Division (CMAD), special needs students are expected to follow the same curriculum as other students in the regular classroom. Although learning from the same curriculum supports the idea of IE (since this is what inclusive is all about), it appears ideal only in principle but not in practice. That is, there appears to be no adaptations being made to the structured and rigid curriculum and thus by default the teacher-directed and whole-classroom teaching continue for all students. This delivery approach undoubtedly impacts upon many students.

Furthermore, within the Faculty of Education (FOE) at the National University of Samoa (NUS) a curriculum has been developed to support MESC policies. These have been developed as specialised courses for teacher trainees who major in special education. The courses focus mainly on teaching methods and strategies to deal with children with special needs within the classrooms and not on curriculum content. This lack of specificity in curriculum is reflected in the following statements from the national curriculum document. The statement implies that not all students' needs will be met within the regular classroom, for there will still be a number of students whose needs will be catered for within a specialized setting:

Where possible all students needs should be met in mainstream schools as these provide the rich social and cultural setting to best develop the social and cultural 
skills necessary to fully operate in the broader community. For a small number of students, learning will best take place in specialist settings ... These students will have ongoing and significant disabilities or impairments and be eligible to receive additional resources through inclusion in the Disability and Impairment programmes operated by the MESC such as attending a special unit where this is the best interest of the student (Government of Samoa, 2006b, p. 22)

Against such a statement, one can question the effectiveness of the inclusive implementation, because the statement is vague and lacking in explicit intent. Emphasis upon curriculum adaptations and accommodation is more favoured in the IE movement.

\section{Examinations}

One of the features of the current education system which could have an impact on including children with special needs concerns examinations. Students are assessed in a national examination at the end of Year 8 to determine entry into secondary schools. Formal examinations and tests have become the norm in the Samoan primary and secondary education in both government and mission schools (Afamasaga, 1999; Barrington, 1968; Coxon, 1996; Male \& Lameta, 1999; Moli, 1993; Petana-Ioka, 1994; Sanerivi, 1998; So’oaemalelagi, 2000; Tavana, 1997). In addition to school-wide tests and examinations, students are also involved in six national exams. Pereira (2006) noted that exams have become a powerful driver for teachers and students. Exams were believed to motivate students to study diligently in class. Furthermore, students' placement in the classroom is determined by these test results and normally students who are less able are grouped together and, in most cases, placed at the back of the class. This type of arrangement denotes an exclusive attitude and mindset which often segregates students with special needs.

\section{Student Teacher Ratio}

The demographics of enrolment are also an important consideration for IE. In 2007 there were 39,578 students enrolled in primary education with 141 Government primary schools, 13 mission primary schools and six private primary-secondary schools. The number of primary schools is currently 160 and a total of 1,273 teachers were teaching in primary schools in 2007. ${ }^{6}$ The Government approved teacher student ratio for primary schools is 1:30 but the teacher student ratio in all primary

\footnotetext{
${ }^{6}$ MESC Educational Statistical Digest 2007, Apia.
} 
schools since 1996 has increased from 1:24 to 1:33 (Government of Samoa, 2006a). This ratio could affect the inclusion of students with special needs in the classroom. Class numbers have been noted in the literature to affect teachers' attitude towards including children with special needs in the classroom (Avramidis, Bayliss \& Burden, 2000; Bradshaw, 2003; Vaughn, Schumm, Jallad, Slusher \& Saumell, 1996).

\section{Support System}

The idea of support, in terms of physical as well as moral support, is vital for implementation of IE policy (Jenkins, 2002; Westwood, 2003; Wrights \& Sigafoos, 1998). However as has been documented this is lacking (Government of Samoa, 2006a, p. 30.) as shown:

- $\quad$ Special needs teachers in special needs units face many challenges in relation to lack of onsite support in establishing inclusive practice;

- Many schools are attempting to provide physical access but there are no national guidelines on specifications for ramp gradients, door widths, railings and ablution facilities; and

- $\quad$ There is a need to develop a comprehensive system of support for IE.

Pereira (2006) also noted a lack of resource and poor infrastructure in the classrooms. She argued that the lack of resources resulted in the utilisation of teacher-directed type learning as opposed to a more child-centred approach. Furthermore, this approach implies that the teacher is the 'holder' of knowledge and the student being reliant upon it. Contemporary learning theory involves learners constructing their own knowledge and development of higher-level thinking skills, both important components of IE.

Furthermore, an attempt was made by the Ministry to develop teaching resources such as, Samoan Sign Language Dictionary \& Inclusive Alphabet and the translation of the UNESCO Toolkit material to promote IE (Government of Samoa 2006b). However, the idea of these being utilised effectively by teachers needs consideration. If IE is based around such documentation the introduction, use and monitoring of the programmes is vital. It is ironic that Western style printed materials have been deemed to be so useful. Moreover, the researcher found that accessing some of the printed Samoan materials of the toolkit was difficult - how easy would it be for 
teachers? Although the intentions cannot be questioned, using a training mode of delivery that was not essentially based upon a needs analysis in terms of the cultural framework and teachers' belief systems has difficulties. Making it difficult to access is also very problematic.

\section{Professional Development}

Another vital aspect that is necessary for IE relates to teacher professional development. This is crucial if policies are to be implemented effectively. However, it is one of the issues highlighted as being of concern for:

- There are high rates of teacher attrition for the service which threatens the quality of teaching and learning;

- There is a need for a teacher support system in place to ensure continuous professional development of teachers and improvement in their conditions of work; and

- Access to education is heavily influenced by the availability of qualified teachers (Government of Samoa, 2006a).

As noted, these issues need addressing if implementation of policies (such as the IE) are to be successful. In-service teacher training is conducted by MESC with occasional assistance of the FOE. The emphasis is upon the training of teachers to teach special needs children and this requires specialist skills and certain types of personalities and aptitudes that are scarce. Recruitment of such people is difficult. However, there is a fallacy here - most of the literature on IE would suggest that the regular class teacher can do it apart from those with very specialist sensory impairments such as deaf and blind (Collins, Branson, Hall \& Rankin, 2001). What is also important to consider is a strategic professional development plan that emphasises the learning of teachers, their motivation and the transfer of learning technology (McDonald, 2009).

As illustrated above, there are several concerns highlighted in the policy document that need to be addressed, for these can greatly affect the implementation of the IE policy. It begs the question - how prepared was/is the Samoan education system in supporting the IE initiative? 


\section{The Toolkit Material}

The IE toolkit called 'Embracing Diversity: Toolkit for Creating Inclusive LearningFriendly Environments' was developed after consultation with a group of Asian countries and with Pacific inputs. It consists of six booklets on the ways and means of supporting IE in Samoa. Essentially, the toolkit material aimed at supporting the teachers' operation with an acknowledgment of family and community participation within the inclusive setting and was first piloted by four primary schools in Samoa mid 2005. The pilot schools soon after show-cased inclusive initiatives at a Pacific inclusive workshop in Samoa late 2005. In September 2006, an in-service workshop for all primary school teachers (one representative from each school) was conducted by a UNESCO consultant. Government teachers as well as teachers from private and mission schools were invited to attend. At the end of the five-day workshop, all participants were given an action plan task for each school to develop and submit to the Ministry of Education within three weeks of the workshop meeting. Fourteen schools (from among those who participated) were selected for implementation of workshop ideas for the consultant's monitoring visit in November 2006 which was undertaken by the workshop consultant herself. Table 3.5 provides a summary of the developments of IE as mentioned in this paragraph.

Table 3.5 Significant developments for Introduction of IE in Samoa

\begin{tabular}{|l|l|}
\hline \multicolumn{1}{|c|}{ Year } & \multicolumn{1}{c|}{ Activity } \\
\hline$<2000$ & $\begin{array}{l}\text { Prior to 2000, NGO's provided education and care for individuals with } \\
\text { special needs }\end{array}$ \\
\hline 2000 & National survey of children with disability (ages 0-14) \\
\hline $2001-2003$ & $\begin{array}{l}\text { Established special needs units within 6 government schools. Developed } \\
\text { teachers' manual for including children with special needs. }\end{array}$ \\
\hline 2004 & $\begin{array}{l}\text { Workshop carried out by overseas consultants in collaboration with MESC } \\
\text { for stakeholders of IE }\end{array}$ \\
\hline 2005 & $\begin{array}{l}\text { - Four primary schools piloted the toolkit } \\
\text { - Pacific workshop on IE (hosted by MESC in Apia) } \\
\text { - Showcased of IE (by pilot schools) initiative utilising the Toolkit material }\end{array}$ \\
\hline 2006 & $\begin{array}{l}\text { - Inclusive workshop for all Samoan teachers using 3 toolkit booklets. } \\
\text { Translation of UNESCO Toolkit material into Samoan language and each } \\
\text { participant received English and Samoan copies of the material. } \\
\text { - Fourteen schools were selected to implement workshop ideas (consultant } \\
\text { to follow up) } \\
\text { Expected Action plans from all primary schools (workshop participants) } \\
\text { on IE }\end{array}$ \\
\hline Onwards & $\begin{array}{l}\text { Monitoring of IE implementation to be carried out by MESC (Special } \\
\text { education coordinator is responsible for this) }\end{array}$ \\
\hline
\end{tabular}

Sources: McCullough, (2006), Samoa Department of Education (2002) 
As indicated above, the education system in Samoa has now moved towards implementation of IE, an initiative set in place in early 2000. These developments were useful for implementing IE but in comparison to other countries (e.g., NZ) there were insufficient overall preparation. For example, more detailed pre and in-service teacher could have been planned.

Figure 3.4 illustrates the current practice of schooling. In this model, all children with special needs were to be included in the regular classrooms. However; special educational support within special units was to be made available for students with severe disabilities (MESC, 2006).

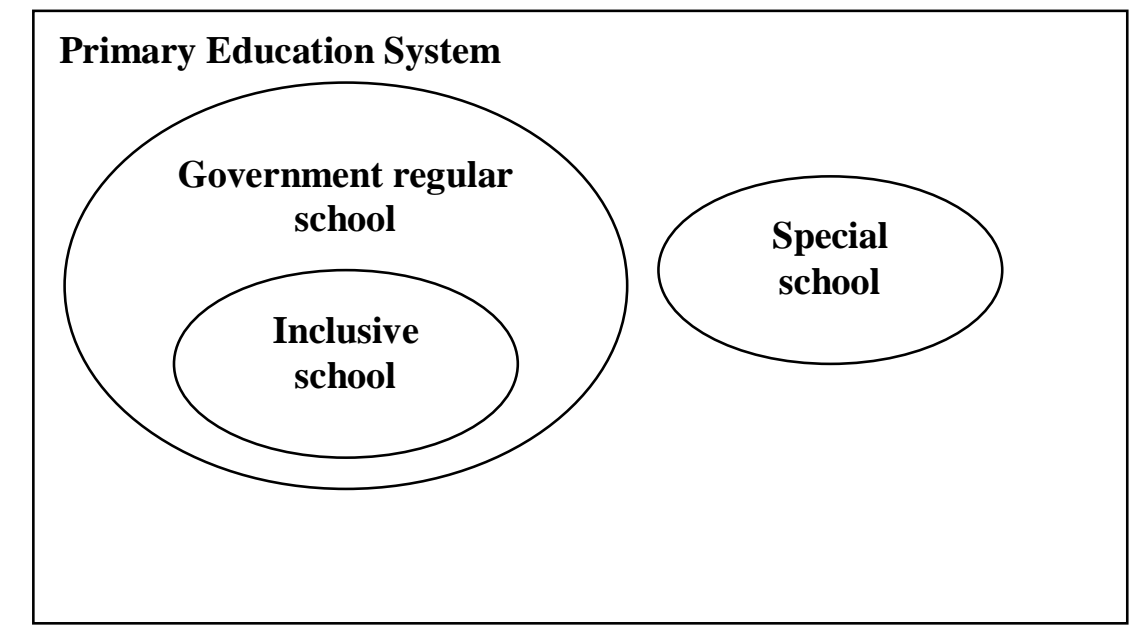

Figure 3.4 Inclusive Education System

\section{Change and Cultural consideration}

The implementation of any policy is undertaken in a specific context and yet so often cultural imperatives are overlooked. Those engaged in change need to be aware of the macro level cultural issues as well as the specific issues relating to culture and education. In the following discussion, consideration is given to both these concerns. 


\section{Samoa and Change}

Va'a (2006) noted that cultural norms and practices (related to social relationships) have undergone certain changes due to outside influences such as those from the Western and Asian cultures. He added that Samoan culture has been influenced resulting in social and cultural change deemed appropriate and not so appropriate. He noted that some Samoans have chosen to dispose of mores which appear irrelevant while retaining those that appear to benefit the Samoan society and "foreign countries” (p. 127). Tuia (1999) noted that some Samoan core values such as love, respect and obedience central to the Fa'aSamoa remained stable. However, I argue in support of Va'a that these values have taken on a change as will be noted later in this thesis.

Auva'a (2003) puts forward an argument concerning continuity and change in Samoan society in relation to educational policies. He asserts that Samoan society due to its hierarchical nature and because of the notion of maintaining its tradition and values, strive to retain the traditional values of the fa'aSamoa. There are some weaknesses in this review, however, because it is based only on the personal perspectives of the author, and draws upon mainly secondary sources rather than empirical data.

The argument presented by Fairbairn-Dunlop (1991) provides more logic when she reasoned that Samoa is committed to its traditional ways but at the same time is seeking to integrate modern ideas and technologies. This view is analogous to the view raised by Va'a (2006) above. Samoa's position in relation to change can be understood from these views thus the implementation of the IE policy could more likely be responded to in the same manner (i.e., if the Samoan people perceive this initiative beneficial to the society, there is more likelihood it would be accepted). On the other hand, the inclusive policy could just be another written document which is essentially disowned and disregarded. 


\section{Conclusion}

This chapter has examined some important areas of local literature significant to the study. It has offered a discussion of political, economic, historical, cultural and social profile of Samoa within which international ideas about disabilities are considered and local ideas about disability and IE phenomenon are explained. It has acknowledged that the implementation of IE is a complex phenomenon and that having policies in place does not guarantee effective inclusion. The literature acknowledges that cultural norms, values and beliefs can make a huge impact on the new initiative. It has highlighted a number of important issues that need to be considered when implementing change as dictated by the IE process adopted in Samoa. What is the status of the disabled person? What is the role of culture in disability? What is the most effective professional development programme? Can outside consultants provide assistance that is transferred? Overall, the literature has documented that Samoa has put in place systems and gained support from outside to implement an IE programme. The question remains however: in the minds of the key stakeholders is it workable and is it working? 


\section{CHAPTER FOUR}

\section{Research Design and Methodology}

\section{Introduction}

This study is a phenomenological oriented study grounded in cultural issues of Fa'aSamoa. It has been designed to generate qualitative data by exploring stakeholders' perceptions concerning the concept of IE and the challenges in the implementation and practice of IE policy in Samoa. It seeks to understand how participants in this setting view the notion of inclusion and what their beliefs were regarding the phenomenon of IE in relation to the Samoan way of doing things (Fa'aSamoa). Furthermore, it seeks to ascertain if this data could be used to develop a framework or model(s) for facilitating IE in Samoa.

This chapter explores the methodology used to achieve the aims of the study. It describes the research design, the setting, participants, methods of data collection and analysis. Constraints that were encountered in the course of the study are also presented. As a point of departure, a cultural metaphor 'ola' illustrates the research procedure.

\section{'Ola’ A Samoan metaphor - Framework for Research Process}

A conceptual framework has been used to connect all parts of the study to ensure it is a meaningful endeavour. In this study, the traditional Samoan concept, ola, has been used as a metaphor to understand the research process including the literature search, problem definition, research design and methods, and the presentation of the report. The concept ola has multiple meanings. First, it is a form of traditional basket; the second one meaning 'life'; and the third meaning refers to' light' which leads to the concept of 'enlightenment'. All of these meanings are incorporated into the metaphor adopted for this study.

\section{Selection and its Symbolism}

Ola is a traditional basket woven from the leaves of the coconut tree. The coconut tree is a commonly found tree in the tropics. To the Samoan people, it is an extremely valuable resource due to the usefulness of all its parts. The 'ola' is made from the very newly developed leaves of the coconut tree, thus a meticulous 
selection of an appropriate leaf that is suitable for this process is crucial otherwise it will not be a satisfactory outcome.

This method of selection characterises the approach that was undertaken during the literature search in this study. The researcher, in searching for a topic for the investigation, conducted an extensive search of the relevant literature, in order to select the topic. The search was then refined to a specific research problem to be investigated. The aim of the study was to examine the stakeholders' views and perceptions about the IE concept and the implementation of the IE policy in Samoa. Therefore the literature that was scrutinized explores the IE concept, the definition, the underpinning models and theories, as well as the impetus for IE within Samoa.

Of equal importance was the extra care taken in the selection of an appropriate methodological approach for gathering the data and this includes the research design, the methods for data collection, and the analysis. A phenomenologically oriented research design grounded in a constructivist paradigm was adopted. This was most appropriate for the study since it captured the lived experiences of participants. The methods of data collection involved using individual and focus group interviews, and employing a thematic analysis approach for data analysis.

\section{Basket Weaving and Interlacing ideas}

The weaving process requires exceptional care so that the ola will have the capacity to hold the contents that will be placed in it. An adept weaver will produce as a final product an effective result, an ola that is firm with no gaps so the contents will stay together in the basket. In relation to this study, the weaving process depicts the interlacing of ideas so that all parts of the research are linked together from literature review to the writing of the final report.

\section{Basket of Food - Source of Life/Knowledge}

The purpose of the ola (basket) is for holding things, mainly food for sustenance - a source of life. Life is the second meaning of ola. An example of food could be fish conceivably received from a collective fishing activity- a norm in the Fa'aSamoa and this is normally shared with others, like families or neighbours. In connection to the study, the knowledge, epistemologies, and philosophies that have been gathered for this study comprise the contents of this basket of knowledge, symbolic of the ola of food. 


\section{Enlightenment}

The aim of this study is to contribute to the international literature and share this knowledge with others. This utilises the third meaning of ola which relates to light. It demonstrates the manner in which the knowledge and findings from this research are intended to enlighten others about how people in this society construct meanings in their lived experiences with respect to IE and their conceptualisation of this concept. This process underpinned by social constructivism is a philosophical method of inquiry employed in this study. ${ }^{7}$

In summary, the 'ola' is a woven basket (i.e., the design framing the study). In the basket there is food and this implies ideas and understandings (i.e., ideas of participants and literature knowledge) which then can 'throw light' on the issue. The phenomenological inquiry emphasises the perceptions of the participants and these are key to the study although the findings are linked to other sources of informants.

\section{Methodological Approach}

This study does not hold the positivist belief that the goal of science is to uncover, observe and measure the truth. Instead, it is based on the post positivist view that the world is a function of people's construction and interpretation of it (Merriam, 1988). Based on this view this thesis uses a constructivist and interpretive perspective because of its consistency with the phenomenological qualitative approach used to investigate the research problem.

Figure 4.1 represents the methodology for this inquiry or how the design for this study was approached. It illustrates the framework that was utilised and includes the combination of philosophical assumptions, research strategies and methods.

\footnotetext{
${ }^{7}$ The 'ola' metaphor contextualises the research process.
} 


\section{Study}

utilises

Philosophical assumptions

Inquiry paradigm

Models for research

Methods
$\downarrow$
underpins
A constructivist worldview

qualitative

underpins

$\downarrow$
employs

Interview, focus group

Figure 4.1 Methodological terminology and structure adopted in the study

The model above denotes how the researcher brings to the choice of a research design assumptions about knowledge claims. Some called it paradigms (Lincoln \& Cuba, 2000; Mertens, 1998) or research methodologies (Neuman, 2000) or philosophical assumptions, epistemologies and ontologies (Crotty, 1998). Such philosophical assumptions underpin an inquiry paradigm that provides specific direction for procedures in a research design. These strategies of inquiry contribute to our overall research approach (Creswell, 2003, p. 6).

\section{Philosophical Assumptions Underpinning the Research Design of the Inquiry}

This research employed a qualitative and phenomenological approach founded on a constructivist epistemology. A qualitative approach is one in which the inquirer often makes known claims based primarily on constructivist perspectives. A constructivist assumption is one where meanings are interpreted and constructed by human beings as they engage with the world. That is, individuals seek understanding of the world in which they live and work. They develop varied and multiple subjective meanings for their experiences, which are socially and historically formed. These meanings are formed through interactions with others hence the notion of social constructivism (constructivism (Berger \& Luckman, 1967; Crotty, 1998; Lincoln \& Guba, 1985; Neuman, 2000).

The aim of the qualitative researcher therefore is to discover meaning of the social world from the perspective of the individuals and groups who are engaged in an ongoing phenomenon, action, or process being investigated. The research therefore relies as much as possible on the participants' views of the phenomenon being 
studied (Creswell, 2003, 2005). Palys (2003) added "qualitative researchers must be open to any new directions that emerge in the context of the [research] because of the unique perspectives of the participants” (p. 160).

The theoretical perspective guiding the research approach was interpretive with a focus on the phenomenon of IE. Ferguson and Ferguson (1996) characterized the methodology associated with the interpretive paradigm as "the systematic collection and analysis of the stories people tell about how they interpret reality” (p. 105). Thus, the study sought to explore stakeholders' everyday experiences, perceptions, beliefs and views concerning IE by understanding the perspective of each person's viewpoint and their relationships with other perspectives. The qualitative research approach was deemed appropriate for this study for it enabled the researcher to seek an understanding of the researched phenomenon from the participants' point of view.

\section{Research Approach and Design}

The decision on the research approach was driven by the:

a) objectives of the research in uncovering participants understanding of the meaning of IE, locating facilitating or inhibiting factors for implementation of IE policies, and to make some contribution to the global literature on IE;

b) understanding that there is a dearth of phenomenological data concerning this issue in Samoa; and

c) researcher's own belief in the capacity of this approach to locate views and experiences of participants in the study. The beliefs and views of stakeholders of IE in Samoa are crucial, and this is why this approach was adopted.

This method of inquiry is powerful because when capturing the participants' lived experiences of a phenomenon, the actual voices become the data that is collected. As Sanga and Niroa (2004, p. 48) note it is particularly valuable for Pacific indigenous research:

the more appropriate research strategies are those that are qualitative in nature because they better serve the methodological purposes of Pacific research. A key purpose is the ability to obtain rich contextual details. The active participation of insiders is integral to indigenous Pacific research for it allows for multiple realities to be captured...each voice to be heard. (Sanga \& Niroa, 2004, p. 48). 
Accordingly, the phenomenological approach appeared to be a perfect fit for the purposes of this research.

\section{Phenomenological Design}

Phenomenology is a philosophy founded by the German philosopher Edmond Husserl in the early twentieth century (Giorgi \& Giorgi, 2003). It is a qualitative research approach which seeks to explore lived experiences (van Manen, 1990) and which endeavours to illuminate meanings of displayed behaviour and events as construed by research participants (Polkinghorne, 1989). This approach involves the researcher identifying the essence of human experiences, as described by participants themselves. The aim is to capture as closely as possible the way in which the phenomenon is experienced within the context in which the experience takes place (Giorgi \& Giorgi, 2003). This means that to study a particular phenomenon, a situation is sought in which individuals have first-hand experiences that they can describe (Giorgi \& Giorgi) as they occurred in their lives. The point is that in order to understand the participants' behaviour the researcher needs to view the phenomenon from the lens of the participants.

In this study, the researcher as a phenomenologist, attempted to view the phenomenon under study from the standpoint of the participants as opposed to her own. This distinctive feature of the phenomenology qualitative approach, as mentioned above, enabled the researcher to delve deep into the participants' experiences in relation to IE.

Other writers (Creswell, 2003; Nieswiadomy, 1993) who have commented on phenomenology suggest that the researcher brackets his or her own experiences in order to understand those of the participants in the study (p. 15). It is in this context that Moustakas (1994) notes that by understanding the lived experiences of others in an unbiased manner enables phenomenology to be not only a philosophy but also a methodology.

A number of studies have utilised the phenomenological research approach to investigate experiences of participants. For example, Campbell (1997) in her paper cited studies from other disciplines that have utilised this approach. In the discipline of geography, Gillian (in Campbell, 1977) described the impact of feminist studies on the discipline of geography and in the field of nurse education Borbasi (1996) 
employed the method to capture the experiences of nurses. Examples such as these have established the phenomenological approach as an appropriate and respected method to investigate the experiences of participants in this study. Furthermore, in the present study, the experiences of the Samoan participants are targeted and using the phenomenological approach was deemed to be more appropriate to achieve this purpose.

\section{Advantages of the Phenomenological Approach}

Denscombe (2007) pointed out a number of advantages of the phenomenological inquiry which were considered in adopting the approach for this study. These are as follows:

- It offers the prospect of authentic accounts of complex phenomena. The social world is a complex phenomenon and the phenomenological approach permits the researcher to cope with that complexity. The phenomenological approach digs deeper into aspects of social reality. The researcher will be able to probe deep into the phenomenon and provide detailed descriptions that reflect the complexity of the social world;

- A humanistic style of research is adopted. In the phenomenological approach, there is deference for people. It has a more humanistic orientation than many other methodologies and the focus on lived experiences represents a style of research that is removed from high-minded, abstract theorizing. Practically, it enables the researcher to be close to the objects of the study;

- It is suited to small-scale research and one of the advantages of the phenomenological research making it suitable for the present study is its cost effectiveness. Since interviews and document analysis was used, it did not require expensive equipment for data collection and analysis. In this study where the researcher herself was the key resource and where budget was limited, the phenomenological research approach was deemed most appropriate; and

- The description of experiences can tell an interesting and meaningful story. The authenticity of the participants' everyday life experiences could become of interest to a wider audience since a number of readers are likely to relate to the participants' experiences. 


\section{Constraints of Phenomenological Approach}

Although the advantages mentioned above indicate phenomenology as a very useful and appropriate approach for this current research, its limitations also need to be considered. These were issues that had to be balanced when undertaking the research. The limitations are outlined below:

- As Denscombe (2007) commented the phenomenological approach lacks scientific rigour and this could have been a drawback for the current research certainly those who adopt a positivist standpoint would make this point. Such a viewpoint however is made from a different paradigmatic perspective and issues relating to scientific rigour need to be understood and interpreted within the phenomenological perspective and its purposes. Furthermore, the phenomenological methodological approach does have techniques and strategies that facilitate validity and reliability of a study. Such techniques detailed in this section ensure confidence in the approach to provide rich narrative data that is real to life and it is data that is valid and reliable;

- The participants define the truth. The truth is defined by the participants and the researcher has to accept what the participants' relate as being the sole truth in this respect. Truth is however a relative position. To the participants their lived experience is truth to them and it is just this that the researcher is interested in. The current research project was actually centred on the participants' own truth (which may or may not be objective truth). It is the subjective aspect that balances objectivism; and

- There could be an imbalance of power. The issue of power relationships is an important consideration in situations where the researcher becomes the sole interpreter of knowledge or assumes control of the discussion. The researcher overcame this potential difficulty by actively promoting participant engagement in the discussion. That is, the researcher adopted a listening strategy (even at times waiting in silence for the conversation to be continued by the participants) but encourage all individuals (who may have felt intimidated by their superiors/researcher) to present their views. This was a critical strategy since the participants' views were crucial to the study. When some individuals were not ready to contribute they were permitted to pass, however the researcher always returned to that individual for comment before discussion on that point was terminated. 


\section{Research Phase}

There were a number of research phases followed for this project. Refer Figure 4.2.

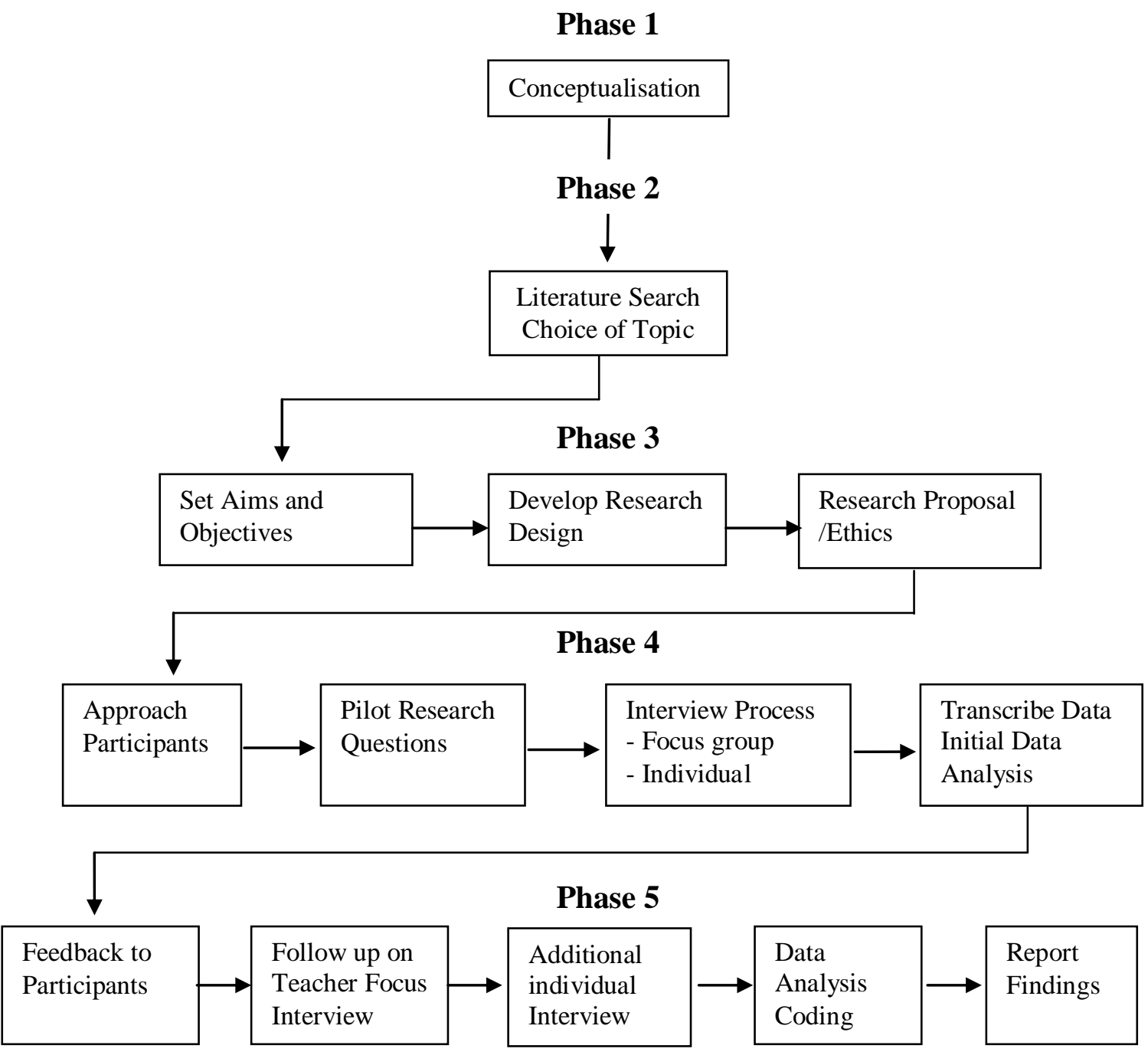

Figure 4.2 Planned research phases

\section{Phase 1 \& Phase 2}

This was concerned with the researcher's conceptualisation of the problem. It was noted that there was discrepancy between IE policies and practices in Samoa. The literature was scrutinized for a clear identification of the problem and through analysing, synthesizing and evaluation of this literature the research question was developed. 


\section{Phase 3}

Research questions for individual and focus group interviews were also developed. Subsequently, the research design was planned. All of this information was detailed in the research proposal and ethics application both of which were submitted for approval before commencement of field work.

\section{Phase 4}

Before approaching participants, approval was sought from the Ministry of Education to gain access to the schools which had been selected for the study. Subsequently, participants for individual and focus group interviews were approached for their consent to participate and dates and times for meetings were decided upon. Before data collection began, questions were first trialled with a number of people from the Ministry, and the Faculty of Education, a community member and a parent who was also a teacher. Some questions were modified and altered following this piloting. Focus group interviews for teachers, parents and Ministry of Education staff were conducted in school staff rooms. Individual interviews for key participants from the Ministry, teacher training and community members were either held in offices or in the home. The interviews were audio taped, transcribed in the Samoan language.

\section{Phase 5}

The transcripts were returned to the participants for their feedback. The returned transcripts were translated into the English language, and the initial data analysis took place. Data was coded, analysed and follow up interviews occurred in two of the schools to examine some of the key ideas emerging from the data. To follow up some of the key issues that emerged from initial analysis, additional interviews were conducted with three key members, a chief (ex MP), a parent of a special needs student from a fee paying school and a prominent teacher educator. Further data analysis and interpretation took place followed by writing of the final report.

\section{Methodology}

After scrutinizing the literature, a research plan evolved. Table 4.1 provides a summary of the research objectives, guiding questions and data collection activities and sources. 
Table 4.1 Overview of Research Objectives and Methodologies

\begin{tabular}{|c|c|c|c|}
\hline Objective & Guiding Questions & Method & Data Source \\
\hline \multirow[t]{3}{*}{$\begin{array}{l}\text { To identify the } \\
\text { beliefs, values, } \\
\text { experiences, } \\
\text { expectations and } \\
\text { practices of key } \\
\text { stakeholders to IE } \\
\text { in Samoa }\end{array}$} & \multirow{2}{*}{$\begin{array}{l}\text { What are the key stake- } \\
\text { holders attitudes and } \\
\text { expectations of IE? } \\
\text { What are key } \\
\text { stakeholders perspectives } \\
\text { about policy introduction } \\
\text { and implementation of } \\
\text { IE? } \\
\text { What do stakeholders } \\
\text { perceive as factors that } \\
\text { could inhibit or facilitate } \\
\text { IE practices in Samoa? } \\
\text { How do stakeholders } \\
\text { view IE in relation to the } \\
\text { Samoan culture? }\end{array}$} & $\begin{array}{l}\text { Focus group } \\
\text { semi-structured } \\
\text { interviews }\end{array}$ & $\begin{array}{l}\text { Teachers } \\
\text { Parents } \\
\text { Curriculum } \\
\text { developers }\end{array}$ \\
\hline & & $\begin{array}{l}\text { Individual } \\
\text { semi-structured } \\
\text { interviews }\end{array}$ & $\begin{array}{l}\text { Teachers educators } \\
\text { Community } \\
\text { members } \\
\text { Ministry of } \\
\text { Education }\end{array}$ \\
\hline & $\begin{array}{l}\text { What are the teachers' } \\
\text { views about their } \\
\text { experiences and } \\
\text { preparation for IE? } \\
\text { How do teachers describe } \\
\text { their experiences of } \\
\text { teaching in inclusive } \\
\text { classrooms? } \\
\text { What are teachers' } \\
\text { practices in inclusive } \\
\text { classrooms? }\end{array}$ & $\begin{array}{l}\text { Focus group } \\
\text { semi-structured } \\
\text { interviews }\end{array}$ & Teachers \\
\hline \multirow[t]{2}{*}{$\begin{array}{l}\text { To develop a model } \\
\text { of explanation that } \\
\text { would assist with } \\
\text { the IE policy and } \\
\text { implementation. }\end{array}$} & \multirow[t]{2}{*}{$\begin{array}{l}\text { What are key- } \\
\text { stakeholders' } \\
\text { expectations for IE? }\end{array}$} & $\begin{array}{l}\text { Focus group } \\
\text { semi-structured } \\
\text { interviews }\end{array}$ & $\begin{array}{l}\text { Teachers } \\
\text { Parents } \\
\text { Curriculum } \\
\text { developers } \\
\end{array}$ \\
\hline & & $\begin{array}{l}\text { Individual } \\
\text { semi-structured } \\
\text { interviews }\end{array}$ & $\begin{array}{l}\text { Teachers educators } \\
\text { Community } \\
\text { members }\end{array}$ \\
\hline
\end{tabular}

\section{Methodological Procedures}

\section{Development of Questions}

Nachmias and Nachmias (1992) noted the importance of constructing questions in such a manner that participants understand them in the same way as the researcher intended. Accordingly, focus and individual interview questions were written both in English and Samoan and the participants were given a choice for their language of preference. Questions were initially written in English for the proposal and were later translated into the Samoan language for those who preferred to be interviewed in the vernacular. All participants preferred discussions to be undertaken in the Samoan language with the exception of participants (teacher educators) from the Faculty of 
Education, National University of Samoa and those from the Ministry of Education who were comfortable using the English language. There were some common questions that were asked of all stakeholders; however, others were developed specifically for stakeholders dependent on their role in IE (refer to Appendix 2 \& Appendix 3).

\section{Piloting}

Questions for the study were trialled with two teacher educators, a key community member who was also a parent, a teacher and a member of the Ministry of education. This was helpful for it clarified questions in facilitated useful instructions, identified inappropriate wording, and questions that were too long, short, easy, difficult, boring, intrusive or offensive. For example, some terms were too technical and these were replaced with more easily understood terms. Piloting the questions also helped to estimate the times for interviewing as well as trialling the coding and classification system for the data analysis (Cohen, Manion \& Morrison, 2000, p. 260).

\section{Participants}

Fifteen Samoan primary teachers from three schools who had been involved in the IE initiative since 2005 were involved in focus group discussions. There was 1 male and 14 females. Twelve teachers were from 2 urban schools and 3 from a rural school. Five of the 15 teachers had enrolled previously in formal special education courses and the rest had participated in IE professional development training. There were 7 curriculum advisors (in-service teacher educators) and 5 parents (three urban and two rural) who had children with special needs who also contributed via the focus groups.

One key member from the Ministry of Education, 1 curriculum advisor, 2 teacher educators (1 with special education background) from the Faculty of Education at the University of Samoa, and 3 community members (one church minister and two community leaders - chiefs) contributed information via the individual interview schedule.

An extra 3 participants were identified for follow up individual interviews during the data analysis phase. There was 1 teacher trainer, 1 community leader (ex MP) and 1 parent from a fee paying primary school which had a special needs unit. These individuals were selected to elaborate upon views after themes that emerged from the data emerged. Due to the nature of IE and the limited population, a purposive 
selection of participants was used and this was established via the researcher's networks in educational settings in Samoa but with guidance from the Ministry of Education Sports and Culture (MESC). All participants were of Samoan descent.

\section{Criteria for Selection of Teachers and Parents}

Given that IE policy was only introduced into the Samoan education system early this century, there was an assumption that teachers had limited knowledge and understanding of the concept and practice but selection of teachers for this research study was based on their assumed knowledge and experience of IE. They were selected from three of the schools which were involved in piloting the IE UNESCO toolkit that was introduced to the Ministry of Education in 2004. The principals of each school selected teachers who had children with identified special needs in their classrooms. There was a range of teacher variables in terms of teaching experience, age, qualifications and position held (Refer Table 4.2). Parents were selected because it was important to ascertain what their views and beliefs were concerning placing their child with special needs in an inclusive setting.

Table 4.2 Characteristics of teachers involved in the study

\begin{tabular}{|l|c|c|c|c|}
\hline \multicolumn{1}{|c|}{ Age } & $\mathbf{2 1 - 3 0}$ & $\mathbf{3 1 - 4 0}$ & $\mathbf{4 1 - 5 0}$ & $\mathbf{5 1 - 6 0}$ \\
\cline { 2 - 5 } & 2 & 7 & 4 & 2 \\
\hline $\begin{array}{l}\text { Years of Teaching } \\
\text { Experience }\end{array}$ & $\mathbf{1 - 1 0}$ & $\mathbf{1 1 - 2 0}$ & $\mathbf{2 1 - 3 0}$ & $\mathbf{3 1 - 4 0}$ \\
\cline { 2 - 5 } & 2 & 7 & 4 & 2 \\
\hline \multirow{3}{*}{ Position } & Teacher & $\begin{array}{c}\text { Senior } \\
\text { Teacher }\end{array}$ & Principal & \\
\cline { 2 - 5 } & 11 & 2 & 2 & \\
\hline \multirow{3}{*}{ Qualification } & $\begin{array}{c}\text { General } \\
\text { Education }\end{array}$ & $\begin{array}{c}\text { Special } \\
\text { Education }\end{array}$ & & \\
\cline { 2 - 6 } & 11 & 4 & & \\
\hline
\end{tabular}

\section{Setting}

The curriculum advisors from the Ministry were interviewed in their offices, teachers were interviewed at their schools and parents were interviewed at their children's schools. One teacher educator was interviewed in the researcher's office and one off campus. One community member was interviewed in his home and two others at the researcher's workplace. 


\section{Data Collection}

The main methods of data collection - individual and focus group interviews, and document analysis - as identified by Denzin and Lincoln (2003) were employed. These methods were selected because they allowed active participation of participants. It also allowed the researcher greater flexibility in terms of refining questions (e.g., the researcher was able to improve on subsequent questions from questions asked earlier). Furthermore, this process provided time to develop broad interpretations of the emerging data, a process noted as important by Creswell (2003).

\section{Focus Group Interviews}

The focus group methodology is a qualitative data collection method which involves an informal small group discussion which centres on a specific topic. The researcher as a moderator poses the question and keeps the discussion focused inviting / encouraging participant involvement. Focus group method has a naturalistic feature and very similar to everyday conversation (Wilkinson, 2003, p. 184).

The naturalistic relaxed nature of the focus group methodology, makes this an appropriate methodology to collect data from participants in this study such as teachers, parents and curriculum developers. A total of 6 focus groups were established: three focus groups of teachers, two focus groups of parents and one group of curriculum developers. Each focus group interview lasted at least 2 hours except for the group with 2 participants which lasted 90 minutes. Participants were allowed 15 minutes break (excluding total interview time) for a snack. Prior to the interview, participants were asked for their language of preference; all preferred their mother tongue - Samoan. The focus group interviews were established in the manner of dialoguing 'talanoa' - which is often used in the Pacific Islands. ${ }^{8}$

\section{Talanoa Method}

Traditional research has been critiqued for it is grounded in Western philosophy and lack of interpersonal relationships between the researcher and participants. This is different to the Pacific way of thinking where variables such as age, gender, or community status of the researcher are likely to influence the results (Smith, 2004; Vaioleti, 2006).

\footnotetext{
${ }^{8}$ The research term 'focus group' is used but it is acknowledged that this was significantly impacted upon by the talanoa process.
} 
Oral tradition continues to be highly valued in Pacific cultures. Talanoa is a tool in which certain "domains of knowledge are constructed and disseminated" within the Pacific as stated by Sanga and Niroa (2004, p. 46). Talanoa is "a personal encounter where people story their issues, their realities and aspirations" and is perceived to be a naturalistic research methodology for Pacific peoples and suitable for undertaking research in this part of the world (Smith 2004; Vaioleti, 2006, p. 23). Talanoa is undertaken in an informal or formal manner where experiences are exchanged without a rigid framework (Outsuka, 2006; Vaioleti, 2006). Literally, talanoa means having a face-to-face chat about nothing in particular, and interacting without a rigid framework (Osaka, 2006; Vaioleti, 2006).

The ease in which the talanoa method is undertaken differentiates it from the more traditional methods of research. Vaioleti (2006) argued that the talanoa method has a lot of flexibility where both the researcher and the participant operate on an equal level in terms of dialoguing an issue; however it can be argued that this may be dependent on the researcher. Talanoa as noted above can be formal or informal that if the researcher decides to be more formal it could affect the mode of the discussion and may not elicit as much information from the participants. On the other hand, if the researcher is less formal, participants would be placed in a relaxed position to be more forthcoming in their views. In this study, the informal aspect of talanoa seemed to have encouraged participants to exchange their views, opinions and beliefs in a more comfortable manner. The data was collected on participants' definition of IE and their perspectives of how IE was experienced and practiced in the classrooms. The researcher believed that the relaxed aspect of the talanoa method made participants weave in and out of the discussion with ease. However, regardless of its potential, the talanoa method has limitations. According to Vaioleti (2006), since both the researcher and participants are constructing and documenting knowledge, over time it may lose its reliability. The likelihood of reproducing similar results, if the study is replicated, may not be high.

As mentioned elsewhere in this chapter, discussions were audio taped with permission of participants and were later transcribed. At the end of discussions, a cultural protocol of koha/gift presentation (in monetary form) was followed. The researcher thanked the participants at the end of each session and requested an opportunity for follow up interviews if this was necessary. 


\section{Advantages and Limitations of Focus Group}

Madriz (2000), argued about the worth of focus groups in reducing the distance between the researcher and the researched plus diminishing the chance of researcher dominating the discussion. Marshall and Rossman (2006) also contend that focus group sessions place the participants in a supportive and relaxed atmosphere. It was assumed that this approach for the participants in this study would be more relaxed since discussing issues in groups is more common. Using this approach often results in the ideas motivating others to contribute viewpoints.

Its value notwithstanding, focus groups can be problematic because of the power dynamics. It was anticipated that such a relationship can readily occur in studies such as the present research endeavours because timid and younger participants may be dominated by their superiors. To overcome this potential disadvantage the researcher can direct questions to those participants who appear less forthcoming. A further limitation according to Marshall and Rossman (2006) is the limited control the researcher has over the situation which can result in trivial issues being discussed impacting upon content validity and time restraints. Adopting a semi-guided approach can get over this problem.

Table 4.3 Organisation of participants for focus group interviews

\begin{tabular}{|c|c|c|c|c|}
\hline \multirow{2}{*}{ Focus Group } & \multirow{2}{*}{ No } & \multicolumn{2}{|c|}{ Gender } & \multirow{2}{*}{$\begin{array}{l}\text { Special needs of children included in regular } \\
\text { classrooms }\end{array}$} \\
\hline & & $\mathbf{F}$ & $\mathbf{M}$ & \\
\hline $\begin{array}{l}\text { Teachers School A } \\
\text { (Urban) }\end{array}$ & 5 & 5 & - & $\begin{array}{l}\text { down syndrome, slow learners (learning } \\
\text { difficulties), hearing impaired/deaf, physical } \\
\text { disability }\end{array}$ \\
\hline $\begin{array}{l}\text { Teachers School B } \\
\text { (Urban }\end{array}$ & 6 & 6 & - & physical disability, slow learners \\
\hline $\begin{array}{l}\text { Teachers School C } \\
\text { (Rural) }\end{array}$ & 3 & 2 & 1 & physical disability, slow learner, hearing impaired \\
\hline Parents School A & 3 & 3 & - & down syndrome, deaf, physical disabled \\
\hline Parents School C & 2 & 2 & - & intellectually impaired, slow learners \\
\hline $\begin{array}{l}\text { Curriculum } \\
\text { Designers }\end{array}$ & 6 & 4 & 2 & \\
\hline
\end{tabular}

\section{Semi Structured In-depth Individual Interviews}

According to Boyne and Neale (2006), individual in-depth interview is a qualitative research technique to examine informants' views on a particular idea or topic. For example, in this study, the participants were asked to describe their experiences, 
views and expectations regarding IE and the implementation of inclusive policies in relation to the data already collected. This technique is useful when the researcher wants detailed “information about a person's thoughts and behaviours or to explore new issues in depth. In-depth interviews should be used if the potential participants may not be included or comfortable talking openly in a group or when the researcher wants to distinguish individuals (as opposed to group) opinions about the program” (Boyne \& Neale, 2006, p. 3).

In this study, individual interviews were conducted with key members of the community (chiefs and the church leaders), the Ministry of Education and teacher educators since the researcher wanted to ascertain their views about IE in addition to the need to distinguish their particular perspectives from the group views. Also, given the hierarchical nature of Samoan society and the standing of some of the key participants in the community, it was more appropriate to interview these individuals on their own. Additional data was collected from three participants: a parent whose child was included in special needs unit (attached to a private school), a teacher trainer, and an ex MP to add richness to data.

An interview protocol consisting of semi-structured questions were administered to individuals in their offices and homes. Semi structured interviews were utilised because of their flexible nature. They were considered appropriate in this context as it allowed the participants more flexibility. The same interview schedule was utilised during focus group discussions - however, there was a variation of questions based on the individual's roles in IE. One of the advantages of using semi formal interviews, according to Mikkelsen (2005), is that it allows space for comparison between views of different participants. Interviews were conducted in the form of 'talanoa' since participants in this study were from an oratory-based culture and participants were therefore more relaxed contributing in this manner.

\section{Advantages/Limitations of Semi Structured In-depth Individual Interviews}

Interviews allow the opportunity to follow-up and elucidate information; furthermore, they reveal additional avenues of questioning that may have gone untapped. The strength of using individual interviews utilising open ended questions lies in the capacity to yield rich data (Marshall \& Rossman, 2006). Individual interviewing can be a more relaxed atmosphere for data collection where people may be more comfortable talking as opposed to filling out a survey (Boyne \& Neale, 
2006). Bell (1999) states that "the advantage of a focused interview is that an outline is established beforehand and so analysis is greatly simplified" (p. 138). These strengths notwithstanding, semi structured open-ended interviews can be limiting in a number of ways. They can for example create large volumes of data and analysis of this huge data set may be time-consuming. Further, as in many data collection techniques, participants may avoid giving their truthful' answer (for many reasons) and unless questions are carefully worded in-depth narratives may not be obtained. There is also the problem of bias - policymakers for example may be biased because of their stake in a programme (Boyne \& Neale, 2006).

\section{Document Analysis}

Document analysis is the systematic exploration of written documents or other artefacts. It involves examination and interpretation of data to uncover meaning and to develop experiential knowledge and understanding (Corbin \& Strauss, 2008). Often document analysis is used in combination with other qualitative research methods for the purpose of triangulation - what Denzin (1970, p. 291) called 'the combination of methodologies in study of the same phenomenon' (Bowen, 2009). In the current research, document analysis was not used to check reliability of participants’ views but was used to add further meaning (richness) to the data.

In this research, documents relating to IE to ascertain policies, procedures, roles, programmes, implementation and other issues were critically analysed. Documentation such as government, education policies and educational reports were explored in a systematic way which assisted with the development of patterns and themes related to the research question(s) and the concept of IE. The researcher used a highlighter to identify the key concepts for example, inclusive education, special needs, disability, every time it appeared in any policy documentation, minutes of meetings, educational reports and programmes. Other terms or inferences which implied emphasis on IE or practices of teachers, phrases or clauses which implied attitude towards disability and education, were also highlighted and placed in categories.

The advantages of document analysis, according to Creswell (2003), are because of its unobtrusive nature and it can be accessed at a time convenient to the researcher. As written evidence, it also saves the researcher the time and expense of transcribing. 


\section{Data Analysis of Individual and Focus Group Interviews}

The interpretive grounded theory methodological approach suggested by Miles and Huberman (1994) was utilised to analyse this data. The answers to the questions were transcribed into written text for analysis. It is important that the researcher safeguards against imposing their own theoretical orientation of the process because it is the participants' true meaning that is being discovered. Given the phenomenological, interpretive nature of this study, the following method of analysis was used to analyse the narratives.

1. After the initial data collection from focus groups, and individual interviews, the initial data analysis was undertaken. Interviews were transcribed, read through a number of times and copies of data were printed. These were given back (personally delivered by the researcher) to participants for their feedback and for them to add any to provide any other information considered important.

2. Next, after two weeks, the researcher collected the feedback transcripts. In some cases the transcripts were not ready/available and so the researcher returned the next day to collect them. Returned data transcripts were then coded after being translated into English.

3. A process of conceptual coding was used, that is, each sentence was scrutinized for concepts being discussed (in relation to the theories and key issues in IE) and these were then coded (labelled) (e.g., teacher commitment).

4. The codes were aggregated into patterns (categories) (e.g., teacher qualities and responses).

5. The identified patterns were considered in the light of previous research and theories, and a number of themes identified (e.g., transfer practice)

\section{Trustworthiness of the Study}

Trustworthiness is a term often used in qualitative research and replaces the terms reliability and validity in quantitative research designs (Graneheim, \& Lundman, 2004; Lincoln \& Guba, 1985). Sandelowiski (1993) argues that issues of validity in qualitative studies should be linked not to 'truth' or 'value' as they are for the positivist, but rather to 'trustworthiness', which 'becomes a matter of persuasion whereby the scientist is viewed as having made those practices visible and, therefore, 
auditable” (p. 2). A study is trustworthy if, and only if the reader of the research judges it to be so. Trustworthy is determined by the credibility, dependability, transferability and confirmability of the study (Sandelowiski, 1993). Guba's model (in Krefting,1991) as shown in figure 4.4 below describes four criteria for evaluating research and then defines each from both a quantitative and qualitative perspective.

Table 4.4 Criteria for research evaluation in qualitative and quantitative approach

\begin{tabular}{|l|l|l|}
\hline \multicolumn{1}{|c|}{ Criterion } & \multicolumn{1}{|c|}{ Qualitative Approach } & \multicolumn{1}{c|}{ Quantitative Approach } \\
\hline Truth value & Credibility & Internal Validity \\
\hline Applicability & Transferability & External Validity \\
\hline Consistency & Dependability & Reliability \\
\hline Neutrality & Confirmability & Objectivity \\
\hline
\end{tabular}

The aim of trustworthiness in a qualitative inquiry is to support the argument that the inquiry’s findings are “worth paying attention to” (Lincoln \& Guba, 1985, p. 290). In this study, trustworthiness was enhanced through the strategies detailed in figure 4.5 below.

Table 4.5 Strategies with which to establish trustworthiness

\begin{tabular}{|l|l|l|}
\hline \multicolumn{1}{|c|}{ Strategy } & \multicolumn{1}{|c|}{ Criteria } & \multicolumn{1}{c|}{ Execution of strategy } \\
\hline $\begin{array}{l}\text { Credibility } \\
\text { “Is an evaluation of } \\
\text { whether or not the } \\
\text { research findings } \\
\text { represent a 'credible' } \\
\text { conceptual interpretation } \\
\text { of the data drawn from } \\
\text { the participants' original } \\
\text { data” (Lincoln \& Cuba, } \\
\text { 1985, p. 296). }\end{array}$ & $\begin{array}{l}\text { Triangulation - } \\
\text { through using } \\
\text { several data } \\
\text { sources }\end{array}$ & $\begin{array}{l}\text { Various data sources (participants) were } \\
\text { used in the acquisition of the data. By } \\
\text { purposeful sampling the researcher } \\
\text { identified all the different stakeholders who } \\
\text { had an interest in IE, including the parents, } \\
\text { teachers, Ministry of Education personnel, } \\
\text { community members, and teacher } \\
\text { educators. }\end{array}$ \\
\cline { 2 - 3 } & Member checking & $\begin{array}{l}\text { At the end of the focus group discussions } \\
\text { the moderator summarised the content. } \\
\text { Participants' opinions were obtained } \\
\text { regarding the accuracy of their own } \\
\text { perspectives and use of language rather } \\
\text { than the interpretation and terminol ogy of } \\
\text { the researcher. }\end{array}$ \\
\hline
\end{tabular}




\begin{tabular}{|c|c|c|}
\hline Strategy & Criteria & Execution of strategy \\
\hline & Peer examination & $\begin{array}{l}\text { Dependability was established by use of } \\
\text { peer debriefing as suggested by Creswell } \\
\text { (2003). The process involved recruiting } \\
\text { someone (a peer debriefer) who asked } \\
\text { questions about the qualitative study so that } \\
\text { the account will resonate with people other } \\
\text { than the researcher. A scholar who was also } \\
\text { a colleague was involved in discussing } \\
\text { various aspects of the research with the } \\
\text { researcher. This gave the researcher an } \\
\text { opportunity to examine the challenges } \\
\text { which arose. }\end{array}$ \\
\hline & $\begin{array}{l}\text { Referential } \\
\text { adequacy }\end{array}$ & $\begin{array}{l}\text { Audio recordings were made during focus } \\
\text { group and individual interviews. Field } \\
\text { notes were also taken for documentation of } \\
\text { findings. }\end{array}$ \\
\hline \multirow{2}{*}{$\begin{array}{l}\text { Transferability } \\
\text { The degree to which the } \\
\text { findings of this inquiry } \\
\text { can apply or transfer } \\
\text { beyond the bounds of the } \\
\text { project (Lincoln \& } \\
\text { Guba, 1985). }\end{array}$} & Nominated sample & $\begin{array}{l}\text { The use of various means of data collection } \\
\text { such as individual and focus group } \\
\text { interviews and document analysis adds } \\
\text { richness and depth to data. }\end{array}$ \\
\hline & Dense description & $\begin{array}{l}\text { Lincoln and Guba (1985) maintain that } \\
\text { "thick description provides others with } \\
\text { what they refer to as a database for making } \\
\text { judgements about the possible } \\
\text { transferability of finding to other milieus" } \\
\text { (in Bryman, 2004, p. 275). To establish the } \\
\text { merit of research in terms of transferability, } \\
\text { the researcher aimed to provide a detailed } \\
\text { description of participants, the context and } \\
\text { procedures so that the reader could make a } \\
\text { judgement concerning the transferability } \\
\text { potential of the study. } \\
\text { Six focus groups were utilised to acquire } \\
\text { 'rich' descriptive data which added to its } \\
\text { transferability. }\end{array}$ \\
\hline \multirow{3}{*}{$\begin{array}{l}\text { Dependability } \\
\text { Is an assessment of the } \\
\text { quality of the integrated } \\
\text { processes of data } \\
\text { collection, data analysis, } \\
\text { and theory generation } \\
\text { (Lincoln \& Guba, 1985). } \\
\text { Durrheim and } \\
\text { Wassenaar (1999, p. 63) } \\
\text { refer to dependability as } \\
\text { "the extent in which } \\
\text { results could be } \\
\text { repeated.” } \\
\text { It is known as reliability } \\
\text { in quantitative research). }\end{array}$} & $\begin{array}{l}\text { Dense description } \\
\text { of research } \\
\text { methods }\end{array}$ & $\begin{array}{l}\text { The presentation of a detailed description } \\
\text { of the methods of data collection, data } \\
\text { processing as well as data analysis } \\
\text { increased repeatability. }\end{array}$ \\
\hline & Triangulation & $\begin{array}{l}\text { The use of more than one method of } \\
\text { triangulation contributed to the richness of } \\
\text { the data. A more comprehensive idea was } \\
\text { obtained of the phenomenon being } \\
\text { investigated. }\end{array}$ \\
\hline & Peer examination & $\begin{array}{l}\text { To add credibility to the data, the } \\
\text { researcher and her supervisors went } \\
\text { through the data during the coding stage. In } \\
\text { addition, she also had an opportunity to } \\
\text { present part of her research to a Pacific } \\
\text { group of researchers within NZ and } \\
\text { subsequently to a Samoan forum for } \\
\text { feedback. }\end{array}$ \\
\hline
\end{tabular}




\begin{tabular}{|c|c|c|}
\hline Strategy & Criteria & Execution of strategy \\
\hline & $\begin{array}{l}\text { Code-recode } \\
\text { procedure }\end{array}$ & $\begin{array}{l}\text { Transcribed data were coded and recoded } \\
\text { in a search for emerging patterns and } \\
\text { themes. }\end{array}$ \\
\hline \multirow{2}{*}{$\begin{array}{l}\text { Confirmability } \\
\text { "Is a measure of how } \\
\text { well the inquiry's } \\
\text { findings are supported } \\
\text { by the data collected” } \\
\text { (Lincoln \& Guba, 1985). } \\
\text { This refers to the } \\
\text { objectivity in } \\
\text { quantitative research. }\end{array}$} & $\begin{array}{l}\text { Confirmability } \\
\text { audit }\end{array}$ & $\begin{array}{l}\text { The reviewing of various data groups, (e.g., } \\
\text { raw data, data reduction and analysis } \\
\text { products, data reconstruction and synthesis } \\
\text { as well as process notes) enhanced } \\
\text { confirmability of the study. }\end{array}$ \\
\hline & $\begin{array}{l}\text { Researcher } \\
\text { positioning }\end{array}$ & $\begin{array}{l}\text { The researcher's position as stated earlier } \\
\text { in chapter four clearly state her stance in } \\
\text { the study. }\end{array}$ \\
\hline
\end{tabular}

(Compiled from: Bryman, 2004; Creswell, 2003; Durrheim \& Wassenaar, 1999; Key, 1997; Krefting, 1991; Lincoln \& Guba, 1985).

\section{Ethical Consideration}

The ethical guidelines provided by Victoria University of Wellington were followed throughout the study. It was contextualised for cultural appropriateness. A detailed account of this was included in the application which followed approval of the proposal. To gain access to the schools the researcher sought permission from the Chief Education Officer of the Ministry of Education through correspondence. A brief outline of the study was stated including the significance of the study to the education system along with the researcher's intended method of data collection, the potential members of the schools who would be asked to participate and how they would be involved. The approval letter was used when the researcher communicated with the head teachers of the individual schools involved.

During the fieldwork, the ethical agreements were closely adhered to for each participant. An information letter was given to each participant to inform them of the study, their expected role in the study, issues relating to the confidentiality of data collected and how their contribution would remain anonymous in the report writing.

Before the information letters were given out, the Samoan protocol concerning the manner in which to approach others was adhered to. In this case, the researcher first approached the participants in person, sounding out the intentions of the study and requesting their consent to participate. This is a more respectful way of engaging in Samoa and the likelihood of the next person responding in a positive manner is guaranteed. Subsequently, the participants were given the information letter 
concerning the study and the consent form. This was with the exception of the participants in the rural areas who were first contacted by the researcher via the school principal. The researcher made clear her intentions, before the information letters were hand delivered by a work colleague who lived in that area. Contact phone numbers were requested from the participants in case contacted at a later date was needed Consent was sought from each participant for the use of their transcripts before each session occurred. These procedures were carried out before the analysis of the data was undertaken.

\section{Perceived Limitations of the Study}

A number of methodologically based limitations could impact on this study. Firstly, given the design of the study generalisability is somewhat problematic; generalisability according to Denzin and Lincoln (2000, p. 786) refers to "the degree to which the findings are applicable to other populations or samples”. The sample in this study cannot be taken as representative of the larger Samoan population. Secondly, although the design is valuable in terms of giving voice to each of the participants, one cannot guarantee that these expressed views are the truth. It was seeking the individuals' perspective - their truth. There is also the constraint of how much information to disclose and how much to keep out of the final report a problem identified by Denzin and Lincoln (2003). Because of the researcher's experience in this context, she was able to make decisions that seemed appropriate. Thirdly, one cannot assume the study to be bias-free. For example, researching into the researcher's own area of teaching as well as interviewing colleagues from her own workplace could be somewhat problematic. At times it is easy for the researcher to inadvertently slip from the researcher role into a colleague or lecturer role and hence caution is necessary to prevent this from occurring. Although the researcher aimed to block out her own experiences and view the phenomenon from the lens of the participants, this may not have always been possible. 


\section{Conclusion}

This chapter has discussed the decisions that were made when considering the research methodology for the study. This was a qualitative phenomenologicaloriented study that was built around cultural issues of Fa'aSamoa. It aimed to describe stakeholders' beliefs, values, and experiences of the IE concept, identifying cultural issues that may have impacted on the implementation of IE in Samoa. The purpose of the study was also highlighted, as well as a description of the choices the researcher made in relation to the phenomenological research approach. The research design which entailed the setting, participants, and methods of data collection and techniques used for data analysis have been detailed; along with constraints that were encountered in the course of the study. The next chapter (Chapter five) presents the results from the data collected. 


\section{CHAPTER FIVE}

\section{Results}

\section{Introduction}

The overall purpose of this research was to examine perceptions of stakeholders concerning the concept of IE in Samoa and to identify the challenges of including students with special needs within the regular classroom and ways of addressing these challenges. There were two specific research objectives which guided the study. Firstly, within the cultural framework, the study was concerned with identifying beliefs, experiences, practices and expectations of stakeholders with regards to the concept of IE and the implementation of this policy in Samoa. The second objective was concerned with the subsequent development of a model(s) of explanation that would assist with the future development of education policies and implementation.

In meeting these objectives, a descriptive phenomenologically oriented research design, which utilised individual and focus group interviews, was employed to obtain data. The objective of this chapter is to interpret and discover meaning of the data, so that conclusions are drawn about the perceptions of stakeholders regarding IE in Samoa.

The results data was obtained from the 6 focus groups and 10 individual discussions. The six key questions of the discussion guide which guided both individual interviews and focus group discussion generated a number of codes. From these codes, six patterns were identified and then three themes that arose from these were identified. The following format of reporting was followed to ensure the data was meaningful: direct quotes relating to the codes were organised under each of the relevant patterns and each quotation from the different groups and individuals were coded in order to differentiate between the responses of certain groups and individuals. The specific codes are outlined in each of the discussed patterns. Themes that arose from the codes and patterns are identified (Refer chapter six) after the presentation of this data. 
The following abbreviations identified in table 5.1 indicate the informant source and in Table 5.2 the patterns and their definitions are identified.

Table 5.1 Abbreviation for the different groups and individuals

\begin{tabular}{|c|l|}
\hline ABBREVIATION & \multicolumn{1}{|c|}{ INFORMANT SOURCE } \\
\hline FSA & Focus Group School A \\
\hline FSB & Focus Group School B \\
\hline FSC & Focus Group School C \\
\hline FCM & Focus Group Curriculum Material \\
\hline FPR & Focus Group Rural Parents \\
\hline FPU & Focus Group Urban Parents \\
\hline InMin & Individual Ministry \\
\hline InCM & Individual Curriculum Material \\
\hline InTr & Individual Trainer \\
\hline InCom & Individual Community members \\
\hline InPnt & Individual Parent \\
\hline
\end{tabular}

An examination of the data revealed a number of commonalities identified as patterns and these are displayed with their definitions in table 5.2 below

Table 5.2 Patterns and definitions

\begin{tabular}{|l|l|}
\hline Patterns & Definitions \\
\hline $\begin{array}{l}\text { 1) Interpretation: } \\
\text { definitions and } \\
\text { philosophy of IE }\end{array}$ & $\begin{array}{l}\text { This refers to definition of/and philosophy about IE as well as } \\
\text { beliefs and understanding of disability and suitable education. }\end{array}$ \\
\hline 2) Teacher Qualities & $\begin{array}{l}\text { Refers to teacher practice (behaviour) such as teaching style, } \\
\text { motivation, commitment, and teacher attitude/beliefs/ } \\
\text { experiences such as feelings, motivation, commitment and } \\
\text { training. }\end{array}$ \\
\hline $\begin{array}{l}\text { 3) Practice: } \\
\text { Opportunities and }\end{array}$ & $\begin{array}{l}\text { Refers to opportunities, restraints that can impact on IE policy } \\
\text { implementation as well as benefits and disadvantages of IE. }\end{array}$ \\
\hline $\begin{array}{l}\text { 4) Policy Issues } \\
\text { Contemporary } \\
\text { Contexts }\end{array}$ & $\begin{array}{l}\text { Refers to perceptions about issues in relation to adoption and } \\
\text { policy implementation of IE model (Ministry role, } \\
\text { sustainability, legal aspects, the adoption model (IE model). }\end{array}$ \\
\hline $\begin{array}{l}\text { 6) Impact of Aiga } \\
\text { (Family) }\end{array}$ & This refers to the perceived relevance of IE to the Fa'aSamoa. \\
\hline
\end{tabular}




\section{The Findings: Codes and Patterns}

The results from this study indicated a range of codes which were categorised into patterns. Each of the patterns is discussed here and the relevant codes identified in this discussion. Narratives are used as illustrations of the codes. In the next chapter (Chapter six), the themes arising from this data are then outlined.

\section{Interpretation - Definitions and Philosophy of IE}

Any discussion about IE raises issues about a whole range of factors, such as disability causes, rights, parenting, and schooling availability. From the participants' responses, four codes pertaining to definition and philosophy of inclusive education were identified. Table 5.3 presents stakeholders variation in the scope of what they perceived to be involved in IE. These variations fall into two categories. First are factors that are related to the perceived cause of exclusion and the notion was that this needs to be a phenomenon to overcome if IE is to be implemented. With this perspective, participants seemed to understand the source of exclusion and what they perceived to be the role of IE to overcome this. The definition here centres upon the deficit model of disability. The category definitions presented in the second column lie outside the student and are dependent upon the individual mindsets and principles necessary for IE to occur.

Table 5.3 Definitions and philosophy codes

\begin{tabular}{|l|l|l|}
\hline \multicolumn{2}{|c|}{ Definition } \\
\hline$\bullet$ Disability & $\begin{array}{l}\text { - Human rights } \\
\bullet \text { Capability/potential }\end{array}$ & $\begin{array}{l}\text { Teacher perspective (constructive } \\
\text { definition) }\end{array}$ \\
\hline
\end{tabular}

\section{Definitions}

\section{Disability}

The findings in relation to the disability definition of IE viewed IE from a disability perspective (i.e., disabilities is viewed in terms of special needs). This implies that the practice of IE was viewed in terms of a dualistic framework- it involved education of students with disabilities being grouped together with students who are not disabled. In other words, the students are being categorised. For example, some participants perceived that inclusive education referred to students who are disabled 
being educated together with the non-disabled children within the same classroom and using the same curriculum. They are viewed however in terms of deficit. One teacher commented:

Inclusive education in my view focuses on children who are not normal, like the disabled students. To me inclusive education is a system where these students who are abnormal or disabled or with disabilities are educated in the same system of education, in the same curriculum. (FCM)

\section{Capability}

In a similar vein, inclusive education was also interpreted by other participants in terms of capabilities - the student's capability to function and to achieve. A number of the participants in this study viewed inclusive education as an education where students who were identified as have high learning potential (more able students) being placed with the less able ones. Terms such as 'weak', 'strong' and 'more able' in relation to learner's ability were terms often used to define the students. The focus for IE in such a view emphasises special needs in terms of learning difficulties:

Inclusive Education is an education where different abilities are put together. Where the slow learners those who have problems with learning are put together with the strong ones [bright learners] within the government schools. (FSB)

\section{Human right definition}

Some people adopted a different orientation. IE was interpreted by them within the framework of human rights and education for all. Their viewpoint was underpinned by the notion of equality and equity which promotes the idea of equal access to benefits made available to the society generally. They perceived that students who are disabled have equal rights as the non-disabled students and need to be educated together:

Village schools were built not only for those who are fully able no it is for those who are able and not very able. They should know their rights. You have the right to be in that school building, you have the right to go to schools. But children are confined in this school scared of people but if there is enough awareness ... (InTr)

Interestingly, the policymakers (Ministry of Education and some teacher educators) were the only ones who interpreted IE from a wider perspective and included children and people from any sector of society who were marginalised by many other 
factors and who had a need to fulfil their potential in life. In this view, disability was viewed in terms of problematic systems around the 'individuals' lives that cause disadvantage such as socioeconomic, poverty, family background. It took into account the concepts of equity, efficiency, equality and relevancy:

Inclusive education as used and interpreted by the Ministry is not just for those children with special needs, it includes everybody, even those kids who are not at school uh ... It also includes those children inside the classrooms (regular] without this type of special needs like you know... [physically and mentally disabled]. In terms of the ministry's interpretation it includes these other kids like a kid who may have stayed up all night and so may arrive at school still tired/sleepy... So special needs kids, who... you know who may come today and are not very interested in the lesson etc ... And those students whose parents are separated and who are downhearted and that type of thing. (InMin)

... so I think my own definition of inclusive education is all encompassing, all embracing including all people from all walks of life, all students/children from all walks of life that need to be educated, need opportunity (support) to move on and fulfil their own potentials. ... I mean when you look at inclusive you are looking at those fundamental key concepts that the ministry has, equity, efficiency, equality, and relevancy. (InTr)

\section{Teacher perspective}

Another perspective that was evident was related to the teacher's attitude. According to one participant, inclusive education depended very much on the teachers' perspective and way of thinking. The implication was that IE would only occur if teachers were inclusive in their thinking and viewed all children from an objective and unbiased position:

It [inclusive education] is broad not a small definition. Because you start from each child by accepting each child as he or she is ... If you can accept this kid [with special needs] as one you want to help, that is inclusive. Once you accept this child as 'I'll take this child he must be in my class regardless of his condition and situation ... you must accept every child as he or she is without any preconditioning like he is the son of the pastor, this child is rich this one is poor... I think inclusive starts from me. I must think, act and behave inclusive. (InTr) 


\section{Summary of IE Interpretations and Philosophy Pattern}

These viewpoints represent a range of interpretations and philosophies about IE. Although these results were not unexpected, it was noted that the deficit approach was more frequently expressed (by the teachers) in spite of recent attempts to modify such views. In some respects, the views are opposing ones - one set of definition viewed IE according to what type of exclusion it was designed to overcome whilst the second defined IE according to the mindset and principles necessary for IE to occur. The definitions included a practice perspective (i.e., students with disabilities being placed with regular classroom students), an abilities perspective (students identified on basis of cognitive, physical and behavioural capabilities), a rights perspective (an equity issue) and an all encompassing interpretation of IE (emphasising the normalisation principle as it relates to all individuals). An interesting interpretation was in relation to the individuals' own construction of the concept of IE: inclusiveness lies within the mindset of the teacher (i.e., the teacher's attitude/perspective of IE was viewed by one participant as the determining factor for inclusion or exclusion).

\section{Teacher Qualities}

A discussion on teacher qualities raised many issues such as teacher beliefs, quality, and teaching strategies. This pattern referred to the teacher's practices (behaviour) such as teaching style and delivery, teacher beliefs and experiences such as feelings, motivation commitment and training. When the data was analysed it found that there were seven codes related to teacher characteristics. These codes were grouped under the following categories: teaching strategies, teacher beliefs and teacher experiences. These are displayed in table 5.4 below:

Table 5.4 Teacher qualities codes

\begin{tabular}{|l|l|l|}
\hline \multicolumn{1}{|c|}{ Teaching strategy } & \multicolumn{1}{|c|}{ Teacher beliefs/emotion } & \multicolumn{1}{c|}{ Teacher experiences } \\
\hline - grouping & $\bullet$ positive beliefs & $\bullet$ training/practice of IE \\
• students as resource & $\bullet$ negative beliefs & $\bullet$ motivation \\
& $\bullet$ feelings/emotions & \\
\hline
\end{tabular}




\section{Teaching Strategy}

\section{Grouping}

The teaching strategies and techniques the teachers utilised were deemed important to establish orderliness in the classroom. These strategies as identified by some participants demonstrated the manner in which teaching was practiced in the classrooms. One of the strategies employed by teachers in this study was in relation to grouping although it was indicated that teachers in this study differed in ways they did this. The data also identified what teachers deemed as the rationale guiding their grouping practices. Some teachers grouped students according to their learning abilities/potential (i.e., all the more able learners together and the less able students in their own group). This type of grouping was considered more appropriate for the teachers' work organisation:

It is that strategy ... where we separate the fast from the slow. It makes it easy for me, to have the slow ones to read a book for that period... the important thing is that they will be able to learn something from what is being taught to the strong ones. (FSA)

It [grouping] makes it easier for me the teacher to teach. Cos there is no reason why they should be put together then the strong children will be faster (excel) and how about the weak children? They should be placed in groups, then organize activities for the weak, average and for those who are a bit stronger [brighter] because they don’t enter school all bright. (FSA)

The notion of separating and grouping students according to their abilities was not necessarily an exclusionary derived practice - it was perceived as a positive strategy by some participants to assist the students. The participants were strongly against the idea of thrusting the children to work on same activity, for they believed that this would be strenuous when the less-able students tried to model the performance of the more capable students:

My idea is to have different groups, the slow children, average and those who are bright... Some of the weak ones will just copy a sentence and others copy from the blackboard. So I classify them into strong and weak I group them [as such] since I now know their abilities and what each student is capable of. But not to put them all in one basket (A e aua le fafao faatasi tamaiti I le ola e tasi) for the mind/brain of the weak child will be forced to do this work [work planned for the more able students. (FSA) 
On the other hand, there were also teachers who grouped students in mixed abilities to perform a task. The belief here as opposed to the views alluded to earlier was that, having students to work in mixed ability grouping, would challenge the slow learners to work diligently to keep up with the more able students:

... To motivate them to mix with the strong ones, and also a challenge for them [weak] so to be able to do the work that the strong ones are able to do, but my own aim is for them to work together. (FSB)

the majority of children are weak or slow learners who don't understand the lesson that is being taught ...Then I mix the not so good children with the good ones and gave them activity to work together on. Most of the time I would spend with the slow ones to show them the work. (FSC)

Further, these teachers felt that by having mixed abilities groups it would allow the more able students to support the less able ones in the classroom:

Reason for grouping my class in mixed abilities, so the strong [bright] students help the weak ones. For example during group work in oral English I would prefer the good student to lead the group. I note in group work that the strong students really help the weak ones. (FSA)

The interesting point here about grouping is that although there were different viewpoints about grouping practices the viewpoints reflected concern for the students concerned. The teachers were keen to help the students but simply had different means of accomplishing this. The findings also indicated that the whole class teaching approach prevailed in the classrooms, but that at times a teacher followed this up with individual attention:

There is a blind student at one of the rural schools. The child responds to individual interaction. So after teaching the whole class she would attend to this student (who is blind). If she [the teacher] is absent then the student would ask that he be taken home. (InTr)

\section{Student as Resource}

The utilisation of more able students to help the teacher in the classroom was another teaching strategy that was noted by a number of participants in the study. This was achieved in various ways. One was the utilisation of the more able students to help the less able ones during class activities: 
... what I am doing with my slow learners, is whoever finishes first of my smart students would go over and help this student [slow one] while I help other students especially if I have many students. (FSB)

Our priorities this year is special assistance for these children. I encouraged my family [staff] for special assistance for these children. In times of grouping the teachers should always be with these children, that is if the teacher groups her/his children according to abilities slow and fast learners...the teacher can always identify a more able child to help the less able. (FSC)

Another way in which students were utilised by one teacher in her classroom was the use of the more capable student in a supervisory manner. These students would monitor the student with special needs and inform the teacher regarding any concerns:

They [students in my class] know what to do ... when he [the child with down syndrome] goes outside they would call out "Miss he is gone outside”. I would then say “Go catch him. Catch him’ and the students would run after him and bring him back. (FSA)

Another variation was for the non-disabled student to work in a supportive role as a buddy. Interestingly the motivation for engaging in such practices was not clearly identified - was it for teacher 'relief' or because of the knowledge of the 'power' of peer teaching opportunities:

Siniva's child [with a physical disability] when she wants to go to the toilet she asks her teacher if she could come to one of my girls (a girl that I have assigned for this task) to take her to the toilet. So would come and pull her to go with her. (FSA)

The use of other students was considered a positive means of dealing with the issues that students with special needs have in a regular classroom setting.

\section{Teacher Beliefs/Emotions}

\section{Positive Beliefs}

The teachers' beliefs and views about inclusive education as well as their experiences regarding their feelings, motivation, commitment and training concerning the inclusive education phenomenon is an important consideration. The data indicated that there was a dissonance in teachers' attitudes, beliefs and experiences in relation to the inclusive education phenomenon. 
With regards to the appropriate educational placement for the students with special needs, teachers' varied in their beliefs in this respect. Some believed that students with, and without physical and intellectual disability, should be taught together within the same classroom:

To me that is what is called discrimination if we try and segregate these people. In school they should emphasize not to isolate this child [with a special needs] from other children in their class. (FSA)

... To me these students should be included in all primary schools in Samoa. And there should not be any discrimination amongst students or even parents. (FSA)

Teachers, who demonstrated a positive attitude towards including these students, took the human's right's position claiming that it was the right of every child to be educated together with peers:

Inclusive education is a right and a need for everyone to be educated mainly children. (FCM)

I really appreciate this concept of inclusive education. I should not be saying these children [with special needs] should be segregated and placed into [Manuia] special schools. To me they should be brought into where the normal children are...To me whether lame, blind or whatever, if I were called a teacher then a teacher for all persons. It should never be said that so and so be here [general school] and so and so be there [special school]. Because if these children with special needs are to be separated, it's like we point fingers at these children. (FSA)

Now the teachers can teach these children within the same classroom other than segregating them. When you look at Education For all it means education for all children. The crippled/lame mix together with the non disabled... I don't know about others but to me I would be very happy to have a child like such in my class. (FSC)

The positive attitude of some these teachers was related to them envisaging these students as their own children and they noted they didn't want their own children to be discriminated against or mistreated by another teacher (i.e., these teachers believed that if they treated these students well, their own children may receive the same treatment from someone else): 
I carry out my work and in the back of my mind are my children, meaning my motivation is driven by the thought that my work will be reflected through my own children. There is a saying that "The fruit of your work for other people's children will come back via your own children”. (FSA)

One of the teachers adopted a positive perspective by viewing teaching in an inclusive classroom as a challenge and motivation. She felt that claiming incapability would diminish her teaching competency. Accordingly, she approached the issue head on:

The child with Down's syndrome that I had the first time I saw him it was like a burden to me because I did not know what to do with this type of child. Then I said to myself it will really diminish my capability as a teacher if I can’t handle this child. It was a challenge for me... This feeling of deep love/compassion for him came upon me and I said to myself, just imagine that this is my own child, I cannot bear to think that the teacher or whoever at school would shove or push him about. So I decided to take him on. (FSA)

There was also the view by one teacher about her changed attitude due to actually implementing inclusive practices. That is, actually accepting the child as her responsibility and the practising of inclusion:

This saying runs true "You will never know how to do something unless you attempt it." (E lemafai ona e iloa se mea pe a e le tago iai e fai). Now that we have attempted it, we find it not so challenging to handle this type of student. Even though we don't know how to use sign language to handle these students but each teacher is trying her best to teach these students. To me these students should be included in all primary schools in Samoa. And there should not be any discrimination amongst students or even parents. (FSA)

\section{Negative Beliefs}

On the other hand, some teachers had a different view regarding appropriate educational placement for a student with a special needs. These teachers felt that if the students with special needs were in the regular school, they should be taught in a separate room with a teacher who was a specialist. The view was that it was not easy - the teacher had to be vigilant in caring for these students for the safety of other students in the classroom: 
What I am hoping now is that there is a special class and a special teacher for these children in their own special classroom and not to mix them with these other children. If I am not vigilant in my room, when they are included the children will end up pushing his wheelchair off the room. That is what I dread. So I think, include them in village schools but separate their own classroom. (FSB)

Aside from teachers who seemed to feel that students with special needs are placed in their own separate room within the school, a participant from the Ministry argued against inclusion. She perceived that for the safety of other children in the classroom, there should be special corners prepared specially within the classroom to place these children:

There should also be corners that have been prepared to place these children for the safety of other children. This is because some children with special needs who are very naughty and may cause harm to other children. Again training have been carried out for teachers so they have the knowledge to handle these group of children. (FCM)

Some participants who supported placement of students with disability in special schools, (particularly those with intellectual impairments) believed that the needs of these students are best met within this special school environment as opposed to the regular classroom:

I don't think we can do away with it [special schools]. If we don't have anything to take the place of those schools, then I think they should be there. Well just look at this boy [with challenging needs] needing all the support and all the help and all the attention. Because more than often these kids needs special individualized attention. I mean you need them to work cooperatively to be able to share and to be able to work as a community of learners. But by the same token they all have specialized needs that need to be addressed and if you look at some of the schools I don't know whether the schools are equipped to do it and whether the teachers are equipped to do it. (InTr)

These participants also believed that placing students with disabilities in special schools and leaving only the non-disabled ones in the regular school would speed up the learning of the non-disabled children: 
If these children [disabled] were put in the special schools as was the rationale/ purpose in establishing these schools for the special needs and leave only the strong ones here, I feel that the learning of these ones in the regular will be way ahead.... Now (with inclusion) if one does not understand I have to redo the same lesson the following day for I am trying to consider the special needs ones. (FSC)

What is not particularly clear about these findings is the degree to which the attitude is based upon concern for the students and/or lack of teacher skill and information about how best to assist the students.

\section{Teacher Emotions}

Experience in this context relates to teacher's feelings and emotions. When describing their feelings concerning teaching children with special needs/disability, there was discordant findings - some teachers were acceptable and others were not so acceptable of the idea and this seemed to be related to their emotional well-being. Some teachers were fearful of the development of IE and described the feelings of dread that engulfed them when they were aware of the Ministry's plan regarding the implementation of the policy. These teachers dreaded the amount of work that they would have to prepare if the disabled students were included:

They just said that schools will be inclusive. That means children with disabilities will be included in Govt School. So many thoughts came to mind, like if these children are disabled and will be taught together with these children [the so called normal ones] it will be difficult plus there will be lots of preparation for the teacher when they are included. (FSB)

I dreaded it when they said that each child will go to their own school for child's easy access to education. I dreaded it because I know it is not easy, it is difficult. What I am hoping now is that there is a special class and a special teacher for these children in own special classroom and not to mix them with these other children. (FSB)

This feeling of concern was captured by one of the teachers who labelled the general classroom as a 'dumping ground' for parents to place their children with special needs so that they could go about their own business:

So these problematic ones who are called special needs dragged the learning of the strong ones and slow down their learning. That is my own view regarding this issue of inclusive education. But the teaching is still ongoing whether I have taken a 
special needs paper (training). The other thing is the program is good [mockery] because these poor students are dumped on us and parents will go about their own business and do what they want and we stay here with the students the whole day. (FSC)

These teachers attributed their lack of experience and knowledge in dealing with these students as having an impact on their attitude and the way they handled these students in their class:

For these disabled in our class it is very hard I am speaking the truth, Last year I had this child (Down's-syndrome) who has now passed away. I just did not know what to do with him. The principal said "all you have to do is to make him quiet ("faafilemu”) or make him settle [calm] down." I hit him with a broom other times when he swears. (FSA)

The feeling of frustration was illustrated in some teachers' voices who admitted to using corporal punishment on the child when there was a display of unfavourable behaviour in class. One teacher explained that she got angry when the child disrupted the class with his behaviour:

All I did as the principal said 'all you have to do is to make him quiet or make him settle down. Calm him [down]. All you have to do is to make him quiet "faafilemu" I hit him with a broom other times and he does swear. (FSA)

... It is just his behaviour ... he would lie down when he feels like it or would put his head in the desk with feet sticking out, his behaviour is very strange. Sometimes I would smack him because I am angry because he disrupts other children. (FSA)

A trainer who attended a workshop on inclusive education noted that some teachers were negative and it was believed this was due to deficiency in teacher knowledge to support students within this setting:

There is a blind student at one of the rural school, the teacher makes a lot of noise in one of the workshops that I attended. She said she does not know how to teach the child... If she [the teacher] is absent then the student would ask that he be taken home. (InTr) 
One participant commented that the sudden shift toward inclusion placed teachers in a dilemma resulting in their reluctance to accept the children in their classrooms:

The difference is that they are pushed straight into the classroom. At this time, teachers are not so accepting... "take them over there don't bring them to us”. Now it has gone back to the problem that was there at the beginning of teachers refusing to take them and children refusing to come to school and parents being scared themselves. Teachers are not ready and also Samoan people. (InCM)

The attitudes outlined above was also voiced by a parent of a child who had been fully included in one of the fee-paying schools (one of the elitist schools in Samoa):

... I remember that there was a problem when we want to put my son into one of the classrooms and the teacher in that level said "Oh no we never taught anyone before with a disability I don’t know what to do, I don't want him in my class”, which was so stupid their attitude, I couldn't believe it, until one teacher a PNG lady offered to teach my child. (InPnt)

What was apparent by such findings was the degree of difficulty in bringing about teacher/school change. Incremental change is often experienced in schools but when it is of a more substantive type teachers seem to find it problematic.

\section{Teacher Experience}

\section{IE Training and Practice}

Teachers can have many experiences that help them teach in the classroom. In much of the literature, training and professional development is deemed important for preparing teachers to work effectively in the inclusive classroom. Experience in this context deals with any training the teachers may have had as preparation to teach within the inclusive classroom. The majority of teachers viewed their lack of training as impacting upon the way they supported the students in the classroom. The way in which teachers described their practices in the IE classroom indicated that they lacked the requisite skills to deal with students with special needs:

Not good if the children are brought into school and we have had no training. It would be good to have more training on sign language etc so we will be able to teach these children. Because if these children are brought into my class I may end up doing something drastic to the child or something. This is because I don't understand his characteristics due to lack of training. (FSB) 
Further, there was an indication from the data that teachers were unconcerned as to whether the student with special needs was engaging appropriately in activities. Some teachers indicated that they didn't want to force the student to do anything and would leave them to do what they wanted:

I have a student with special needs who was at the special schools... her special need is more on the physical side... Issue is that when she is lazy then I leave her to do what she wants. (FSA)

Another participant stated that keeping the student quiet was important and there was the use of rewards to ensure that this occurred:

Sometimes when I noted that he [child with down syndrome] is angry with me I would then send a student to the canteen to buy him an ice pop to keep him quiet/ settle him down. Then I would give him a news print ( paper) and crayon so all he does is scribble, All I do is to keep him quiet (fa'afilemu). (FSA)

One teacher voiced his concern over his lack of knowledge in handling the student with special needs and accordingly placed the student with a group of average learners but was unconcerned about what happened:

I don't have a deaf child and I don't know how to sign. There is a mentally challenged child in my class ... I place him in the group with average learners so if he learns anything [or] not well that is up to him because I don't want to force him or speak to him in a forceful manner cos I note that when I speak to him in a forceful manner his makeup seems to change [laughs] ... in case I ended up spanking him and cause him harm [shared laughter]. (FSC)

Some teachers purposely did not concern themselves with students with disabilities:

Yes there are children that other teachers ignore like sick children who are called disabled who are in the class are deaf (leaga taliga). Some teachers mainly ignore those who are mainly sick and weak (tamaiti tele ina mama'i ma vaivai) and tend to focus on good children. (FSB4)

A few participants perceived that the implementation of inclusive education was simply just another initiative (amongst many others that the Ministry implemented). This added to the teachers' uncertainty and impacted upon attitude: 
Well that is another thing, the EFA comes in, the Inclusive comes in, poor teachers are lost as to what the exact/real thing is, remember when too many things come crowding in, then the only option is to throw it in the rubbish. (InCM)

I know that we are nowhere near meeting the requirements the need ... I mean like now they are also trying to introduce the multilevel teaching uh ... (InTr)

\section{Teacher Motivation}

A few teachers voiced their views about what motivated them to teach a child with a disability in the classroom. Essentially, it was intrinsic motivational factors that motivated the teachers. For example, the feeling that there was a 'blessing' from their own children if a good deed was done:

I always do my best in carrying out my job for I am driven by the thought that my own work will reflect back via my own children. I believe in this saying that "the fruits of my work will bounce back to me [reflect] through my own children.” (FSA1)

One participant also noted parents' appreciation of teachers' work as being motivational:

This is a God given job and I don't segregate children. These children who are weak, who came without any knowledge have improved a lot. There was one child who used to attend one day a week, but ever since he came into my class he has never missed a school. What inspires, me are positive responses from parents who came and thank me. (FSA)

\section{Summary of Teacher Qualities Pattern}

Overall, the data indicated a range of characteristics pertaining to the teacher - in particular, these were related to teaching style, delivery, attitude towards inclusion, as well as motivation. Teaching style with respect to grouping indicated various ways in which teachers grouped students within their classrooms. The view of grouping children according to their abilities was noted as a preference by a number of teachers, as opposed to grouping in mixed abilities. Rationale for grouping according to different ability was often mentioned in relation to the convenience for teachers' work organisation and preparation (i.e., the teacher will be able to focus work according to students' learning ability). More, this was viewed as a less strenuous approach for the slow learners, who try to catch up with the fast ones. Grouping 
students by mixed abilities, was perceived as important for two reasons; one concerned the more able student assisting the less able one, and secondly, there was a view that grouping students together regardless of ability would encourage/challenge the less able learners to strive harder. Other teachers viewed ability-based grouping as more convenient for class organisation. The data in relation to motivation indicated that some teachers were intrinsically driven by the notion of blessing for their own children (i.e., through performing a good deed to other children placed in their care). Further, positive responses from parents' were viewed as an inspiration for teachers. The data displayed a difference in attitude to inclusion whereby some teachers were more supportive while others preferred specialised classrooms for students with disabilities. Furthermore, it was also revealed that teachers' practices of IE varied. Some teachers were challenged to respond in a positive manner to teach students with special needs while others perceived the regular classroom as the 'main dumping' place, for parents to place their children with special needs. There was an indication that some teachers were indifferent to the learning needs of those students with special needs who are in their care. These varying viewpoints indicate a range often a continuum of viewpoints about IE practices.

\section{Practice: Opportunities and Restraints}

Any discussion which concerns an implementation and practice of an initiative highlights issues relating to what factors impede or enhance practice. The data denoted many factors which the participants viewed to impede and enhance the implementation of IE policies. From the participants' responses, twelve codes related to inhibiting factors and four related to facilitating factors for inclusive education were identified. These were categorised under restraints and opportunities. Five codes related to benefits of IE were also identified. 
Table 5.5 Opportunities and restraints codes

\begin{tabular}{|c|c|c|}
\hline \multicolumn{3}{|c|}{ Teacher Practice } \\
\hline Restraints & Opportunities - Support & Benefits \\
\hline $\begin{array}{l}\text { - } \text { teacher attitude } \\
\text { - } \text { teacher overload } \\
\text { - } \text { teacher } \\
\text { training/knowledge } \\
\text { - } \text { resource/facilities } \\
\text { - } \text { experts } \\
\text { - family attitude } \\
\text { - training course contents } \\
\text { - } \text { time } \\
\text { - teacher student ratio } \\
\text { - financial factor } \\
\text { - moral support } \\
\text { - learning delay }\end{array}$ & $\begin{array}{l}\text { - } \text { community-chiefs } \\
\text { - } \text { parents } \\
\text { - church leaders } \\
\text { - influential people }\end{array}$ & $\begin{array}{l}\text { - } \quad \text { student learning } \\
\text { - } \text { student value/sense of } \\
\text { belonging } \\
\text { - } \quad \text { smooth transition } \\
\text { - } \text { teacher benefit } \\
\text { - } \text { raise } \\
\text { awareness/reduce } \\
\text { discrimination }\end{array}$ \\
\hline
\end{tabular}

\section{Restraints}

The data indicated that there were a number of perceived factors that could inhibit the implementation of IE. These were teacher factors such as attitude, overload, time to implement, knowledge/training issues and other factors including, teacher-student ratio, lack of/inefficient training, resource and facilities difficulties, finance and lack of support.

\section{Teacher Attitude}

Teacher's unfavourable attitude towards the child with special needs was perceived to be a constraint. A few participants felt that some teachers make value judgement based on the child's background and then develop a stereotyped attitude towards the child. Furthermore, the teacher and family relationship was perceived to affect the manner in which the teacher perceived the student in the classroom. For example, some teachers have an unfavourable relationship with the student's family, which in turn impacted the decisions they made regarding the student:

Some teachers look at the child's background and then decide not to like the student. Some teachers have some disagreement with parents which influences his/her attitude towards the child. (FSA) 
It does happen in cases where the teacher is from same village (where the school is located). So that thing tends to happen e.g., dispute between the teacher and maybe parents or family of the child in the village fono. So it started off from the home and is brought into the classroom and the teacher would have it out on the poor child. (FSB)

According to some participants, the teacher's attitude is very significant - it could become a barrier to the student's participation in schooling discouraging development. For example, if the teacher has an authoritarian style of class management it could discourage the student from coming to school:

I see the teacher as a barrier to the child's education if the child refuses to come to school due to the teacher's characteristic (if the teacher too strict and hit the child resulting in the child refusing to attend school). (FSB)

On the other hand, a committed teacher who has a positive attitude towards educating students and is capable of change was considered an asset in IE. A teacher is needed who could accommodate changes in the classroom, develop strategies and work towards developing useful policies:

Lots of preparation like a load to poor teachers however teachers believe that children need to be educated and if teachers are not dedicated then... yes one can feel it in one's heart when work is delivered to the children. (FSC3)

Again it comes back to commitment and in making change. ...I really think the first step is that there really needs to be a change in attitude, people's mindset because once you changed your mindset, once you change your attitude about something and you believe in it, you'll 'fight tooth and nail' to make sure that it goes there. And it's just like a teacher, if you feel for it, you'll make sure that something is done you know, but if you don't feel for it I mean, if you don't have the passion [articulated very passionately] if you don’t have that passion about something it is not worth it ... (InTr)

It was further noted that developing a good rapport between the teacher and student was perceived to be a bonus for the student's learning which, in turn, could impact on the implementation of inclusive policy:

He normally comes and sits in my room especially when his teacher is away from school, because when she does not come to school he does not want to come as well. (FSA) 


\section{Teacher Overload}

A number of participants viewed the inclusion of students with special needs within the regular classroom as meaning an additional impact on the teachers' work, in terms of over-load of extra work:

We should note the time that goes into the teaching, is not a long time to teach and to prepare students for exams. So if we include the students with special needs ... cos all the students will be mixed within one classroom it will slow down teachers teaching ... the goals that the teacher is trying to achieve not only for the strong students (tamaiti malolosi) but also the weak students as well as for the disabled in the classrooms. What I mean is that the teacher will be slow in covering the syllabus. (FCM)

The secret of a good teacher is to be able to identify what each child needs and give them that because when you have too many children in your class you can't do that. All you can do is to baby-sit them and make sure that they behave themselves. You can't give them individual attention. You don't have enough time in the day to do that. I think that's the challenge that children have here. Unfortunately if they have a child in the classroom that needs a lot of attention then the child just doesn't get it. (InPnt)

\section{Training and Knowledge}

Participants viewed lack of teacher knowledge and special training about teaching students with special needs in the classroom as a constraint. Teachers in particular felt that this lack of training and knowledge led to their inadequacy to support the student adequately. It was also noted it could lead to teacher frustration, which in turn could affect the way in which the teacher responded to the student:

... not good if the children are brought into school and we have had no training. It would be good to have more training on sign language etc so we will be able to teach these children. Because if these children are brought into my class I may end up doing something drastic to the child or something. This is because I don't understand his needs due to lack of training. (FSB)

This concern was affirmed by the parent of a student with special needs who was involved in the inclusive initiative: 
A lot of different disability we cannot identify so we need to train people. There was a boy in a regular school who has muscular dystrophy and the teacher cannot identify it and it got worse till doctor diagnose and send him overseas for treatment. We don’t have specialist, physio, language therapist etc. (InPnt)

One view expressed was that if there was lack of teacher experience and knowledge to assist these students it would result in these them being placed in special schools:

... I feel that this is the same reason why teachers out in the schools are strongly complaining, because they have blind and deaf students, and they don't have the experience and do not know how to sign, ...that is why children end up at special schools like Malolo and Fiafia because they know that is where they get the proper training [teaching support], the teachers in such settings understand... (InTr)

The parent whose child attended the fee paying school commented on the need for teacher training to ensure teachers were aware of the issues and could support the students in the general classrooms:

So we decided to do some teacher awareness evenings and training so teachers come in the evenings for training, so we explained some things about special education and that some children are born different, they just have to accept them.. The kids were more accepting than adults. (InPnt)

\section{Resources/Facilities}

Teaching resources, as well as facilities, were perceived by participants to impact on IE initiatives. Technical resources for carrying out teaching and learning in the classroom were considered as inadequate which was then linked to the teacher's feelings of annoyance. The inadequacy of facilities was often commented upon:

...it is very hard cos we do it manually for there are no machines, no printer ...If the teacher has three classes (multigrade) one has to group (due to differing abilities within each level itself.) ... there are no machines everything is manually done and the teachers sacrifice their time. The work is ok and is manageable but I just want to have this frustration out cos once it is out then one feels relieved.... because not only there are not enough teachers cos there is only one teacher to more than one class (multigrade). Children are difficult, and the children who are strong (meaning good academically) are educated together with the slow ones. (FSC) 


\section{Experts}

Teachers with expertise were also viewed by several participants as a valuable resource and model for IE but it was noted there were insufficient numbers of teachers with such experience. In particular, there was a need for experienced teachers of the hearing and visually impaired:

Now the school committee is involved by supporting principals and teachers in things needed for the development of the school. There is a need to have people with the expertise in sign language and brailing to come in and assist teachers who don't have the skills in these areas. (FCM)

... we don't have the facilities in normal schools for students to be fully included. So if a deaf child comes in ... not only [we don't have] the facilities but teacher expertise. At this point in time special schools should be there still. (InTr)

There are not enough qualified teachers who have the expertise to teach these children especially in terms of Braille. Since there is not one but more students who have visual impairment in Samoa compared to very few teachers who have this expertise or skills where are these students expected to be educated? If the visual impaired students would all be educated in a special class due to limited expertise then we lose the purpose of inclusion. (FCM)

The importance of drawing upon this expertise and utilising it within a regular school setting was noted and commented upon:

There is a teacher at one of the government schools who is very good she used to teach at the special school for the deaf.... It is a bonus for this school to have this type of teacher. It's really good how you can have a teacher who has been teaching at special school but is now teaching in a regular school. (InTr)

I went to a program at Sauni Unit so the group said not to use sign language with him just talk to him I like these programs where people could come and share their expertise on how to support these children ... it also helps the teachers. (FPU)

\section{Family Attitude}

Some participants identified family attitude to affect IE. For example, there was a view that some parents were reluctant or ashamed to bring the children into the school: 
.... Parents are one barrier when they are ashamed to bring their children to school.

Even now there are children who are hidden at home and are not taken to school...so I think the barrier lies with the parents when parents are reluctant/ ashamed to send their kids to school... but children should be brought to school. (FSC)

Parents are other barriers. Cos there was this special needs unit that was established in one village. Children were enrolled and placed in this class together with a special needs trained teacher. What happened was that as soon as the people who were involved in organizing the program left, parents became a bit slack in bringing the children with special needs and with health conditions to school. Its like parents are ashamed to bring their children to school. This seemed to affect the children's attendance, despite the children showing an interest in school. (FCM)

It was further noted that lack of collaboration between parents and teachers could be a barrier. This was particularly in relation to supporting students with their homework and encouraging them to come to school:

If parent and teachers do not work together then it becomes a barrier. In terms of homework and bringing them to school. (FSB)

Furthermore, participants presented the view that parents were not enforcing school attendance and that if their children were not very academic:

My heart is with the slow learners for some of them attend school once a week. Parents are too slack in sending children to school. Children who are slow learners are well known for missing schools. They would attend once a week. (FSB)

Indeed, some families considered money spent on putting a child with disability into school, as money wasted. The view was that it was not worth it to educate the child with a disability:

Some families tend to have this view that money should be spent on the normal child than on the child with special needs (i.e., money spent on a special needs is money wasted). (FSB)

A church leader noted that some families needed to take more responsibility for the disabled child and ensure school attendance:

Overall in our Samoan families, the less able the child the less attention given to this child [in terms of education] then s/he is left at home, like he is frowned upon 
whereas this child should be given first priority like he should be brought to school for his development for his own good. (InCom)

These comments raise important issues about the interaction, roles and responsibilities of parents to school and vice versa.

\section{Course Content}

Aside from those barriers that were related to families, another constraint according to some participants, concerned courses offered in special education. There are no courses that taught Braille so teachers were required to support these students without the necessary skills, resources or knowledge:

Here, there is no course which says this is how you do sign language etc. I feel this is the reason why teachers out in the schools are strongly complaining because they have blind and deaf students... they don't have the experience and do not know how to sign, ...that is why children end up at special schools ...because they know that is where they get the proper training, the teachers in such settings understand ... Well sign-language, Braille, we don't have enough of those in our courses. Teachers who major in special needs education need training in Braille and sign language. (InTr)

We need to put in more practical courses for training of teachers who actually major in special education. At the moment there are many loopholes in our inclusive education, not only we don't have facilities, we don't have the teachers those with the expertise. Even qualified lecturers like us we feel that we are still not well prepared to carry out this training. We need to have professional development ourselves. (InTr)

\section{Time Factor}

A number of participants viewed the inclusion of children with special needs in the general classroom as time consuming, especially when other students required the attention of the teacher. The teacher is a busy person with lots of other things to do and thus time is important so s/he will be able to offer support to all students. Thus this could impact on the support offered for the student with special needs:

There are three students with special needs in my class...it is very difficult [teaching in the regular class plus special needs children] especially if there are three special needs children as well. ...there is hardly any time to spend with those 
students who need my help remember this is a weak class. I try to allocate my time to all students. (FSA)

I have had no training in this area. However the only thing I dread is the amount of time that will be spent in preparation for this child (FSB).

Because if you put together the weak and the good [students] the fast ones will wait for the slow ones and time runs out. (FSB)

\section{Student Teacher Ratio}

The high number of children in a class was considered to impact upon the teacher's attitude and the implementation of IE policies. For example, some participants felt that due to the high number of students plus students with special needs, the teacher would decide to forgo or postpone the teaching of the student with special needs to the following day, for she had to deal with the needs of the more able ones first:

The other barrier is if there are too many children already in my class plus these children [special needs] then it will slow down the running of the program. These children will work slow and will slow down the work of other children. If there are many children with good minds plus these children, I will not have an opportunity to be with the child and then I would say "Leave that child to be taught tomorrow and teach [only] these children. (“ia tuu ia lena tamaititi sei a'oa'o taeao ae fai nai tamaiti ia). (FSA)

Attitude of teachers are mainly negative because ... the student teacher ratio is the other one, there is only one teacher to 30 students in a classroom. In those countries [West] there is the teacher and the teacher aide whereas here we don't have teacher aides. (InTr)

\section{Delay Learning}

The time that is needed to assist students with special teaching needs has already been indicated as an important factor. In a similar vein, a number of participants perceived the inclusion of students with disabilities into the regular classroom as a disadvantage, on the basis that it restrained the learning of other students mainly the more able and fast learners:

The other barrier is if there are too many children already in my class plus these children [special needs] then it will slow down the running of the program. These children work slow and will slow down the work of other children. If there are 
many children with good minds plus these children, I will not have an opportunity to be with the child with disability. (FSA)

In my heart I want him to be educated here. But I have this feeling that these types of students slows down the learning of other students. (FPR)

\section{Finance}

Barriers in terms of finance were perceived by participants to affect parents' aspiration for sending children to school:

With those families who don't send children to school, when asked for reason as to why children are not sent to school, the answer is that parents cannot afford to, meaning not enough money to send children to school. Some families have the money but parents are so slack, not emphasizing the importance of education. Some children attend school but would stay home again when there is no money for school fees (this is money collected by village school committee themselves for school maintenance etc since school building is the sole responsibility of the village not government. (InCom)

\section{Moral Support}

A further barrier was related to the lack of support for teachers trained in IE. It was indicated that this could adversely affect their motivation to teach:

I know that these young students go into these special units in the mainstream schooling system. I think that some of them are very passionate about it but I also think that some of them felt that they are alone and are not supported. So it was easy not to be passionate about it because nobody else is interested. (InTr)

\section{Opportunities - Support}

In many ways factors that were expressed by participants that facilitated IE tended to parallel factors that inhibited the implementation of this policy. The facilitating factors for IE were generally regarded as supportive factors and these included assistance from people in the community such as council of chiefs/orators, parents, church leaders (pastor), and other influential individuals.

\section{Community - Council of Chiefs/Orators}

Support was perceived by most of the participants to enhance the implementation of the IE policy and to facilitate IE. For example, the council of chiefs and orators (the 
Alii and faipule) was noted as undertaking a major role within the village - for example, they have the authority to enforce the compulsory education law within the village. Indeed, they imposed a penalty on families who do not send the children to school:

In our village [rural] governance by Alii [chiefs] and Faipule [orators] is very important. They are very strict about sending children to school. There is a penalty imposed on those families whose children are not sent to school. If a family fails to submit to village rules, the village council will then take action, and make a decision to banish them from the village [a normal Samoan punishment. (InCM)

Community support is very important and should be emphasized by the ministry. It used to be ongoing ... This should be enforced for I feel that if this partnership is encouraged and works well then it's a good thing for the development of inclusive education program. (FCM)

\section{Parents and Family}

Family members were also considered an important source of support for students and IE. Indeed, many considered parental support as crucial. For example, parents being involved in school meetings and activities as well as offering support for their children's school work was perceived as being beneficial. It was noted by one informant that having a good understanding of how they would support their children at home was perceived as an imperative:

It is important for parents to have a good understanding of ways to support their children at home. This is because education does not end in the classroom. There is a time when children take homework home... (FCM)

Parents support is very crucial, if there is anything that I need they can provide. At this point in time there is close partnership between school and parents. Parents come in and help with reading, of the at risk child. Once a week, one hour is set aside for this session. That is what I mean that this relationship is very important and they are my right hand, if I am away from my class at some stage a parent would pop in and take care of the children though I am not always away. They are aware that this is in the educational policies and the school committee and the ministry of education have discussed it. I would not undervalue their support. (FSA) 
Parents of my special needs children remain in the school ground and would only leave when school ends. Their children would go to them during interval, stay with them and have lunch. (FSA)

A number of parents voiced their willingness to offer support for teachers, even coming to school to help the teacher in the classroom. One parent said how she was always happy to support teachers and be responsive to teachers' needs for she realized the importance of education for her children:

I enjoyed coming to teachers and parents' meetings.... I just attend and see what teachers views are put together with parents ideas/views those are good things that I like. Whatever the teachers need I am always happy to serve. I did not have a good education but I now focus on my children for I know that this is their future. So I always try to do what teachers want because of my children's future. (FPR)

If the teacher needs help from us parents then I will come and sit beside him. So the teacher does her teaching and I will show him how to write letter ' $\mathrm{A}$ '. My desire is for my child to keep coming to school. If I notice that he refuses to come, then I must stand up, take his hand and come with him to school. There are days when we arrive at school and he asked me to stay at school not leave. So I can do that duty of remaining at school so that he will stay in school. That will be my own way of supporting the teacher herself. (FPR)

Though parents (the mothers) positively discussed school involvement, one principal noted that there was a decline in parent participation at school.

They (parents) are very happy and ... their stories when they came in here and share tea with us is that it is a very good program. However two weeks after none came back. (FSC3)

Not only could parents provide support, but at times, other family members can provide the necessary support and assistance, inside and outside the classroom. For example, siblings could assist with activities and tasks in the daily teaching schedule:

There is one school that we visited where the brother of the blind student came in to help his brother. The brother is not blind but he came into the classroom to help (support) his brother. (FCM) 
The collaborative support from colleagues and parent in terms of sign language was perceived very important for IE. For example, one teacher spoke positively about how she recruited the help of a mother and another colleague to help her learn to sign:

If he sees me talking he would understand [meaning lip read). The only problem is his hearing which is not good. Because I have not been trained in sign language I would ask his mother who then would teach me some sign language. There is also another lady next to my room who would also help me with how to sign. (FSA)

\section{Church Leaders}

The church leaders were viewed to be highly respected and influential persons within the village and seen to be able to largely influence parents' and families' decisions:

I know that in my own village people look up to the pastor even these distinguished ones in the village Doctors, Lawyers, they all respect what the pastor says, perhaps it's because they feel that it is something to do with God's authority (I am here as to serve God).The pastor can control unfavourable things that occur within the village. You need to know how to present a subject matter in a very diplomatic way so people will accept it. (InCom)

Our pastor does not take part in village meetings (fono) except in church board meetings. And when he shares his views the church members are normally respective and in support of his views. (InCom)

Some participants felt that church leaders and those who are involved in Sunday school teachings should have a good understanding of how to be inclusive in their Sunday school activities:

... It is important that the pastors or church ministers and those carrying out Sunday school teaching have an understanding of ways to support the students in an inclusive situation. (FCm)

The data certainly indicated that church leaders played a very active role in supporting children's education by encouraging parents and families about the importance of education:

Our pastor (church minister) is very active in pushing for children/s education. When he preaches in church, he encourages the parents to send children to school He objects to children not attending school. He is carrying out his duty ... (InCM) 
This church leader himself noted the same idea and he commented on his supporting role in encouraging parents in ways to support their children. He did this by using a number of strategies such as helping students with their homework or by sending them to the study centre at the pastor's residence where they [children] could get additional help:

I am concerned and I urge parents to do something for their children, they should be there to help with their homework, and if they cannot help their children with their work then send them to the study centre where there are teachers to help them. Most parents are smart but don’t have time to help their children, but parents who are supportive of their children their children do very well. (InCom)

Inclusive is a must for all children i.e., the pastor's house is a place where all children should be educated. (InCom)

Moreover, the church leader also indicated playing a proactive role in seeking educational and job opportunities for students and youth in his village:

Education is very valuable to me if there are children not at school I urge parents to take them to school. If parents cannot afford school fees we would pay so there are children who go to school free for parents cannot afford to pay school fees. I said to them there is no such thing as cant do, so I would look for jobs for them [parents] , now they have jobs. (InCom)

I push parents to take children to school. Most youth stay home so I have sought jobs for them ... I become very unhappy with parents if I found out that there is a child or student not at school. I have enrolled into colleges most of the students who dropped out of school and now have been put back into schools. (InCom)

Through my study centre I was able to negotiate with a college in New Zealand who every year offer two scholarships for two students from my village. scholarship covers everything except for the airfare that is covered by student. Yes I went Asamo (A Samoan notion of getting something free from someone else) because I want something for the children in my village. (InCom)

This church leader indicated his commitment and value for education because he believed that people were the most important asset and by educating them, it recognises this value. He believed that by educating the people additional assets would accumulate: 
I feel what the pastor should do is not try and build a new church. These things are already built but look at educating people first. People are more important than cars and houses. People are most valuable assets in this world. If we use money on educating the children first then hundred new houses will be built in the future. (InCom)

The church leader elaborated on a model he utilised in his parish for educational support of children in his village. This involved the establishment of a study centre and drawing on the expertise of his church members. He believed this to be a very cost efficient way of offering extra educational support for students and youth, not only in his parish but also students from nearby villages:

We said to our selves we need to have a study centre ... I have many qualified teachers [college, tertiary level] in my village like I have 10 qualified teachers who could help with this program. They are deacons in my ministry, and because I am their pastor they listen to me so they are willing to volunteer without being paid ... There are also matais (titled men) of the village who come in to help with the Samoan language. Teachers are not there to teach but only to supervise and answer students' queries regarding their homeworks and assignments ... The main objective for setting up this study centre is to support the students in their education ... Education is very valuable to me. (InCom)

\section{Politically Influential People}

One other factor that was indicated in the data to facilitate IE was the utilisation of political persons who had strong village affiliation and/or someone in parliament who could advocate for minority groups:

Also be good to identify some parents in villages to form a group. Because I still want somebody, a very strong (influential) person like a matai [titled person]. It really makes a difference when you have people like that who can actually advocate. We want somebody who has a strong political affiliation with villages cos it is a weight. Otherwise and then of course looking at somebody who maybe in parliament. So I think at the end of the day it's those types of things. (InTr)

\section{IE Benefits}

It was believed by some participants in the study that IE brings benefits that need to be harnessed for the education of all students. For example, students learning from each other, the opportunities of developing values of being accepted and belonging, 
smooth transitioning to work/society, development of teacher expertise, being more aware and reducing discrimination were all factors cited as benefits arising from IE.

\section{Student Learning}

The data in relation to the student learning benefit, indicated that both students with and without a disability learn from each other by being educated together within the same classroom. For example in terms of social skills:

Good because one child will learn something from other children, they should play and be happy together. S/He should not have any feelings like [they are different]. Mixing with other children will impact on them [the student with special needs] as well. (FPR)

It was also felt that by being within the same classroom, the non-disabled student would learn not only skills (such as sign language), but could also learn some ideas as to how take care of any disabled sibling at home:

Yes the other children in the class will benefit from it in terms of learning the sign language as well as they will be able to learn to care for these children whose minds are affected (It is possible to tell the class not to be harsh on these children but the important thing is in terms of communication like sign language. (FSA)

There is a lot of help from students without special needs for those with disabilities...Children in the class can also learn some methods from this child (with a disability) as to how he could be supported. They can also apply the same method to support a child in their families who may have a disability and does not come to school (FSA).

Learning together within the same classroom was also perceived as beneficial for the student with special needs. For example, the worth of the student in terms of his contribution to discussions was recognised by this informant:

I also feel that [in] true inclusive education students should be able to share their skills that learning... remember our learning not only isolated but seem to have only one viewpoint only you (teachers viewpoint not the class) not from the viewpoint of this child and that child just yourself ... you can come up with case studies and problem solving to work in so children share their views and one kid can help another and the student with a special needs realizes that s/he also has something to contribute. (InTR) 
Including children with special needs into the government schools was recognised by some parents as contributing to their children's motivation to attend school. It could impact positively on learning outcomes for the student with learning difficulties:

My daughter was at Fiafia School. When she was at Fiafia she always had this interest to write ... When she was moved over here she is very happy. Now there is a big difference [in her learning] ... Now there is a big difference in her work is able to copy from the board. Here she enjoys it because there are lots of activities to be involved in. At Fiafia she only draws pictures ... She likes school and when she is told there is no school the next day, she sulks (gets angry) from morning til night time ... Yes this school is suitable for her. (FPU)

Another parent compared placement in the special school to the regular school. Placement in the regular school was perceived to improve the child's learning significantly:

He seems to have excelled since he was moved over here. All he did at Malolo (special school) was draw ... and now he is very fast especially in Maths...Like I said before he was not born with a hearing impairment. His speech is developing fast now at Moana school especially in Maths, because at Malolo he only used sign language and some sounds he cannot sound correctly. I guess because [here] the children talk to him all the time so he has developed ... After a while being at Moana school he was able to count numbers and verbalise. So I said to my family see he can learn. (FPU)

\section{Student Value/ Sense of Belonging}

Another benefit related to the feelings of self-worth developed by the student with special needs. By being in a context where a range of others could place value upon the student's contributions, it provided an opportunity for the student to grow in terms of self-worth.

I think inclusive has a good aspect to it in that children SN will realize that they are all important and valued. (FSA)

...there are different ability of the child. And if being put together they are likely to learn if teacher meet his needs. (FSB)

I think if the child with SD and the normal child are taught together the children with SN will realize that they are similar to other children. So they are not to be made to feel that they are different. (FSB) 
Furthermore, the sense of being valued could result in feelings of belonging which could impact upon classroom performance:

To me that is inclusive even though activities are different but students are learning from the same book/syllabus that thing is called inclusive in my thinking. It is involvement of the student and participation within the classroom. They have a sense of belonging to the classroom that they own this classroom and are able to communicate with their peers. That is inclusive; they are involved though activities are different. (FCM)

...They work together as peers, mates, teachers and partners and they have a feeling that this belongs to them. One student learns from the other (FCM).

There are benefits for the disabled in the disabled schools for they feel more at home being with other disabled students and there is no finger pointing (meaning discrimination) but in terms of inclusive they should go together with the good students. They should stay there for the whole year. But I think the most important person is the teacher. (InTr)

\section{Job Transition}

IE was perceived as to have a long-term vocational benefit for the students with special needs. It could ease their transition into the real world when they sought employment at the end of their schooling years:

... they should mingle with the students who are mentally sound cos if they go to special schools the more they are segregated from the world (chuckle). If you want to have a job be well educated, to become a manager you'll end up working with people with good minds (lelei mafaufafu) You'll have to go through this socialization process before you get to the top because you are not going to be segregated all your life. Some of them (sp needs) think that they'll go up there in their education and then come back and teach at the blind school etc but then it is ok but ... (InTr)

\section{Teacher Benefit}

IE was also perceived as beneficial to the teacher. It was believed that the teacher could learn significantly from the experience of having a student with special needs in the classroom. For example, teacher could learn sign language, develop a greater understanding of students' learning needs, interpret behaviour better and so on. 
The benefit is that the teacher will learn from it herself, because if I have a deaf child then I will try to learn how to sign. So in that sense I will benefit from it as a teacher and the child will be happy. (FSA)

Through inclusive I will be able to understand what these disabled want. Because I will be able to learn the language of the deaf because they will sign to me and I will be able to understand. (FSB)

\section{Raise Awareness and Reduce Discrimination}

Another benefit identified by some of the participants related to the contributions that these students could make. Having them in the classroom provided an opportunity the teachers to recognise these students as contributing and unique individuals, like all the other students. It provided an opportunity to understand these students as members of the community.

To me I can see the importance of this inclusive program for the many talents and abilities of many students [with special needs] which before have not been generally noted are more and more coming (to the fore) into public notice now. (FCM)

Furthermore, because of this it was likely to reduce finger pointing and discrimination against them.

So that those children with special needs won't feel that they are different from those [children] who attend government schools. The children with special needs should be put together with those children without special needs so the children who are strong won't look at the other child with special needs and say oh this sick child goes to the special school. (FSA) 


\section{Summary of Opportunities and Constraints Pattern}

These findings on restraints and opportunities with regards to IE revealed a number of factors which the participants felt could impede or enhance the implementation of the IE policies. It also identified a number of benefits of IE. Impediments included teacher overload, teacher knowledge/training, resources, facilities, family attitude, training course content, time, high-class numbers, finance, support, and teacher attitude. There were four codes identified which related to facilitating factors. These were concerned with support of community leaders - chiefs, parents, church leaders as well as influential people (political arena). Overall, the concept of support was identified as a most significant factor for facilitating IE, and in particular, moral support, was identified as useful. The data in relation to benefits of IE indicated it could be beneficial to learning, creating a sense of belonging, a notion of being a valued member of society, employment transition opportunities, as well as awareness benefit in contributing to a reduction in discrimination.

\section{Policy Issues}

Discourses of IE policy revolved around issues such as the role of ministry of education, training, resources, teacher supply, costs, sustainability, legal aspects, expectations and models of implementation. The data identified five codes related to policy implementation as illustrated in table 5.6 below:

Table 5.6 Codes on policy related issues

\begin{tabular}{|c|}
\hline Policy Implementation Issues \\
\hline $\begin{array}{l}\text { - } \text { Ministry role } \\
\text { - Expectations } \\
\text { - } \text { Sustainability } \\
\text { - } \text { Legal aspect } \\
\text { - } \text { Adopted model }\end{array}$ \\
\hline
\end{tabular}

\section{Ministry Role}

Several gaps were raised by the participants in relation to the role of the Ministry in supporting the IE initiative. The Ministry was criticised by some participants for its radical and sudden decision regarding implementation of IE: 
...it's still going rough and tough but it's still because the ministry cannot turn back now, [we are already moving] the only difference is where the emphasis is. So there are programs by the ministry but if these programs could have been stalled a little and not to rush trying to become inclusive all of a sudden I feel that in the end everything will fall into its proper place and people will accept it graciously, and willingly and would keep on going ... (InCM)

This move on the part of the Ministry to implement IE policy seemed to cause confusion for people, especially given the earlier unsuccessful attempt to integrate children in regular schools. This initiative was only operational for a brief time and then terminated. Some participants criticised the manner in which the Ministry handled this initiative:

I understand where the ministry is trying to move towards. For inclusive education to take place in all schools. What I don't understand is why they developed those special needs units in the first place. That is exactly what I want to find out at this point in time? All of a sudden, I don't think it's been there five years ah? ... Cos my understanding of those special needs units is, the children with special needs are placed into the special needs facilities room and were taught by the teacher who was trained in special education. (InTr)

If we look at the system as well, when we tried to build up special units when they build special units to be able to accommodate students to mainstream education, what have they done they close the units? (InTr)

Furthermore, some participants felt that the failure of the earlier initiative was indicative of the lack of effective collaboration that occurs between the parties concerned. A related issue was whether the special schools should be dismantled but according to a number of respondents this was unwise because these schools had a continuing role - to support some of the students who could not be included in government schools:

So if you look at all these it's like you know you looking at a society where you can have everybody in a set up where they can all work together, all willing to learn something but that is not the reality. I think the reality is if these special units in the mainstream have failed, simply that's the answer. They can't do it. I mean, really people should have the mentality, principals teachers, people who have been specially trained for these units they really should have that mentality that they 
should make that work. Because if they make that work then they'll say we can do away with these institution. (InTr)

There were differing views at times expressed by the personnel within the Ministry and those in teacher education. Lack of transparency of intentions and policies appeared to be the issue here for some participants were unaware about many issues related to these educational reforms:

... we are still unsure as to what is actually happening with inclusive education. Because they set up all these special needs units but they are lying idle they are not being used. The children are going straight into normal classroom. (InTr)

Some participants questioned the government's commitment to IE and the drive behind this initiative. It was viewed by some that Samoa was emulating an overseas imported model and was equated to 'fashions' that appear and disappear:

Because the trend you see in overseas countries which I feel Samoa is following. It started off with special needs unit integration then they went for inclusion it’s like a I mean all of a sudden all schools were going for inclusive education all teachers, people they trying to make all schools inclusive and then it's like a fashion that comes and goes and then after say ah at this time a lot of schools have gone back to special needs school ... (InTr)

Furthermore, IE was viewed by some as a policy that was dictated and mandated and the teachers were on the receiving end of such developments without adequate consultation or training:

... what it is like now is I guess it is all part of dictatorship. You know when they say "Make all schools inclusive then everyone runs for inclusion” without knowing that teachers suffer ... that workshop that I went to makes me realize that. (InTr)

One participant noted a high number of at risk students in the general classroom and she voiced her concern about how IE would help address this problem:

Cos I'm thinking that if you look at at-risk students we have now it is so vivid. Maybe we are failing students so therefore; even with our idea of inclusive education we are not supporting these students in the system. If we look at percentages of students with disabilities physical and mental in these other schools and take the at risk from maybe year four or five from the last five years, you'll find that maybe $90 \%$ fall in this group. ( $(\mathrm{InTr})$ 
Some participants were concerned about the monitoring role of the ministry and this was also expressed by a participant (from within the Ministry) who conceded that there were some inconsistencies:

The monitoring program two weeks ago they went to Savaii [the other island] I did not go because other things came up, but we are planning a monitoring visit in another couple of weeks, specifically on these children with special needs and disabilities, we want to know how truthful is the inclusive going on, for now I am telling you it is on but I don’t know how successful it is. (InCM)

... training has already been carried out with teachers. At this point in time in terms of looking at children with special needs a lot of the trainings that has happened in the area of inclusive education focused on those children with special needs. (InMin)

Furthermore, the government was criticised for a number of reasons - teacher supply, teacher remuneration (etc). Some teachers felt that the government did not promote a partnership in terms of expectations and remuneration. Teachers' salaries for example, remained unnegotiated despite the extra demands to implement new ideas.

But the rationale for this system or approach/program is to response to the shortage of teachers. When we ask for our salaries the MESC pushes this on us other than trying to identify why there is a shortage of teachers -it is because of salaries. (FSC)

Some others took a wider perspective and were critical of the government's policy on disabled people in general. It was felt that the government needed to support disabled people in the villages as they did in the school in terms of facilities and human resources:

I think the government should send these children to school free. Also those who educate the children. There should be a special needs teachers in each school to teach these children. (FPU)

\section{Expectations}

There were several expectations that were raised by participants in relation to the concept of IE and implementation of this policy. The majority of participants felt that IE was something that should be practiced more in the Samoan classrooms: 
Continue practicing inclusive teaching in the classrooms ... I feel that one way of enhancing and developing this inclusive education program is doing and keep on doing. Continue doing it. (Fai faaauau pea le inclusive lea ua fai nei i totonu o potu aoga). (FCM)

Moreover, there was a view that to improve this IE initiative, it was important to have training for teachers. One area of training need that was raised concerned braille and sign language, not only for teachers but parents as well:

My hope/expectation is for trainings to take place so I will have an understanding how to teach inclusively. (FSB)

The other area for the ministry to look at is to have ongoing training for teachers. Don't let it come to an end. (FCM)

To improve this program there needs to be special training for teachers on Braille, sign language and other teaching skills. True we took some papers at NUS [re special needs courses] but it is far from adequate. There should be enough resources, good facilities for children to use. Carry out a special training for parents and communities. For some special needs students to be able to get jobs. (FSC)

Some others went further and suggested there was a need to have sufficient qualified experts, and that it was necessary to upgrade the training programme to a degree course which would be an incentive for student teachers. Having people who were committed to push IE initiatives was perceived as crucial:

I think for FOE I think one of my dreams is to have enough people who are qualified in the area of special needs. We really like to see if special needs courses have a particular option for those who want to pursue this particular area ... its really sending out the message that we feel that this is very important that needs to be pursued ... So providing this, the students will see it as something that is important, critical, is crucial. (InTr)

One of the expectations raised by some participants was for MESC to be supportive in terms of resources used by teachers' classroom teaching:

My expectations and hope is that the MESC should be well prepared in terms of resources so the program will be carried out cos there are more than one classes. For example a photocopy machine, I would not be lazy [to teach if these are provided. (FSC) 
Resources such as Braille are needed [for blind students] but for children with intellectual handicap there should be games for them to play with. (FSA)

Moreover, some participants felt that it was important to ensure that educational provisions were in place to support those students who left school early and were roaming in town or ended up in prison. This was the recognition of the value of an after-care provision.

In Samoa it's just that we ...find that there are kids who are loners although there are people there but they are still loners in some cases that may spark those negative behaviours and in some cases we may say it never happen to us. To me it's better to ensure that the system is in place that will help support these students ... it would be very good to find out what is it that sparked those sort of behaviour and you may find that they have not been supported in the school system or in the homes or by the community. (InTr1)

A further expectation expressed by some was for children with special needs to be able to access their local village schools or schools close to them, so that they would be able to access education. The idea was that schools in Samoa (from primary to tertiary level) become inclusive:

My expectations and hope is to help the children of Samoa. They should be taken to schools closer to them. I expect that whatever time they leave home or parents...they should be able to learn something even if it be in his attitude or behaviour. (FSA)

Inclusive education should be enforced in all village primary schools as well as in high schools and colleges and tertiary level (FSA).

The expectations of parents was also discussed. It was noted for example, that that parents should be more supportive in bringing or sending the children to school as well as reduce labelling of them:

An expectation is for parents to enjoy bringing children to school ... also to reduce labelling of sick children. (FSA)

However, some parents had high expectations for their children and regardless of the nature of special needs, these parents believed that their children had gifts and talents to share. They hoped therefore that the educational experience would help their children enhance these gifts in order for them to earn a living: 
My hope for my son cos he won an art activity in their class ...I feel that maybe he will be a good artist I said to him draw well if you cannot do academically well at least that is something for you to earn some money. (FPU)

One of the teachers also noted that many children with special needs have talents like other students and had high expectations of them. She expected these students in her class to be able to complete school and earn a living, so they could support themselves and their families:

My expectations are for the child to have a good life. For the child to be able to learn to read and write The child to have a good (happy) environment ... some students within these special school ...have lots of talents which they use to earn some money. My expectation is that by the end of their schooling, these children are able to earn a living to support them as well as their families. (FSA)

Undoubtedly, this is a vision that many parents would have. One key community member noted:

There is no other goal [for sending them to school] other than for children to be smart and know how to be in control of his mind and behaviour. Because if he has a good mind (becomes smart) he will get a job to earn a living for himself and his family in future. And that is the blessing from the Lord. (InCom)

\section{Sustainability}

As noted above, many of the aspirations that were raised placed the onus on the government. More than half of the participants indicated the need for the Ministry to be supportive in terms of resources and training to support teachers and students in the classroom. Funds however were identified as necessary for the sustainability of the IE program:

The gist of it all is in relation to funds, to have enough funds, if there are enough funds then these workshops will be carried out as well as development of resources so teachers will be able to improve the teaching for children with special needs within the general classrooms. (FCM)

\section{Policy and Legal Considerations}

A number of participants felt that all students with special needs should be included in their own village schools, but felt that the Samoan government had a long way to go in terms of achieving IE as part of the mainstreaming process: 
So I think even though we haven't really reached our target in terms of ensure that inclusive education is part of mainstreaming I think that is where we are working towards... But I think the way I look at it now is we still have a long way to go in terms of achieving inclusive as such so that it is part of mainstreaming because that seems to be the trend, trying including in mainstream education. (InTr)

Policies signify commitment to an initiative. The development of the IE policy signifies Samoa's commitment to IE. However policy is one thing and implementation is another (i.e., it can be rhetorically ideal but less so in practice). A number of participants expressed this view - there was a need for action on part of the government with regards the implementation of policies and less talking needed:

I think we have to acknowledge that we are doing something. We have to acknowledge that now there are policies in place. Because it's very important that we have these policies in place. We also have to acknowledge these EFA and MDG goals are there also to ensure that these things are being supported but now it's like it is saying no more talk but action it's like now the policies are there and people have talked and talked and talked now action at all different level. (InTr)

One participant argued that the government intervention in the form of legislation would be useful - he suggested that sign language become an official language.

The common factor that deaf people resort to due to frustrations is rock throwing ... they become very aggressive because they want to tell you something but they can't tell you and even if they can, you don't understand and when you don't understand you don't give a damn, so they become very violent ... NZ has made it an act of parliament to recognize sign language as a third language of NZ. We should have something like that. Language is power, knowledge is power expressed through language, if cannot verbalize no matter how much power one has in the mind it will burst within the mind and cannot come out. (InCM)

When discussing aspects related to policy development, a number of participants viewed the importance of ensuring teacher involvement in policymaking. It was believed by some that this would facilitate more meaningful decisions and understanding by teachers. It could be considered as an incentive for implementation:

These policies are written by principals. But to me I feel that everyone who is involved in education should be involved. Teachers should be involved in policy making cos teachers are implementers. I feel that I have to have something in the 
policy that I feel is suitable and relevant to my situation. Not have someone else write a policy and I am expected to teach it. (FCM)

\section{IE Adoption Model}

The special needs units that were established by the government at the beginning of the new century for the purposes of integration of special needs, was perceived by a number of participants as a model that should be re-adopted for Samoa. These special needs units were attached to a few government primary schools and all students who had special needs (in terms of physical, sensory and intellectual impairment) were placed in these special needs units with a special needs trained teacher. The participants felt that this was an effective support system for a student with special needs, whereby s/he would receive individual support:

if the special needs units were still running, the children who are in the special needs units will eventually be included. Because initially the plan was that the endresult was to be inclusive but the process was via the establishment of special needs units. The special units that were established the overall aim is to become inclusive, they go to regular classroom and come back here to their classroom ... If the student goes to the general classroom, the special needs teacher would go and support the student in the general classroom. (InCM)

The notion of collaborative work between special schools and government schools was also raised. For example, some participants viewed the idea of partnership between special schools and government schools and for teachers from both schools to team-teach as important:

... the ministry should try and collaborate, request special schools with special needs ... get them to start coming and use special needs units but they can start off with special needs units then gradually file into regular classrooms ... Then special needs teacher can work with them and start placing them into classes ... that is what I'm saying, we need these specialist to team teach because with us ... we should look at ... a way to merge schools special education and a regular school ... Well if we really want inclusive education to happen ... otherwise here we go, the children [special needs] come and if they find it unsuccessful then they will go back again to the special school. (InTr) 
Furthermore, this collaboration between the two systems of education, the special and government schools, was viewed as an important way to ease students' transition into full inclusion:

There should be closer collaborative work with the government schools. We and the ministry should try and do some negotiation like that. But the ministry should try and collaborate, request special schools, get them to start coming and use special needs units but they can start off with special needs units then gradually file into regular classrooms. But at least they are starting to be in an environment where lots of normal students are. Then special needs teachers can work with them and start placing them into classes. (InTr)

It was also noted that the collaboration of the two systems of education could be an advantage in that there could be opportunities to share expertise. For example, one participant felt that the special school could support the Ministry through providing support in organising Braille workshops:

Our blind association's role is the production of Braille, we hope to provide workshops for teachers as far as Braille is concerned, we have conducted several workshops on Braille ... If the Ministry of Education can do that it would be very good. The blind society produces the Brailled book then we give it to the student in the classroom but the teacher should be able to know how to Braille. There should be training. The Ministry has already carried out two trainings two years back. There should be more training ... (InCM)

With regard to incentives (as detailed above), one teacher felt that it would be useful policy to offer professional development abroad. For example, if the government would offer a scholarship for training (out of the country), to extend knowledge especially in special areas such as Braille, it would be highly motivating to the teacher and of significant benefit to the students:

If the Education system would be supportive of us going overseas to be educated (in IE) so I could obtain a special certificate...If there is a challenge given to me for example, if I achieve a certain goal in my teaching profession then I would be awarded a scholarship to go for professional development ... overseas ... If there is such a thing (incentive) then I would put all my effort into doing this thing (meaning teaching these students) so that I will get an opportunity to go ... (FSA) 


\section{Summary of Policy Issues Pattern}

These findings on policy related issues revealed five codes. These are related to Ministry role, expectations, sustainability, legal/policy implementation issues and the adopted model of IE. Regarding the ministry role, it was criticized for its readiness to quickly implement IE. Participants felt that the ideals of a truly IE had a long way to go before it became a reality. In relation to this, participants expressed several expectations. This included having teacher training and support systems in place for students with special needs. Participants acknowledged the importance of having set policies but were questioning the practicality of these policies. Some viewed collaborative work between the special schools and government schools as a possible way to initiate inclusion of students with special needs into the government schools.

\section{Traditional-Contemporary Contexts}

Discussions on traditional and contemporary education often highlight matters which related to local and Western knowledge, inclusiveness and exclusiveness. The data identified four codes that were related to educational inclusiveness in the context of the Fa'aSamoa (Samoan culture). These are displayed in table 5.7 below:

Table 5.7 Codes for traditional and contemporary contexts

\section{Traditional-Contemporary contexts}

- Local inclusiveness

- Western exclusiveness

- Values and beliefs

- Local knowledge

\section{Local-Inclusiveness}

The Samoan society is a collective society where the concept of 'I' and 'me' are nonexistent but the terms 'we' and 'us' are the norm (Figiel, 1996). Some participants described the Samoan way of doing things especially in terms of village governance as very collective and inclusive. For example, regardless of the hierarchical manner in which the Samoan society is organised, everyone (the chiefs, orators, women and untitled men) works collectively for unity and development of the village. Some participants alluded to this inclusive nature of the Fa'aSamoa which they indicated could work to the advantage of IE: 
To me when we look at the saofaiga (seating) in the village (village council) it is inclusive. Because you start from the high ranking chiefs to the taulele'a (untitled men) they are all included in the meeting. Yes whether they are sitting behind the posts (at the rear end of the fale) they are all listening (tuning) in to the discussion so when it comes to activities, taulele'a would depart (from the meeting place) and so are the tulafale to carry out own activities (according to their ranking) then they all come together with their part of the activity to build up solidarity in the village. So inclusive in relation to Fa'aSamoa, the Fa'aSamoa is inclusive because everybody helps in development of the nu'u (village) that is the way it is. (FCM)

Young men (taulele'a). Not only included in activities in village meetings but young men of the village (taulele'a) prepare the matai's meal which at the same time a learning experience for these taulele'a. (FCM)

Another manner in which the notion of inclusiveness is demonstrated in the Fa'aSamoa is through inclusion of family members. This refers to family members from rural areas who seek lodgings with families in the urban areas for work and schooling purposes. It is a cultural practice for these family members to be housed by their relatives in the urban areas. Thus, it is very common for students to be accommodated by relatives in town for education as this participant commented:

Our own life as a Samoan is inclusive, very inclusive ... Even a Samoan family who is set up as nuclear family is even inclusive. It involves in village activities, extended families and church ... Even children are involved in Sunday schools, church youth groups ...The Fa'aSamoa is very much inclusive there is hardly any time for anyone, for privacy ... We work and earn money etc and we become more included in our families by supporting and developing our families. Not only that but the majority of students who are sent (by rural relatives) to live with us ... [relative requesting] "my poor daughter send her to school and try and be kind to her" (this is a common occurring in Samoa with rural relatives) They are all included like this ... (FCM)

This inclusiveness of the Samoan society was commented upon by most participants when the IE phenomenon was discussed during interviews.

The Samoan culture or Fa'aSamoa is putting children together and not to set apart. My views/thoughts are based on my own experience growing up in Samoa, observing the Fa'aSamoa - the Samoan culture. (FPR) 


\section{Western-Exclusiveness}

The collective and inclusive nature of the Samoan society as noted above runs counter to the individualistic and exclusive nature of the formal education system that was introduced into the Samoa society. A number of participants perceived the nature of this Western education as contributed to disability. This is due to its market-driven goals such as getting a job and earning a living as opposed to traditional education goals which aim at life skills. These traditional educational goals were perceived more relevant to Samoan people’s life and aspirations.

Because the Western influence initiated when missionaries arrived and then education was removed from the family and this disability notion came out very clear whereas in the traditional Samoan the role of the family is education, to educate its members. We now try to educate because of the changed goals and values of the modern society that we are in now, that we have to go to school, we have to get a piece of paper certificate. Our traditional learning does not need those things ... because of the requirements of the new education system now this disable has become very clear ... You learned at home. If old men carry out their canoe carving of the village would come to observe. If fine mats are woven then others would observe and that is learning. Now there is a big challenge for these people because of the palagi system. (InCom)

But if there is no palagi system but have the pastors school and education within the village, whatever the village are involved in. What amazes me is that this child is not taken to school but if physically ok ... will go to the plantation, learn how to bring firewood etc that is education. So these other children attend the Western school and this kid would go to the plantation. Whereas if there have been no Western education, then all children including this poor kid run chores. (InCM)

This point made above regarding the exclusive nature of the formal education, was reiterated by some participants who believed that formal education established the ideology of exclusion in Samoa because individuals now tended to compete as individuals as opposed to working on group goals:

We can understand inclusive as part of our community even though we have moved away from the so called idea of inclusive because of education, with education we have become very competitive every man for himself ... (InTr) 
The Samoan society grounded in Christian beliefs and values acknowledges the notion of togetherness. Thus, from a Christian perspective the idea of segregation was perceived by some participants as an inappropriate way of doing things in the Samoan culture since it was contrary to Christian beliefs:

I don't think it is appropriate in our culture. It is like these people who are not fully developed (atoatoa) in mind are being put away/set aside/push aside/segregate. But our culture and the bible claims this is not the will of our Lord to discriminate against people. Just bring those sick people and put them together with the strong ones then they will be in a happy and good environment. (FSA)

In the Samoan way and thinking there should not be any separation of those people that God created. (FSC)

This act of segregating instigates negative consequences for students because it fosters within the students the belief that they are different or sick:

Yes because all creation are Gods and it's like we have put them down ( lowering their position) and they have a feeling that they are sick people but if we bring them into these types of schools (govt schools) ... (FSA)

It is like we have set a barrier to their development in terms of knowledge and mind (iloa ma le mafaufau) by segregating them. It's like they are being put down like they are sick. Yes because all creation are Gods and it's like we have put them down (lowering their position) and they have a feeling that they are sick people but if we bring them into these types of schools (govt schools) ... yes like what other teachers have said, they came in with hardly any knowledge at all but now there is a big change in their learning. (FSA)

\section{Values and Beliefs}

The notion of alofa (love) was perceived by a number of participants as a core value of Fa'aSamoa - it is a value that is intended to be part of every Samoan. According to these voices, a Samoan person would give all s/he has to accommodate others. This core value is being questioned however and there is a metamorphosis in lifestyle because it seems some Samoans are becoming more individualistic in their thinking. Thus, one consequence of this is that money is driving many people. This materialistic thinking could impact on the manner in which people offer service and support to those who are less fortunate or are disabled. One participant alluded to this notion of love and giving: 
The very nature of the Samoan is alofa, the Samoan does not talk about this concept alofa but that is its very nature s/he will give all s/he has (E sae iai ma le pa'u) for other relatives or for the next person. When a relative would visit from another village even though they have little or nothing they should still make an effort to give what they have for this relative who has come to visit. These days people are becoming palagi (in the likes of a white man) too fast, we are money orientated. (InCM)

Previously, family members cared for their elderly and youngsters and other community members but as indicated changes seem to be noted. Some participants indicated that the introduction of the formal education was perceived to have impacted upon the thinking of people because some were now more individual focused and tending to overlook family obligations:

If I think about inclusive its very much a Samoan thing but we are losing it cos ... we are going to be very individualistic in things that we do ... When you look at inclusive now its like that contradiction whereby we were inclusive ...we have sick people we ... look after our elders and our young people, we look after everybody. We even looked after the people in the home in villages who are pipili (the lame) we really looked after them even the young kids ... you make sure that they are part of us. And now its like all of a sudden with this [formal] education being introduced, somehow I think we lost that we suddenly ... it became to do with the mind to be able to get from here to there. So no longer do we accommodate for those people because it was only the mobile ah ... (InTr)

The notion of caring for family was however still important to many people. For example one participant referred to the idea of blessing as a result of caring for parents and elderly (as opposed to placing into a home to be cared for by others). It was argued that the concept of rest home was a Western concept contradicting the Fa'aSamoa's notion of caring. This same notion of caring can extend itself to become a village responsibility.

Because we are at this era, in that people's way of living is changed. People go to work to earn and if the couple both work there is no one to take care of the old lady so she is taken to the old home to be cared for by others. The question therefore is, where is your blessing that should come from your parent, because you are not looking after them ... Because the Samoan culture believes that taking care of one's parents brings one's blessings. I believe that derives from bible doctrines - the 
notion of "Honor thy mother and father and thy days will be long upon the land that the God thy Father give thee.” (InCom)

This belief was related to IE in terms of support and the manner in which people's actions of caring and support used to be driven by love and a sense of responsibility other than material things and money. Tied in with this concept of caring is the idea of being blessed through such deed.

\section{Local Knowledge}

Some participants noted that if ideas are not 'locally owned', it would take time before the new idea is accepted by local people. Inclusive education was seen as a new and global imperative hence it was considered it would take some adjustments before accepted whole-heartedly:

My own belief is that most of these ideas we are using are outside ideas. I'd like Samoa to take the credit for coming up with all these but deep down I know that this was very much a push from overseas and that is why it [Inclusive Education] is going to take longer. Because we don't own the idea. (InTr)

Utilising the expertise of the native people to deal with their own issues (since they have the best understanding of how to deal with the issue) was noted:

... The most crucial factor is that you being a Samoan have your own methods and ways to carry out a matter in a simple manner. That is your own unique Samoa knowledge ... what I am saying is we are certainly better off in our own country and land and our people to do our own work. ... Most people would come introduce/implement something then go, and if it does not go well one cannot call them back to come and fix it for it needs extra money to bring them back. (InCM)

This of course has implication for such policies as IE and furthermore the compliant nature of the Samoan culture can be a positive means of moving forward. Obviously, being familiar with such characteristics seems important then when implementing new programmes.

There are many good things that we can do ourselves, however, challenging all they can do is to give $\$ \$ \$$ to get resources and we can sway ... our people can be very adjustable, very receptive when they understand. That is what I noted in my visit. Teachers are dreading and scared (of bringing in children with disabilities] saying they will break all louvers etc and I said, "which one is important the louver 
or the child, buy new louver.” But you see they come up with all excuses [as to why student with disability not be included] so when they run out of all excuses then would concede with a grin. (InCM)

\section{Summary of Traditional and Contemporary Contexts Pattern}

These findings on IE in the context of the Fa'aSamoa (Samoan culture) revealed four codes. These relate to inclusiveness as a local concept and this reflects the inclusive nature of the Samoan culture. Participants described the nature of the Fa'a Samoa as very inclusive and there was a general view that inclusiveness has always been an element of the Samoan culture, inherent in the act of any Samoan person. Conversely, the concept of special education was perceived as a Western concept which introduced the notion of segregation, and viewed as culturally inappropriate in the context of Fa'aSamoa. IE was interpreted as just another element that emphasised an individualistic orientation, slowly replacing the traditional values. The inherent Samoan values (i.e., love, respect) was also perceived as gradually changing from within to accompany changes in life-styles. This was reflected in the manner whereby the elderly were always cared for at home in the past, however nowadays, in some families, the elderly have been become the responsibility of the old people's home. The utilisation of local expertise was regarded as important and participants believed that local people are not very receptive of ideas if they do not own it. In relation to the IE policy there was an opinion that if this was an initiative from outside and not initiated by people from within this context, it would take a long time before people would take to it.

\section{Impact of Aiga (Family)}

The home and the aiga was viewed as having a significant impact on the development of the individual. Analysis of data identified three codes that were related to the impact of the aiga on the child's learning. These codes as stated in table 5.8 below include student development, parents' beliefs and actions, and learner's worth. 
Table 5.8 Family impact related codes

\begin{tabular}{|l|l|}
\hline \multicolumn{1}{|c|}{ Impact of Aiga } \\
\hline - & Student development \\
- & Parents beliefs and actions \\
- & Worth of learner \\
\hline
\end{tabular}

\section{Student Development}

When discussing factors that impacted on the child's learning at school, several participants perceived the home as a particularly significant contributing factor to the student's learning. It was further indicated that the child's behavioural problems were attributed to the home environment, which then impacted in the school setting:

These are the same behavioural problem they bring from home and the teacher tried her hardest to manage... (FSC3)

A further observation made was that children who were well instructed and supported at home are well behaved and excel in their learning:

Problem arises from home, because if child is instructed well by parents they will never veer off track. One can easily note a child whose parents never give him good instructions those ones keep going off the track. Those children who I note are fast in class are children of those parents who are good, and supportive of children education ... (FSB)

Some teachers believed, however, that parents of special needs children were often over-indulgent and this pampering of the child was perceived as being unhelpful to the child's development on entering the classroom:

From home most children have been spoiled and at home ... they get worse. They are brought from their homes pampered (faapelepele) ... it gives off a wrong signal to the teacher, that they are incompetent and when they are brought into the classroom the teacher would not take any notice or be concerned to teach them (aoao) for already teacher has come to the conclusion that the child is disabled and is incompetent. (FSA) 


\section{Parents' Beliefs and Actions}

In Samoa, families were the sole decision makers in relation to choice-making regarding the child's education. The enactment of the compulsory education law (i.e., for all children to be at school) notwithstanding, there are still non-attending children and because there is no enforcement of the law, the final decision as to the child's education still resides with families. There is an expectation of a partnership being developed between the education system and the villages. However, in some villages chiefly governance is not strong thus decision making in relation to the child's education is very much a family concern. The following comments indicated this:

We really feel for him [the student with special needs] for he is not coming to school anymore, but the family makes the decision. (FSC)

It is my own decision (to bring my child to the government school) for she was at Fiafia (special school) for four years ... she is very keen but her keenness does not match with school. (FPU)

When discussing preference for educational placements for their children, the data indicated that parents of students with special needs preferred government school placement over special schools for their children. Parents also indicated their willingness to support the teacher in the classroom by assisting their children:

In my heart I want him to be educated here [government school]...My own thinking is for them to be educated together, If the teacher needs help from us parents then I will come and sit beside him. So the teacher does her teaching and I will show him how to write letter 'A' ... (FPR)

As noted above, parents of children with special needs generally preferred regular classroom placement for their children, and perceived the placement of their children within the special school setting as unhelpful to children's intellectual development:

... to help develop in his learning by mixing with other students. I wanted him away from Malolo special school because he is only learning sign language and not going very far in his learning. (FPU)

It is my own decision [to bring her to the regular school] since she was at Fiafia for four years however she is very keen but her keenness does not match with what is taught at the school. She is intellectually ok but slow ... (FPU) 
The above comments demonstrated that some parents had high expectations for their children regardless of their special needs and they felt that the ability of their children exceeded the type of learning that occurred in the special school environment.

\section{Worth of Learner}

What was of most interesting were the parents' perceptions of special education. Parents of students with special needs believed that if their children are placed in special schools, they are looked down upon and are considered low status:

I don't know about other parents but I think if they are placed in special schools the child will be very low in status (less important). But if they are brought here the parents will be happy, the child will be happy. If they are placed in special schools people look down on them and say "Take them to where the sick children are ..." (FPU)

This same feeling was echoed by some teachers who felt that segregating students was like an act of 'put down'. Further, these teachers believed that segregating students impacted on their self-esteem - it would make them feel different and/or sick:

It [placing them in special schools] is like we have set a barrier to their development in terms of knowledge and mind (iloa ma le mafaufau) by segregating them. It's like they are being put down like they are sick. Yes because all creation are Gods and it's like we have put them down [lowering their position] and they have a feeling that they are sick people but if we bring them into these types of schools (govt schools). (FSA)

An interesting finding was the relating of the concept of negligence to specialised placement. The act of being separated through specialised programming implied that it was an alien concept to one parent.

I brought him here [government school] cos I want him to just come and play and enjoy. My family urged me to take him to Malolo [special school] but I said no I cannot just neglect him ... (FPU) 


\section{Summary of Family Impact Pattern}

These findings relating to home and family influence on the student's education indicated that the participants believed strongly that the home environment influenced the students' characteristics, which impacted upon their behaviour and attitude as well as their approach to learning. There was also a view that some parents spoiled their children which was not considered helpful for the children in terms of their physical and mental development. It was also noted that defacto decision making concerning the child's education, rest with the family. Furthermore, parents of children with special needs have a preference for government school placement for their children. This preference for government schools, was based on parents' belief that placement within the special school places the child at an inferior position. Moreover, to some parents there was a belief that placing the child in a special school environment seemed to demonstrate an act of abandonment.

\section{Conclusion}

This chapter has presented the results on codes and patterns that emerged from the data. There were six patterns that emerged which were related to interpretation and philosophy of the IE concept, characteristics of teachers in the IE setting, constraints and opportunity in IE, issues related to policy, the pattern on tradition and contemporary contexts as well as the pattern related to family impact on education. Interpretations varied ranging from disability and ability definition, to IE as a human rights concept to the all encompassing definition of IE. The all encompassing definition implied that inclusiveness is a concept that is constructed in the minds of people. That is, the individual (in this case the teacher) has to develop an inclusive mindset in order act inclusively. The pattern related to teacher characteristics indicated various teaching styles used by teachers in their teaching practices. Moreover, teachers' attitudes and beliefs of their feelings and experiences concerning IE revealed that teachers were supportive of the idea of IE however were under stress concerning the practical aspect. There was a view that the government was too radical in its move towards IE for it appeared that it was far from ready for the implementation of this initiative. Although the concept of inclusive was perceived as an element of the Samoan culture the notion of inclusiveness as applied to teacher practice was absent in the classroom. Participants attributed this to the very structured nature of the Western formal education. The results also indicated that it would take time for IE to be fully accepted by people since it was an idea that 
appeared to have been initiated from outside other than from the Samoan people. In this vein it was indicated that support (moral and technical) from the government and the community was imperative if IE was to occur.

The analysis of these patterns yielded three major themes (refer appendix 1): understanding, attitude and practice conundrum; support and interdependence and transfer practice which will be the focus of the next chapter. An examination of these themes came up with a meta theme which highlighted a paradox between the Samoan culture and IE. The following chapter (Chapter 6) presents a discussion of the findings and draws together the findings and implications in a holistic meaningful manner. 


\section{CHAPTER SIX}

\section{Discussion}

\section{Introduction}

The aim of this study was to examine the views of stakeholders in Samoa concerning the concept of IE and the implementation of the borrowed policy in this context. This was based on the understanding that identification of factors that could impinge on, or facilitate IE, could assist in the development of a model(s) or framework(s) that would assist in enhancing inclusive practice and other policy implementations. Many of the ideas that are in the international literature concerning the concept of IE were also relevant to the Samoan context. However, there were also significant cultural ideas that emerged which could help in facilitating change implementation. Furthermore, there are also arguments concerning special education placement that are worth consideration.

Utilising a phenomenological research approach, individual interviews and focus group discussions were employed to obtain qualitative data with regards to beliefs, experiences, and expectations of stakeholders about IE and the practice and implementation of this policy in this context. The analysis of the data identified a number of codes (see Chapter five) which were categorised into five patterns namely: 1. interpretation and philosophies of IE; 2. teacher qualities; 3. opportunities and restraints; 4. policy issues; 5 . traditional and contemporary contexts, as well as 6 . impact of Aiga (family). These patterns were further analysed and organised into three major themes namely: Theme 1 - understanding, attitude and practices conundrum; Theme 2 - support and interdependence; and Theme 3 - the transfer of training issues. These three themes subsequently formed a meta theme which was the paradox of the Samoan culture and IE implementation. As previously mentioned, the codes and patterns ascertained from the group and individual interviews as appeared in the preceding chapter were the primary data sources of these themes.

This chapter will discuss the implications of these findings. Firstly, the discussion of the findings in terms of identified patterns will be presented, followed by a description and discussion of the themes that are embedded in the findings (Refer appendix 1). Subsequently a proposed model for IE implementation is presented and discussed in relation to emerging themes. In order to connect this to the idea of 
borrowed policy, an educational policy development model is presented as a framework to understand the notion of policy development in this context.

\section{Interpretations and Philosophies of IE}

The findings on pattern of interpretations and philosophy of IE, showed a difference in perspectives amongst the participants regarding the definition, the beliefs and practices of IE. As reported by the international research literature, the definition and interpretation of IE differs from culture to culture and even within the same culture. As noted, this difference in definition leads to different conceptualizations and practices of IE (Clark, Dyson, Millward, \& Skidmore, 1997; Dyson \& Millward, 1997; Florian, 1998; Topping \& Malone, 2005). This phenomenon has occurred in the findings of this research. It was clear from the data that there was a contradiction regarding the interpretation of the IE concept from the point of view of the policy makers (technocrats), Ministry personnel, teacher educators and the (policy implementers) teachers, and parents/community. The policy makers' interpretation was very much aligned with that of UNESCO, which included a very encompassing definition (that is any child with special needs). The implementers (teachers) as well as parents and community members interpreted IE in terms of disability, as well as in relation to special needs in the context of learning ability or potential. This difference in views is clearly noted from this comment:

... you also need to look at the attitudes, the mindset of people you know, so whether we see the same thing, whether we read the same thing whether our ideas are the same in terms of what is inclusive education ... cos the way I see it now people think that they know but we still have different ways of looking at it and implementing it. (InTr)

The discrepancy in definition, particularly those grounded in a disability perspective, is reflected in the stakeholders' exclusive mindset which can be located in the deficit discourse of disability. In this view students with special needs are still seen as 'apart' from others and not as 'a part' of a group.

It can be argued that this inconsistency in interpretation and understanding of IE could well be attributed to the level in which this group operate, and their access to education and discussion on this topic. For example, policy makers travelled more and attended more conferences at the macro level where educational issues are dialogued as opposed to teachers who were limited in their opportunities to attend 
such meetings. As a result information is therefore restricted for the teachers as it is disseminated from the central policy makers or top down. Weiner (2005) asserted that an issue with the top down approach is the lack of discussion concerning policy aims and priorities with teachers. Furthermore, policies are mediated and transformed at multiple points of intersection (for example at the national policy making level, teacher trainer, School Review Officers, principals through to teachers and students in the classroom). Often, one teacher represents the staff at training and in turn is expected to transfer these ideas to the staff. ${ }^{9}$ If the teacher failed to grasp the ideas from the training the information is likely to be communicated inefficiently to other staff members. One day workshops are usually not effective means of dissemination information or developing skills for classroom use. According to Hoban (2002) a 'one-off workshop' does not guarantee that change will occur because there is no consideration given to the challenges of the classroom environment as well as lack of support offered for teachers to deal with change.

To overcome such problems there are a range of possibilities. Training could be conducted in such a way that it is effective and more relevant to teachers' needs but there also needs to be ongoing support to consolidate ideas. Furthermore opportunities should be made available to policy implementers to attend conferences (local and international) and attend workshops. One participant mentioned that an incentive to teach students with special needs would be to get an opportunity to go overseas for specialised training in special education.

\section{Teacher Quality Attitudes, Experiences and Practices}

The second pattern regarding teachers' preparation, experiences and practices of IE revolved around a range of teacher beliefs and practices about IE as illustrated in Table 6.1 below.

Table 6.1 Beliefs and Experiences Variability

\begin{tabular}{|c|c|c|}
\hline \multirow{2}{*}{$\begin{array}{l}\text { Practices/ } \\
\text { Behaviour }\end{array}$} & \multicolumn{2}{|c|}{ Beliefs } \\
\hline & Positive & Negative \\
\hline Positive & Very few participants & One or two participants \\
\hline Negative & More than half of the participants & Several participants \\
\hline
\end{tabular}

\footnotetext{
${ }^{9}$ In-service trainings are often carried out for a week or for a couple of days and one teacher is selected either by the principal or SRO as representative of a school to attend with the expectation that at the end of the training the teacher will train other staff members.
} 
The majority of participants (teachers) revealed very positive beliefs about the value and benefits of the IE concept/idea. However, their actions demonstrated a negative attitude towards practice. For example, a contradictory statement (from one participant) "it is the right of the students with a special needs to be included however there should be corners in the classroom to place them so they do not disrupt the class” clearly indicates inconsistencies. Attitudes like this are contrary to the IE philosophy-practice approach, but it appears that this type of belief structure is common. For example, Shruggs and Mastropieri (1996) in their study of teacher attitudes towards mainstreaming found two thirds of the study population were supportive of integration but only one third believed in its practice. One conclusion that can be drawn is that, in the minds of many of the participants, IE was a social phenomenon where students become part of the group, but learning was not necessarily a key objective. Such comments emerged from a considerable number of participants, mainly teachers:

I have a student with special needs who was at the special schools ... her special need is more on the physical side ... issue is that when she is lazy then I leave her to do what she wants. (FSA)

Sometimes when I notice that he [child with down syndrome] is angry with me I would then send a student to the canteen to buy him an ice pop to keep him quiet/ settle him down. Then I would give him a news print ( paper) and crayon so all he does is scribble, all I do is to keep him quiet ( fa'afilemu). (FSA)

Indeed such attitudes reflect the position of the classroom simply being a repository for locating the students where 'mainstreaming' becomes 'main-dumping' (Stainback \& Stainback, 1990; Thomas, Walker, \& Webb, 1998). This was a term used in the United States to describe the process of placing disabled children in the mainstream schools without consideration given to adequate preparation or resources. These attitudes may be reflective of a lack of professional responsibility, lack of skill and can lead to further exclusion of students, thus professional development is crucial for teachers to take on a different mindset towards inclusion.

There were also a number of teachers who were not accepting of the idea of IE and the implementation of the policy. They stated an unwillingness to have students with special needs in their classes and suggested separate classes for these students, with special trained teachers. This implied that not all children would be welcome and 
hence barriers had already been erected. For some of these teachers, including students with special needs in their classrooms was such a strain that some resorted to use of physical punishment to manage student's unfavourable behaviour. The use of corporal punishment is prohibited in the educational policies. However it has become a contentious topic. This is because it contradicts with cultural beliefs concerning child upbringing and discipline in this context. Cultural beliefs regarding child upbringing and discipline in Samoa are grounded in the biblical idea that 'sparing the rod would spoil the child'. Some teachers still resort to this manner of discipline, an indication that teachers' cultural/religious beliefs can impact deleteriously on their teaching practice.

Teachers who were positive in their beliefs and practices, were those who had experiences with a child with disabilities. Some of these were mothers who had raised a child with a disability. Leroy and Simpson (1996) noted that such experience leads to a confident attitude towards teaching children with special needs. One or two teachers claimed that they did not initially agree with the IE. However when they actually practiced it, their way of thinking changed. The experience had a direct impact on the way the teachers dealt with a new phenomenon. This notion of change in attitude and belief due to practice perhaps is explained by Guskey (2002) and Fullan (1991). They proposed a view that professional development does not lead to change in teachers' beliefs and attitude. Rather change in teachers' practices, beliefs and attitudes result from classroom experience of improved student outcomes. Although the concept of attitudinal change may appear insignificant due to the few participants who alluded to this, it remains important because it implies that change can occur, given time and practice. Such a thesis may need further exploration in Samoa where priority is often upon practicality.

A Samoan adage from one participant "e le po pea se nu'u” (literally meaning “a nation won't stay dark forever") is analogous to this change. An interpretation to be drawn from this is that there is room for change but changing attitudes takes time. Smith and Leonard, (2005) argued that positive attitudes and beliefs are necessary for IE to occur. However, positive attitudes emerge as a result of training experience, which provides the teachers with the knowledge and understanding of this phenomenon. Thus teacher professional development, such as that developed by McDonald (2001) which incorporated cultural and local dimensions to ensure transfer of the learning, would be a useful tool to draw upon for IE to occur. 
Of most significance in this discussion is the notion of commitment made by the teacher. This sense of commitment was an important teacher attribute enabling change to occur (McDonald, 2001). The findings alluded to the importance of having teachers who were committed and who had a passion for teaching and this was perceived as a facilitator for change:

And its just like a teacher if you feel for it, you'll make sure that something is done you know, but if you don't feel for it I mean, if you don't have the passion (articulated very passionately) if you don't have that passion about something it is not worth it and at the same time. I know that these young students [teachers] ... who go into these special units in the mainstream schooling system ... uh I think that some of them are very passionate about it [teaching] but I also think that some of them felt that they are alone and are not supported. So it was easy not to be passionate about it because nobody else is interested. (InTR)

Again it comes back to commitment and in making change if I know the way I was taught it doesn't help, then I should change especially when we want our children to be competitive in today's world. So at the end of the day I ask myself, If I know I can't change then I should get out and if you think you can't make a difference in the learning of students then that is the thing no one can tell you but you ask yourself should I continue? (InTR)

One participant referred to the Samoan concept of 'asamo'10. This approach was employed by one of the participants to seek educational support for some students from his village to be educated in New Zealand. What was of most significance was the manner in which this 'asamo' concept was used in this context. It signifies a sense of commitment on the part of this individual (a church leader) to the education of students. This act of commitment is vital in ensuring implementation of change. However, having a sense of commitment is a dispositional quality, something not readily taught. Attitude is not something that is easy to change. However it can be argued that educating people about the value of education can impact on a mindset and training and education can make a big difference in changing attitude and mindset.

\footnotetext{
${ }^{10}$ Asamo is a Samoan concept with refers to the humble manner in which someone asks another individual for something, normally in an unconditional manner.
} 


\section{Opportunities and Restraints}

The pattern on opportunities and constraints reflects the factors that were perceived as enhancers and barriers to IE. Given that the availability or lack of these impacted on IE the concept of support assumes importance and indeed support is noted as one of the main factors for enhancing IE practices (Vaughn \& Schumm, 1995). The participants in the current study perceived support as a most significant facilitating factor for satisfactory implementation of IE. The support identified by participants included teaching resources/facilities, professional support in terms of teacher professional development/expert knowledge as well as social and moral support from school colleagues, families, and the community. These support dimensions are outlined in Table 6.2.

Table 6.2 Dimensions of support

\begin{tabular}{|l|l|l|}
\hline \multicolumn{2}{|c|}{ Support for teachers in IE classrooms/implementation change } \\
\hline Dimension & Type of support & Definition \\
\hline $\begin{array}{l}\text { Physical/Technical/ } \\
\text { Tangible }\end{array}$ & Resources, facilities & $\begin{array}{l}\text { Teaching resources/ reading etc, } \\
\text { infrastructure/facilities in the school to } \\
\text { facilitate inclusion of children with } \\
\text { special needs }\end{array}$ \\
\hline Professional & $\begin{array}{l}\text { Training, professional } \\
\text { development, knowledge, } \\
\text { course ideas/materials }\end{array}$ & $\begin{array}{l}\text { Ideas needed to enhance teachers } \\
\text { knowledge }\end{array}$ \\
\hline Social & $\begin{array}{l}\text { Collegial } \\
\text { Spiritual, Tapua'i } \\
\text { (Prayerful) }\end{array}$ & $\begin{array}{l}\text { Support provided by school } \\
\text { community, principal/staff } \\
\text { Family (Aiga) village, church, }\end{array}$ \\
\hline
\end{tabular}

\section{Physical/Technical Support}

Factors that were highlighted in this study, and located in the literature (Avramidis \& Norwich, 2002) that affect teachers' attitude, included the educational context - the Ministry, policy, teacher factors and student related factors. Factors related to the educational context, and policy included the curriculum, funding, resources, and facilities. In particular, the data indicated that the Ministry had failed in their role of providing support in terms of resources, facilities to support students with disabilities and salaries for teachers. Support in terms of teaching resources was noted as crucial for inclusion, as it affects teaching practices (Jenkins, 2002; Westwood, 2003). In many Samoan classrooms there is a lack of resources generally for teachers to draw upon. Pereira (2005) detailed this in her thesis arguing that lack of resources resulted 
in teachers' utilising teacher-centred teaching approach and rote learning as opposed to child-centred approach. Participants, in this study indicated that there were limited teaching resources to support classroom teaching and learning, and in line with Pereira's work the teacher-direct approach appeared to be very much in use in the classroom. This is at odds with the child-centred approach which is fundamental to IE and has an implication on the IE policy.

Furthermore, many teachers revealed their frustration over the already high number of children in their classes, in addition to students with special needs. Teachers felt that this would impact on time and preparations and which in turn would affect the quality of teaching. One of the teaching strategies that teachers utilised in the classroom was grouping. They believed that grouping students in mixed abilities would lead to less able learners learning from more able ones. Johnson and Johnson (1989) indicate that from their cooperative learning studies, it states that it scaffolds the learning but also helps the more able to understand better (when they have to help others). Therefore an important consideration here is that teaching pedagogies that support collaborative/cooperative learning need to be utilised by teachers to assist with the inclusion of these students in the curriculum.

Some teachers were critical of the Ministry for not considering incentives for teachers (such as salaries) but felt that the Ministry could still demand innovative practices from the teachers. A comment by one teacher indicated that salary is an extrinsic incentive for teachers:

When we ask for our salaries the Ministry pushes this (inclusive education) to us other than trying to identify why there is a shortage of teachers it is because of salaries. I must tell you that the ... there are no machines everything is manually done and the teachers sacrifice their time ... I just want to have this frustration out cos once it is out then I feel relieved. (FSC)

One interesting finding related to motivation, is grounded in the notion of blessing. For example, a few teachers stated that they were motivated to take good care of students so their own children will be treated well by others (and this appeared to mean blessing for their children). The concept of blessing can be argued as an impetus for good behaviour for Samoan people - for example, an individual could be motivated to perform a good deed such as serving the family, parents, or matai because of this blessing. 
Considerable research has demonstrated that teachers have intrinsic and extrinsic needs to be motivated. However, Hynds and McDonald (2009) believed that extrinsic motivation has been somewhat overlooked. Clearly if teachers are not inspired or motivated to implement ideas, then the implementation of educational policies could be problematic.

\section{Professional Support}

Support in terms of training emerged as one very significant theme in this study. Almost all teachers believed that there was insufficient training to empower them to support children with special needs in the classroom. The mixed feelings of fear, frustration, and stress in teaching students with special needs were attributed to lack of knowledge resulting from inadequate training. Once again, similar to the international literature, factors that influenced teachers' attitude concerned the teachers' lack of training and knowledge, as well as severity of the student's disability (Dupoux et al., 2005; Ward, Centre \& Bochner, 1994). It is not surprising that a considerable number of teachers in the study, did not find it an issue to include those who were labelled slow learners and students with mild physical disabilities but found the inclusion of children with severe disabilities and those in wheel chairs more problematic (Forling, Douglas, Hattie, 1996; Leyser \& Tappendorf, 2001; Scruggs \& Mastropieri, 1996). This attitude could be attributed to a lack of empathy for children who appear to be very different or simply the fear of the unknown. Pereira (2005) argued that one of the reasons why some teachers engaged less with students who have special needs was due to the teachers' perceptions that low achieving students come from low status/poor families. Teachers were less motivated to be involved with these students. One teacher commented about unfavourable attitude of some teachers towards students considered less able:

Yes there are children that other teachers ignore like sick children who are called disabled who are in the class, are deaf (leaga taliga). Some teachers mainly ignore those who are mainly sick and weak (tamaiti tele ina mama'i ma vaivai) and tend to focus on good children. (FSB)

Clearly this type of attitude is not conducive to inclusive practices. As noted earlier, lack of training to deal with students with special needs results in teachers' unfavourable attitudes towards these students. One teacher educator commented on this lack of training: 
I think realistically there is a lot to be done, There is still a lot of support that need to be in the working in schools and also in the training of teachers themselves. For me there is still a lot to be done ... so the way I look at it we still have a fair way to go. (InTr)

The issue of training was noted by the researcher and the consequences observed in the classroom. For example, one teacher's management plan was to use rewards to stop the student from behaving inappropriately. However, this is of course a misunderstanding. Rewards should only be utilised when students are engaged in appropriate behaviour. The teachers' lack of training (or inadequate training) was likely to result in further management problems.

Sometimes when I noted that he [child with down syndrome] is angry with me I would then send a student to the canteen to buy him an ice pop to keep him quiet/ settle him down. Then I would give him a news print (paper) and crayon so all he does is scribble, All I do is to keep him quiet (fa'afilemu). (FSA)

This above statement implies, that a real need for effective training of teachers is required so that it can impact on teacher attitudes and behaviour and build teacher knowledge.

Although the data highlighted that teachers' behaviour and attitude were a significant issue for inclusion, a further explanation related to the exam-oriented nature of the curriculum. Shephard (cited in Gipps, 1994) noted that during exam preparations, some teachers took less notice of students who had difficulty in learning. A number of comments from participants mainly teachers, indicated that this was occurring. Teachers felt stressed about covering the curriculum and including children with disabilities or special needs could impact on their perspective.

In Samoa, Pereira (2005) found that almost a quarter of teachers in her study indicated that the Year 8 National examination led teachers to concentrate on potential students and ignore less strong students. The goal for these teachers was to mainly teach to cover the curriculum and to prepare students for an exam. The National Exam at the end of primary school year (year 8) is a critical event for 'streaming' students to top colleges. Teachers teaching at these levels tend to focus on completing the curriculum and preparing students to pass. Skrtic (1991) has criticised the market driven nature of current schools and the inflexibility of the prescribed curriculum in meeting the needs of students with difficulties. 
Consequently, Samoan teachers tend to focus on the (few) students who are more likely to raise the profile of the school and pay less attention to the rest of the class. Evidence of this was gained during data collection at one of the schools. The researcher noted that students in this level were camping in school for a period of intense preparation for the National Examination but it was a selected group of students and not the less potential students (even though they would be sitting the same exam). In other primary levels, assessment by way of examination for student placement at the end of year is a very significant event with teachers aiming to teach all the curriculum content in preparation for the examination.

Selective national examinations add pressure on teachers, which in turn impacts upon classroom pedagogies. The literature has shown that when schools, teachers and students prepare for high-stakes formal testing, teaching and learning can be restricted to that content and skills to be examined in the exam (Broadfoot \& Pollard, 2000; Brown, Mc Callum, Taggart, \& Gipps, 1997; Meadmore, 2001; Popham, 1999). Accordingly, the streaming and graded structure of the education system in Samoa, whereby students are streamed according to their potential, can be argued as working against the inclusion principles. This type of arrangement leads to the development of an exclusive mindset, and teachers continue to exclude students whom they feel would not boost the school profile as well as the teachers' status in the community. As long as the curriculum continues to be driven by exams and stakes testing, the implementation of IE will be problematic.

Effective training was identified by participants as necessary, but it needs to be effective training grounded in the cultural values of the participants. McDonald's (2001) study on the transfer of training strategies in a Polynesian island context would be a useful model to draw upon. He identified three major determinants of training effectiveness which need to be embedded in a cultural frame of reference for transfer of training to occur. These were - "teacher's individual characteristics, trainer/training qualities and social support structures.” (p. 195). The teachers' individual psychological, social and professional skills and behaviour were seen to be important for the introduction of training ideas into classroom. In addition, the trainer and training programme were also perceived as important for transfer of training to occur. McDonald noted that a trainer who met the participants' expectations and who could develop a relevant course with interactive, participatory structures was more likely to facilitate change in the classroom (p. 267). If there was 
insufficient training for teachers, and most importantly, if this training was not judged by the teachers to be effective to cater for their needs, then there was a likelihood that teachers would continue to give less attention to students whom they see as problematic in the classroom. McDonald (2005) noted that teachers in the Pacific need to be culturally empowered to implement ideas and that existing aid programmes do not always incorporate the technology of transfer for this to occur.

\section{Social/Spiritual Support}

It was clear from the findings that the teachers found support from other colleagues to be a crucial energizing force. An example of this type of support was the sharing of expertise such as teaching one another sign language skills. The international literature has pointed to the critical role of collegial social support in the work setting for it reduces the issue of 'burnout' (Blasé 1986, Jackson et al., 1986, RodgersJenkinson and Chapman 1990). McDonald (2001) also proposed a number of factors that facilitated the transfer of training ideas from training courses into the classroom and one of these significant factors was support from colleagues. According to McDonald, this support has a psychological aspect in that it served as a protective mechanism for the teacher (from being ridiculed by those in authority positions who may have opposing views). This idea was contained in the current study whereby the support from family, community and health department in forming a partnership was also raised by many participants as crucial for implementation of IE and the most critical factor was the support from the village (community).

There is still a lot of support that is needed in the schools and also in the training of teachers themselves. For me realistically there is still a lot to be done ... but I think we still have to make that part and parcel of partnership between NUS, the community, the health system and the education system. So the way I look at it, we still have a fair way to go. (InTr)

Although the value of community support was perceived crucial, unfortunately the data revealed that there was inconsistency in this respect. This lack of consistency clearly could affect the implementation of IE.

The notion of community support is very important and should be emphasized by the ministry. It used to be ongoing and now hardly hear of it. This should be enforced for. I feel that if this partnership is encouraged and works well then a good thing for the development of inclusive education program. (FCM) 
Many participants also viewed the village support system a critical success factor for facilitation of educational change. This can be attributed to the solidarity at the village level, under the governance of the council of chiefs and orators. For example, the village provides the school building and selects a school committee to manage school funds. The pastor was also perceived as a prominent highly regarded figure in the village and was considered to have a crucial role in counselling families (Aiga) regarding the value of education. It can be argued that support from this level is another determining factor in establishing effective IE. One participant commented:

Our pastor (church minister) is very active in pushing for children/s education. When he preaches in church he encourages the parents to send children to school He objects to children not attending school. He is carrying out his duty. (InCM)

The pastor in the study also commented on his role in the village in relation to children's education. This seems to highlight the importance of pastors' role in supporting children's education and this support model is something that is worth considering in enacting change in this context.

The main objective for setting up this study centre is to support the children (not a fee paying school) but to support children and students in their education. (InCM)

Not only was the pastor perceived to have a valued role in supporting children's education but the community leaders (matais/chiefs) as well:

I think the govt has already developed a policy for compulsory education I think it is the part of the community (Alii ma faipule) to enforce all children within their village to go to school. (FPU)

Furthermore, parents' supporting role in helping out in the classroom was perceived in a positive light. However there was inconsistency in their involvement, and this raises a number of questions. How comfortable are parents in this context in giving support in the classroom? Are teachers skilled in managing other adults in the classroom? This inconsistency can possibly be understood if reference is made to Hofstede's (1980) model in terms of the hierarchical nature of this society. The classroom implies power and jurisdiction where the teacher is the authority and parents may feel intimidated and less comfortable in such an environment. In previous times, parents were not permitted to intrude into the classroom. Therefore, regardless of the policies concerning the importance of parents' participation in the 
classroom, they may still feel alienated in this setting and equally teachers may feel threatened by parents' presence. Therefore, support that is expected of parents may not be so forthcoming and this could be a valuable source of support that is negated.

Another type of support to consider is the spiritual dimension. There is in Samoa a spiritual in-depth support termed 'Tapua'i' which is derived from the notion of worship. Although this was not articulated in the interviews in this study per se, this spiritual form of support is an essential part of the Samoan culture for it connects to the notion of success as illustrated by this dictum, “A le tapua'ia se faiva e le i'u manuia” literally meaning “A task not supported will not be successful.” When people are supportive and 'feel' for the success of a task or even an innovation (individual or collective) they are involved in this 'tapua'i' concept, by praying/hoping for the success of the task. In terms of IE implementation, success of this kind of support can be via the support of all individuals involved. Even teachers can be influenced by their chiefs and families (that is, when the individual is aware that the family/village community are supportive of an innovation that they are part of, they would also have a sense of duty and commitment to their call).

This section has demonstrated the many ways in which support was administered and the value of support in enacting change. Next will be a discussion related to benefits of IE.

Interesting ideas emerged concerning IE benefits. The data indicated that IE was beneficial for all students as well as the teacher. It was indicated that IE could lead to a sense of self worth and sense of belonging for students with disability and it also reduced discrimination against these students. The literature noted the academic benefits (Madden \& Slavin, 1983), social benefits (Guralnick, 1990; Johnson \& Johnson, 1987; Strain \& Odom, 1986; Van den Pol, Crow, Rider \& Offer, 1985) as well as benefits in terms of communication skills (Cullinan, Sabornie, \& Crossland, 1992) that occurs by being included. There was also mentioned benefits for the teachers in that that they would learn new ways to understand these students. This is an issue related to professional development mentioned by Guskey (2002) and Fullan (1991) for they noted that change in teacher attitude was a result of classroom experience and students outcome as opposed to professional development. 
Although the benefits of IE as articulated by participants is worth noting, what is crucial however is for IE to become a reality and not just an idea. The majority of teachers had positive beliefs about IE but this was not evident in their practices.

\section{Policy Issues: Professional Development and Change}

The pattern on policy issues was concerned mainly with the notion of training and the need for professional development. Leberman, McDonald and Doyle (2006) have clearly identified the importance that participants have to the transfer of knowledge in terms of making them ready to utilise ideas on the job. As previously noted, there was a contradiction in rhetoric and practice - what participants said and what appeared to be their practices. For example, participants were generally supportive of IE as an idea; however in practice there appeared to be a disagreement amongst the participants and, as noted earlier, the literature indicated that generally teachers were accepting of inclusion at the conceptual level. However, they were not as supportive in terms of practice. It is important therefore to offer possible explanations as to this difference between policies or theory and practice. Simply put, why was there a lack of transfer of ideas from training into the classroom setting?

One explanation of the discrepancy in policy and practice could be explained by the manner in which IE was introduced. Some participants criticized the 'radical' implementation and the lack of discussion/consultation.

They just said that schools will be inclusive that means children with disabilities will be included in government school So many thoughts came to mind, like if these children are disabled and will be taught together with these children [the so called normal ones] it will be difficult plus ... I thought there will be lots of work preparation involved when they are included. (FSB)

$\ldots$ if this program could have been stalled a little and not to rush to become inclusive all of a sudden, I feel that in the end everything will fall into its proper place and people will accept it graciously, and willingly and would keep on going. (InCM)

It became even more problematic when it was perceived to be yet another policy/idea to implement: 
Well that is another thing, the EFA comes in, the inclusive comes in, poor teachers are lost as to what the exact/real thing is, remember when too many things come crowding in, then the only option is to forget about it. (InCM)

When we ask for our salaries the Ministry pushes this (IE) to us ... I just want to have this frustration out cos once it is out, then I feel relieved. (FSC)

This lack of consistencies in policies that lead to practice can be explained by the power relation phenomenon in the Polynesian culture where those in authority retain control (Hofstede, 1980). Hofstede maintains that individuals in societies, characterised by higher levels of power distance, tend to follow formal codes of conduct, and are reluctant to disagree with superiors. Samoan culture is typical of this and can assist with the explanation some of the teachers' behaviours (or lack of). For example, in the interviews, teachers were unaware of the toolkit material in the school. They had not seen or heard about it, yet each (school) had received a kit from the Ministry. From observation and experience of this researcher (as a teacher then a University lecturer) the principal is perceived as the authority figure and all issues pertaining to the school organization (which include distribution of teaching resources) are managed by the principal. Most important documents remain with the principal and, being limited in number, may be shared with other colleagues but often teachers don't access such resources (unless compelled to do so). This explanation fits the findings of this study.

Notwithstanding the probability of the above explanations, a further explanation for this discrepancy in policy and practice concerns the type and amount of pre and inservice training that teachers may have been exposed to. The findings indicated that teachers still maintained a teacher directed delivery style regardless of the training undertaken about the child centred education approach. Even some teachers who have had training in special needs education did not effectively include students with special needs, which implies that these teachers did not have sufficient and effective training to cope in an inclusive classroom. One teacher educator commented about the gap in special needs courses offered at the pre-service level as well as the need for professional development for teacher educators themselves:

We need to put in more practical courses for training of teachers who actually major in special education. At the moment there are many loopholes in our inclusive education not only we don’t have facilities, we don't have the teachers 
those with the expertise. Even qualified lecturers like us we feel that we are still not well prepared to carry out this training. We need to have professional development ourselves. (InTr)

It was noted in the literature that a lack of teacher knowledge and training affected teachers' attitude towards inclusion. For example, Rose (2001) reported from her interview with principals and teachers, that training was an area of concern which impacted on teachers' confidence to teach in an inclusive environment. This could be the reason that explains the contradiction in policy and practices. Therefore there is a call for effective training of teachers so to be able to effect change in the classroom. However, if teacher educators themselves are in need of professional development, this is also a critical issue that needs addressing. How could teacher educators train teachers if they themselves are limited in knowledge and skills? Professional development programmes often do not effectively use the transfer of training strategies to effectively implement changes in the classroom and McDonald (2009) views this as a major cause of training failure. Pre-service and in-service training need to be developed and conducted in such a way that ideas and skills used in the training programme can be transferred into the classroom. It is important however to understand that the cultural dimension of transfer be considered (McDonald, 2002, 2004, McDonald \& Hynds, 2010). As noted elsewhere in this chapter, the model indicated by McDonald (2001) could be a model that can be a useful one to follow.

One of the key issues in transfer relates to the process of change. Change takes time. It can be argued that resistance and ambivalence regarding innovation are part and parcel of a somewhat complex and changing system of meaning, stratification and control where Samoan life and education are concerned. There was a view from a few participants that IE, as an educational reform, will only be adopted slowly as a teacher pedagogy because teachers do not 'own' the idea. Va'a, (2006) maintained that people in the Samoan society support change if there is perceived benefit from it. This view was also voiced by another participant (ex MP personal communication, May 4, 2010). On the other hand, people resist change if there is no perceived benefit from it (ex MP personal communication, May 4, 2010).

A very positive view relating to change, concerned the idea of 'received blessings'. This notion of 'blessing' is founded on the biblical discourse that 'what you do to others, will come back to you'. A considerable number of participants articulated the idea of blessings received, as a result of caring for/and honoring one’s parents (which 
is grounded in the same discourse of giving and receiving). Some teachers were more willing to accept students with special needs in the classroom because they believed that they and their children would receive some 'blessings'. The idea of blessing was therefore a motivational force. In this respect, people are motivated to perform well in the eyes of the parents or of the head of the household because they desired some sort of blessings. This statement has demonstrated that some cultural beliefs pertaining to some individual could lead to positive attitude to inclusive practice.

The findings indicated that teachers' resistance to change was attributable to lack of support in terms of resources and training. However, a keen observer can note that in Samoa teachers can sometimes have a tendency to do what they believe in, regardless of what policies state (Pereira, 2005). An example of this resistance to change was also noted in the implementation of previous educational policies such as the bilingual policy. Oral English was designed to be introduced in yr 2 (10\% of the programme). In year 3 oral English is supplemented by written English (20\% of the programme) which would then increase to $30 \%$ in year 4, 40\% in Year 5 and 50\% in Years 6, 7 and 8 (Lameta, 2000). Teachers ignored this policy and continued to focus on teaching English as a subject and language of instruction based on their belief that it would enhance students’ performance during examinations. Va'a (2006) claimed that Samoa had chosen to abandon the mores which are no longer relevant and retain those that are beneficial to the Samoan "society and in foreign countries” (p. 127).

It can be argued that the introduction and implementation of the IE policy appeared to be confronted by the same resistance. As noted earlier, the majority of teachers, (particularly those in Year 8) were concerned about covering the curriculum for end of year examination. The Year 8 National Examination was related to certification, selection and monitoring of students achievement in different curriculum areas (Coxon, 1996; Education Policy and Planning Development Project Committee 1995a; Government of Western Samoa 2000). The exam driven nature of the curriculum therefore drove teachers to prepare students for exams and hence there was a spirit of competitiveness amongst the teachers to gain high pass rates. It is noted by some (Evans \& Lunt, 2002; Lloyd, 2000; Loxley \& Thomas, 2001) that the market driven policy and legislative framework of the twentieth century which emphasises academic excellence, choice and competition contradicts the underlying principles of inclusion policy. This nature of competitiveness can limit the attention given to students who have less potential. The focus is on the high achieving students 
who would secure a good exam result and thereby elevate the teachers' profile and status in the education system and the community.

Accordingly, for IE to occur, the curriculum needs to become less exam oriented and focus more on functional assessment. This could also reduce competition amongst teachers and students themselves. In this manner, teachers are more likely to treat all students equitably and develop an environment that is conducive to inclusive learning. Competition amongst teachers which could impact on students being competitive themselves can develop exclusionary barriers for students with special needs.

\section{Traditional and Contemporary Contexts}

The pattern on traditional and contemporary contexts raise a number of key issues related to formal and traditional form of education - the concept of borrowed ideas/policy. The idea of traditional and contemporary type of education was raised due to their nature of inclusiveness and exclusivity. A number of participants argued that the traditional form of education was more inclusive in nature and could be an advantage for IE. On the other hand, the more structured and exam oriented nature of the formal education system was considered very exclusive and was argued to be the cause of exclusion of the less advantaged students.

We now try to educate because of the changed goals and values of the modern society that we are in now, that we have to go to school, we have to get a piece of paper certificate. Our traditional learning does not need those things ... because of the requirements of the new education system, now this disable has become very clear ... Now there is a big challenge for these people because of the palagi system. (InCom)

It was argued that the Samoan values had undergone some change due to the introduction of the Western formal education. A Samoan individual acts upon love, care and compassion, values common to the Polynesian people (Ritchie \& Ritchie, 1979). However this appears to have changed due to the goals and values of the borrowed education system. There was a view that people are becoming more materialistic and individualistic in their thinking and actions which impacts upon the way they care for their family members. 
We can understand inclusive as part of our community even though we have moved away from the so called idea of inclusive because of education, with education we have become very competitive every man for himself ... If I think about inclusive its very much a Samoan thing but we are losing it cos we are going in one direction, we are going to be very individualistic in things that we do. (InTr)

The notion of borrowed ideas was mentioned as something that impacted on implementation. For example it was clearly stated that if ideas are initiated from outside it would be very unlikely that people will accept it graciously.

My own belief is that most of these ideas we are using are outside ideas. I'd like Samoa to take the credit for coming up with all these but deep down I know that this was very much a push from overseas and that is why it [Inclusive Education] is going to take longer. Because we don’t own the idea. And again because inclusive has been introduced through the school system. (InTr)

The formal system is very much something that we have adopted it wasn't ours so in the same way they want to sort of use it [inclusive education policy] more or less to try and manage the formal education systems of the countries either manage or to ensure that they can control it through the formal system. (InTr)

This notion of borrowed ideas is related to the work of Phillips and Ochs (2003) and their model of policy borrowed. It is important to consider the impetus for the policy, the appropriateness of the borrowed idea to the cultural context as well as whose interest it serves. It is well established that if individuals do not initiate an idea they do not feel ownership of it and thus are unlikely to take it on board.

\section{Impact of Aiga}

A common position identified was the importance of the culture in the findings. This was made so apparent because it was a clash of Western ideology with the values of a traditional society. For example, the data indicated that the family (alga) impacted on children's education regardless of government law on compulsory education. Thus, the family was the significant factor determining many aspects of educational outcome. For example, if a family was of a low socio-economically status, the child's education would be affected:

There are some families who don't wish for their children to go to their village school but end up here. For example a boy in a wheelchair who ended up here ... however it is the family's decision ... so I think the barrier lies with the parents 
when parents are reluctant/ashamed to send their kids to school ... but children should be brought to school. (FSC)

Likewise, if education is not valued by the family, the child would be disadvantaged.

With those families who don't send children to school, when asked for reason as to why children are not sent to school, the answer is that parents cannot afford to, meaning not enough money to send children to school. Some families have the money but parents are so slack, not emphasising the importance of education. Some children attend school but would stay home again when there is no money for school fees. (InCM)

These could clearly affect educational opportunities for some children and in turn impact the implementation of the IE. For example some comments pointed to this same issue:

$\ldots$ in some families, the less able the child the less priority given to this child [in terms of education] then $\mathrm{s} /$ he is left at home ... whereas this child should be given first priority like he should be brought to school for his development for his own good. (InCom)

The concept of family is a core value in Samoa, and an individual without a family would have no sense of identity. A Samoan family is one unit bonded together by a sense of responsibility towards one another. One participant referred to the school environment as a family, thus this was a clear indication of the value of family in the lives of these individuals. In relation to IE, the data indicated that IE provided a sense of belonging for the student who appears to be different thus the notion of belonging brings a sense of self worth. Although the data alluded to the notion of family values weakening, the researcher believes that this is something that is worth further investigation.

The analysis of the patterns above highlighted three themes which will now be discussed. This will be followed by a discussion of the meta theme as an overall analysis of the findings. Given the nature of the last two patterns which lay emphasis on cultural issues, these were woven together with other patterns and a meta theme was developed located as a paradox in culture and IE. 


\section{Theme 1: Understanding, Attitude and Practice Conundrum}

This theme summarises all key ideas related to understanding as well as attitude and practice of IE. This theme was particularly related to beliefs and practices of IE and there were mixed feelings regarding IE. The above discussion indicates a key point that there was a disconnection between policymakers and implementers in their interpretation and understanding of IE. The data showed that participants mainly teachers, and even teacher trainers have an inclusive mindset which did not conform to practice. Overall, participants were idealistic and/or unrealistic about the IE concept. For example, participants believed in the importance of inclusion grounded in the human rights discourse. However, in practice, there was a resistance. The teaching practice did not conform to the IE principle, for there was still a teacher directed and whole class teaching approach to learning in the classrooms, which tended to exclude students who were disadvantaged. Teachers who are the key implementers of policies were constrained by the implementation of IE due to lack of training and knowledge to deal with children with special needs. However, it was found that one of the causes of constraints for teachers was attributed to the exam oriented nature of the curriculum that drove teachers to complete the syllabus on which students would be examined. Inclusion of children with special needs therefore was perceived in a pessimistic view for it delayed the teaching of the curriculum. The understanding about IE, the attitudes and practices was a mixed bag - indicative of a number of issues such as recognizing that change is difficult, teacher involvement and training is necessary, expectations of IE were unclear.

\section{Theme 2: Interdependence and Support}

The second major theme that emerged relates to interdependence and support but it is important to note that this theme overlaps with the previous theme. The importance of support was clearly identified in this study and was perceived as either a facilitating or inhibiting strategy for IE. This support included resources to support teachers' classroom pedagogy, support through trainings, as well as social and spiritual support from colleagues, family and community members. Technical resources and facilities to support inclusion were viewed to be important. However, it was found that teachers were the most important resources. Teachers need support to teach children with special needs in an inclusive classroom. This support was through professional development and training to gain the knowledge to teach in an 
inclusive classroom. Furthermore, the social support from teachers' colleagues was deemed important for the teachers to implement ideas into the classroom. Formation of partnerships between the health sector, community and school (as support systems) was deemed crucial but most significant was the support from the family and village level in physical, social and spiritual forms. This support was deemed critical for facilitation of educational change. The concept of teacher qualities in terms of commitment and a passion to teach children with special needs was also viewed as a factor for enhancing IE. The notion of support is particularly important in a Polynesian setting and time and time again the respondents indicated the value of support for implementing IE. Teacher resistance to IE were affected by factors related to educational environment and policies, factors related to the teachers, the students, as well as those related to the school.

\section{Theme 3: Transfer of Training Issues}

This theme on the transfer of training has indicated that there was a contradiction in what teachers believe in and their actual practice. This section highlighted a number of explanations as to this discrepancy. For example, the power relationship between teachers and the school authorities was noted as one factor that could impact on passing of information from those in authority to the classroom level. The lack of support for teachers (illustrated in theme two) also appeared to discourage teachers from implementing ideas. Teachers needed to be motivated and some incentives that were highlighted concerned remuneration as well as overseas training for some teachers. However, an interesting finding in relation to motivation concerns the notion of blessings. Some participants were motivated by the notion that having a caring and kind attitude to others (children in their care) would bring blessings. This means that teachers' cultural and biblical beliefs impacted on their classroom instructions.

Given that the issue of training was highlighted as one significant reason for teacher resistance to change, teacher professional development is highly recommended. Thus, factors such as those identified by McDonald (2002) in his study on transfer of training in the cultural context, would be a useful tool for organising IE training in this context. Transfer is complex though and what was indeed indicated in this study is the complexity of the issue. For example, reference was made to before, during and after training issues that need to be considered in the implementation of IE. What 
was indicated was that a strategic plan of transfer was needed to successfully implement IE.

\section{Meta Theme: The Paradox of the Samoan Culture and IE Implementation}

In surveying the data collected and the emergent themes, a meta theme can be identified. The meta theme refers to an over arching umbrella that encapsulates much of the study. The meta theme that emerged from this research study points to a paradox that exists in the interaction of the concept of IE and Samoan culture. The findings showed that the Samoan perceptions of IE were grounded in the social as well as the medical/deficit model of disability. The data revealed that Samoan beliefs about people with disabilities hinge on the notion of competence and ability. The Samoan axiom articulated by some participants "E leai se isi e le aoga" "No one is ineffectual" implied a positive view about those who appear as having special needs in this society. There was a general view that the individual with a disability or special needs is part of the family regardless of his/her disability. The participants alluded to the fact that the Samoan culture was already inclusive prior to the introduction of the IE phenomenon. Indeed this was a very inclusive perspective grounded in the social paradigm of disability. However, the deficit/medical model of disability also emerged from the data. This raises the question- as to why there is a contradiction in beliefs and practice of the IE phenomenon in this context.

The findings indicated a contradiction between the Samoan culture and the goals of formal education which impacted on IE. The participants perceived the introduction of formal education (Western-type) in the 19th century as an exclusive paradigm which tended to exclude people. The model of policy borrowing by Ochs and Phillips (2002) can shine light on this discrepancy. Policies that are borrowed cannot be argued as value free for it brings with it values of the context from where it is borrowed (i.e., for most colonised nations, the values of the colonisers). Furthermore, it could be driven by political agendas and conditions which cause contradictions for those who are expected to implement policies.

As has been shown in the findings, some participants believed in the principles of inclusion (as being humane and moral) however this belief took on a different dimension as soon as it entered the classroom. The concept of disability that was 
absent in the more traditional type of Samoa education appeared strongly rooted in the Western form of education:

... the Western influence initiated when missionaries arrived and then education was removed from the family and this disability notion came out very clear whereas in the traditional Samoan the role of the family is education, to educate its members. So disability did not come out very obvious then because, you don't have to travel to be educated. You get educated in the village and family. Because the missionary established formal education, education is now removed from the family/homes. And so it comes to something like - "How is the kid be taken to school” "O le a faapefea la ona ave le tama i le aoga?” Is there a wheelchair? (InCom)

Traditional education according to these participants was more relevant for Samoan people when life-skills were needed to survive in this context. People with disability survived in this context for they were able to help with family chores and participate in activities:

But if there is no palagi system but have the pastors school and education within the village, whatever the village are involved in [traditional] what amazes me is that this child is not taken to school but if physically ok, he will go to the plantation, learn how to bring firewood etc that is education. So these other children attend the Western school and this kid would go to the plantation. Whereas if there have been no Western education, then all children including this poor kid would go to the plantation to clear the weeds and run chores ... (InCM)

With the Western formal education the concept of 'who is able' and 'who is not' emerged. Hence the ideology of separate education was introduced for those regarded as less able. This separatist model contradicts with the mores of the Samoan society (i.e., the collective manner in which the society is organised). The introduction of IE policy as an international initiative, driven by the belief that all children have a right to participate together in an inclusive environment (within the regular classroom) does not seem to be working well however. This is because with the 'market-driven' goals of the formal education system emphasis is only on the elitist, and the fittest scholars to do best in this educational environment. Examinations and assessments are used to assess and value students, and the status of a child with special needs is minimised. Teachers were burdened by exams and the idea of including students with special needs in the classroom who may limit 
achievement levels was considered unfavourable. One of the main issues that emerged from the findings was concerned with teachers lacking the knowledge and understanding to cope with students with special needs in the classroom and the need for teacher training. Hence a lack of knowledge and training, the imposition of external exams (which have become markers of success for both students and teachers) all impact significantly on teacher attitudes to create an inclusive environment.

Also indicated in this study is the idea that some of the Samoan values are slowly disintegrating and being replaced by the Western value of individualism 'A man for himself' as some participants noted. This thesis argues that the introduction of the Western model of education driven by individualistic values works against the collective values of a society, where people do things in a communal manner, care for their own in their own unique ways. The Samoan values of love, respect, reciprocity can be suggested to sit favourably with IE. However if, like what some of the participants believed some of these values seem to be disappearing, then the likelihood of support afforded for students with special needs is minimal.

The notion of IE need not be lost however because although there is this conflict between the individualist and collectivist orientation there are a range of options to promote an acceptable development. IE needs to be framed in a culture of support in terms of resource help, professional development, collaborative strategies, cooperative learning approaches, parent-teacher whole-school approach to help all students. This is the true spirit of IE anyhow. It seems its intentions have been subverted somewhat in Samoa.

Overall, the study indicated in a number of ways a very graphic clash of values, beliefs, attitudes and practices. This raises very important issues relating to globalisation, borrowed ideas, cultural identity and the right to choose.

\section{Multi-Systems Models: IE Interpretation and Policy Usage}

As a means of discussing IE implementation and change in Samoa, a model explaining interactions between different components of the implementation system has been developed from the study findings but set within the boundaries of policy borrowing. The systems model emphasises how the views of the participants are interpreted in context. The figure 6.1 identifies the key issues of this understanding 
and although this study centres on one component of the framework, the stakeholders' perceptions, are linked to all other aspects. This study is therefore a snap-shot view of a policy that has been borrowed and implemented. It is a study of the perspectives of a process.

The model below (figure 6.1) outlines the perceptions and experiences of the participants in the study set within a range of defining contexts. These contexts have been interpreted as 'frames of influence' that interact with one another as well as the policy implementation issues (transfer; practice, attitude and understanding; independence and support) identified by participants. The international, cultural, educational, programming and individual worldviews interact with one another to work towards meeting the needs of the students - and in turn, the key implementation issues (themes) were defined as impacting upon, and interacting with the student.

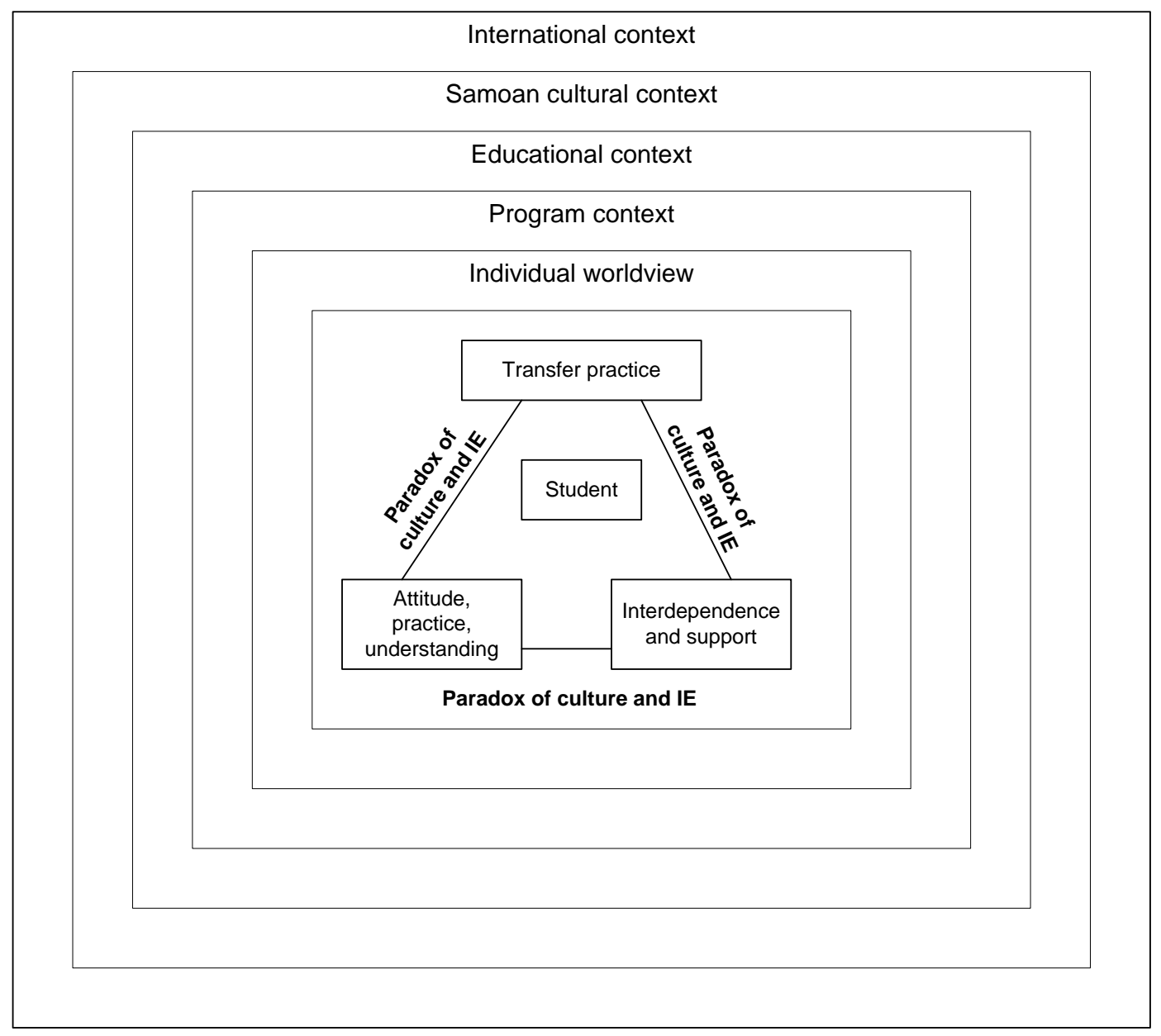

Figure 6.1 A systems model of interpreting IE implementation 
In this model the emphasis is upon interactions and influences that have resulted in the location of the different themes. The international context provides the foundation for understanding the IE concept and these understandings came to bear upon Samoa in the late 1990s and beginning of the new millennium. This philosophy and practice was imported into Samoa and interacted with the Samoan context and educational system and eventually a programme was developed to assist teachers. This resulted in the teachers, parents and others in the community being exposed and dealing with a new policy. This study examined key stakeholders perceptions of the implementation of the policy and its impact/influence upon schools and students. The three key themes that were identified were understanding-attitude-practice challenges, interdependence-support needs, and transfer problems.

This model although arising from the current study, could have benefits and relevance to other policy implementations in Samoa and indeed in other countries. Considerable caution needs to be used however if such a model is used in other contexts without fully considering specific settings and issues.

The systems model of IE implementation highlights the findings and contextual elements involved in educating students in an inclusive manner. It provides a framework for understanding the participants' perspectives. These perspectives were related to the different aspects of the process and data arose from their thoughts and experiences. However, this snapshot view of the process needs to be considered in relation to the overall policy borrowing and using phases. It would seem useful then to develop a (revised) model of borrowing that could be used for future planning and implementation of new policies. This model (figure 6.2) is a modified version of Phillips \& Och (2003) and its strength lies in the cybernetic quality and its dynamic orientation. It is not an account of something that has happened (as in the Phillips \& Ochs model) but a model to explain how borrowing could happen in the future. It is accommodating in that it permits a review of stages with the option of returning to a previous stage to revise details.

The model illustrates the process to consider to develop effective educational policies in Samoa and could also be applicable to a similar context. As noted earlier, this is a cybernetic model that is considered useful for it allows space for interactions/negotiations between stages. For example at one stage if it was realised that an aspect was overlooked or not attended to correctly in the current or previous 
stages there would be the potential for adaptation and modification at those stages.

Herein lies the strength of this model.

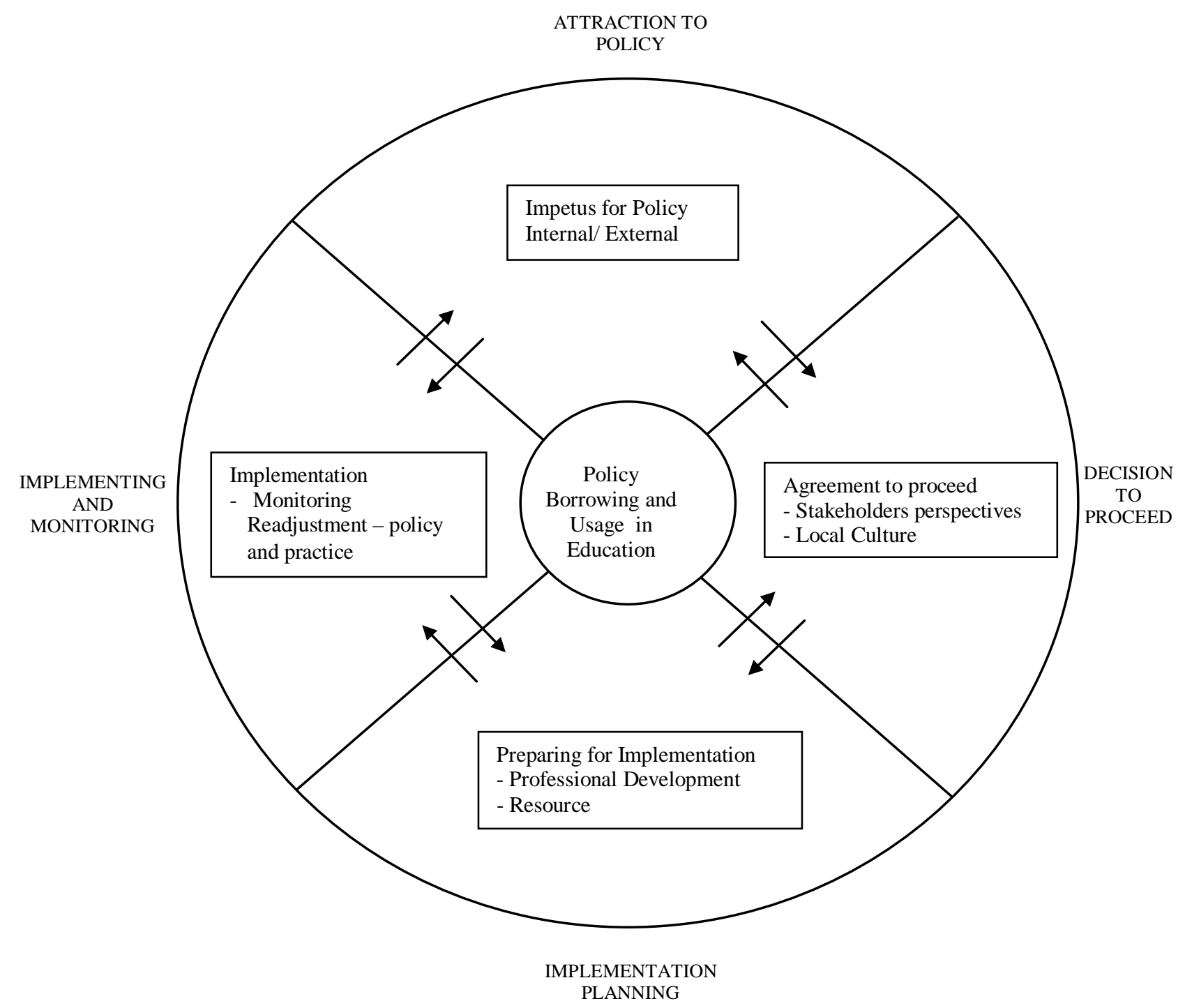

Figure 6.2 Education Policy Systems Development Model

There are four stages involved in this development model. The first stage is concerned with the impetus for policy and it illustrates the importance of considering the impulse that drives the new policy. A range of considerations are important at this stage. Did the need for policy originate from an internal force such as public awareness? Or was it driven solely by an external force driven by a global convention or international policy? Both of these issues are significant. For example, if it is an internal drive, are the forces a legitimate valid expression or a political manoeuvre? If external, how relevant will it be to the Samoan context? In both scenarios, ownership concerns are important and such issues were highlighted in the findings of the current study. 
The next stage is agreement to proceed (to adopt the new idea/policy). It is important that there is transparency of the development and that the actors have credibility and experience in policy making and policy implementation. If stakeholders feel comfortable about the value and benefits of the policy for the local context, then the likelihood of resistance is minimal.

The third stage concerns preparation for implementation and this often will involve planning of professional development and preparation of resources. As shown in this research, there is a need for professional development to prepare the individuals to implement policies. Lack of training, professional development and awareness will impact significantly on the implementation and result in resistance to change, as demonstrated in this study.

The fourth stage is implementation and the monitoring of that is particularly important. As shown in the data the monitoring process was not implemented effectively. In this current project, teachers experienced emotional strain and yet this would have been identified if more MESC support and monitoring had been undertaken. Monitoring is essential for it permits evaluation of the implementation and assesses the need for change. Furthermore, evaluation facilitates decisionmaking in terms of implementation strengths and weaknesses, permitting adjustments to policy and practices. For example, was the professional development effective? Is the policy meeting needs for which it was developed or should a new policy be developed? What outcomes are being achieved?

The value of this model lies in its dynamic nature as a process that enables forward thinking and planning and then backwards alterations, adjustments and modifications.

\section{Implications for Practice}

The outcomes of this research have clear implications for practice and provide an opportunity for the Ministry of Education, teacher educators/trainers, programme designers to assess their practices in ways to support the teachers in their classroom practices. While in theory IE seems idealistic, this study has indicated in practice that this is not the reality. Participants (mainly teachers) were hesitant about including students with special needs in the classroom. It is within this context of understanding that the following implications arise from the study: 
1. There is a need for the Ministry of Education to offer ongoing support for teachers after the implementation phase of the programme. This can be via consistent monitoring by the special education specialist based in the Ministry. There is also a need for the Ministry to provide incentives to keep teachers in the work force and to be motivated to teach in an inclusive classroom. Increase in salary is probably important but also additional resources, recognition for teachers (etc) could be planned for.

2. Effective training transfer needs to be planned. There is a need for training that is effective for teachers at the pre and in-service level so teachers will be able to transfer ideas into classroom practices. Professional development programmes need to embody the key transfer of training principles to ensure impact on the job.

3. Professional development for teacher educators is crucial. Teacher educators need the knowledge to develop training courses that cater for the needs of teachers to enable teachers to teach in an inclusive classroom. Courses on interactive teaching strategies such as cooperative pedagogies must be a consideration. Teacher educators need to understand the transfer of training technology.

4. With principals being the authority figure in school, it is important that there is good communication and transparency between the principal and teachers so teachers will gain the support to transfer ideas from a training programme into the classroom. Principals need effective leadership training themselves to incorporate a facilitative role within their role description and be aware of transfer strategies.

5. As mentioned above, there must be support systems/strategies in place for the teachers, not only to enable them to carry out their practices in the classroom, but to give them the confidence to be involved in inclusive practices. An emphasis upon self-efficacy is important if teachers are to be more comfortable with their role in IE.

6. It is also important for the programme designers and outside consultants to take into consideration support from the village level. This is because the authority from this level impacts significantly on what occurs in the village school. 
7. There is a need to utilise local expertise to develop culturally appropriate/relevance programmes that meet teachers' and students' needs in addition to undertaking training of teachers. Given their local knowledge, they have a better idea as to the cultural needs of teachers and how to meet these needs. The advantage of this is driven by the belief that locally owned programmes may be met with less resistance due to the notion that people feel ownership over such initiatives. However as aforementioned, local trainers must also be well trained themselves.

8. There needs to be an acknowledgement of the spirit of IE and how best to achieve it. It has always been intended that it be beneficial to all via its emphasis upon collaboration and equity. However, because of the pervading influence of the Western competitive educational approach it does not yet sit comfortably in Samoan schools. The student-centred learning approach and interactive teaching approaches have much to offer here, and policy makers need to be aware of the potency of such approaches to ensure academic and social outcomes.

\section{Limitations of the Study}

The findings of this study should be interpreted within the context of the research limitations. The depth and breadth of the research process needs to be considered. Only those schools who were involved in the piloting of the teachers' manual programme (toolkit) were targeted. There could have been a different perspective from teachers who did not experience the programme. Furthermore, given the phenomenological/qualitative nature of the study generalisability cannot be gauged anyhow.

Piloting of study questions for focus group interviews could have been undertaken with a focus group other than with individuals and this could have improved the manner in which focus group discussions occurred. Furthermore, it would add validity to the study if the students (special and non-special needs) views were included given that they are also key stakeholders affected by the IE policy.

Another limitation concerns geographical issues. For example, the researcher resided in another country during the study period and accordingly access to participants was limited to the number of trips that could be planned. Although adequate data was collected, some follow-up face to face interviews were not possible. A further 
limitation of this study relates to the time when the data was collected - the IE policy was implemented early this century and it may have been too early to evaluate it.

The phenomenological nature of the study certainly has a strength and presents a unique perspective. However, it also has limitations - for example it does not identify 'truth' as such. The data is based on individual's perceptions which may or may not be an accurate representation of truth. The participants' perceptions are just that.

\section{Conclusion}

This chapter has examined the main findings and its implications. It has shown that the implementation of the IE policy has suffered many challenges. Participants (mainly teachers) were supportive of IE as a pedagogical idea however it appeared not to be realistic in practice for many people. The exam-driven nature of the Samoan curriculum, and the lack of knowledge to deal with varied needs of students, placed teachers under stress and this led to antagonism and rejection of IE in practice. Most significantly and an important consideration is, if IE is to be made a reality, there is a need for much improved teacher professional development (in terms of quality and quantity ) to cater for the cultural needs of teachers. The Toolkit should be regarded as an introduction only. There is also a need for additional support strategies to enable teachers to transfer learned ideas into practice. Furthermore, a rethink is needed about the competitive goals of the school curriculum and reduce the continued exclusion of those children who appear less able. The next chapter concludes the thesis by summarising the main findings and exploring other possibilities for future research. 


\section{CHAPTER SEVEN}

\section{Conclusion}

\section{Introduction}

This chapter restates the central aim of the thesis, the methodology used to answer the research questions and summarises the main findings. The central argument of the thesis is that although the introduction and implementation of the IE (policy) has increased awareness of the rights of all children, particularly children with special needs and disabilities, to have access and equal participation in education, those with special needs and disabilities are being further marginalised and excluded in this school setting. Contradictions and lack of professional development and training which would afford teachers the knowledge to support these children in the classroom as well as onsite support for teachers is perceived to be contributing to social exclusion and further marginalisation of children with special needs and disabilities.

\section{Central Aim of the Thesis}

The purpose of this thesis was to examine Samoan values, beliefs, aspirations and perspectives about the concept of IE, as well as the practice and implementation of the IE policy in this context. It also aimed to develop a model(s) or framework(s) to facilitate additional IE initiatives and other policies in Samoa and in similar contexts. The phenomenological approach that is founded on a constructivist interpretivist paradigm, was employed to answer the research questions.

The first question examined key stakeholders' attitudes, expectations of the IE concept and their perspectives about the introduction and implementation of this policy. It aimed to discover the participants' beliefs about IE and their aspirations regarding the implementation of the IE policy in Samoa.

The second question considered teachers' views about their experiences and preparation for IE. This aimed at examining views of the implementers of policies. It aimed to ascertain the preparations teachers made in advance of the implementation of IE. Furthermore, it sought to find out how teachers felt about this IE and how they practiced it in the classrooms. 
The third question considered factors the three stakeholder (policymakers, teachers and community members) groups perceived to impact IE practices in this context. It aimed to investigate the challenges that emerged in the introduction and implementation of IE as an educational reform.

Finally, the fourth question explored the manner in which the Samoan culture and IE interacted within the educational context. This question was intended to locate whether there was interplay between the concept of IE and the Samoan culture.

\section{Summary of Main Findings}

The findings showed that while Samoan policies may have a strong focus on IE as a strategy to achieve EFA, there was a significant disconnection between the stated policies and the IE practices. This confirms that if there is lack of participation between actors at all levels, implementation of policies is unlikely to succeed.

As demonstrated in this research, participants were idealistic about IE in rhetoric however they were unrealistic in practice. Their perceived lack of knowledge about special needs and limited training affected the attitude and perspectives of the participants towards the students. Thus, the participants' perspectives were often grounded within the deficit and medical paradigm of disability. The Ministry was viewed as offering limited support for implementation of IE, especially in terms of training and professional development for teachers. The concept of support through training was one of the key findings in the study.

The study found that although support in terms of resources and facilities are crucial for implementation and practice of IE, the most useful resource was the teacher who had been well trained, competent and committed to teach students with special needs in the classroom. Training was perceived to be critical for teacher empowerment and the subsequent development of more favourable attitudes towards these students. It was also found that in order for teachers to transfer ideas learnt from training and professional development into classroom practice, support was viewed as essential as this would encourage teachers in their endeavours. The support that was most valued arose from work colleagues as well as families and community. Inherent in this notion of support was the Samoan concept of support termed 'tapua' $i$ ' which is demonstrated in a spiritual form. It plays a very significant role in the lives of the Samoan people. This support, offered in a prayer like manner, is pivotal for success 
in activities that Samoan people take part in. Thus if the village, the community and the Samoan society as a whole are supportive of the implementation of change or a new initiative, there is more likelihood of success. On the other hand, success is not probable without support.

The study found that there was a paradox that existed between participants' cultural beliefs and the nature of IE. According to the participants, IE is a local concept given the inclusive and collective nature of the Samoan culture. This view seemed to suggest that the teachers would have an inclusive mindset and should therefore be more inclusive in their classroom practice. However, this was found not to be the case in this study. It was identified that teachers and participants had a very inclusive mindset and behaved inclusively in their everyday activities outside the classroom, but as soon as they entered the classroom, practices and mind set became more exclusive. This was attributed to the goals of the formal education system, and the exam driven and competitive nature of the curriculum. In this setting the teachers tended to focus on the more able students who could not delay the teaching of the syllabus and accordingly less attention was directed towards students with special needs. Therefore there was a competition for good grades, the sole aim being to secure a good job. In this system, the more able students, 'the fittest', are the ones who survive and the less able are disadvantaged. It is a ‘sink or swim’ philosophy.

There have been calls for the Ministry of Education to consider the utilization of functional assessment as opposed to examination to assess students' performance and learning outcomes; and, as noted earlier, the importance of training and professional development for teachers cannot be overemphasized. Teachers need the skills and knowledge to manage the diverse needs of learners in an inclusive classroom, however they are unlikely to transfer these learnt skills without being supported.

The second objective of the study was the development of a model(s) for facilitating IE development and a framework of understanding of borrowed policies. Based on the findings in this study, a systems model was therefore developed for understanding IE implementation. The model posits the perceptions and experiences of the participants in the study set within a range of defining contexts called 'frames of influence'. These frames entail international, cultural, educational, programming and individual perspectives which interact with one another and work towards meeting students' needs. In a similar vein, key implementation issues or themes 
(transfer problems, practice-attitude-understanding challenges and interdependencesupport needs) that emerged from the findings also impact upon and influence the student. Further to this, a more general framework of understanding about borrowed policies has been adapted (from the work of Phillips and Ochs (2003) to further develop ideas about the antecedents, situational events and consequences of introduced policies. In utilising these two explanatory accounts, an improved understanding of IE and borrowed policies in general can be achieved.

\section{Recommendations for the Future}

Generally the literature shows that transfer of an idea, including changing attitude and behaviour, takes time and will not be achieved with one course or training session (Hoban, 2002); it is crucial that transfer be aided by giving on-going support to teachers in the classroom. This support on the ground as put into practice is essential for two reasons:

a) to ensure transfer of knowledge, skills and attitudes about IE

b) to boost morale, motivation and self efficacy. For example, recognition and acknowledging the skills teachers already have with an expectation with additional support that improved performances can be achieved. Getting the teachers to believe in their capabilities is crucial.

Therefore, MESC and NUS ongoing support to the teachers for a period of time to enable them to change their behaviour and learn new techniques is imperative. There is over-whelming evidence in this study that indicates an urgent need for training and professional development for teachers, both at the in-service and pre-service level. There is a need for MESC to organise practical training workshops for teachers, promoting the skills needed for inclusive classrooms. The importance of ongoing teacher support is critical. A number of teachers in the study commented that the Ministry did not undertake steady monitoring after teacher training workshops on IE and this type of support is crucial especially if teachers are expected to transfer ideas from training to the classroom. The previous lack of support for teachers who were involved in the integration initiative of 2001 was shown to impact negatively and teachers felt discouraged (Tufue, 2001). Ongoing support was deemed to be one of the critical elements if teachers are to change their practices. 
Although a number of participants were supportive of specialised training, this probably could not be an efficient model to adopt at this point. This is due to the small percentage of students in this category (blind and deaf who need specialised support) that are found in the classrooms. A model that is worthwhile to consider is training of resource teachers to support these students. However what is worth noting is the need for professional development for teacher educators and trainers themselves.

There is also a need for the Ministry to review approaches used to assess students' performance and learning outcomes. One suggestion would be that functional assessment be considered as opposed to examination. It is well established that not many students perform well during examinations thus the use of functional and outcome based assessment should be considered as an alternative and in this way it can be argued that the notion of equity has been achieved.

\section{Future Research Questions}

From this current research project ideas for future research needs have arisen. For example:

1. There is a need for research on achievement improvements. For example, has the IE initiative improved students' outcomes.

2. An evaluation study (based upon Kirkpatrick’s, 1998) needs to be undertaken to investigate the overall impact of the Toolkit. This approach would assess at different levels the impact of the Toolkit; data needs to be obtained on satisfaction, what was learnt, what was transferred and how the professional development impacted on the system.

3. There is a need to research the views and perspectives of students with special needs and locate their needs and best options for schooling.

4. The needs and skills of teachers should be assessed, so that planning to help all students can be implemented.

5. Investigate at the community level processes and approaches that would help leaders to promote IE ideas. 
6. Survey teacher educators to locate needs about how to support pre and in-service teachers to work in IE settings.

7. Research needs to be undertaken to evaluate the policy usage model.

8. Investigation concerning fa'aSamoa and disability is needed. For example, how do people cope with the dissonance about fa'a Samoa and the negative attitude about disability.

Undertaking such research would further help to prioritise IE as an important issue and would provide useful practical suggestions.

\section{Concluding Statements}

The research problem that has been examined in this study is that policy makers drive policy without sufficient consideration of the educational, economic, political, and cultural effects. An area of concern that was investigated in this thesis from the perspective of the participants was whether the introduction and implementation of IE would address the issue of high risk children in Samoan classrooms. The thesis concludes that the introduction of the IE policy has not sufficiently addressed the needs of children with special needs nor the teachers. The IE policy was driven by the concept that every child has a right to participate and be included in regular classrooms. Indeed, rather than creating an inclusive environment where all children participate, the introduction of the IE policy created another form of exclusion. This is partly because the Ministry did not appear to be ready for this initiative. The data has shown that the needs of teachers for training and professional development have not been fully addressed which has led to a negative attitude towards inclusion practice in the classroom. Furthermore, transfer of training strategies need to be given a high priority to facilitate impact in the classrooms. On the other hand, as suggested elsewhere in this thesis, change takes time and this research simply provides a baseline on the IE initiative after less than 10 years since its inception. It may be that given sufficient time, teachers and others may become more accommodated to IE and hence ensure more favourable outcomes. 


\section{Departing Thoughts}

IE is rooted in the concept of rights, equity, cost effectiveness, and quality in education. This raises a number of questions:

1. Should IE be imposed because it is a cost effective type of education as others argue; or has it become a requirement based on the notion of the rights of the child to participate? Is it simply cost effective if the supports and professional development are not offered... which in turn ensures it may fail.

2. How does the concept of inclusion equate to the idea of quality? Or is it promoted for social purposes only with a disregard for academic learning outcomes? Or is IE just a fashionable policy that Samoa has adopted simply because other countries have adopted it? Is it "a fashion that comes and goes" as one participant commented?

3. How will the system respond to the problem of high failure rates in the classroom as more special needs students are included? Or is it driven by a dictatorial agenda as a few participants alluded to? There was a view that IE was dictated by the government thus, whatever the government says goes, without considering the practicality of the policy.

4. Perhaps some students would be better accommodated in special schools rather than in IE schools? What is the guarantee that IE will not create another form of exclusion? This study indicated that this may already be happening. There needs to be research on the effectiveness of special schools in catering for the needs of special needs children in Samoa. Several participants commented on the need to have the two systems (special and inclusive education) operate concurrently. Perhaps because of the under-lying inclusive nature of the society, the stigma of being in a special school is not so significant for later development.

5. What are the rights and responsibilities of teachers, students, parents, community, MESC in relation to IE? How do these 'fit' with IE and segregated education?

These are questions that the researcher feels are pertinent for policymakers who implement IE policies. As noted elsewhere in the thesis, there are already a high number of at risk children identified in Samoan classrooms. A number of these children are disadvantaged not necessarily because they cannot learn but due to a 
range of variables, such as socio-economic status. Some families cannot afford their children's education and some families fail to see the value of an education. Furthermore, educational policies that overlook teachers who do not have the capacity/competence (or commitment) to deal with the various needs of students are inappropriate. There is indeed a need for the government to ensure that the IE initiative leads to more students being included within the education system and not promote another form of exclusion. Training support and professional development for teachers to attain knowledge and attitudes favourable for inclusion is a crucial requirement if the true spirit of IE is to be fostered. The value of support for teachers to support students in the classroom is the determinant that will ensure the success or failure of IE.

A concern that was raised at the outset and throughout this thesis was whether IE would address the high number of children who are at risk in the classrooms. This thesis concludes that the introduction of IE in Samoa has created another type of exclusion rather than promoting a more inclusive learning environment. It is suggested that the government needs to act more decisively in terms of planning, resource allocation and teacher professional development. Having a transparent feasible and coherent 'student-teacher' orientation would facilitate IE more readily. 


\section{References}

Abadiano, H., \& Turner, J. (2004). Professional staff development: What works? New England Reading Association Journal, 40(2), 92-97.

ADB (2005). Disability brief: Identifying and addressing the needs of disabled people. Retrieved June 24, 2010, from www.adb.org/Documents/Reports/Disabled-People-Development/disabilitybrief.pdf

Aefsky, F. (1995). Inclusion confusion: A guide to educating students with exceptional needs. Thousand Oaks, CA: Corwin Press, Inc.

Afamasaga, G. T. (1999). Quality in education. Paper presented at the World Bank/ACER Conference, Nadi, Fiji.

Afamasaga. G. T. (2006). The challenge in education. In A. So’o, U. F.Va’a, T. Lafotanoa \& J. Boon (Eds.), Samoa national human development report. Sustainable livelihoods in a changing Samoa (pp. 81-100). National University of Samoa: Centre for Samoan Studies.

Ainscow, M. (1999). Understanding the development of inclusive schools. London: Falmer Press.

Altman, B. M. (1981). Studies of attitudes toward the handicapped: The need for a new direction. Social Problems, 28(3), 321-337.

Al-Zyoudi, M. (2006). Teachers' attitudes towards inclusive education in Jordanian schools. International Journal of Special education. 21(2), 55-62.

Antonak, R. F. (1994). Development and psychometric analysis of an indirect measure of attitudes toward individuals with mental retardation using the errorchoice method. Mental Retardation, 32(5), 347-355.

Asian Development Bank (2000). Country assistance plan 2001-2003: Samoa. Manila: The Author.

Auva'a, T. (2003). Continuity and change: Education policy and historiography of education in Western Samoa. Unpublished Masters Thesis. James Cook University.

Avramidis, E., Bayliss, P., \& Burden, R. (2000). A survey into mainstream teachers' attitudes towards the inclusion of children with special educational needs in the ordinary school in one Local Education Authority. Educational Psychology, 20(2), 191-211.

Avramidis, E., \& Norwich, B. (2002). Mainstream teachers' attitudes towards inclusion/integration: A review of the literature. European Journal of Special Needs Education, 17(2), 129-147.

Baker, J. M., \& Zigmond, N. (1990). Are regular education classess equipped to accommodate students with learning disabilities? Exceptional children, 56, 525526. 
Ball, S. J. (1987). The micro-politics of the school: Towards a theory of school organisation. London: Methuen.

Banerji, M., \& Dailey, R. (1995). A study of the effects of an inclusion model on students with specific learning disabilities. Journal of Learning Disabilities, 28(8), 511-522.

Barkley, R. A. (1998). Attention deficit hyperactivity disorders: A handbook for diagnosis and treatment ( $2^{\text {nd }}$ ed.). New York: Guilford.

Barnartt, S. N., \& Kabzems, V. (1992). Zimbabwean teachers' attitudes towards the integration of pupils with disabilities into regular classrooms. International Journal of Disability, Development and Education, 39(2) 135-146.

Barnes, C., Mercer, G., \& Shakespeare, T. (1999), Exploring disability; A sociological introduction. Malden, MA: Polity Press.

Barrington, J. M. (1968). Education and national development in Western Samoa. Unpublished PhD Thesis. Victoria University of Wellington, Wellington, NZ.

Barry, A. L. (1995). Easing into inclusion classrooms. Exceptional Leadership, 52(4), 4-6.

Barton, L (1996). Sociology and disability: some emerging issues. In L. Barton (Ed.), Disability and society: Emerging issues and insights (pp. 3-17). New York: Addison Wesley Longman.

Bell, J. (1999). Doing your research project ( $3^{\text {rd }}$ ed.). Buckingham: Open University Press.

Bellanca, J. (1996). Designing professional development for change. A systemic approach. Highett, Victoria, Australia: Hawker Brownlow.

Bennett, T., Deluca, D., \& Burns, D. (1997). Putting inclusion into practice: perspectives of teachers and parents. Exceptional Children, 64, 115-131.

Berger, P. L., \& Luckmann, T. (1967). The social construction of reality. A treatise in the sociology of knowledge. Garden City, NJ: Anchor Books.

Berryman, J. D. (1988). Attitudes toward mainstreaming: Factorial validity for a lay population. Educational and Psychological Measurement, 48, 231-236.

Biklen, D. (Ed.). (1985). The complete school: Integrating special and regular education. New York: Columbia University, Teachers' College Press.

Biklen, D. (1992). Schooling without labels: Parents, educators and inclusive education. Philadelphia: Temple University Press.

Blasé, J. (1986). A qualitative analysis of sources of teachers stress: Consequences for performance. American Educational Research Journal, 23, 13-40.

Blasé, J. (1987). Dimensions of effective school leadership: the teacher's perspective. American Educational Journal, 24(4), 598-610. 
Blasé, J. (1988b). Dimensions of effective school leadership: the teacher's perspective. American Educational Research Journal, 24(4), 589-610.

Blasé, J., \& Anderson. G. (1995). The micropolitics of educational leadership:From control to empowerment. Wellington House: Cassell.

Borbasi, S. A. (1996). Capturing the experience of the clinical nurse specialist through phenomenology. In P. Willis \& B. Neville (Eds.), Qualitative research practice: Adult education. Ringwood, Victoria: David Lovell Publishing,

Bowen, G. (2009). Document analysis as a qualitative research method. Qualitative Research Journal, 9(2) 27-40.

Boyd, D., \& Bee, H. (Eds.). (2006). Lifespan development (4 ${ }^{\text {th }}$ ed.). Pearson Education, Inc.

Brennan, B. (2002). A secondary college principal's perspective on student safety, security and success. In D. Stewart (Ed.), Legal risk management, safety security and success in education. Proceedings of the $11^{\text {th }}$ annual conference of the Australia and New Zealand Education Law Association, Brisbane, 47-56.

Bradshaw, L. G. (2003). Brunei SENA teachers speak out. Studies in Education, 8(1), $1-10$.

Bradshaw, L., \& Lawrence, M. (2006). Attitudes to and concerns about inclusive education: Bruneian in-service and pre-service teachers. International Journal of Special Education, 21(1), 35-41.

Brinker, R., \& Thorpe, M. (1983). Evaluation of integration of severely handicapped students in regular classrooms and community settings. Princeton, NJ: Educational Testing Service.

Brinker, R., \& Thorpe, M. (1984). Integration of severely handicapped students and the proposition of IEP objectives achieved. Exceptional Children, 51, 168-175.

Broadfoot, P., \& Pollard, A. (2000). The changing discourse of assessment policy: The case of English primary education. In A. Filer (Ed.), Assessment: Social Practice and Social Product (pp. 11-22). London: Routledge and Falmer.

Brooks, L., \& Dansereau, D. F. (1987). Transfer of information: An instructional perspective. In S. M. Cormier \& J. D. Hagman (Eds.), Transfer of learning: Contemporary research and applications (pp. 121-150). San Diego, CA: Academic Press, Inc.

Brown, M., McCalum, B., Taggart, B., \& Gipps, C. (1997). The validity of national testing at age 11: The teacher's view. Assessment in Education 4(2), 271-293.

Brown, R. C. (2005). Inclusive education in Middle Eastern cultures: The challenge of tradition. In D. Mitchell (Ed.), Contextualizing inclusive education: Evaluating old and new international perspective (pp. 253-278). Oxfordshire: Routledge Taylor \& Francis.

Bryman, A. (2004). Social research methods ( $2^{\text {nd }}$ ed.). New York: Oxford University Press. 
Campbell, B. (1997, April). Phenomenology as research method. Seminar Paper ALRNNV Seminars. Victoria University of Technology. Retrieved July, 28, 2009 from http://www.staff.vu.edu.au/syed/alrnnv/papers/bev.html

Callagher, J. J. (2006). Driving change in special education. Baltimore: Paul H. Brookes Publishing Co.

Chang, V., \& Chin, K. L. (1999). Cultural issues in teaching and learning. Journal of the Australian and New Zealand Student Services Association, 14, 3-16.

Clark, C., Dyson, A., Millward, A., \& Skidmore, D. (1995). Dialectical analysis, special needs and schools as organizations'. In C. Clark., A. Dyson \& A. Millward (Eds.), Towards inclusive schools? (pp. 78-95). London: David Fulton.

Clark, C., Dyson, A., Millward, A., \& Skidmore, D. (1997). New direction in special education: Innovations in mainstream schools. London: Cassell.

Cohen, L., Manion, L., \& Morrison, K. (2000). Research methods in education (5 $^{\text {th }}$ ed.). London: Routledge Falmer.

Cohen, A. R. (2005). The voice of the field of special education: Historical context and Issues. In A. Mungai \& E. Kogan (Eds.), Pathway to inclusion: Voices from the field (pp. 1-28). Lanham: University Press of America.

Coleridge, P. (1993). Disability, liberation and development. Oxford: Oxfam.

Collins, B. C., Branson, T. A., Hall, M., \& Rankin, S. W. (2001). Teaching secondary students with moderate disabilities in an inclusive academic classroom setting. Journal of Developmental and Physical Disabilities, 13(1), 41-59.

Conte, A. E., (1994). Blurring the line between regular and special education. Journal of Instructional Psychology, 21(2), 103-113.

Corbin, J., \& Strauss, A. (2008). Basics of qualitative research: Techniques and procedures for developing grounded theory ( ${ }^{\text {rd }}$ ed.). Thousand Oaks, CA: Sage.

Coxon, (1996). The politics of modernisation: Education in Western Samoa. Unpublished PhD Thesis, University of Auckland, Auckland.

Coxon, E. (2003). "Education policy-making at the intersection.” In E. Coxon \& A. Taufe'ulungaki, A. (Eds.), Global/local intersections: Researching the delivery of aid to Pacific Education. (pp. 67-86). Auckland: Research Unit of Pacific Education, University of Auckland.

Creswell, J. W. (2003). Research design qualitative, quantitative, and mixed methods approaches $\left(2^{\text {nd }}\right.$ ed.). Thousand Oaks: Sage Publications.

Crisp, C. (2007). The efficacy of intelligence testing in children with physical disabilities, visual impairment and/or the inability to speak. International Journal of Special Education 22(1), 137-141.

Crotty, M. (1998). The foundations of social research: Meaning and perspective in the research process. St. Leonards: Allen \& Unwin. 
Cuban, L. (1990). Reforming again, again, and again. Educational Researcher, 19(1), 3-13.

Cullinan, D., Sabornie, E. J., \& Crossland, C. L. (1992). Social mainstreaming of mildly handicapped students. The Elementary School Journal, 92(3), 339-351.

Daniel, H., \& Garner, P. (1999). Introduction. In H. Daniel \& P. Garner (Eds.), World Yearbook of Education 1999: Inclusive education (pp. 1-10). London: The Stationery Office.

Daveta, M. L. (2009). Inclusive education for children with disabilities in Fiji: Teacher perspectives and attitudes. Unpublished Master's Thesis, Waikato University.

Davidson, J. W. (1967). Samoa mo Samoa: The emergence of the independent state of Western Samoa. Melbourne: Oxford University Press.

Darocill, C. E. (1989). Teacher attitudes towards mainstreaming. Canadian Journal of Special Education, 5, 1-13.

Deese, J. (1958). Transfer of training: The psychology of learning. NY: McGrawHill.

Denscombe, M. (2007). The good research guide ( $3^{\text {rd }}$ ed.). For small-scale social research projects. Maidenhead, Berkshire, England: McGraw Hill/Open University Press.

Denzin, N. K. (1970). The research act: A theoretical introduction to sociological methods. New York: Aldine.

Dolgoy, R. (2000). The search for recognition and social movement emergence: Towards an understanding of the transformation of the fa'afafine in Samoa. Unpublished PhD Thesis, University of Alberta, Canada.

Doll, E. A. (1972). A historical survey of research and management of mental retardation in the United States. In E. P. Trapp \& P. Himelstein (Eds.), Readings on the exceptional child ( $2^{\text {nd }}$ ed.), (pp. 47-97). New York: Appleton CenturyCrofts.

Dunn, L. (1968). Special education for the mildly retarded: Is much of it justifiable? Exceptional Children, 35, 5-22.

Dupoux, E., Wolman, C., \& Estrada, E. (2005). Teachers' attitudes toward integration of students with disabilities in Haiti and the United States. International Journal of Disability, Development and Education, 52(1), 45-60.

Duranti, A. (1990). Doing Things with words: conflict, understanding, and change in a Samoan Fono. In K. Gegeo-White \& G. M. White (Eds.), Disentangling: conflict discourse in Pacific Societies (pp. 459-89). Stanford, CA: Stanford University Press. 
Duranti, A. (1992). Language in context and language as context: The Samoan respect vocabulary. In A. Duranti \& C. Goodwin (Eds.), Rethinking context: Language as an interactive phenomena (pp. 77-99). Cambridge: Cambridge University Press.

Durrheim, K., \& Wassenaar, D. (1999). Communicating design: Writing and evaluating research proposals. HOP: Press Pretoria.

Dyson, A., \& Millward, A. (1997). The reform of special education or the transformation of mainstream schools. In S. J. Pijl, C. Meijer \& S. Hegarty (Eds.), Inclusive education: A global agenda (pp. 51-67). London: Routledge.

Edman, I. (Ed.). (1928). The works of Plato. New York: Simon \&Schuster.

Engelbrecht, P., \& Snyman, H. (1999). Educating pre-service teachers in inclusive education: Reflections of the Stellenbosch experience in South Africa. International Journal of Special Education, 14(1), 96-100.

Epps, S., \& Tindal, G. T. (1987). The effectiveness of differential programming in serving students with mild handicaps: Placement options and instructional programming. In M. C. Wang, M. C. Reynolds \& H. J. (Eds.), Handbook of special education: Research and practice. Learner characteristics and adaptive education (pp. 213-248). New York: Pergamon Press.

Ehrich, L. C. (1996). The difficulties of using phenomenology: A novice researcher's experience. In P. Willis \& B. Neville (Eds.), Qualitative research practice in adult education. Ringwood, Victoria: David Lovell Publishing.

Elkins, J. van Kraayenoord, C. E., \& Joblin, A. (2003). Parents' attitudes to inclusion of their children with special needs. Journal of Research in Special Educational Needs, 3(2), 122-129.

Elliot, S. N., \& Sheridan, S. M. (1992). Consultation and teaming: Problem solving among educators, parents and support personnel. The Elementary School Journal, 92(3), 315-338.

Esera, E. (1996, 11 March-16 October). Teacher education quality improvement project: Report on the evaluation of the teachers' inservice programme in Western Samoa, Apia. Department of Education.

Espin, C.A. (1998). Individualized education programs in resource and inclusive settings. The Journal of Special Education, 32(3), 164-174.

Evans, J., \& Lunt, I. (2002). Inclusive education: Are there limits? European Journal of Special Education. 17(1), 1-14.

Fairbairn-Dunlop, P. (1991). 'E au le Inailau a Tamaitai': Women, education and development Western Samoa. Unpublished $\mathrm{PhD}$ Thesis, Macquarie University, Sydney.

Fairbairn, D., \& Associates. (1998). Case study social impacts of economic reforms Samoa: 1998. Suva, Forum Secretariat. 
Fakolade, O. A., Adeniyi, S. O., \& Tella, A. (2009). Attitude of teachers towards the inclusion of special needs children in general education classroom: The case of teachers in some selected schools in Nigeria. International Electronic Journal of Elementary Education, 1(3), 155-169.

Ferguson, P., \& Asch, A. (1989). Lessons from life: Personal and parental perspectives on school, childhood, and disability. In D. Biklen, A. Ford, \& D. Ferguson (Eds.), Disability and society (pp. 108-140). Chicago: National Society for the Study of Education.

Ferguson, D. L., \& Ferguson, P. M. (1996). Communicating adulthood. Topics in Language Disorders, 16(3), 52-67.

Figiel, S. (1996). Where we once belonged. Auckland: Pasifika Press.

Fishbein, M., \& Ajzen, I. (1975). Belief, attitude, intention, and behaviour: An introductory to theory and research. Reading, MA: Addison-Wesley.

Fitzgerald, M. (1993). Culture and disability in the Pacific: When does a difference make a difference? Network, 3(2), 7-13.

Florian, L. (1998). Inclusive Practice: What, why and how? In C. Tilstone, L. Florian \& R. Rose (Eds.), Promoting inclusive practice (pp. 1-26). London and New York: Routledge Falmer.

Florian, L. (2005, reprinted). Inclusive practice: what, why and how? In K. Topping and S. Maloney (Eds.), The Routledge/Falmer reader in inclusive education (pp. 29-40). London: Routledge/Falmer.

Florian, L. (Ed.). (2007) The Sage handbook of special education. London: Sage Publications.

Forlin, C., Jobling, A., \& Caroll, A. (2001). Preservice teachers' discomfort levels toward people with disabilities. The Journal of International Special Needs Education, 4, 32-38.

Forlin, C. (2003). Pre-service teacher education: Involvement of students with intellectual disabilities. International Journal of Learning. 10, 317-326.

Forlin, C. (2004). Promoting inclusivity in Western Australian schools. International Journal of Inclusive Education, 8(2), 183-200.

Forlin, C., Hattie, J., \& Douglas, G. (1996). Inclusion: Is it stressful for teachers? Journal of Intellectual and Developmental Disability, 21, 199-217.

Forest, M. (1987a). More education integration. Downsview, Ontario: G. Allan Roeher Institute.

Forest, M. (1987b). Start with the right attitude. Entourage, 2, 11-13.

Forest, M. (1988). Full inclusion is possible. IMPACT, 1, 3-4.

Forlin, C. (1995). Educators' beliefs about inclusive practices in Western Australia. British Journal of Special Education, 22(4), 179-185. 
Forlin, C., Douglas, G., \& Hattie, J. (1996). Inclusive practices: How accepting are teachers? International Journal of Disability, 43, 119-133.

Freeman, D. (1984). Margaret Mead and Samoa: Making and unmaking of an anthropological myth. Cambridge: Harvard University Press.

Fuchs, D., \& Fuchs, L. (1994). Inclusive schools movement and the radicalization of special education reform. Exceptional Children, 60(4), 294-309.

Fulcher, G. (1989). Disabling policies. London: Falmer.

Fullan, M. G. (1991). The new meaning of educational change. London: Cassell.

Fullan, M., \& Miles, M. B. (1992). Getting reform right: What works and what doesn’t. Phi Delta Kappan, 73, 745-752.

Fullan, M. (1993). Change forces. New York: Falmer Press.

Gallagher, J. (2006). Driving change in special education. Baltimore: Paul H. Brookes Publishing Co.

Gallagher, J., \& Clifford, R. (2000). The missing support infrastructure in early childhood. ECRP, 2(1), 1-26.

Garet, M., Porter, A., Desimone, L., Birman, B., \& Yoon, K. (2001). What makes professional development effective? Results from a national sample of teachers. American Education Research Journal, 38(4), 915-945.

Gerber, E. R. (1975). The cultural patterning of emotions in Samoa. Unpublished $\mathrm{PhD}$, University of California, San Diego.

Giangreco, M. F., Cloninger, C. J., \& Iverson, V. S. (1998). Choosing outcomes and accommodations for Children (COACH): A guide to educational planning for students with disabilities ( $2^{\text {nd }}$ ed.). Baltimore: Paul H Brookes Publishing Co.

Giangreco, M. F., Dennis, R., Cloninger, C., Edelman, S., \& Schattman, R. (1993). I've counted Jon: Transformational experiences of teachers educating students with disabilities, Exceptional Children, 59(4), 359-372.

Giangreco, M. F. (1997). Key lessons learned about inclusive education: summary of the 1996 Schonell Memorial Lecture. International Journal of Disability, Development and Education, 44(3), 193-206.

Gilson. P. (1970). Samoa 1830 to 1900: The politics of a multi-cultural community. London: Oxford University Press.

Gillies, R. M. (2004). The effects of cooperative learning on junior high school students during small group learning. Learning and Instruction, 14(2), 197-213.

Giorgi, A., \& Giorgi, B. (2003). Phenomenology. In J. A. Smith. (Ed.), Qualitative Psychology: A Practical Guide to Research Methods (pp. 25-50). London: Sage.

Gipps, C. (1994). Development in educational assessment: What makes a good test? Assessment in Education 1(3), 283-291. 
Goggin, G. \& Newell, C. (2003). Digital disability: The social construction of disability in new media. Massachusetts, USA: Rowman \& Littlefield.

Good, T., \& Brophy, J. (1990). Looking in classrooms (5 ${ }^{\text {th }}$ ed.). Harper and Collins: New York.

Gould, S. J. (1981). The mismeasure of man. New York: Norton.

Government of Samoa. (1995). Western Samoa education policies 1995-2005. Education policy and planning development project. Apia, Samoa: Author.

Government of Samoa. (2001). Housing and population census, Statistics Department, Samoa.

Government of Samoa. (2002). Strategy for the development of Samoa 2002-2004. Economic opportunities for all. Apia, Samoa: Treasury Department Economic Policy Planning Division.

Government of Samoa. (2003). Education statistical digest 2003. Policy, planning and research division. Apia, Samoa: Office of the Minister of Education Sports and Culture.

Government of Samoa. (2004). Demographic indicators, Statistical Services Division, Ministry of Finance Retrieved October 1, 2006 from http://www.spc.org.nc/prism/Country/WS/stats/soc/Demographic.htm

Government of Samoa. (2005). Strategy for the development of Samoa 2005-2007: 'Enhancing people choices'. Apia, Samoa: Author.

Government of Samoa. (2006a). Strategic policies and plan July 2006-June 2015. Apia, Samoa: Office of the Minister of Education Sports and Culture of Samoa.

Government of Samoa. (2006b). National curriculum policy framework. Apia, Samoa: Office of the Minister of Education Sports and Culture of Samoa.

Government of Samoa. (2006c). Special needs education policy: A policy about the importance of special education within an inclusive educational approach for all. Apia, Samoa: Office of the Minister of Education Sports and Culture of Samoa.

Government of Samoa. (2007). Education for all. Mid-decade assessment report. Apia, Samoa: Author.

Government of Samoa. (2008). Strategies for the Development of Samoa, 20082012. Apia, Samoa: Author.

Graffam, J. (2005). Just think about it. Disparity: Policy, Practice \& Argument, 3(1), $15-16$.

Grattan, F. J. H. (1948). An introduction to Samoan custom. Apia, Western Samoa: Samoa Printing \& Publishing Company Ltd.

Graneheim, U. \& Lundman, B. (2004). Qualitative content analysis in nursing research: concepts, procedures and measures to achieve trustworthiness. Nurse Education Today, 24,105-112. 
Guaralnick, M. J. (1990). Major accomplishments and future directions in early childhood mainstreaming. Topics in Early Childhood Special Education, 10(2), $1-17$.

Guskey, T. R. (1986). Staff development and the process of teacher change. Educational Researcher, 15(5), 5-12.

Guskey, T. R. (1995). Professional development in education: In search of the optimal mix. In T. R. Guskey \& M. Huberman (Eds.), Professional development in education: New paradigms \& practices (pp. 114-131). New York: Teachers College Press.

Guskey, T. R. (2002). Professional development and teacher change. Teachers and Teaching Theory and Practice, 8(3/4), 381-394.

Guskey, T. R. (2003). What makes professional development effective? Phi Delta Kappan, 84(10), 748-750.

Hallahan, D. P., \& Kauffman, J. M. (2003). Exceptional learners: Introduction to special education ( $9^{\text {th }}$ ed.). Boston: Allyn \& Bacon.

Harris, R. \& Stephenson, J. (2003). Inclusion of students with severe intellectual disability in Italy. Special Education Perspectives, 12, 65-70.

Harris, L., \& Associates, (1986). The ISD survey of disabled American into the mainstream. New York: Louis Harris and Associates.

Harris, L \& Associates. (1987). The ICD survey 11: Employing disabled American. New York: Louis Harris and Associates.

Harris, L \& Associates. (1989). The ICD survey 111: A report card on special education. New York: Louis Harris and Associates.

Harth, R. (1977). Attitudes and mental retardation: Review of the literature. In C. J. Drew, M. L. Hardman, \& H. P. Bluhm (Eds.), Mental retardation: Social and educational perspectives (pp. 4-14). St Louis: Mosby.

Haskins, R., \& Gallagher, J. (1981). Models for analysis of social policy: An introduction Norwood, NJ: Ablex.

Heiman, T. (2004). Teachers coping with changes: Including students with disabilities in mainstream classes: An international view. International Journal of Special Education, 19(2).

Henderson, B. (1994). Inclusion: Educating students with and without disabilities. New England Journal of Public Policy, 10, 99-105.

Hoban, G. F. (2002). Teacher learning for educational change: A systems thinking approach. Buckingham, UK: Open University Press.

Hobbs, T. \& Wrestling, D. L. (1998). Promoting successful inclusion through collaborative problem solving. Teaching Exceptional Children, 31(1), 12-19. 
Hofstede, G. (1986). Cultural differences in teaching and learning. International Journal of Intercultural Relations, 10, 301-320.

Hofstede, G. (1980). Culture's consequences: International differences in work related values, Thousand Oaks, CA: Sage Publications, Inc.

Huang, H. H., \& Diamond, K. E. (2009). Early childhood teachers' ideas about including children with disabilities in programmes designed for typically developing children. International Journal of Disability, Development and Education 56(2), 169-182.

Huffer, E. \& So’o, A. (2001). Samoan views on consensus and dissent. In T. Lafotanoa, A. So’o, S. Lameta, K. Afamasaga-Fuata'i, S. Vaai, F. P-U. Aiavao \& E. Esera (Eds.), Measina a Samoa 2000, 28-33. National University of Samoa, Institute of Samoan Studies.

Hynds, A., \& McDonald, L. (2009). Motivating teachers to improve learning for culturally diverse students in New Zealand: Promoting Māori and Pacific Islands students achievement. Professional Development in Education, 36(3), 525-540

Idol, L. (1997). Key questions related to building collaborative and inclusive schools. Journal of Learning Disabilities, 30(4), 384-394.

Irmsher, K. (1995). Inclusive education in practice: The lessons of pioneering school districts. Eugene, OR: Oregon Schools Study Council, University of Oregon. (ERIC Document Reproduction Service No. ED 380913.

Jackson, S. E., Schwab, R. L., \& Schuler. R. A. (1986). Toward an understanding of the burnout phenomenon. Journal of Applied Psychology. 71(4): 630-40.

Jahnukainen, M., \& Korhonen, A. (2003). Integration of students with severe and profound intellectual disabilities into the comprehensive school system: Teachers' perceptions of the education reform in Finland. International Journal of Disability, Development and Education, 50, 169-180.

Jenkins, J. R., Pious, C. G., \& Jewell, M. (1990). Special education and the regular education initiative: Basic assumptions. Exceptional Children, 56(6), 479-491.

Jenkins, H. J. (2002). A continuum based approach to inclusive policy and practice in regular schools. Special Education Perspectives, 11, 56-71.

Jindal-Snape, D. Douglas., W., Topping, K. J., Kerr, C., \& Smith, E. F. (2005). Effective education for children with autistic spectrum disorder: Perceptions of parents and professionals. The International Journal of Special Education, 20(1), 77-87.

Johnson, D. (2006). Comparing the trajectories of educational change and policy transfer in developing countries. Oxford Review of Education, 32(5), 679-696.

Johnson, D., \& Johnson, R. (1987). Learning together and alone. Englewood Cliffs, New Jersey: Prentice Hall.

Johnson, D. W., \& Johnson, R. T. (1989). Leading the cooperative school. Edina, MN: Interaction. 
Johnson, D., \& Johnson, R. (1984). Classroom learning structure and attitudes toward handicapped students in mainstreamed settings: A theoretical model and research evidence. In R. Jones (Ed.), Attitudes and attitude change in special education (pp. 118-142). Reston, VA: Council for Exceptional Children.

Jones, R. L., \& Guskin, S. L. (1984). Attitudes and attitude change in special education. In R. L. Jones (Ed.), Attitudes and attitude change in special education: Theory and practice (pp. 1-20). Reston VA: Council for Exceptional Children.

Jordan, L., \& Goodey, C. (1996). Human rights and school change: The Newham story. Bristol, UK: Centre for Studies in Inclusive Education.

Kagan, D. (1992). Professional growth among pre-service and beginning teachers. Review of Educational Research, 62(2), 129-170.

Karagiannis, A., \& Cartwright, G. F. (1990). Attitudinal research issues in integration of children with mental handicaps. McGill Journal of Education, 25(3), 369-382.

Karagiannis, A., Stainback, W., \& Stainback, S. (1996). Rationale for inclusive schooling. In S. Stainback \& W. Stainback (Eds.), Inclusion: A guide for Educators (pp. 3-15). Baltimore: Paul Brookes Publishing.

Katsiyannis, A., Conderman, G., \& Franks, D. (1995). State practices regarding inclusion. Remedial and Special Education, 16(5), 279-287.

Kauffman, J. (1994). Places of change: Special education's power and identity in an era of educational reform. Journal of Learning Disabilities, 27(10), 610-618.

Kauffman, J. M., \& Hallahan, D. P. (1995). The illusion of full inclusion: A comprehensive critique of a current special education bandwagon. PRO-ED, Inc., 8700 Shoal Creek Blvd, Austin, TX 78757-6897.

Keesing, F. M. (1934). Modern Samoa. Stanford: Stanford University Press.

Kerber, A., \& Smith, W. (1962). Educational issues in a changing society. Toronto, Canada: Ambassador Books.

Key, J. P. (1997). Qualitative research. Retrieved July 24, 2007, from http://www.okstate.edu/ag/agedcm4h/academic/aged5980a/5980/newpage21. htm

Kirkpatrick, D. L. (1998). Evaluating training programs: The four levels ( $3^{\text {rd }}$ ed.). San Francisco, CA: Berrett-Koehler Publisher Inc.

Kisanji, J. (1999, March). Historical and theoretical basis of inclusive education. Keynote address for the workshop on inclusive education in Namibia; The challenge for teacher education. Khomasdal, Windhoek, Namibia.

Klinger, J. K. (2004). The science of professional development. Journal of Learning Disabilities, 37(3), 248-255. 
Knight, T. (2000). Inclusive education and educational theory: Inclusive for what? Melbourne Studies in Education, 41, 17-43.

Krefting, L. (1991). Rigor in qualitative research: The assessment of trustworthiness. The American Journal of Occupational Therapy, 45(3), 214-222.

Kuba, N. (1995). Report of persons with disabilities in Western Samoa. Japanese Overseas Cooperation Volunteers, Samoa Office.

Lameta, E. (2005, September). Non-Formal educ ation in Samoa: Report of the research study. Apia.

Leberman, S., McDonald, L., Doyle, S. (2006). The transfer of learning: Participants' perspectives of adult education and training. Aldershot, UK: Gower.

Lieberman, L. M. (1988). Preserving Special Education. Weston: Nobb Hill Press Inc.

Lene, D. (2005). The development of policy planning and support services for people with disabilities (15 years + ) in Samoa. Unpublished Masters Thesis, University of Newcastle. Australia.

LeRoy, B., \& Simpson, C. (1996). Improving students outcomes through inclusive education. Support for Learning, 11(1), 32-36.

Lewis, A. (1995). Children's understanding of disability. London: Routledge.

Leyser, Y., \& Tappendorf, K. (2001). Are attitudes and practices regarding mainstreaming changing? A case of teachers in two rural school districts. Education, 121(4), 751-761.

Lilly, M. S. (1988). The regular education initiative: A force for change in general and special education. Education and Training in Mental Retardation, 23, 253260.

Lincoln, Y. S., \& Guba, E. G. (1985). Naturalistic inquiry. Beverly Hills, California: Sage.

Lincoln, Y. S., \& Guba, E. G. (2000). Paradigmatic controversies, contradictions, and emerging confluences. In N. K. Denzin \& Y. S. Lincoln (Eds.), Handbook of qualitative research ( $2^{\text {nd }}$ ed., pp. 163-188). Thousand Oaks, CA: Sage.

Lindsay, G. (2003). Inclusive education: critical perspective. British Journal of Special Education, 30 (1), 3-12.

Liu, D. M. (1991). A politics of identity in Western Samoa. PhD Thesis, University of Hawai'i.

Livneh, C., \& Livneh, H. (1999). Continuing professional education among educators: predictions of participation in learning activities. Adult Education Quarterly, 49, 91-106. 
Lloyd, C. (2000). Excellence for all children - false promises! The failure of current policy for inclusive education and implications for schooling in the $21^{\text {st }}$ century. International Journal of Inclusive Education, 4(2), 133-151.

Loreman, T. (2002). Teacher education and inclusion. Paper presented at the XIIIth World Congress of Inclusion International, Melbourne, Australia.

Lortie, D. C. (1975). School teacher: A sociological study. Chicago: University of Chicago Press.

Loxley, A., \& Thomas, G. (1997). From policy to the real world: An international comparison of special needs administration. Disability and Society, 12(2), 27391.

Fullan, M. (1993). Change forces, London: Falmer.

MacMillan, D. L., Semmel, M. I., \& Gerber, M. M. (1995). The social context: Then and how. In D. P. Hallahan (Ed.), The illusion of full inclusion: A comprehensive critique of a current special education bandwagon. Austin, TX: PRO-ED.

Macpherson, C. (1994). Changing patterns of commitment to island homelands: A case study of Westerns Samoa. Pacific Studies, 17(3), 83-116.

Madden, N., \& Slavin, R. (1983). Mainstreaming students with mild academic handicapped: Academic and social outcomes. Review of Educational Research, 53, 519-569.

Madriz, E. (2000). Focus groups in feminist research. In N. K. Denzin \& Y. S. Lincoln (Eds.), Handbook of qualitative research ( $3^{\text {rd }}$ ed., pp. 641-649). Thousand Oaks CA: Sage.

Mageo, J. M. (1991). Male transvestism and cultural change in Samoa. American Ethnologist 19(3), 443-59.

Mageo, J. M. (1997). Samoa, on the Wilde side: Male transvestism, Oscar Wilde, and liminality in making gender. Ethos, 24(4), 588-627.

Ma'ia'i, F. (1957). A study of the developing pattern of education and the factors influencing that development in New Zealand's Pacific dependencies.

Unpublished Master's Thesis, Victoria University, New Zealand.

Male, A., \& Lameta, E. (1999). Curriculum reconstruction to achieve Samoa's National goals. In Educating Pasefika positively: Pacific Islands Educators' Conference. Auckland, Ministry of Education.

Marshall, C., \& Rossman, G. B. (2006). Designing qualitative research (4 ${ }^{\text {th }}$ ed.). Thousand Oaks: Sage Publications.

Marston, D. (1996). A comparison of inclusion only, pull-out only, and combined service. The Journal of Special Education, 30(2), 121-132.

Matson, J., Mulick, J. (Eds.). (1991). Handbook of mental retardation (2 ${ }^{\text {nd }}$ ed.). Elmsford, NY: Pergamon Press. 
McCullough, R. (2000). Special needs education survey project and recommendations. Samoa Department of Education \& United Nations Development Programme.

McCullough, R. (2005). Case study and manual on guidelines for action to include children with disabilities in school systems and the EFA monitoring process. Christchurch, NZ: Author.

MCullough, R. (2006, 1 October). Inclusive education workshop report. UNESCO and Samoa Ministry of Education, Sports and Culture. Apia.

McDonald, B. L. (2001). Transfer of training in a cultural context. A Cook Islands study. Unpublished $\mathrm{PhD}$ Thesis, Victoria University of Wellington, New Zealand.

McDonald, B. L (2002). Training culture shock: Acknowledging the significance of culture for transfer of training. The International Journal of Learning, 9, 705716.

McDonald, B. L. (2004). Inclusive education professional development: Working across cultures. In V. Heung \& M. Ainscow (Eds.), Inclusive education: A framework for Reform. Proceedings of the international Conference on Inclusive Education 16-19 December 2003 (pp. 83-96). Hong Kong: Centre for Special Needs and Studies in Inclusive Education, The Hong Kong Institute of Education.

McDonald, B. L. (2005). Training impact: Maximising aid projects. In K. Sanga, C. Chu, C. Hall \& L. Crowl (Eds.), Rethinking aid relationships in Pacific education (pp. 143-160). Wellington, NZ: He Parekereke, Institute for Research and Development in Māori and Pacific Education, Victoria University of Wellington and Institute of Education, University of South Pacific, Suva.

McDonald, L. (2009). Teacher change: A dynamic interactive approach. International Journal of Learning, 6(10), 623-636.

McDonald. L., \& Hynds, A. (2010). Culture and diversty: Teachers professional development experiences under scrutiny. In V. Green \& S. Cherrington (Eds.), Delving into diversity: An international exploration of diversity issues in education (pp. 221 - 231). Hauppauge, NY: Nova Science Publishers.

Mc Gregor, S., \& Forlin, C. (2005). Attitude of students towards peers with disabilities: Relocating students from an education support centre to an inclusive middle school setting. International Journal of Whole schooling, 1, 18-30.

McKinstry, G., \& Price, P. (2004). Review of policy and legislation on disability in Pacific island countries. Pacific Islands Forum Secretariat.

McLaughlin, M. J., \& Jordan. A. (2005). Push and pull: Forces that are shaping inclusion in the United States and Canada. In D. Mitchell (Ed.), Contextualizing inclusive education: Evaluating old and new international perspectives (pp. 89113). Oxfordshire, UK: Routledge Taylor \& Francis.

Meadmore, D. (2001). Uniformly testing diversity? National testing examined. AsiaPacific Journal of Teacher Education 29(1), 19-30. 
Meleisea, M. (1987a). Lagaga: A short history of Western Samoa. Suva: University of the South Pacific.

Meleisea, M. (1987b). The making of modern Samoa. Suva: Institute of Pacific Studies, University of the South Pacific.

Meleisea, M. (2000). Governance, development and leadership in Polynesia. MacMilan Brown Centre for Pacific Studies, University of Canterbury.

Menzies, H., \& Falvey, M. A. (2008). Inclusion of students with disabilities in general education. In T. C. Jimenez \& V. L. Graf (Eds.), Education for All: Critical issues in the education of children and youth with disabilities (pp. 131166). San Francisco: Jossey Bass.

Meredith, K. (2009). Disability, education and development: Perspectives from Tokelau. Unpublished Master's Thesis, Victoria University of Wellington. Wellington.

Merriam, S. B. (1988). Case study research in education: A qualitative approach. San Francisco: Jossey-Bass Publishers.

Mertens, D. M. (1998). Research methods in education and psychology: Integrating diversity with quantitative and qualitative approaches. Thousand Oaks, CA: Sage.

Meverech, Z. R. (1995). Teachers' paths on the way to and from the professional forum. In T. R. Guskey \& M. Huberman (Eds.), Professional development in education: New paradigms and practices (pp. 151 -171). New York: Teachers College Press.

Mikkelsen, B. (2005). Methods for development work and research: A new guide for practitioners. New Delhi: Sage Publications.

Miles, M. B., \& Huberman, A. M. (1994). Qualitative data analysis ( $2^{\text {nd }}$ ed.). Thousand Oaks, CA: Sage Publications.

Mitchell, D. (Ed.). (2005) Contextualizing Inclusive Education: Evaluating old and new international perspectives. Routledge: Taylor \& Francis Group.

Mittler, P. (2000). Working towards inclusive education: social contexts. London: Fulton.

Moli, S. F. (1993). Towards a relevant science education for Western Samoa:A'oa'oga tau Saienisi mo Samoa i Sisifo. Unpublished Masters' Thesis. University of Waikato, Hamilton.

Moore, D., Anderson, A., Timperley, H., Glynn, T., Macfarlane, A., Brown, D., \& Thomson, C. (1999). Caught between stories: Special education in New Zealand. Wellington: NZCER.

Moustakas, C. (1994). Phenomenological research methods. Thousand Oaks, CA: Sage. 
Mulitalo, F., Pesamino, M., \& Lene, D. (2007, October). Inclusive education workshop. Status report on inclusive education, Apia, Samoa.

Myles, B., \& Simpson, R. (1989). Regular educators' modification preferences for mainstreaming mildly handicapped children. Journal of Special Education, 22, 479-489.

Nachmias, C., \& Nachmias, D. (1992). Research methods in the social sciences $\left(4^{\text {th }}\right.$ ed.). New York: St Martins’ Press.

Naicker, S. M. (2005). Inclusive education in South Africa: An emerging pedagogy of possibility. In D. Mitchell (Ed.), Contextualizing inclusive education: evaluating old and new international perspectives (pp. 230-252). London: Routledge Taylor \& Francis.

Neuman, W. L. (2000). Social research methods: Qualitative and quantitative approaches ( $4^{\text {th }}$ ed.). Boston: Allyn and Bacon.

Nieswiadomy, R. M. (1993). Foundations of nursing research ( $2^{\text {nd }}$ ed.). Norwalk, CT: Appleton \& Lange.

Nilholm, C. (2003). Perspektiv på specialpedagogik [Perspectives on Special Education] (Lund:Studentlitteratur). European Journal of Special Needs Education, 11(1).

NJCLD, (National Joint Committee on Learning Disabilities) (2000). Professional development of teachers. Learning Disability Quarterly, 23(1), 2-6.

Ochs, E. (1988). Culture and Language Development: Language acquisition and Language socialization in a Samoan village. Cambridge: Cambridge University Press.

Odden, H., \& Rochat, P. (2004). Observational learning and enculturation. Educational and child psychology 21(1), 39-50.

OECD, (Organisation for Economic-operation and Development), Centre for Educational Research and Innovation. (1998). Staying ahead. In-service training and teacher professional development. Paris: Author.

O'Hanlon, C. (Ed.). (1995). Inclusive education in Europe. London: David Fulton.

Oliver, M. (1992). Changing the social relations of research production. Disability, Handicap and Society 7(2), 101-114.

Oliver, M. (1996). Understanding disability: From theory to practice. Basingstoke: Palgrave.

O’Meara, J. T. (1990). Samoan planters: Tradition and economic Development in Polynesia. Fort Worth: Holt, Rinehart and Winston, Inc.

Opdal, L. R., Wormnaes, S., \& Habayeb, A. (2001). Teachers’ opinions about inclusion: A pilot study in a Palestinian context. International Journal of Disability, Development, and Education, 48(2), 143-162. 
Oskamp, S. (1991). Attitudes and opinions ( $2^{\text {nd }}$ ed.). Englewood Cliffs, NJ: Prentice Hall.

Otsuka, S. (2006). Talanoa research: Culturally appropriate research design in Fiji. NSW, Australia: University of Sydney.

Pajares, F. M. (1992). Teachers' beliefs and educational research: Cleaning up a messy construct. Review of Educational Research, 62(3), 307-322.

Palys, T. (2003). Research decisions: Quantitative and qualitative perspectives $\left(3^{\text {rd }}\right.$ ed.). Scarborough, ON: Nelson.

Patton, M. Q. (1990). Qualitative evaluation and research methods ( $2^{\text {nd }}$ ed.). Newbury Park, CA: Sage.

Paquette, D., \& Ryan, J. (2001). Bronfenbrenner's ecological systems theory. Retrieved July 30, 2010, from http://www.psy.edu/psicafe/keytheorists /bronfenbrenner.htm

Pearl, S., \& Tony, K. (1999). The democratic classroom: Theory to inform practice. Creswell, NJ: Hampton Press.

Penuel, W., Fishman, B., Yamaguchi, R., \& Gallagher, L. (2007). What makes professional development effective? Strategies that foster curriculum implementation. American Educational Research Journal 44(4), 921-958.

Pereira, J. (2005). Aspects of primary education in Samoa: Exploring student, parent and teachers perspectives. Unpublished $\mathrm{PhD}$ Thesis, University of Otago, Dunedin.

Perkins, D., Barell, J., \& Fogarty, R. (1989). Teaching for transfer. Palatine, IL: Skylight Publishing.

Petana-Ioka, K. M. (1994). Secondary education in Western Samoa: Developments in the English curriculum 1960 -1990. Unpublished Master's Thesis, University of Otago.

Peters, S. (2004). Inclusive education: EFA Strategy for all children. World Bank, Nov.

Pfeiffer, D., Sam, A. A., Guinan, M., Ratcliffe, K. T., Robinson, N. B., \& Stodden, N. J. (2004). Ethnic and religious perspectives on disability and the helping professions. The Social Science Journal, 41, 683-687.

Pijl, S., \& Meijer, C., (1991). Does integration count for much? An analysis of the practices of integration in eight countries', European Journal of Special Education, 6(2), 100-11.

Pijl, S. J., \& Meijer, C., (1994). New perspectives in special education: A six country study of integration. London: Routledge.

Pijl, S. J., Meijer, C., \& Hegarty, S. (Eds.). (1997). Inclusive education: A global agenda. London: Routledge. 
Poasa, K. H., Mallinckrodt, B., \& Suzuki, L. A. (2000). Causal attributions for problematic family interaction: A qualitative, cultural comparison of Western Samoa, American Samoa, and the United States. The Counselling Psychologist 28(1), 32-60.

Polkinghorne, D. E. (1989). Phenomenological research methods. In R. S. Valle \& S. Halling (Eds.), Psychology: Exploring the breadth of human experience (pp. 41 -60). New York: Plenum Press.

Pearpoint, J., \& Forest, M. (1992). Foreword. In S. Stainback \& W. Stainback (Eds.), Curriculum considerations in inclusive classrooms: Facilitating learning for all students (pp. 15-18). Baltimore: Paul H. Brooks.

Phillips, D. (2009). Aspects of educational transfer. In R. Cowen \& A. Kazamias (Eds.), International handbook of comparative education (pp. 1061-1077). Dordrecht, Netherlands: Springer.

Phillips, D., \& Ochs, K. (2003). Processes of policy borrowing in education: Some analytical and explanatory devices, Comparative Education, 39(4), 451-461.

Ochs, K., \& Phillips, D. (2004). Processes of educational borrowing in historical context. In D. Phillips \& K. Ochs (Eds.), Educational policy borrowing: Historical perspectives. Oxford Studies in Comparative Education (pp.7-23). Oxford, UK: Symposium Books.

Popham, W. J. (1999). Where large scale educational assessment is heading and why it shouldn't. Educational Measurement: Issues and Practice 18, 13-17.

Price, P., Radio, L., \& Toga, J. (1999). Global trends in disability issues: A South Pacific perspective. Asia Pacific Disability Rehabilitation Journal, 10, 2.

Reetz, L. J., \& Hoover, J. H. (1992). The acceptability and utility of five reading approaches as judged by middle school learning disabled students. Learning Disabilities Research \& Practice, 7, 11-15.

Ritchie, J., \& Ritchie, J. (1979). Growing up in Polynesia. Sydney: George Allen \& Unwin.

Ritchie, J., \& Ritchie, J. (1985). Etipu e rea. Polynesian socialisaiton and psychological development. Occasional paper no. 28. University of Waikato, Hamilton, New Zealand: Centre for Māori Studies and Research.

Rioux, M. (2007). Disability rights in education. In L. Florian (Ed.), The Sage handbook of special education (pp. 107-116). London: Sage publication.

Roach, V. (1995). Beyond the rhetoric. Phi Delta Kappan, 77, 295-299.

Robeyn, I. (2006). Three models of education, Theory and Research in Education, $4(1), 69-84$.

Rodgers-Jenkinson, F., \& Chapman, D. W. (1990). Job satisfaction of Jamaican elementary school teachers. International Review of Education, 36(3), 299-313. 
Rombo, J. L. (2007). School cultural features and practices that influence inclusive education in Papua New Guinea: A consideration of schools in Southern Highlands province. Unpublished Master's Thesis, The University of Waikato. School of Education, Hamilton, New Zealand.

Rose, R. (2001). Primary school teacher perceptions of the conditions required to include pupils with special educational needs. Educational Review, 53(2), 147156.

Rouse, M., \& Florian, L (1998). Inclusive education in the market-place. International Journal of Inclusive Education, 1(4), 323-336

Rowland, S. (2000). The inquiring university teacher: The society for research into higher education. Buckingham: Open University Press.

Safford, P., \& Safford, E. (1996). A history of childhood and disability. New York: Teachers College Press.

Sale, P., \& Carey, D. (1995). The sociometric status of students with disabilities in a full-inclusion school. Exceptional Children, 62(1), 6-19.

Salend, S. (1984). Factors contributing to the development of successful mainstreaming programs, Exceptional Children, 50, 409-419.

Salisbury, C. L. (2006). Principals’ perspectives on inclusive elementary schools. Research \& Practice for Persons with Severe Disabilities, 31(1), 70-82.

Samoa Department of Education. (2002). Including children with special learning needs in all schools: Teacher's Manual. Apia.

Sandelowiski, M. (1993). Rigor or rigor mortis: the problem of rigor in qualitative research revisited. Journal of Advances in nursing Science, 16(2) 1-8.

Sands, D. J., Kozlesky, E. B., \& French, N. K. (2000). Inclusive education for the 21st century. Belmont, CA: Wadsworth.

Sanerivi, L. (1998). Samoa. In M. Bray \& L. Steward (Eds.), Examination systems in small states: Comparative perspectives on Policies, Models and Operations. (pp. 87-96). London: Commonwealth Secretariat.

Sanga, K., \& Niroa, J. (2004). First steps and small beginnings in Vanuatu education research. In K. Sanga \& J. Niroa (Eds.), Rethinking Vanuatu education together. Suva: Institute of Pacific Studies.

Sanga, K. (2005). Self-evaluating a donor-funded Pacific initiative: value, lessons and challenges. In K. Sanga, C. Chu, C. Hall \& L. Crowl (Eds.), Re-Thinking aid relationhips in Pacific Education. (pp. 105-115). Suva: Institute for Research and development in Māori and Pacific Education and Institute of Education University of the South Pacific.

Schafer, W., \& Olexa, C. (1971). Tracking and opportunity. Scranton, PA: Chandler. 
Schwartz, S. H. (1992). Universals in the content and structure of values: theoretical advances and empirical tests in 20 countries. In M. Zanna (Ed.), Advances in Experimental Social Psychology (pp. 1-65). Orlando, FL: A cademic Press.

Schoeffel, P. (1979). Daughters of Sina: A study of gender, status and power in Western Samoa. Unpublished PhD Thesis, Australian National University, Canberra.

Scruggs, T. E., \& Mastropieri, M. A. (1996). Teacher perceptions of mainstreaming/ inclusion, 1958-1995: A research synthesis. Exceptional Children, 63, (1) 59-75.

Secretariat, P. I. F. (2002, 11 - 12 December). Forum Education Minister's Meeting. Paper presented at the Forum Education Minister’s Meeting. Suva, Fiji.

Semmel, M. I., Gerber, M. M., \& MacMillan, D.L. (1995). A legacy of policy analysis research in special education. In D. P. Hallahan (Ed.), The illusion of full inclusion: A comprehensive critique of a current special education bandwagon (pp. 39-57). Austin, TX: PRO-ED.

Shankman, P. (1976). Migration and underdevelopment: The case of Western Samoa. Boulder: Westview Press.

Sharma, U., Forlin, C., Loreman, T., \& Earle, C. (2006). Preservice teachers’ attitudes, concerns and sentiments about inclusive education: an international comparison of novice pre-service teachers. International Journal of Special Education, 21(2), 80-93.

Shore, B. (1982). Sala'ilua: A Samoan mystery. New York: Columbia University Press.

Shore, B. (1996). Culture in mind. New York, Oxford: Oxford University Press.

Sikes, P., Lawson, H., Parker, M. (2007). Voices on: teachers and teaching assistants talk about inclusion. International Journal of Inclusive Education, 11(3), 355370 .

Skidmore, D. (2004). Inclusion: The dynamics of school development. Buckingham: Open University Press.

Skrtic, T. M. (1986). The crisis in special education knowledge: A perspective on perspective. Focus on Exceptional Children, 18(7), 1-16.

Skrtic,T. M. (1991). Behind special education: A critical analysis of professional culture and school organisation. Denver CO: Love Publishing.

Slee, R. (Ed.). (1993). Is there a desk with my name on it? The politics of integration. London: The Falmer Press.

Slee, R. (2005). Education and the politics of recognition: Inclusive education - an Australian snapshot, In D. Mitchell (Ed.), Contextualizing inclusive education: evaluating old and new international perspectives (pp. 139-165). London: Routledge Taylor \& Francis. 
Slee, R., \& Allan, J. (2001). Excluding the included: a reconsideration of inclusive education. International Studies in Sociology of Education, 11(2), 173-191.

Smith, F. (1990). Western Samoa: An investigation into the socioeconomic status of the disabled. Vanuatu: United Nations ESCAP Pacific Operations Centre.

Smith, R., \& Leonard, P. (2005). Collaboration for inclusion: Practitioner perspectives. Equity \& Excellence in Education, 38(4), 269-279.

Smith, L. T. (2004). Building research capability in the Pacific, for the Pacific and by Pacific peoples. In T. Baba, O. Mahina, N. Williams \& U. Nabobo-Baba (Eds.), Researching the Pacific and indigenous peoples: Issues and perspectives (pp. 416). Auckland: Auckland Centre for Pacific Studies, University of Auckland.

Snow, J. (1989). Systems of support: A new vision. In S. Stainback, W. Stainback, \& M. Forest (Eds.), Educating all students in the mainstream of regular education (pp. 221-231). Baltimore: Paul H. Brookes Publishing Co.

So’o, A., Va’a, U. F., Lafotanoa, T., \& Boon, J. (Eds.). (2006). Samoa National Human Development Report. Sustainable livelihoods in a changing Samoa. National University of Samoa: Centre for Samoan Studies.

Sooaemalelagi, F. L. (2000). Year 8 national examination in Samoa: A case study. National University of Samoa, Paper presented at Pacific Association of Teachers Educators Conference.

Staff, (1988). Special education costs about twice the price of regular education. Education of the Handicapped, 14(25), 1-4.

Stainback, S., \& Stainback, W. (1987a). Integration versus cooperation: A commentary on educating children with learning problems: A shared responsibility. Exceptional Children, 54, 66-68.

Stainback, W., \& Stainback, S, (1987b). Facilitating friendships. Education and Training in Mental Retardation, 22, 10-25.

Stainback, S., \& Stainback, W, (1988). Educating students with severe disabilities in regular classes. Teaching Exceptional Children. 21, 16-19.

Stainback, W., \& Stainback, S. (1990). The support facilitator at work. In W. Stainback and S. Stainback (Eds.), Support networks for inclusive schooling: Interdependent integrated education (pp. 37-48). Baltimore: Paul H. Brooks Publishing Co.

Stainback, S., \& Stainback, W. (Eds.). (1992). Curriculum considerations for inclusive classrooms: Facilitating learning for all students. Baltimore: Paul $\mathrm{H}$. Brookes Publishing Co.

Stainback, W., \& Stainback, S. (1995). Controversial issues confronting special education. Boston: Allyn \& Bacon.

Stainback, S., \& Stainback, W. (Eds.). (1996). Inclusion: A guide for educators. Baltimore, MD: Paul. H. Brookes. 
Stainback, W., Stainback, S., \& Bunch, G. (1989a). Introduction and historical background. In S. Stainback, W. Stainback, \& M. Forest (Eds.), Educating all students in the mainstream of regular education (pp. 3-14). Baltimore: Paul H. Brooks.

Stainback, S., Stainback, W., \& Forest, M. (Eds.). (1989). Educating all students in the mainstream of regular education. Baltimore: Paul H Brookes Publishing Co.

Stainback, S., Stainback, W. Jackson, H. J. (1992). Toward inclusive classrooms. In S. Stainback \& W. Stainback (Eds.), Curriculum considerations in inclusive classrooms: Facilitating learning for all students (pp. 3-17). Baltimore: Paul H. Brooks.

Stout, R. T. (1996). Staff development policy: fuzzy choices in an imperfect market, Education Policy Analysis Archives, 4(2). Retrieved 31 April 2010 from http://epaa.asu.edu/epaa/v4n2.html

Strain, P. S., \& Odom, S. L. (1986). Peer social initiations: Exceptional children. Exceptional Children, 52(6), 543-551.

Strully, J. (1986, November). Our children and the regular education classroom: Or why settle for anything less than the best? Paper presented at the $13^{\text {th }}$ annual conference of the Association for Persons with Severe Handicaps, San Francisco.

Strully, J. (1987, October). What's really important in life anyway? Parents sharing the vision. Paper presented at the $14^{\text {th }}$ conference of The Association for Persons with Severe Handicaps, Chicago.

Subban, P., \& Sharma, U. (2006). Teachers' perceptions of inclusive education in Victoria, Australia. International Journal of Special Education, 21(1), 42-52.

Sutherland, M. (2000). Why are students failing? Is mainstreaming the cause? Proceedings of the Western Australian Institute for Educational Research Forum. Retrieved November, 2005, from 1http://education.curtin.edu.au /waier/forums/2000/Sutherland.html

Sutter, F. K. (1980). Communal versus individual socialisation at home and in school in rural and urban Western Samoa. Unpublished PhD Thesis, University of Hawai'i, Honolulu.

Swart, E., Engelbrecht, P., Eloff, I. \& Pettipher, R. (2002). Implementing inclusive education in South Africa: Teachers attitudes and experiences. Acta Academia, 34(1) 175-189.

Taufe'ulungaki, A. M. (1988). Language Attitudes and their implications for language planning in Tonga. Unpublished $\mathrm{PhD}$ Thesis, University of Birmingham, England, United Kingdom.

Tavana, G V. (1997). Cultural values and education in Western Samoa: Tensions between colonial roots and influences and contemporary indigenous needs. International Journal of Educational Reform 6(1), 11-19. 
Terzi, L. (2005). 'Beyond the dilemma of difference: The capability approach to disability and special educational needs'. Journal of Philosophy of Education, 39(3), 443-459.

Terzi, L. (2008). Justice and equality in education: A capability perspective on disability and special educational needs. New York: Continuum.

Thaman, K .(1997). Reclaiming a place: towards a Pacific concept of education for cultural development. The Journal of the Polynesian society, 106(2), 119-130.

The Centre for Samoan Studies. (2006). Samoa National Human Development Report: Sustainable livelihood in a changing Samoa. Apia Samoa: National University of Samoa.

Thomas, G., (1997). Inclusive schools for an inclusive society, British Journal of Special Education, 24(3), 103-07.

Thomas, G., Walker, D., \& Webb, J. (1998). The making of the inclusive school. London: Routledge.

Thomas, G., \& Loxley, A. (2001). Deconstructing special education and constructing education. Buckingham: Open University Press.

Tolley, H. (2003). Basic education: Globalising the local. Unpublished Master's Thesis, University of Auckland, Auckland.

Tomlinson, S. (1982). A Sociology of special education. London: Routledge and Kegan Paul.

Topping, K., \& Maloney, S. (2005). The Routledge Falmer reader in inclusive education. London: Routledge Falmer.

Trainer, M. (1991). Differences in common: Straight talk on mental retardation, Down syndrome, and life. Rockville, MD: Woodbine house.

Triandis, H. C. (1989). Cross-cultural studies of individualism and collectivism. In J. J. Berman (Ed.), Nebraska symposium on motivation 1989: Cross cultural perspectives. Lincoln: University of Nebraska Press.

Trumbull, E., Rothstein-Fisch, C., Greenfield, P. M., \& Quiroz, B. (2001). Bridging cultures between home and school: A guide for teachers. Mahwah, HJ:

Lawrence Erlbaum.

Tsoi, Hoshmand, L. L. S. (1989). Alternate research paradigms: A review and teaching proposal. Counselling Psychologist, 17(1), 3-79.

Tufue, R. (2004). Perceptions of regular primary school teachers about the integration of children with disabilities into regular schools in Samoa. A comparative study. Paper presented at the PATE National University of Samoa.

Tuia. T. (1999). Samoan culture and education in the European context: A case study based on one Samoan family from different generations. Unpublished Master's Thesis, University of Queensland, Brisbane. 
UNESCO. (1994). The Salamanca statement and framework for action on special needs education. World Conference on Special Needs Education: Access and Quality, Salamanca, Spain, 7-10 June, 1994.

UNESCO. (1994). World conference on special needs education: Access and quality. (Final Report). Salamanca: Author.

United Nations. (1989), Convention on the rights of the child, New York; UN.

UNESCAP. (2002). Biwako millennium framework for action towards an inclusive barrier-free and rights-based society for persons with disabilities in Asia and the Pacific. Retrieved February 15, 2007, from

http://www8.cao.go.jp /shougai/english/biwako/contents.html

Va'a, R. (1987). A study of teacher-pupil interaction during Science lessons in two Samoan primary schools. Master's Thesis. University of the South Pacific. Suva

Va’a, U. F. (2006). The Fa'asamoa. In A. So’o, U. F.Va’a, T. Lafotanoa \& J. Boon (Eds.), Samoa National Human Development Report. Sustainable Livelihoods in a Changing Samoa (pp. 113-135). National University of Samoa: Centre for Samoan Studies.

Vaioleti, T. M. (2006). Talanoa research methodology: A developing perspective on Pacific research. Waikato Journal of Education, 12, 21-34.

Vandercook, T., Fleetham, D., Sinclair, S., \& Tet- lie, R. R. (1988). Cath, Jess, Jules, and Ames ... a story of friendship. Impact, 1(2), 18-19.

Van den Pol, R., Crow, R. E., Rider, D., \& Offner, R. (1985). Social interaction research in an integrated preschool. Topics in Early Childhood Special Education, 4, 59-76.

van Kraayenoord, C. E., Elkins, J., Palmer, C., \& Rickards, F.W. (2000). Literacy, numeracy and students with disabilities. Chaps. 1-8. Training and Youth Affairs. Retrieved October 1, 2009, from http//www.gu.edu.au /school/cls/clearinghouse /2000_literacy/volume_one.pdf

van Manen, M. (1990). Researching lived experience: human Science for action sensitive pedagogy. Albany, New York: State University of New York Press.

Vaughn, S., \& Schumm, J. S. (1995). Responsible inclusion for students with learning disabilities. Journal of Learning Disabilities, 28(5), 264-270.

Vaughn, S., Schumm, J., Jallad, B., Slusher, J., \& Saumell, L. (1996). Teachers' views of inclusion. Learning Disabilities Research and Practice, 11(2), 96-106.

Veenman, S., van Tulder, M., \& Voeten, M (1994). The impact of inservice training on teacher behaviour. Teaching and Teacher Education, 10, (1), 303-317.

Villa, R. A., Thousand, J. S., Meyers, H., \& Nevin, A. (1996). Teacher and administrator perceptions of heterogeneous education. Journal of Exceptional Children, 63, 29-45. 
Waddington, E. M., \& Reed, P. (2006). Parents' and local education authority officers' perceptions of the factors affecting the success of inclusion of pupils with autistic spectrum disorders. International Journal of Special Education. 21(3), 151-164.

Walberg, H. J., \& Genova, W. J. (1982). Staff, school and workshop influences on knowledge use in educational improvements efforts. Journal of Educational Research, 76, 69-80.

Wallace, P. R. (1992). An incremental transfer approach to instructional design. In J. G. Hedberg \& J. Steele (Eds.), Educational technology for the clever Country: Selected papers from EdTech'92, (151-155). Canberra: AJET Publications.

Wang, M. C., Reynolds, M. C., \& Walberg, H. J. (1989, September). A rebuttal to Vergason and Anderegg: Who benefits from segregation and murky waters? Phi Delta Kappan, pp. 64-67.

Ward, J., Centre, Y., \& Bocher, S. (1994). A question of attitudes: integrating children with disabilities into regular classrooms. British Journal of Special Education, 21 (1), 34-39.

Watson, J. (2004). Teachers' talk: Perceptions of Queensland secondary teachers about students with learning difficulties. Retrieved July 14, 2005 from http://www.aare .edu. au/04pap/cra04084.pdf

Weatherly, R., \& Lipsky, M. (1977). Street level bureaucrats and institutional innovation: implementing special educational reform', Havard Educational Review, 47, 171-97.

Weiner, H. (2005). Designing and implementing an ethical and effective inclusion program: A district administrator's perspective on professional development. In A. Mungai \& E. Kogan (Eds.), Pathway to Inclusion: Voices from the Field. (pp. 63-85). Lanham: University Press of America.

Westwood, P. S. (2003). Commonsense methods for children with special educational needs: Strategies for the regular classroom (4th ed.). London: Routledge Falmer.

Westwood, P., \& Graham, L. (2000). How many children with special needs in regular classes? Australian Journal of Learning Disabilities, 5(3), 24-35.

Wilkinson, S. (2003). Focus groups, In J.A. Smith (Ed.), Qualitative psychology: A practical guide to research methods (pp. 184-204) London: Sage Publications.

Wolery, M., Werts, M. G., Cladwell, N. K., Snyder, E. D., \& Lisowski, L. (1995). Experienced teachers' perceptions of resources and supports for inclusion. Education and Training in Mental Retardation and Development Disabilities 30, 15-26.

Worth, P. (1988, December). Empowerment: Choices and change. Paper presented at the annual conference of The Association for Persons with Severe Handicaps, Washington, DC. 
Wrights, S. L., \& Sigafoos, J. (1998). Parent views on the placement of students with special needs in regular classrooms at an Australian primary school. Australian Journal of Special Education 22, 30-37.

Yelon, S. (1992). MASS: A model for producing transfer. Performance Improvement Quarterly, 5(2), 13-23. 


\section{Appendices}

APPENDIX 1: $\quad$ Table of Findings on Codes, Patterns and Themes

APPENDIX 2: $\quad$ Focus Group Questions

APPENDIX 3: $\quad$ Semi Structured Interview Guide

APPENDIX 4: $\quad$ Focus Group Information Sheet

APPENDIX 5: $\quad$ Information for Individual and Focus Discussions

APPENDIX 6: $\quad$ Consent Form

APPENDIX 7: $\quad$ Letter seeking approval to undertake research in schools

APPENDIX 8: $\quad$ Ethics Letter of Approval 
APPENDIX 1

Table of Findings - Codes, Patterns and Themes

Table 5.9 Codes, Patterns, Definitions and Themes

\begin{tabular}{|c|c|c|}
\hline $\begin{array}{l}\text { CODES AND } \\
\text { DEFINITIONS }\end{array}$ & $\begin{array}{l}\text { PATTERNS AND } \\
\text { DEFINITIONS }\end{array}$ & THEMES \\
\hline $\begin{array}{l}\text { 1.1Disability } \\
\text { Inclusive Education is } \\
\text { defined in terms of } \\
\text { physical, and mental } \\
\text { disability }\end{array}$ & \multirow{4}{*}{$\begin{array}{l}\text { 1. Interpretation, beliefs about } \\
\text { disability and education } \\
\text { (This refers to definition } \\
\text { of/and philosophy about IE } \\
\text { as well as beliefs and } \\
\text { understanding of disability } \\
\text { and suitable education) }\end{array}$} & \multirow{10}{*}{$\begin{array}{l}\text { 1. Understanding, attitude and } \\
\text { practices conundrum- } \\
\text { (This refers to the differing } \\
\text { viewpoints and practices of IE) } \\
\text { 2. Support and interdependence: } \\
\text { (This refers to support received } \\
\text { from Ministry (MESC), } \\
\text { colleagues, family and } \\
\text { community) } \\
\text { Transfer practice (This refers to } \\
\text { professional development) }\end{array}$} \\
\hline $\begin{array}{l}\text { 1.2Capability } \\
\text { Inclusive education } \\
\text { is/defined in terms of } \\
\text { ability (learning difficulty } \\
\text { or learning disability) }\end{array}$ & & \\
\hline $\begin{array}{l}1.3 \text { Human rights } \\
\text { Inclusive education is } \\
\text { defined in terms of rights } \\
\text { of the disabled children to } \\
\text { be educated together with } \\
\text { the non disabled children } \\
\text { within the sale learning } \\
\text { environment }\end{array}$ & & \\
\hline $\begin{array}{l}\text { 1.4 Teacher perspective } \\
\text { Definition of inclusive } \\
\text { Education is perceived as } \\
\text { driven by teacher } \\
\text { perceptions of children } \\
\text { s/he teaches }\end{array}$ & & \\
\hline $\begin{array}{l}2.1 \text { Grouping } \\
\text { This refers to teaching } \\
\text { strategy used by teacher } \\
\text { such as grouping students } \\
\text { according to same and } \\
\text { mixed abilities }\end{array}$ & \multirow{6}{*}{$\begin{array}{l}\text { 2. Teacher qualities and } \\
\text { responses } \\
\text { (This refers to the personal, } \\
\text { psychological } \\
\text { characteristics of teachers } \\
\text { and responses to challenges } \\
\text { and opportunities of IE). It } \\
\text { looks at teacher practice } \\
\text { (behaviour) which include: } \\
\text { teaching style, motivation, } \\
\text { commitment, and attitude, } \\
\text { beliefs and experiences) }\end{array}$} & \\
\hline $\begin{array}{l}2.2 \text { Students as resource } \\
\text { Students can be use as } \\
\text { resource persons to support } \\
\text { teacher in classroom }\end{array}$ & & \\
\hline $\begin{array}{l}\text { 2.3 Positive belief } \\
\text { This refers to positive } \\
\text { attitude towards IE }\end{array}$ & & \\
\hline $\begin{array}{l}2.4 \text { Negative belief } \\
\text { The attitude of some } \\
\text { teachers towards IE }\end{array}$ & & \\
\hline $\begin{array}{l}2.5 \text { Emotion } \\
\text { Teachers have This refers } \\
\text { to feelings about IE }\end{array}$ & & \\
\hline 2.6 IE training/practice & & \\
\hline
\end{tabular}




\begin{tabular}{|c|c|c|}
\hline $\begin{array}{l}\text { CODES AND } \\
\text { DEFINITIONS }\end{array}$ & $\begin{array}{l}\text { PATTERNS AND } \\
\text { DEFINITIONS }\end{array}$ & THEMES \\
\hline $\begin{array}{l}\text { This refers to teachers' } \\
\text { experiences in IE }\end{array}$ & & \\
\hline $\begin{array}{l}2.7 \text { Motivation } \\
\text { This refers to what } \\
\text { motivate teachers to } \\
\text { practice IE }\end{array}$ & & \\
\hline $\begin{array}{l}3.1 \text { Teacher attitude } \\
\text { This refers to unfavourable } \\
\text { attitude that hinder IE }\end{array}$ & \multirow{11}{*}{$\begin{array}{l}\text { 3. Opportunities and restraints } \\
\text { (This refers to } \\
\text { opportunities, restraints } \\
\text { that can impact on IE } \\
\text { policy implementation as } \\
\text { well as benefits of IE) }\end{array}$} & \\
\hline $\begin{array}{l}\text { 3.2Teacher overload } \\
\text { This refers to IE as an extra } \\
\text { load for teachers }\end{array}$ & & \\
\hline $\begin{array}{l}3.3 \text { Teacher training } \\
\text { This refers to training as } \\
\text { important for IE }\end{array}$ & & \\
\hline $\begin{array}{l}\text { 3.4 Resource/facilities } \\
\text { This refers to resource as } \\
\text { crucial for IE }\end{array}$ & & \\
\hline $\begin{array}{l}3.5 \text { Expertise } \\
\text { This refers to lack of } \\
\text { expert knowledge to } \\
\text { enhance IE }\end{array}$ & & \\
\hline $\begin{array}{l}\text { 3.6 Family attitude } \\
\text { This refers to family } \\
\text { attitude acting as a barrier } \\
\text { to IE }\end{array}$ & & \\
\hline $\begin{array}{l}\text { 3.7 Course content } \\
\text { This refers to deficiency in } \\
\text { courses offered }\end{array}$ & & \\
\hline $\begin{array}{l}3.8 \text { Time } \\
\text { Refers to IE as time } \\
\text { consuming thus a barrier }\end{array}$ & & \\
\hline $\begin{array}{l}3.9 \text { Teacher/student ratio } \\
\text { High student/ teacher ratio } \\
\text { can be a barrier to IE }\end{array}$ & & \\
\hline $\begin{array}{l}3.10 \text { Funds } \\
\text { Funds is considered crucial } \\
\text { for enhancing IE }\end{array}$ & & \\
\hline $\begin{array}{l}\text { 3.11 Moral support } \\
\text { Lack of moral support can } \\
\text { affect teacher motivation }\end{array}$ & & \\
\hline $\begin{array}{l}\text { 3.12 Learning delay } \\
\text { IE delays learning of other } \\
\text { students }\end{array}$ & & \\
\hline $\begin{array}{l}3.13 \text { Community/ chiefs } \\
\text { Community support via } \\
\text { chiefs is crucial for IE }\end{array}$ & & \\
\hline 3.14 Parents & & \\
\hline
\end{tabular}




\begin{tabular}{|c|c|c|}
\hline $\begin{array}{l}\text { CODES AND } \\
\text { DEFINITIONS }\end{array}$ & $\begin{array}{c}\text { PATTERNS AND } \\
\text { DEFINITIONS }\end{array}$ & THEMES \\
\hline \multicolumn{3}{|l|}{$\begin{array}{l}\text { Parents' support is } \\
\text { considered crucial for IE }\end{array}$} \\
\hline \multicolumn{3}{|l|}{$\begin{array}{l}\text { 3.15 Church leaders } \\
\text { Pastors are considered } \\
\text { important to encourage } \\
\text { family's about the } \\
\text { importance of education }\end{array}$} \\
\hline \multicolumn{3}{|l|}{$\begin{array}{l}3.16 \text { Influential people } \\
\text { Utilisation of people who } \\
\text { could influence decision } \\
\text { making at the macro level } \\
\text { is positive for IE }\end{array}$} \\
\hline \multicolumn{3}{|l|}{$\begin{array}{l}3.17 \text { Student learn } \\
\text { IE benefits both the student } \\
\text { with special needs and the } \\
\text { non special needs student }\end{array}$} \\
\hline \multicolumn{3}{|l|}{$\begin{array}{l}3.18 \text { Student value/ sense } \\
\text { of belonging } \\
\text { IE gives the student with } \\
\text { special needs a sense of } \\
\text { belonging and being } \\
\text { valued }\end{array}$} \\
\hline \multicolumn{3}{|l|}{$\begin{array}{l}\text { 3.19 Smooth transition } \\
\text { IE facilitates transition into } \\
\text { jobs at post school }\end{array}$} \\
\hline \multicolumn{3}{|l|}{$\begin{array}{l}\text { 3.20 Teacher benefit } \\
\text { Teacher herself benefits } \\
\text { from IE for she will learn } \\
\text { skills e.g. sign language } \\
\text { from students with special } \\
\text { needs }\end{array}$} \\
\hline \multicolumn{2}{|l|}{$\begin{array}{l}3.21 \text { Raise awareness } \\
\text { Reduce discrimination } \\
\text { IE raises awareness of } \\
\text { needs and abilities of } \\
\text { students with special needs }\end{array}$} & \\
\hline $\begin{array}{l}\text { 4.1 Ministry role } \\
\text { Ministry is criticised by } \\
\text { several as not ready for IE }\end{array}$ & \multirow{4}{*}{$\begin{array}{l}\text { 4. Policy issues } \\
\text { (This refers to perceptions } \\
\text { about issues related to the } \\
\text { Ministry support role for } \\
\text { IE) }\end{array}$} & \\
\hline $\begin{array}{l}\text { 4.2 Expectations } \\
\text { Refers to aspirations of the } \\
\text { people for IE - for IE to be } \\
\text { practiced more and have } \\
\text { adequate training and } \\
\text { resources }\end{array}$ & & \\
\hline $\begin{array}{l}\text { 4.3Sustainability } \\
\text { Adequate funds to sustain } \\
\text { IE is crucial }\end{array}$ & & \\
\hline $\begin{array}{l}\text { 4.4 Legal aspect } \\
\text { Policies for IE are made } \\
\text { available but }\end{array}$ & & \\
\hline
\end{tabular}




\begin{tabular}{|c|c|c|}
\hline $\begin{array}{l}\text { CODES AND } \\
\text { DEFINITIONS }\end{array}$ & $\begin{array}{l}\text { PATTERNS AND } \\
\text { DEFINITIONS }\end{array}$ & THEMES \\
\hline $\begin{array}{l}\text { implementation is another } \\
\text { question }\end{array}$ & & \\
\hline \multicolumn{2}{|l|}{$\begin{array}{l}\text { 4.5Adopted model } \\
\text { IE model with special } \\
\text { needs units attached to the } \\
\text { general school or } \\
\text { collaboration of special } \\
\text { and general school }\end{array}$} & \\
\hline $\begin{array}{l}5.1 \text { Local inclusiveness } \\
\text { The Samoan culture is a } \\
\text { collective and inclusive }\end{array}$ & \multirow{4}{*}{$\begin{array}{l}\text { 5. Traditional contemporary } \\
\text { contexts } \\
\text { (This refers to the inclusive } \\
\text { nature of the traditional } \\
\text { education compared to the } \\
\text { exclusive features of the } \\
\text { formal education) }\end{array}$} & \\
\hline $\begin{array}{l}5.2 \text { Western exclusiveness } \\
\text { The Western type of } \\
\text { formal education is } \\
\text { exclusive in nature }\end{array}$ & & \\
\hline $\begin{array}{l}\text { 5.3Values and beliefs } \\
\text { Samoan values and beliefs } \\
\text { (love) seemed to change } \\
\text { and could impact on } \\
\text { support offered for } \\
\text { students with special needs }\end{array}$ & & \\
\hline $\begin{array}{l}5.4 \text { Local knowledge } \\
\text { Utilisation of local persons } \\
\text { is an advantage since over } \\
\text { recruiting an outsider who } \\
\text { does not understand the } \\
\text { local protocol. }\end{array}$ & & \\
\hline $\begin{array}{l}\text { 6.1 Student development } \\
\text { The Aiga (family home) } \\
\text { impacts on student's } \\
\text { learning and behaviour }\end{array}$ & \multirow{3}{*}{$\begin{array}{l}\text { 6. Impact of aiga (family) } \\
\text { This refers to issues such } \\
\text { as the authority the family } \\
\text { has on the student's } \\
\text { education }\end{array}$} & \\
\hline $\begin{array}{l}\text { 6.2 Parents beliefs and } \\
\text { actions } \\
\text { Parents are sole decision } \\
\text { makers regarding the } \\
\text { student's education } \\
\text { (whether the student } \\
\text { should be sent or not to } \\
\text { school) }\end{array}$ & & \\
\hline $\begin{array}{l}\text { 6.3 Worth of learner } \\
\text { Placement in a special } \\
\text { school was perceived as an } \\
\text { act of negligence }\end{array}$ & & \\
\hline
\end{tabular}




\section{APPENDIX 2}

\section{Focus Group Questions For}

\section{Practising Teachers}

1. What is your understanding of the term inclusive education?

2. Explain to me whether you think inclusive education is an appropriate teaching approach for Samoan classrooms and fa'aSamoa?

3. How do you describe your experiences teaching in an inclusive classroom?

4. How would your school/classroom be made more inclusive? How are you as teachers be motivated to be more inclusive in your teaching?

5. What do you see as barriers to or enhancers for implementing inclusive education initiatives in your classroom/school?

6. What do you view to be parents' role in your school/classroom concerning inclusive education?

7. What do you see as the community's role in implementation of inclusive ideas in schools?

8. Outline any training or education you have had on inclusive and special education?

9. Give me your thoughts and feeling about how inclusive education is working in your school?

10. What would you hope for in the future for inclusive education?

\section{Parents}

1. What is your understanding of the term inclusive education?

2. Explain to me inclusive education an appropriate teaching approach for Samoan classrooms and fa'aSamoa?

3. What do you think could be barriers/enhancers for implementing inclusive education strategies in your child's school?

4. How do you think inclusive education strategies would benefit your child?

5. How do you view inclusive education? Explain whether you feel it is an ideal type of education for Samoa?

6. What do you see to be your role as a parent of a child in an inclusive classroom? 
7. Explain to me how you think the Samoan schools/classrooms would become more inclusive?

8. Explain to me whether you think the community has a role to play in promoting inclusive education ideas?

9. Explain to me whether you think inclusive education is appropriate to the Fa'aSamoa (Samoan way)?

10. Give me your thoughts and feelings about how inclusive education is working in Samoa?

11. What would you hope for in the future for inclusive education?

\section{Curriculum Material Assessment Division (CMAD)}

1. What is your understanding of the term inclusive education?

2. Explain to me whether you think inclusive education is an appropriate teaching approach for Samoan classrooms and fa'aSamoa?

3. Give me your thoughts and feelings regarding the introduction of inclusive education policies i.e., How were policies introduced into the Samoan government? What principles underlie the policies?

4. Explain to me whether you believe teachers have a good awareness of inclusive policies?

5. Explain to me whether you think inclusive education is beneficial for the Samoan education system?

6. What do you perceive as factors that would hamper and/or facilitate inclusive education initiatives in Samoa?

7. How do you think teachers are supported in the implementation of these policies i.e., explain the support mechanisms that are available for teachers in new innovations such as these?

8. What resource material are in place to accommodate the needs of children with disabilities/learning difficulties in classrooms? Explain to me whether and how the current school curriculum is catering for the diverse needs of students in the classroom.

9. Can you give me your thoughts and feelings about how inclusive education is working in Samoa?

10. How does the concept of inclusive education fit in with the Fa'aSamoa (Samoan way)?

11. What would you hope for in the future for inclusive education? 


\section{APPENDIX 3}

\section{Proposed Individual Interview Questions For:}

\section{Ministry of Education Personnel}

1. What is your understanding of the term inclusive education?

2. What are your views regarding the introduction of inclusive education policies i.e., How were policies introduced into the Samoan government? What principles underlie the policies - Who are involved in development of policies regarding inclusive education?

3. Explain to me whether you think teachers have a good awareness of inclusive policies?

4. Give me your thoughts and feelings on how policies are implemented in schools and in teacher training institutions?

5. Explain to me whether inclusive education is beneficial for the Samoan education system?

6. What do you perceive as factors that would hamper and/or facilitate inclusive education initiatives in Samoa?

7. How are teachers supported in the implementation of these policies i.e., explain the support mechanisms that are available for teachers in new innovations such as these?

8. How does the notion of inclusive education fit in with the Fa'aSamoa (Samoan way)?

9. Can you give me your thoughts and feelings about how inclusive education is working in Samoa?

10. What would you hope for in the future for inclusive education?

\section{Teacher Educators}

1. What is your understanding of the term inclusive education?

2. Give me your thoughts and feelings regarding the introduction of inclusive education policies i.e., How were policies introduced into the Samoan government? What principles underlie the policies?

3. What can promote or hamper inclusive education courses in the teachers' training institution?

4. Give me your views on inclusive education courses for pre-service teachers?

5. How does inclusive education benefit children in the Samoan classrooms? 
6. Outline what trainings/education you have had on inclusive and special education?

7. Explain about the processes/strategies and approaches that would best help implement inclusive policies in Samoa?

8. How does the concept of inclusive education fit in with the Fa'aSamoa (Samoan way)?

9. Give me your thoughts and feelings about how inclusive education is working in Samoa?

10. What would you hope for in the future for inclusive education in Samoa?

\section{Key Community Members}

1. What is your understanding of the term inclusive education?

2. Give me your thoughts and feelings regarding the introduction of inclusive education in Samoa?

3. What role does the community play in the implementation of inclusive education?

4. How does inclusive education fit in with the Fa'aSamoa (Samoan way)?

5. How does inclusive education benefit teaching and learning in the Samoan classroom?

6. What could act as barriers or facilitators for inclusive education in Samoan schools/classrooms?

7. Give me your thoughts and feelings on how you think the Samoan society (e.g., villages, churches, schools) become more inclusive?

8. Explain to me what you think the role of the church and community leaders (Chiefs - matai) is in promoting inclusive practices?

9. What are your thoughts and feeling about how inclusive education is working in Samoa?

10. What would you hope for in the future for inclusive education in Samoa? 


\section{APPENDIX 4}

\section{Focus Group Information Sheet}

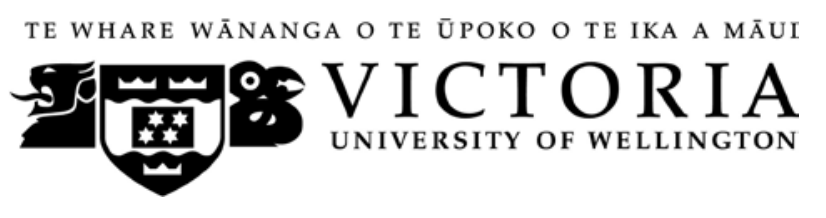

Te Kura Akoranga Matauranga

\section{Participant information sheet for the study on Inclusive Education in Samoa}

\section{Researcher: Rasela Tufue-Dolgoy}

The study is designed to examine views of stakeholders of inclusive education in Samoa about inclusive education. As stakeholders your contribution is imperative to this study. As a participant, you will be involved in a focus group interview which will be carried out in a form of "talanoa session" with six or more people. The session will be two hours long at the most. Ground rules for carrying out the focus group interview are stated in the attached form, and the researcher is more than willing to discuss the contents of this form with you if there are any queries.

The University requires that ethics approval be obtained for research projects involving human participants

The project will ensure that the following will be adhered to:

1. Participation is voluntary and participant may withdraw at any time prior to or during data collection

2. Participants' identity and information that will be obtained will strictly confidential

3. Participants will be fully informed about the nature of the research and provided with feedback.

Responses collected from the research will form the basis of my written report which will be submitted to the University of Wellington for marking. The final thesis report will be placed in the University of Wellington library as well as in the library of the National University of Samoa.

To ensure confidentiality and anonymity, all reports will be carefully scrutinised to ensure that no contextual details could lead to the identification of a participant or institution. The researcher aims to undertake transcription of the data herself and all written material as well as the tapes will be kept in a password protected computer file/filing cabinet. All written and audio recordings will be destroyed three years after the research has been completed.

If after reading this you would like to participate in this project, please complete the attached consent form and give it to Rasela Tufue-Dolgoy at the Faculty of Education, National University of Samoa.

Faafetai ma lou faaaloalo lava

\section{Researcher's contact details}

Rasela Tufue-Dolgoy, Faculty of Education

National University of Samoa, Tel: 20072, Ext 191/130, Email;rtufue@yahoo.com 


\title{
APPENDIX 5
}

\section{Information for Individual and Focus Discussions}

\author{
TE WHARE WĀNANGA O TE ŪPOKO O TE IKA A MĀUI \\ squa \\ Information Sheet \\ PERCEPTIONS AND EXPERIENCES OF STAKEHOLDERS
ABOUT INCLUSIVE EDUCATION IN SAMOA \\ RESEARCHER: Rasela Tufue-Dolgoy \\ POSITION: PhD student
}

\section{INFORMATION FOR PATICIPANT re: ETHICS}

The project will ensure that the following will be adhered to:

1. Participation is voluntarily and participants may withdraw at any time prior to or during data collection.

2. Participants' identity and information that will be obtained will be strictly confidential.

3. Participants will be fully informed about the nature of the research and provided with feedback.

\section{INFORMATION RE: RESEARCH PROJECT}

There are a number of ways of meeting the needs of students with special teaching needs in an education system. This study is concerned with gaining views on approaches that best meet the needs of such students. It will focus on teachers (etc) views on inclusion. Inclusion is a change in educational philosophy and practice, and is one means of meeting the needs of students with disabilities within the general classroom. For teaching practices to be most effective, it is important to assess perceptions of stakeholders. Studies focusing on teachers, views and perceptions have been numerous but few have focussed on other stake-holders' views. This study aims to obtain information regarding views and perceptions of those involved in inclusive education in Samoa. It is crucial to gather information from stake holders because it is important to understand the full range of their views about inclusive education practices. This study may provide guidance with regards to practices within the Samoan government schools as well as in the Samoan education system as a whole. 


\section{RESEARCH OBJECTIVES}

The objectives of the study are to:

1. gain insight to factors that inhibit and/or enhance the implementation of inclusive education initiatives in Samoa

2. bring forth ideas for development of a model or framework that is culturally appropriate for promoting education of students with special teaching needs in Samoa.

\section{PARTICIPANT INVOLVMENT}

Participants who agree to participate in the research project will be interviewed either as a member of a group or as an individual. The individual interviews will take up 40 to 45 minutes of the participant's time. Focus group discussions will be approximately 120 minutes. The interviews will be audio-taped and transcribed by the researcher herself. Interviews are to commence late June 2007. An outline of the interview questions is attached to this sheet.

\section{FEEDBACK FINDINGS}

On completion of the data analysis, a summary of findings will be sent to each participant if requested. It is also anticipated that the findings will be used for publication and conferences presentations

\section{PROTECTION OF PRIVACY}

The researcher is aware that it is her responsibility to ensure that confidentiality and anonymity is adhered to regarding identity of individual and their institution. All reports will be carefully scrutinised to ensure that no contextual details could lead to the identification of a participant and/or institution. The researcher aims to undertake transcription of the data herself and all written material as well as the tapes will be kept in a pass-word protected computer file/filing cabinet. All written and audio recordings will be destroyed 3 years after the research has been completed.

If after reading this you would like to participate in this project, please complete the attached consent form and give it to Rasela Tufue-Dolgoy at the Faculty of Education, National University of Samoa. Thank you for your cooperation.

\section{Researcher's contact details}

Rasela Tufue-Dolgoy

Faculty of Education

National University of Samoa

Tel: 20072, Ext, 191/130

Email: rtufue@yahoo.com 


\section{APPENDIX 6}

\section{Consent Form}

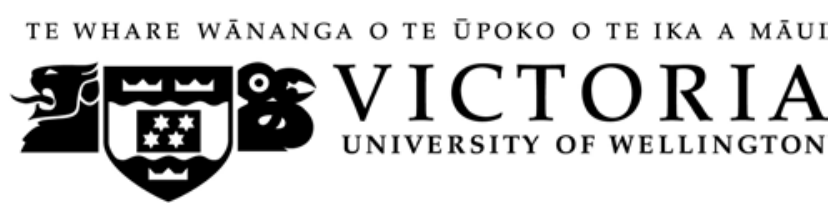

CONSENT TO PARTICIPATE IN RESEARCH

\section{Project title: \\ Perceptions and Experiences of Stakeholders about Inclusive Education in Samoa \\ Please read information below, tick each box if you agree then sign if you wish to be part of this research}

I have been given and understood an explanation of this research project. I have had an opportunity to ask questions and have them answered to my satisfaction.

$\square \quad$ I understand that I may withdraw from this project prior to/or during data collection without having to give reasons or without penalty of any sort.

I understand that any information I provide will be kept confidential to the researcher and the supervisor(s).

$\square$ I understand that the published results will not use my name, and no opinions will be attributed to me or my institution in any way that will identify me or my institution.

I understand that the tape recording of interviews will be electronically wiped 3 years after the research has been completed

$\square \quad$ I understand that the data obtained my be used for conference papers and /or publications

I understand that the data I provide will not be used for any other purpose other than as described in the information sheet

I understand that I can receive a summary of the findings if I request it

I agree to take part in this research

Name:

School/Organisation:

Address for postal purposes:

Signature:

Date: 


\section{(Samoan Version of Consent Form) Maliega e auai i le su'esu'ega}

\section{Ulutala o le Su'esu'ega:}

Aoaoga Tofilauo'o: Vaaiga faalemafaufau ma poto masani a e a'afia i aoaoga e aofia ai tagata uma

Fa'amolemole faitau fa'amatalaga, fa'ailoga pusa ma saini lou suafa pe a e finagalo e te auai i lenei su'esu'ega

Na ou taulimaina ma malamalama i fa'amatalaga e fa'atatau i lenei su'esu'ega. $\mathrm{Na}$ mafai ona ou fesili ma faamalieina tali mo a'u fesili.

Ua ou malamalama e mafai ona ou faama'amulu mai i lenei suesuega a o le’i fa'atinoina le aoina/pe a o aoina fo'i fa'amatalaga e aunoa ma le fa'asalaina o a'u, po o le fesiligia fo'i o au i le mafua'aga.

Ua ou malamalama so'o se fa'amatalaga ou te tu'uina atu mo lenei su'esu'ega ia tau lava o le o lo o fa'atinoina le suesega ma lana faiaoga ia mafai ona silasila iai.

Ua ou malamalama e le fa'ailoaina atu a'u po o lo'u igoa po o ni a'u faamatatalga aemaise fo'i la'u matagaluega ini fa'amaumauga po o ni lomiga i lenei su'esu'ega.

Ua ou malamalama o ni fa'amatalaga o le a f'a'amaumauina e fa'aaoga ai la'au pu'eleo o le a fa'aleaogaina pe a mavae le tolu o tausaga talu ona mae'a lenei su'esu'ega.

Ua ou malamalama o fa'amatalaga o le a fa'amaumauina e ono fa'aogaina mo ni fonotaga ma ni lomiga

Ua ou malamalama e le fa'aaogaina fa'amatalaga ua ou tu'uina atu mo se isi lava fa'amoemoe se'i vagana ai mafua'aga ua ta'ua i lenei pepa o fa'amatalaga.

Ua ou malamalama e mafai ona ou maua mai se faamatalaga e uiga i lenei su'esu'ega pea a ou mana'omia

Ua ou malie ou te auai i lenei su'esu'ega

Suafa: Aoga/Faalapotopotoga:

Tuatusi: Saini: Aso: 


\title{
APPENDIX 7
}

\section{Letter to undertake Research in Schools}

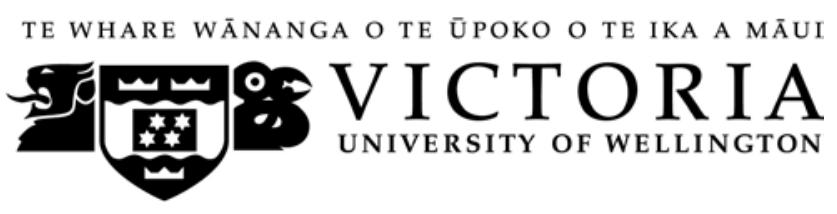

\author{
School of Education Studies \\ Te Kura Akoranga Matauranga
}

10 July 2007

\author{
Afioga Levaopolo Tupae Esera \\ Chief Education Officer \\ Ministry of Education Sports and Culture \\ Malifa
}

Dear Sir

\section{REQUEST TO UNDERTAKE RESEARCH IN SCHOOLS}

With due respect, I wish to request your permission to undertake research in 3 primary schools either in Upolu or in Savai'i. The research project is for fulfilment of the $\mathrm{PhD}$ degree that I am currently undertaking at the Victoria University of Wellington, my lead supervisor is $\mathrm{Dr}$ Lex McDonald. I have already received ethical approval from the University to undertake this research. The project looks at examining perceptions of stakeholders of Inclusive education in Samoa about inclusive education.

I would like to work with primary schools that were involved in the toolkit pilot program in 2005. These schools are chosen because of their inclusive programs. I aim to undertake group interviews with selected teachers at a place and time where it won't interrupt with their teaching hours.

I am ready to begin as soon as you have granted permission and hope to complete the data collection phase by November this year.

I deem the findings from this research as to have benefits and scientific value for Samoa and its education system. My results have the potential to assist in decision making and policy development both at the national and local level with respect to inclusive education initiatives.

Please feel free to contact me at the Faculty of Education (National University of Samoa), ph 20072, ext 191/130 for any further queries.

Fa'afetai tele ma lo’u fa'aloalo lava.

Rasela Tufue-Dolgoy

Special Education Lecturer

Faculty of Education

National University of Samoa - Email: rtufue@yahoo.com 


\section{APPENDIX 8}

\section{Ethics Letter of Approval}

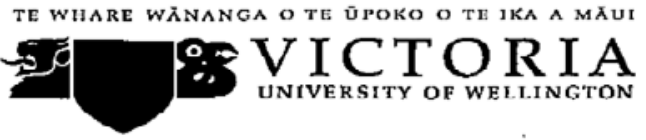

27 June 2007

Rasela Dolgoy

Victoria University of Wellington College of Education

$\mathrm{C} /$ - School of Education Studies

Karori

Wellington

\section{Dear Rasela}

\section{RE: Ethies application AARP SEDS $/ 2007 / 31$}

I am pleased to advise you that your ethics application 'Perceptions and experiences of stakcholders in Samoa about inclusive education', with the requested amendments, has been approved by the Faculty of Education Ethics Committee.

Good luck with your research.

Yours Sincerely

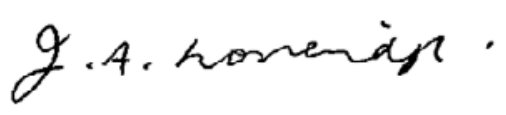

Dr Judith Loveridge

Convenor

Faculty of Education Ethics Committee 